RAFAEL AGUIAR RODRIGUES SILVA

ANÁLISE COMPARATIVA DO DESEMPENHO SÍSMICO DE EDIFÍCIOS COM SISTEMA DE ISOLAMENTO DE BASE 


\section{ANÁLISE COMPARATIVA DO DESEMPENHO SÍSMICO DE EDIFÍCIOS COM SISTEMA DE ISOLAMENTO DE BASE}

Dissertação apresentada à Escola Politécnica da Universidade de São Paulo para obtenção do título de Mestre em Ciências.

Área de concentração: Engenharia de Estruturas

Orientador: Prof. Dr. Carlos Eduardo Nigro Mazzilli 
Autorizo a reprodução e divulgaçāo total ou parcial deste trabalho, por qualquer meio convencional ou eletrônico, para fins de estudo e pesquisa, desde que citada a fonte.

Este exemplar foi revisado e corrigido em relaçăo à versão original, sob responsabilidade única do autor e com a anuểncia de seu orientador.

São Paulo, de de

Assinatura do autor:

Assinatura do orientador:

Catalogação-na-publicação

Silva, Rafael

ANÁLISE COMPARATIVA DO DESEMPENHO SISMICO DE EDIFÍCIOS COM SISTEMA DE ISOLAMENTO DE BASE / R. Silva - versāo corr. -- Sāo Paulo, 2019.

$141 \mathrm{p}$.

Dissertaçāo (Mestrado) - Escola Politécnica da Universidade de São Paulo. Departamento de Engenharia de Estruturas e Geotécnica.

1. Terremoto 2.Sismo 3.Isolamento 4.Tempo 5.Elastômero I.Universidade de Sāo Paulo. Escola Politécnica. Departamento de Engenharia de Estruturas e Geotécnica II.t. 
Aos meus familiares, por compartilharem todas as dificuldades, sacrifícios e vitórias. 


\section{AGRADECIMENTOS}

Agradeço em primeiro lugar à minha família e esposa por todo o apoio e incentivo, sempre me ajudando a superar as dificuldades e não desistir perante os obstáculos.

Agradeço à Escola Politécnica da Universidade de São Paulo, por ter permitido meu ingresso no programa, por todos os ensinamentos, pela disponibilidade do espaço e dos recursos e aos professores da escola, pela disposição e acolhimento.

Ao professor Carlos Eduardo Nigro Mazzilli, que me deu a oportunidade de tê-lo como orientador. Agradeço-o por todos os ensinamentos, pela paciência e pela dedicação, sempre se mostrando disposto a ajudar e contribuir com meu desenvolvimento no programa.

Agradeço à Pollyana Gil Cunha Amaral, por todo o incentivo acadêmico e profissional. Pela indicação e recomendação ao professor Carlos Eduardo Nigro Mazzilli, pelas contribuições e pelo apoio.

Agradeço à Patricia Murad Quintero por todo o suporte dado, sendo sempre muito solícita. Agradeço a todos os demais, que contribuíram de forma direta ou indireta para este trabalho, no âmbito técnico ou moral. 


\section{RESUMO}

Este trabalho apresenta os conceitos e fundamentos da análise sísmica de estruturas considerando o isolamento de base, bem como mostra sua aplicação a um estudo de caso, no qual uma edificação é analisada comparativamente considerando a base fixa à fundação e com isolamento por aparelhos do tipo Lead Rubber Bearing (LRB). Para proceder a essas análises, um estudo inicial é apresentado, comparando os métodos mais usuais de análise sísmica, dentre eles o método estático das forças laterais equivalentes e os métodos dinâmicos do espectro de resposta e do histórico no tempo. Nesta avaliação inicial, conclui-se que os métodos dinâmicos são mais fidedignos e facilmente aplicáveis, com base na tecnologia disponível atualmente; portanto, opta-se pelo método do histórico no tempo para realização das análises considerando o isolamento de base.

Os resultados obtidos por este estudo permitem verificar o desempenho superior das estruturas com isolamento, tanto na redução das acelerações absorvidas, que consequentemente produzem menores esforços na estrutura, como nos menores deslocamentos relativos observados, sem comprometer o atendimento aos demais critérios de segurança sugeridos pelo Eurocódigo 8 (2005).

Palavras-chave: análise sísmica, terremoto, isolamento de base, apoios elastoméricos, domínio do tempo. 


\begin{abstract}
This work addresses the concepts and fundamentals of the seismic analysis of structures considering base isolation, as well as it shows its application to a case study, in which a building is comparatively analyzed considering the base fixed to the foundation and isolated by Lead Rubber Bearing (LRB) devices. To proceed to these analyses, an initial study is presented, comparing the most common seismic analysis methods, among them the static equivalent lateral forces and the dynamic response-spectrum and time-history methods. In this first evaluation, it is found that the dynamic methods are more reliable and easily implemented based on the currently available technology; therefore, the time-history method is selected to carry out the base-isolated analysis.

The results of this study allow one to realize the superior performance of the base-isolated structures, not only with respect to the reduced accelerations absorbed, consequently generating smaller internal forces in the building, but also to the smaller relative displacements observed, without compromising the meeting of the safety criteria suggested by the Eurocode 8 (2005).
\end{abstract}

Keywords: seismic analysis, earthquake, base isolation, lead rubber bearing, time history analysis. 


\section{ÍNDICE DE FIGURAS}

Figura 1: Eventos sísmicos recentes. Fonte: USGS (acesso em 06/05/2018)........................ 12

Figura 2: Aceleração espectral em estruturas com base fixa e isolada. Fonte: Symans (2003)

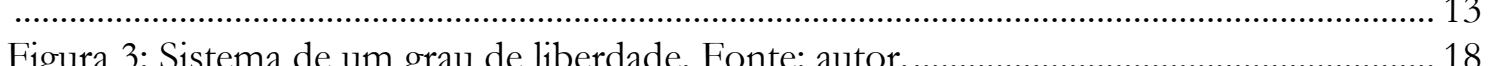

Figura 3: Sistema de um grau de liberdade. Fonte: autor................................................... 18

Figura 4: Vibração livre não amortecida. Fonte: Adaptado de Clough e Penzien (1995).... 20

Figura 5: Vibração livre amortecida. Fonte: Adaptado de Fardis (2015)................................ 21

Figura 6: Amplificação dinâmica em função da taxa de amortecimento. Fonte: Fardis

(2015)

Figura 7: Taxa de deslocamento relativo em função da taxa de amortecimento. Fonte:

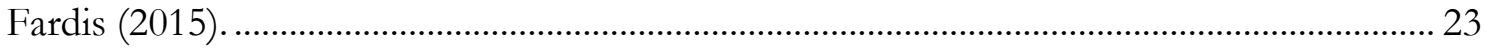

Figura 8: Exemplos de espectros de resposta individual e normativo. Fonte: autor. ............ 34

Figura 9: Exemplo de acelerograma - El Centro. Fonte: Sun (2011) .................................... 35

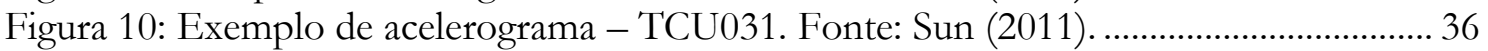

Figura 11: Funções-envoltória. Fonte: Adaptado de SeismoArtif (2018)................................. 37

Figura 12: Acelerograma e Espectro de potência - Sismo Lexington. Fonte: Adaptado de

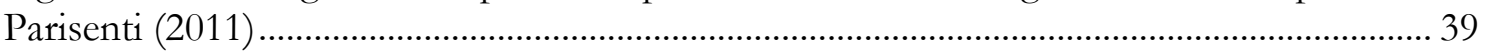

Figura 13: Acelerograma e Espectro de potência - sismo Caucete; Fonte: Adaptado de

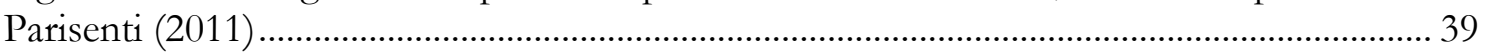

Figura 14: Acelerograma HT0,20gC. Fonte: autor-Seismoartif .............................................. 43

Figura 15: Aderência dos acelerogramas ao espectro elástico. Fonte: autor ............................ 43

Figura 16: Condições para regularidade vertical. Fonte: Adaptado do Eurocódigo 8 (2005).

Figura 17: Forma do espectro de resposta elástica $\boldsymbol{S a} \boldsymbol{a}, \boldsymbol{e}$. Fonte: Eurocódigo 8 (2005)....... 57

Figura 18: Exemplo de conexão flexível. Fonte: Adaptado de Arsen em www.arsenflex.com

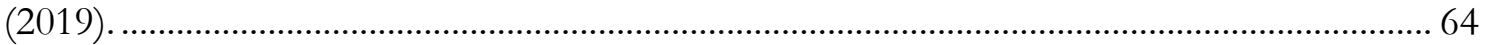

Figura 19: Comportamento histerético e rigidez efetiva de um dispositivo. Fonte: autor... 67

Figura 20: Espectro de Resposta para aplicação do MER em estruturas com isolamento

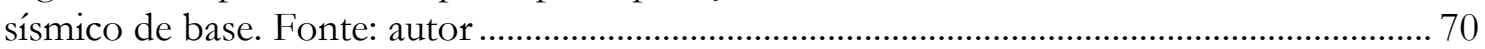

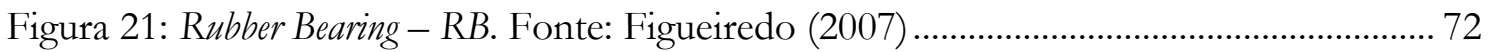

Figura 22: Comportamento do RB. Fonte: Adaptado de Wiles (2008).................................... 73

Figura 23: Comparativo dos comportamentos histeréticos RB, HDRB e LRB. Fonte:

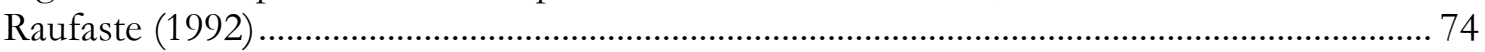

Figura 24: Seção transversal LRB. Fonte: Adaptado de Jingtong em www.bearing-pad.com

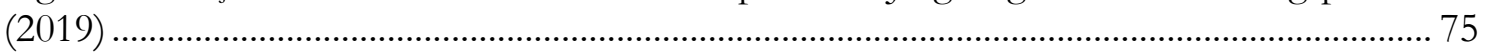

Figura 25: Comportamento do LRB. Fonte: Adaptado de Wiles (2008).................................. 75

Figura 26: Dispositivos de fricção. Fonte: Figueiredo (2007) .................................................. 76

Figura 27: Modelo histerético bilinear do LRB (em vermelho) e modelo histerético

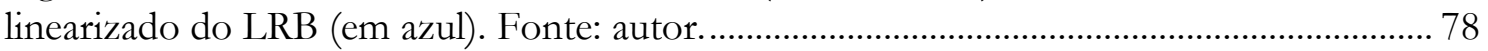

Figura 28: Planta dos pavimentos acima do piso térreo. Fonte: autor...................................... 84

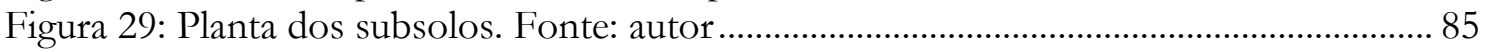

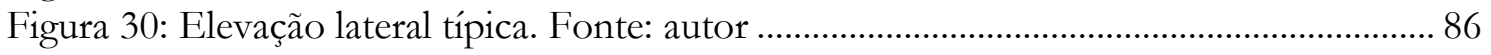

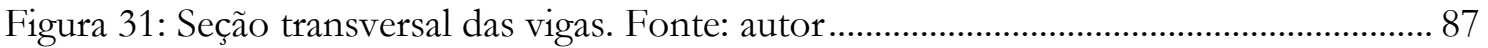

Figura 32: Vistas isométricas dos modelos de análise. Da esquerda para a direita, modelo

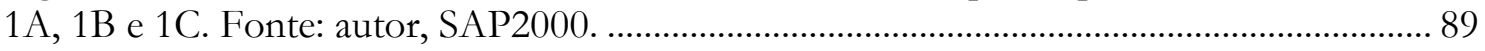

Figura 33: Plantas dos modelos de análise. Da esquerda para a direita, modelo 1A/1B e 1C.

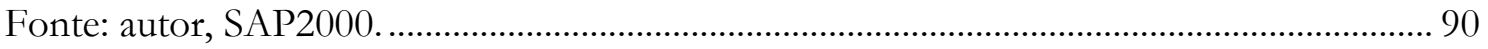

Figura 34: Geometria dos modos de vibração de 1A com massas distribuídas. Fonte: autor, SAP2000. 
Figura 35: Espectros de resposta. Fonte: autor....................................................................... 95

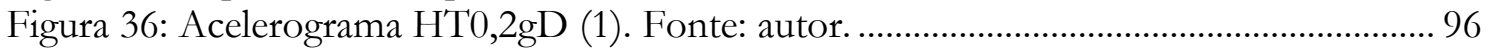

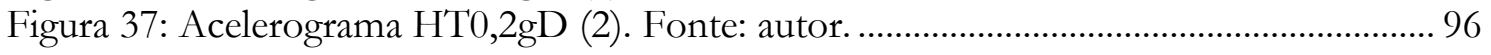

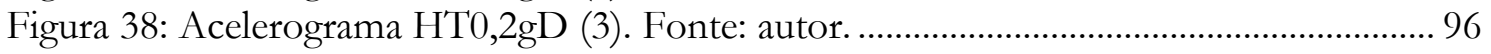

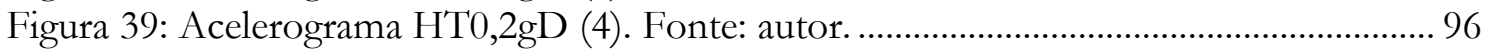

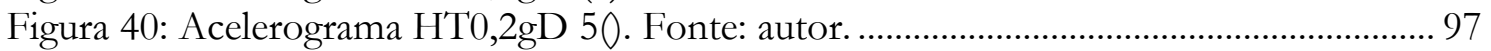

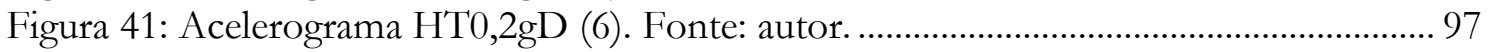

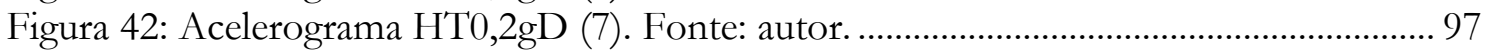

Figura 43: Acelerograma HT0,2gD (7). Fonte: autor................................................................ 98

Figura 44: Forças cortantes na base - Hx e Hy - Modelo 1A. Fonte: autor. .......................... 99

Figura 45: Forças cortantes na base - Hx - Modelo 1A. Fonte: autor................................... 100

Figura 46: Forças cortantes na base - Hy - Modelo 1A. Fonte: autor................................... 100

Figura 47: Forças cortantes na base - Modelos 1A, 1B e 1C. Fonte: autor........................... 101

Figura 48: Deslocamentos relativos - direção x - Modelo 1A. Fonte: autor............................. 102

Figura 49: Deslocamentos relativos - direção y - Modelo 1A. Fonte: autor........................... 103

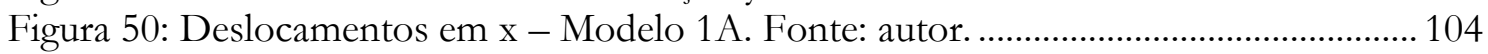

Figura 51: Deslocamentos em y - Modelo 1A. Fonte: autor. ................................................... 105

Figura 52: Deslocamentos no topo nas direções x e y-Modelos 1A, 1B e 1C. Fonte: autor.

Figura 54: Forças cortantes na base - Hx e Hy - Modelo 1A. Fonte: autor. ......................... 116

Figura 55: Forças cortantes por pavimento - Hx e Hy - Modelo 1A. Fonte: autor. ...........117

Figura 56: Deslocamentos relativos com isolamento - Dx e Dy - Modelo 1A. Fonte: autor.

Figura 57: Desvio entre pavimentos normalizados - Modelo 1A. Fonte: autor. .................. 119

Figura 58: Parâmetro de estabilidade $\boldsymbol{\theta}$ - Modelo 1A. Fonte: autor. ........................................ 120

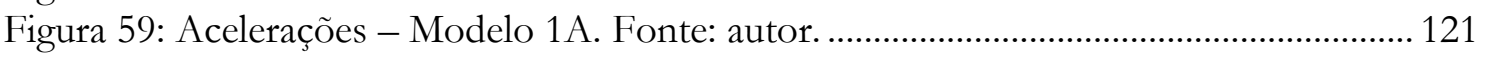

Figura 60: Forças cortantes na base - Hx e Hy - Análise 2. Fonte: autor............................. 123

Figura 61: Forças cortantes por pavimento - Hx e Hy - Análise 2. Fonte: autor. ............... 123

Figura 62: Deslocamentos relativos - Hx e Hy - Análise 2. Fonte: autor. ............................ 124

Figura 63: Desvios entre pavimentos - Hx e Hy - Análise 2. Fonte: autor........................... 125

Figura 64: Parâmetro de estabilidade - Análise 2. Fonte: autor.............................................. 126

Figura 65: Distribuição de força cortante em x - Análise 3. Fonte: autor. ............................. 129

Figura 66: Distribuição de força cortante em y - Análise 3. Fonte: autor............................... 129

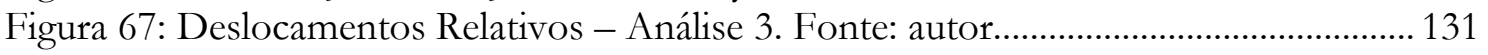

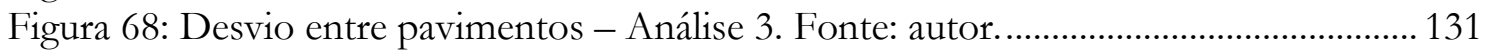

Figura 69: Parâmetro de estabilidade - Análise 3. Fonte: autor................................................ 132 


\section{ÍNDICE DE TABELAS}

Tabela 1 - Coeficientes de importância. Fonte: Adaptado de Eurocódigo 8 (2005)............. 31

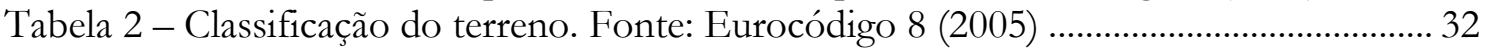

Tabela 3 - Coeficientes de comportamento. Fonte: autor ...................................................... 45

Tabela 4 - Métodos permitidos. Fonte: Eurocódigo 8 (2005) ................................................ 54

Tabela 5 - Coeficientes “ $\boldsymbol{C t}$ ” e " $\boldsymbol{x}$ ”. Fonte: Adaptado de Eurocódigo 8 (2005) .................... 56

Tabela 6 - Parâmetros para espectro de resposta. Fonte: Adaptado de Eurocódigo 8 (2005)

Tabela 7 - Somatório de carregamentos e massas por pavimento - 1A. Fonte: autor ......... 88

Tabela 8 - Somatório de carregamentos e massas por pavimento - 1B. Fonte: autor.......... 89

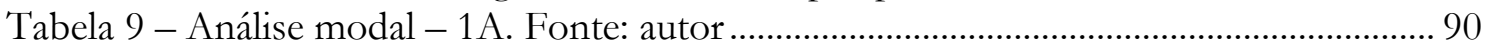

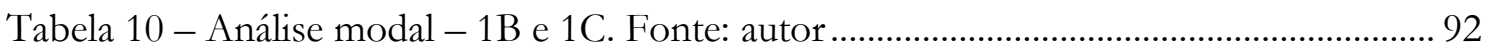

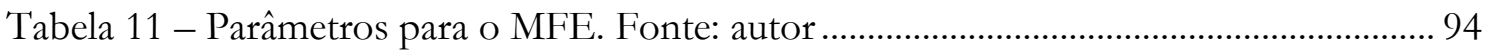

Tabela 12 - Forças laterais equivalentes - 1A. Fonte: autor ................................................... 94

Tabela 13 - Deslocamentos relativos - direção x - Modelo 1A. Fonte: autor....................... 102

Tabela 14 - Deslocamentos relativos - direção y - Modelo 1A. Fonte: autor....................... 103

Tabela 15 - Coeficiente de análise de $2^{\mathrm{a}}$ ordem - direções x e y - Modelo 1A. Fonte: autor

Tabela 16 - Coeficiente de análise de $2^{\mathrm{a}}$ ordem - direções x e y - Modelo 1B. Fonte: autor

Tabela 17 - Coeficiente de análise de $2^{\mathrm{a}}$ ordem - direções x e y - Modelo 1C. Fonte: autor

Tabela 18 - Critério de limitação de danos - direções x e y - Modelos 1A, 1B e 1C. Fonte:

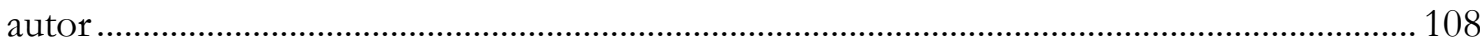

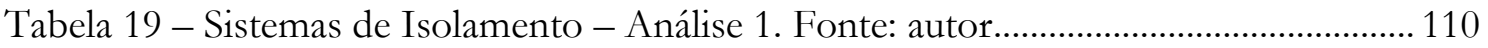

Tabela 20 - Dimensionamento Iterativo LRB 15\%. Fonte: autor ......................................... 111

Tabela 21 - Cargas verticais nos pontos de isolamento definidos para o modelo 1A. Fonte:

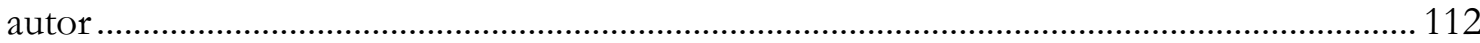

Tabela 22 - Cargas verticais nos pontos de isolamento definidos para o modelo 1A. Fonte:

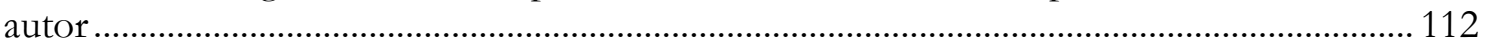

Tabela 23 - Propriedade iniciais de cada tipo de isolamento. Fonte: autor ........................... 114

Tabela 24 - Propriedades dos Isolamento para taxas de amortecimento de 15\% e 30\%.

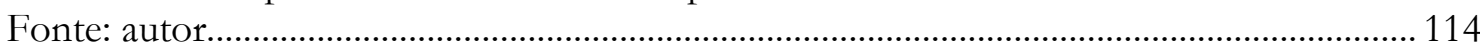

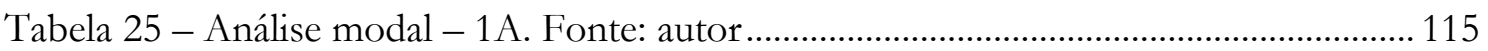

Tabela 26 - Propriedades do Isolamento para a Análise 2 - FNA2-15. Fonte: autor ....... 122 Tabela 27 - Propriedades dos Isolamento - taxas de amortecimento de $10 \%$ a 30\%. Fonte: autor 


\section{ÍNDICE}

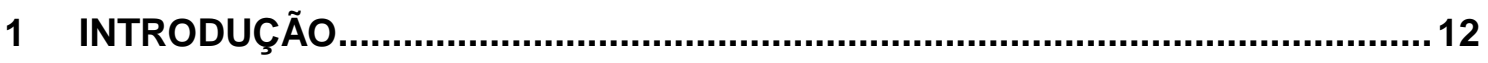

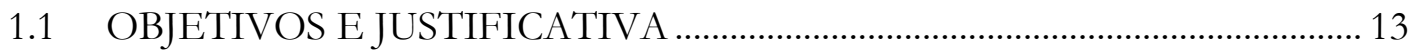

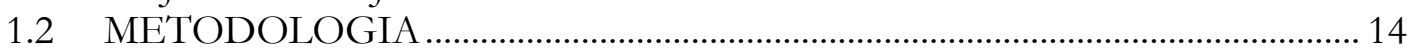

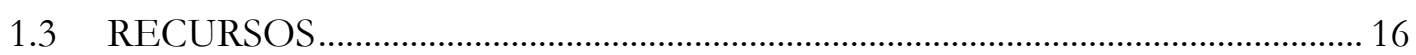

2 FUNDAMENTOS DA ANÁLISE DINÂMICA LINEAR ....................................... 17

2.1 SISTEMAS DE UM GRAU DE LIBERDADE …........................................... 17

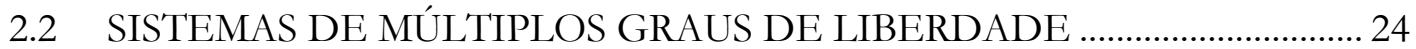

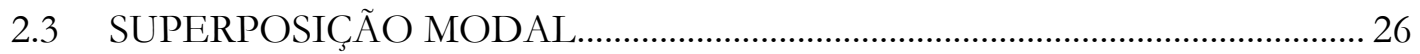

3 ANÁLISE SÍSMICA DE EDIFICAÇÕES ........................................................ 29

3.1 DETERMINAÇÃO DA AÇÃO SÍSMICA ……………........................................ 29

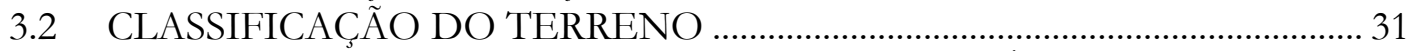

3.3 ESPECTRO DE RESPOSTA DE ACELERAÇÕES SÍSMICAS ...................... 32

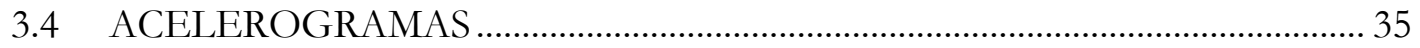

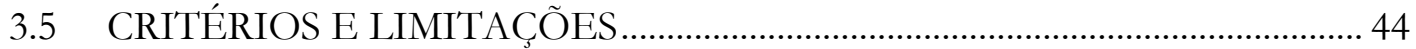

3.6 CARREGAMENTOS E COMBINAÇÕES ..................................................... 52

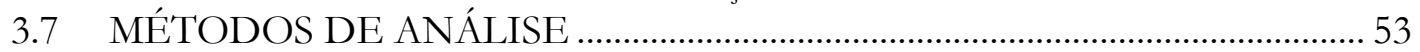

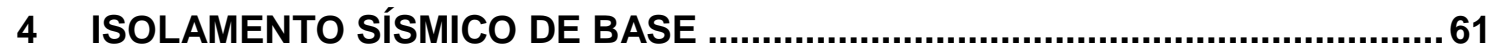

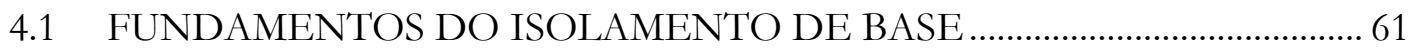

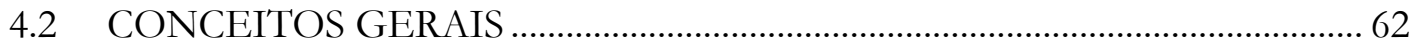

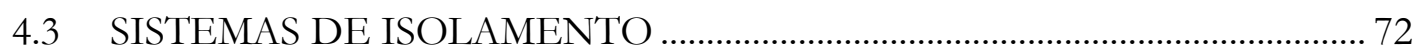

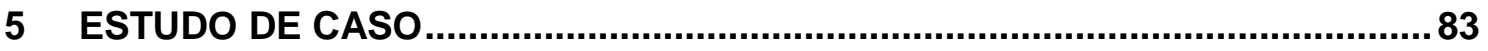

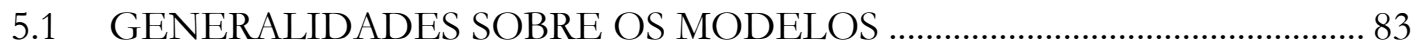

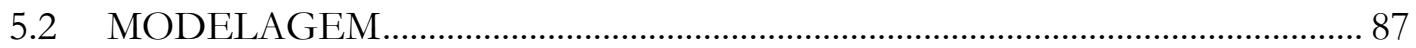

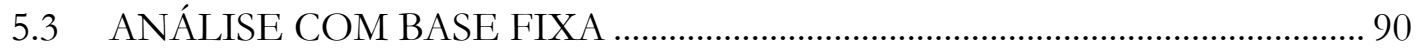

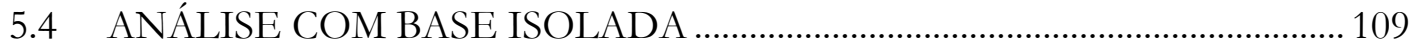

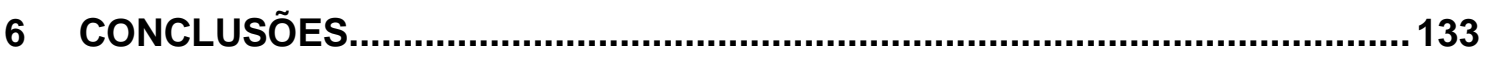

6.1 QUANTO AO COMPARATIVO ENTRE MÉTODOS .................................. 133

6.2 COMENTÁRIOS QUANTO À UTILIZAÇÃO DO ISOLAMENTO DE

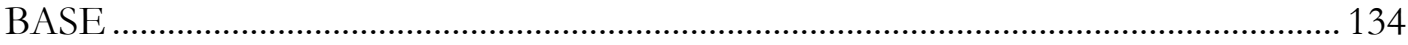

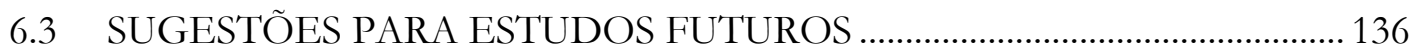

7 REFERÊNCIAS BIBLIOGRÁFICAS ............................................................. 137 


\section{INTRODUÇÃO}

Quando comparado ao dimensionamento estrutural em geral, o dimensionamento sísmico é um ramo relativamente recente. A Figura 1 apresenta as atividades sísmicas de magnitude superior a 2,5 na escala Richter, que ocorreram recentemente no mundo; o tamanho dos círculos é proporcional à magnitude, enquanto as cores representam o período em que ocorreram, sendo as laranjas mais recentes e as amarelas e brancas mais antigas.

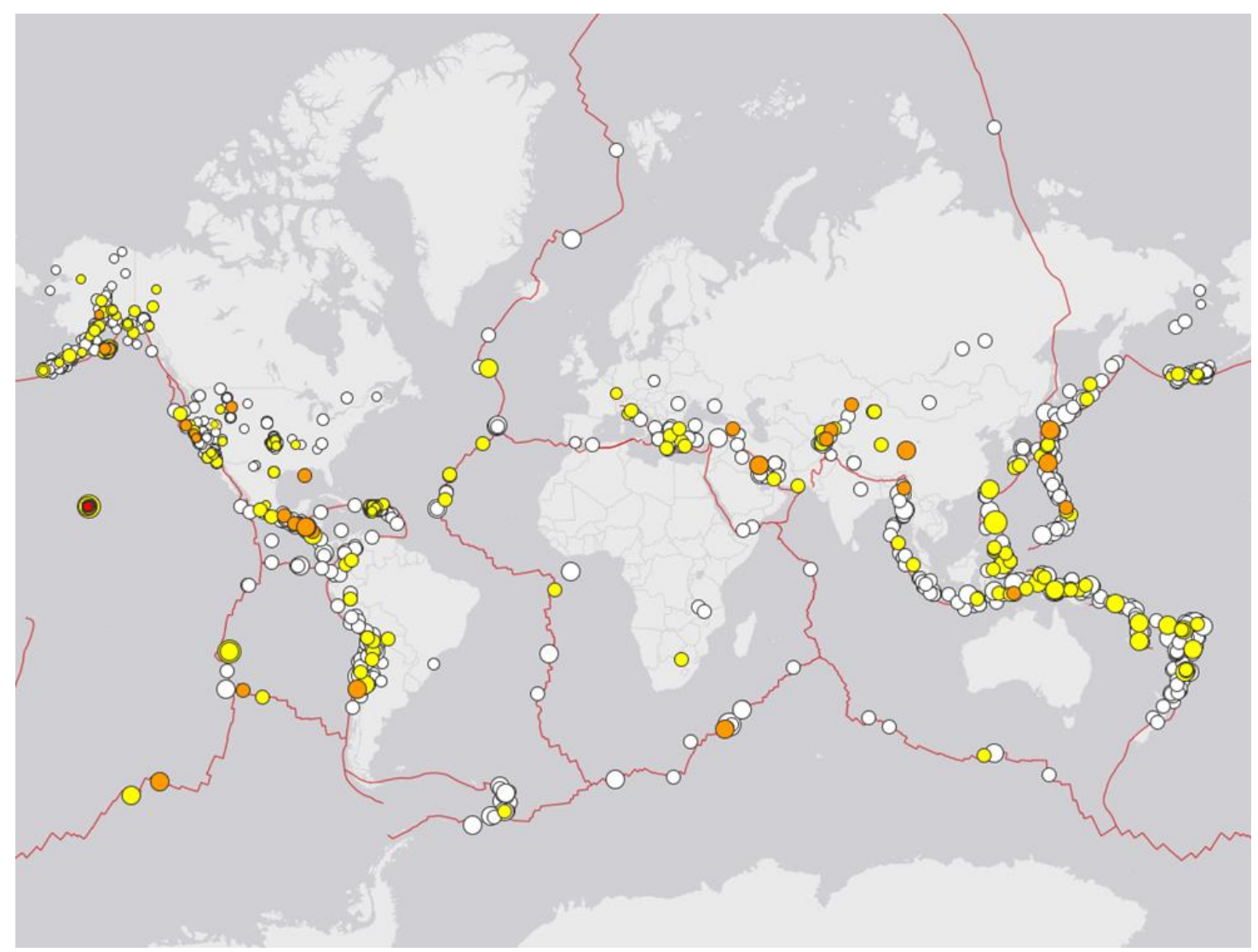

Figura 1: Eventos sísmicos recentes. Fonte: USGS (acesso em 06/05/2018).

O Brasil, mesmo sendo considerado um país de baixa atividade sísmica, possui uma norma técnica específica para projetos de estruturas sismo-resistentes - NBR 15421 (2006). Muito embora essa norma apresente as provisões necessárias para determinação dos esforços sísmicos e análise das respostas estruturais, ela é limitada apenas às características sísmicas do Brasil e se mostra bastante incompleta quando comparada a normas sísmicas internacionais, como o Eurocódigo 8 (2005) ou a ASCE/SEI 7 (2016). Atualmente, em um mundo globalizado, diversas vezes engenheiros brasileiros participam de projetos internacionais, que podem estar situados em regiões de maior atividade sísmica; portanto, é de grande interesse científico estudar e compreender cada vez mais esse campo, buscando 
um amadurecimento dos conceitos atuais, o desenvolvimento de novas tecnologias e a extensão dos dados previamente analisados.

\subsection{OBJETIVOS E JUSTIFICATIVA}

Projetos sismo-resistentes tradicionais, com a base fixa, geralmente são projetados para possuírem uma rigidez elevada, de forma a resistir aos esforços gerados pela atividade sísmica. Esse conceito muitas vezes resulta em estruturas bastante pesadas que, mesmo que não colapsem durante uma atividade sísmica, frequentemente necessitam de reparos e intervenções para que possam voltar a serem utilizadas com segurança. Uma outra forma de combater essas ações sísmicas é tentar reduzir a transmissibilidade do terreno para a estrutura, para que esta precise resistir apenas a uma parcela minorada desses efeitos. Essa redução pode ser obtida por meio do isolamento da base do edifício, aumentando o período natural da estrutura e, consequentemente, reduzindo as acelerações transmitidas para esta, conforme ilustrado na Figura $2^{1}$.

Além da redução nos esforços resultantes dessas acelerações, os dispositivos de isolamento absorvem a maior parte dos deslocamentos, fazendo com que a superestrutura responda tanto quanto possível como se fosse um corpo rígido. Essas condições podem permitir a concepção de estruturas menos rígidas, além de garantir que ela continue operacional durante e imediatamente após um terremoto.

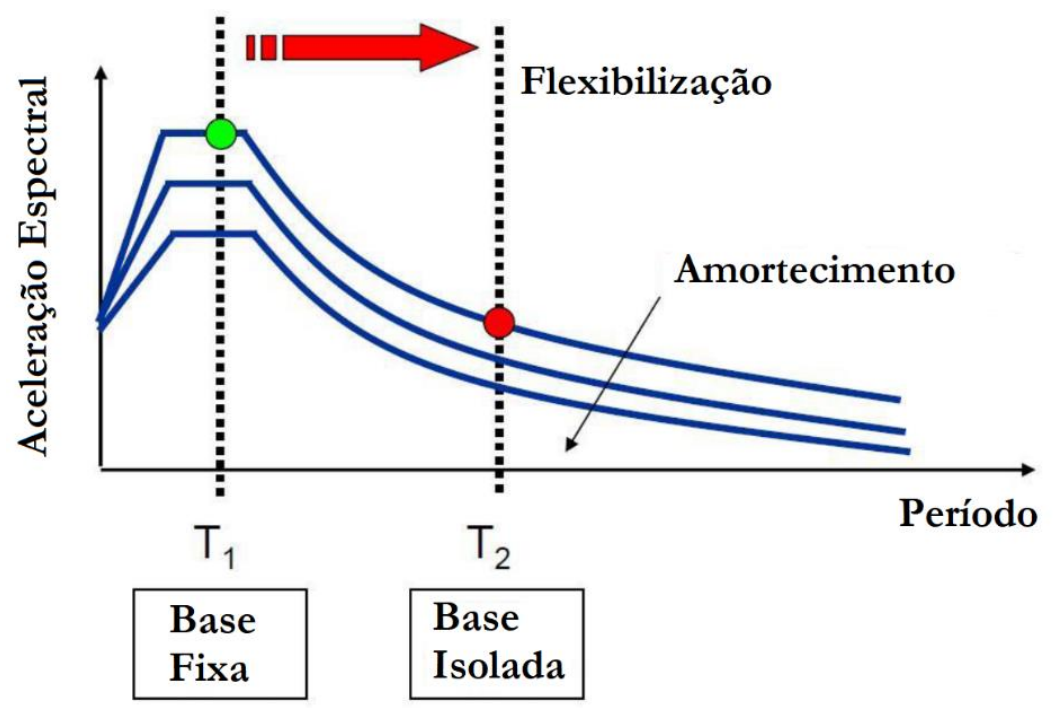

Figura 2: Aceleração espectral em estruturas com base fixa e isolada. Fonte: Symans (2003)

\footnotetext{
${ }^{1}$ No item 3 é estabelecida a relação de proporcionalidade entre a aceleração espectral e os esforços sísmicos.
} 
Este trabalho tem o objetivo principal de avaliar o desempenho sísmico de sistemas de base isolada para edifícios de concreto armado, comparando os resultados desse sistema em relação a estruturas concebidas com a base fixa.

Para tanto, é explorado o dimensionamento sísmico segundo três dos métodos mais utilizados, nomeadamente o método das Forças Equivalentes (MFE), espectro de resposta (MER) e análise no domínio do tempo (MHT), comparando as respostas de cada método.

O conceito de isoladores sísmicos de base e suas possíveis aplicações são abordados, apresentando alguns dos tipos de aparelhos disponíveis e explorando as limitações na utilização desse tipo de sistema em relação a algumas configurações estruturais relevantes. Um dos dispositivos de isolamento sísmico composto por elastômero laminado com um núcleo de chumbo, designado por Lead Rubber Bearing (LRB), é estudado em detalhe, permitindo entender como são feitos seu dimensionamento e sua aplicação em uma análise sísmica. Pretende-se examinar a eficiência dos isoladores em um modelo específico, considerando diferentes aspectos sísmicos, como intensidades variadas e diferentes tipos de terreno. O dimensionamento dos isoladores também é realizado considerando diferentes parâmetros sísmicos, de modo a compreender qual a influência que certas modificações no sistema de isolamento têm nas respostas estruturais.

A NBR 15421 (2006) regulamenta apenas o dimensionamento sísmico de estruturas usuais, construídas de forma convencional, portanto não estão previstas considerações referentes ao dimensionamento de estruturas isoladas sismicamente. Logo, nesta pesquisa são utilizadas as provisões das normas internacionais do Eurocódigo 8 e da ASCE/SEI 7, apresentando, oportunamente, as similaridades de algumas das definições em relação às apresentadas pela NBR.

\subsection{METODOLOGIA}

Inicialmente é feita uma breve apresentação dos conceitos fundamentais da análise dinâmica com um e múltiplos graus de liberdade. Em seguida, são discutidos os parâmetros para determinação dos carregamentos sísmicos e os requisitos que devem ser atendidos pelas estruturas. Os métodos de análise sísmica disponíveis são apresentados, dando maior enfoque àqueles que são utilizados nesta pesquisa, especificamente o método das forças laterais equivalentes, a análise espectral e a análise no domínio do tempo. Para esta última, utilizam-se acelerogramas gerados artificialmente, onde os fundamentos para sua determinação são apresentados resumidamente conforme Quintero (2017). Para a geração 
dos acelerogramas, o software SeismoArtif (2016) é utilizado em sua versão acadêmica. Por meio do método de integração numérica de Newmark, os acelerogramas gerados pelo SeismoArtif são aplicados como excitação, permitindo recuperar o espectro de acelerações e verificar sua aderência ao espectro de resposta elástica das normas utilizadas.

$\mathrm{Na}$ sequência, são apresentados alguns sistemas de isolamento de base comumente utilizados, analisando suas vantagens e limitações e apontando as consequências em relação a algumas configurações estruturais de interesse.

Em benefício da compreensão, mas sem comprometer a generalidade, a análise é fundamentada no desempenho de alguns estudos de caso definidos. Propõe-se um sistema estrutural de um edifício de seis pavimentos, com dois subsolos adicionais, nas configurações de base fixa (1A) e base isolada (2A). A configuração (1A) é analisada comparativamente para os três métodos de análise sugeridos: método das forças laterais equivalentes, análise espectral e análise no domínio do tempo.

Para as análises iniciais, são gerados dois modelos de cálculo tipo shear building, onde um modelo mais simplificado possui as massas de cada laje concentradas no respectivo centro de massa, e o segundo tem as massas de cada pavimento distribuídas em seus respectivos elementos. Utiliza-se um modelo tridimensional, que leva em consideração todos os elementos estruturais e suas propriedades geométricas, em seu devido arranjo em relação ao modelo global.

A configuração $2 \mathrm{~A}$ é analisada considerando somente o caso das massas distribuídas de forma similar à configuração anterior.

Também são propostos modelos derivados de 1A, considerando uma situação com a redução de dois pavimentos 1B (mais rígida) e outra com a remoção do núcleo rígido e das paredes estruturais 1C (mais flexível). Essas alterações têm o objetivo de alterar significativamente as propriedades sísmicas do sistema analisado, permitindo verificar o impacto desses novos sistemas em relação aos diferentes métodos de análise adotados.

Os resultados do modelo de base fixa são comparados entre si, com o objetivo de estudar a eficiência dos métodos de análise apresentados, quantificando o desvio entre seus resultados e avaliando as diferenças quando são consideradas massas concentradas ou distribuídas. Em seguida, são avaliadas, comparativamente, as respostas da configuração 1A e $2 \mathrm{~A}$, de forma a identificar as diferenças, vantagens e desvantagens geradas quando o isolamento sísmico é aplicado em uma edificação, assim como seu desempenho estrutural. 
O modelo 2A é avaliado com base no sistema de isolamento LRB. São propostas diversas configurações, com base em dimensionamentos que considerem diferentes parâmetros, de modo a verificar como sistemas de isolamento com diferentes dimensões e propriedades se comportam para um mesmo modelo estrutural.

Os modelos são analisados por meio de um pacote comercial de análise estrutural, SAP2000 e os comparativos são feitos com base nas acelerações percebidas ffloor acceleration), nos deslocamentos provocados (max displacements and interstory drifts) e nas forças cortantes na base (base shear).

\subsection{RECURSOS}

O desenvolvimento deste estudo prevê a utilização de auxílio computacional para realização das análises. São utilizadas linguagens de programação, como o MATLAB e Visual Basic, para realizar cálculos simplificados e para compilação dos dados necessários para outros estudos. Para análises mais complexas, pressupõe-se a disponibilidade do software de modelagem estrutural SAP2000. A geração dos acelerogramas artificiais é feita com auxílio do software SeismoArtif 2016. 


\section{FUNDAMENTOS DA ANÁLISE DINÂMICA LINEAR}

\subsection{SISTEMAS DE UM GRAU DE LIBERDADE}

De forma breve, este item apresenta os fundamentos essenciais da análise dinâmica linear, na justa medida para permitir sua utilização no estudo da resposta de estruturas sob ação de sismos. Não se tem, portanto, a preocupação com a apresentação detalhada do assunto que, de resto, pode ser encontrada em textos clássicos, tais como Chopra (2003) e Clough e Penzien (1995). Em dinâmica, graus de liberdade referem-se às coordenadas generalizadas de um sistema, a partir das quais se pode determinar sua configuração completa.

Em um problema estático, ou quase-estático, em que os carregamentos ou os deslocamentos são aplicados de forma muito lenta, as forças inerciais, derivadas da massa e da aceleração, são desprezáveis e, portanto, podem ser desconsideradas na análise estrutural. Consequentemente, o caráter quase-estático permite que seja descartado também o amortecimento intrínseco na estrutura, fazendo com que a equação de equilíbrio das forças, para um sistema de apenas um grau de liberdade (SGL), seja simplificada para a forma:

$$
k x(t)=p(t)
$$

onde:

$k$ : rigidez da estrutura

$x$ : deslocamento do corpo

$p$ : força externa aplicada

$t$ : tempo

Por outro lado, quando os carregamentos ou deslocamentos sofrem variações rápidas em relação ao período natural do sistema de um grau de liberdade, ele responde de forma dinâmica às excitações, fazendo com que seja necessário considerar as forças inerciais e o amortecimento na equação do movimento. Tomando-se como exemplo o sistema de um grau de liberdade apresentado na Figura 3, onde uma força $p(t)$ é aplicada a um corpo de massa $m$, suportado por uma estrutura de rigidez $k$ e amortecimento viscoso linear inerente $c$, causando um deslocamento $x$ : 


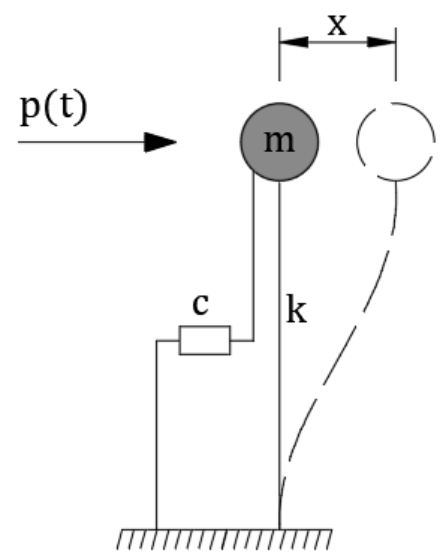

Figura 3: Sistema de um grau de liberdade. Fonte: autor.

a equação do movimento (ou de equilíbrio dinâmico) pode ser escrita na forma:

$$
m \ddot{x}(t)+c \dot{x}(t)+k x(t)=p(t)
$$

Essa mesma equação pode ser reescrita em função de alguns parâmetros comumente utilizados em análises dinâmicas. Sendo $\omega$ a frequência natural não amortecida do sistema, expressa em radianos por segundo, e $\xi$ a taxa de amortecimento em relação ao amortecimento crítico $c_{c r}$, definido em (2.13); e conhecendo as expressões que as determinam:

$$
\begin{gathered}
\omega=\sqrt{\frac{k}{m}} \\
\xi=\frac{c}{c_{c r}}
\end{gathered}
$$

pode-se dividir a equação do movimento pela massa e rearranjar os parâmetros de forma a escrevê-la na forma:

$$
\ddot{x}(t)+2 \omega \xi \dot{x}(t)+\omega^{2} x(t)=\frac{p(t)}{m}
$$

Incluindo-se agora a variável $x_{e s t}$, definida pelo deslocamento equivalente que ocorreria no sistema caso a força $p(t)$ fosse aplicada em caráter quase-estático, ou seja, $x_{\text {est }}(t)=$ $p(t) / k$, é possível finalmente escrever a equação do movimento como:

$$
\ddot{x}(t)+2 \omega \xi \dot{x}(t)+\omega^{2} x(t)=\omega^{2} x_{e s t}(t)
$$

Nessa forma, tem-se a equação do movimento definida em função da frequência natural do sistema, da taxa de amortecimento em relação ao amortecimento crítico e do deslocamento estático. 
Um sistema dinâmico similar pode ser representado, considerando uma excitação de suporte $x_{g}(t)$, ao invés de uma força aplicada $p(t)$. Assim, o segundo membro da equação (2.2) passa a ser descrito pelas forças inerciais, geradas a partir da movimentação do suporte, que podem ser expressas por $m \ddot{x}_{g}(t)$. Analogamente à equação (2.6), pode-se escrever a equação do movimento em função da frequência natural do sistema e da porcentagem de amortecimento, ou seja:

$$
\ddot{x}(t)+2 \omega \xi \dot{x}(t)+\omega^{2} x(t)=-\ddot{x}_{g}(t)
$$

\subsubsection{Vibração livre}

A vibração livre ocorre quando há ausência de excitação no sistema, ou seja, $p(t)=0$. Considerando-se inicialmente a ausência de amortecimento, a equação da vibração livre não amortecida fica:

$$
\ddot{x}(t)+\omega^{2} x(t)=0
$$

cuja solução geral pode ser escrita na forma:

$$
x(t)=\operatorname{asen}[\omega t-\theta]
$$

onde as constantes $a$ e $\theta$ dependem das condições iniciais, e $\omega$ é a frequência natural não amortecida do oscilador de um grau de liberdade. Considerando que esse sistema não é amortecido e, portanto, não possui dissipação de energia, o movimento, uma vez iniciado, continuará indefinidamente, definindo o caráter conservativo do sistema.

Neste sistema, conhecendo-se para um tempo inicial $t=0$ o deslocamento $x(0)=x_{0}$ e a velocidade $\dot{x}(0)=\dot{x}_{0}$, pode-se escrever a solução da equação de vibração livre como:

$$
x(t)=x_{0} \cos (\omega t)+\frac{\dot{x}_{0}}{\omega} \operatorname{sen}(\omega t)
$$

A Figura 4 ilustra a oscilação descrita pelo sistema não amortecido. 


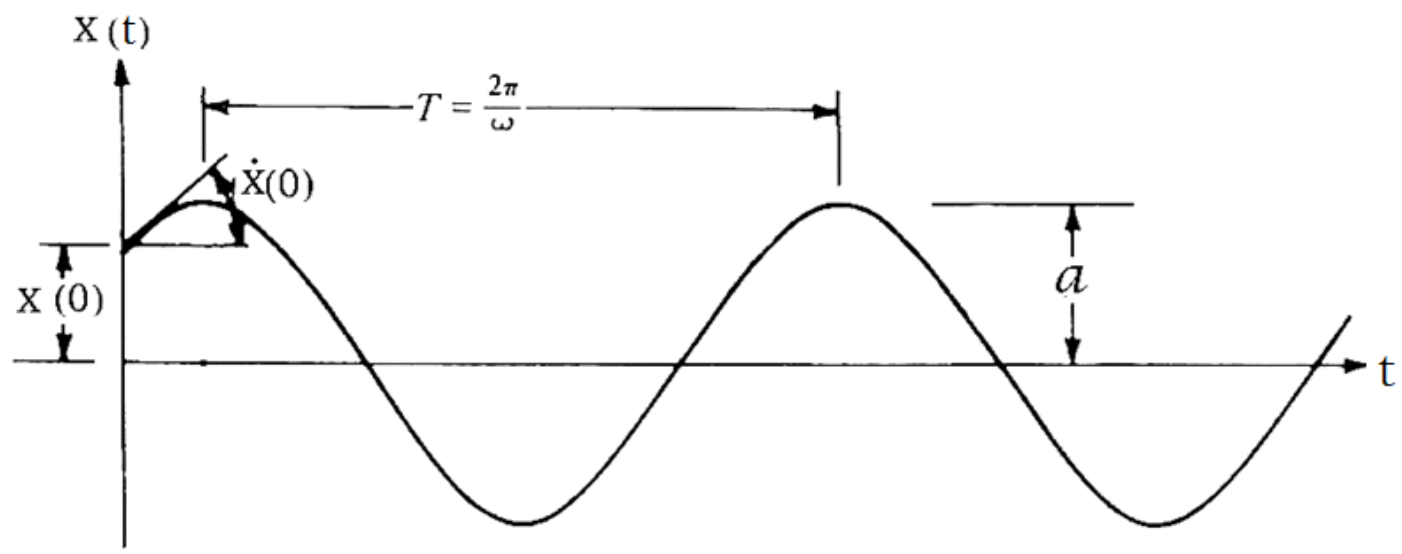

Figura 4: Vibração livre não amortecida. Fonte: Adaptado de Clough e Penzien (1995).

Do sistema apresentado, é possível relacionar também a frequência cíclica natural do sistema $f$, expressa em Hertz, e o período natural $T$, expresso em segundos, conforme:

$$
f=\frac{1}{T}=\frac{\omega}{2 \pi}
$$

Introduzindo-se o amortecimento ao sistema de vibração livre apresentado na equação (2.8), obtêm-se a equação para a vibração livre amortecida que é dada por:

$$
\ddot{x}+2 \omega \dot{x}+\omega^{2} x=0
$$

A quantidade de amortecimento necessária para que o movimento deixe de ser oscilatório regressivo, passando a um movimento que tende assintoticamente a zero com o passar do tempo, é chamado de amortecimento crítico, definido por:

$$
C_{c r}=2 \sqrt{k m}
$$

A maioria dos problemas sísmicos da Engenharia Civil, inclusive os que serão abordados neste trabalho, possui taxa de amortecimento $\xi$, definida em (2.4), inferior à unidade (dito caso subcrítico); para este caso, a solução geral de (2.12) é:

$$
x(t)=a e^{-\xi \omega t} \operatorname{sen}\left[\omega_{D} t-\theta\right]
$$

onde $\omega_{D}$ é a frequência natural amortecida, dada por $\omega \sqrt{1-\xi^{2}}$. A Figura 5 mostra a variação do deslocamento em função da taxa de amortecimento admitida, por número de ciclos, admitindo-se $\dot{x}(0)=\dot{x}_{0}=0$. 


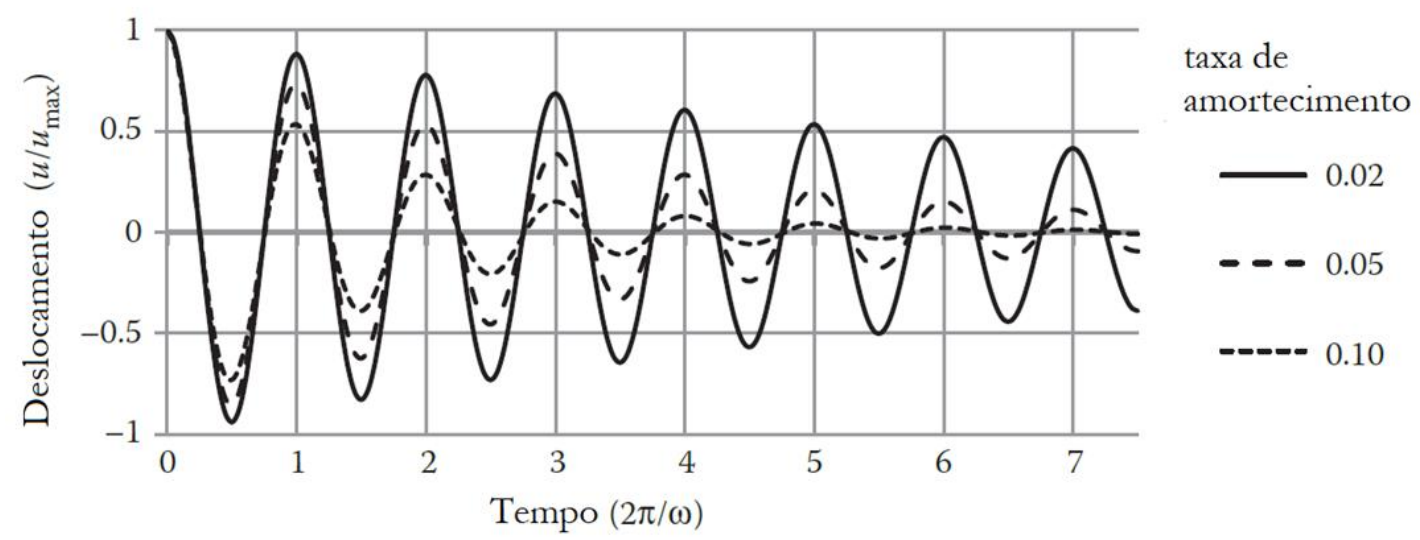

Figura 5: Vibração livre amortecida. Fonte: Adaptado de Fardis (2015).

Para estruturas de concreto armado, é usual a adoção de uma taxa inerente de amortecimento estrutural de $5 \%$, a qual gera uma frequência natural amortecida $\omega_{D}$ bastante próxima da frequência natural não amortecida $\omega$.

\subsubsection{Vibração forçada}

Para que seja possível tirar algumas importantes conclusões a respeito das respostas de um sistema de um grau de liberdade sob vibração forçada, examina-se um sistema com carregamento harmônico de amplitude $p_{0}$ e frequência $\omega_{p}$, ou seja, um carregamento dado por $p(t)=p_{0} \operatorname{sen}\left(\omega_{p} t\right)$ aplicado à equação (2.2). Para o caso proposto, a solução homogênea é dada por (2.14), enquanto a solução particular é definida por:

$$
x(t)=x_{e s t} B_{d} \operatorname{sen}\left[\omega_{p} t-\phi\right]
$$

$B_{d}$ é um fator adimensional que expressa a magnificação do deslocamento dinâmico em relação ao estático para o sistema e $\phi$ é o ângulo de fase entre a resposta e a excitação, que se revelam, respectivamente, como:

$$
\begin{gathered}
B_{d}=\left\{\left[1-\left(\frac{\omega_{p}}{\omega}\right)^{2}\right]^{2}+\left(2 \xi \frac{\omega_{p}}{\omega}\right)^{2}\right\}^{-\frac{1}{2}} \\
\phi=\arctan \frac{\left(2 \xi \frac{\omega_{p}}{\omega}\right)}{1-\left(\frac{\omega_{p}}{\omega}\right)^{2}}
\end{gathered}
$$

Representando-se em um gráfico, conforme apresentado na Figura 6, o fator de amplificação dinâmica $B_{d}$ em função da relação entre frequência do carregamento e a natural da estrutura, para diferentes níveis de taxa de amortecimento, obtém-se a seguinte resposta: 


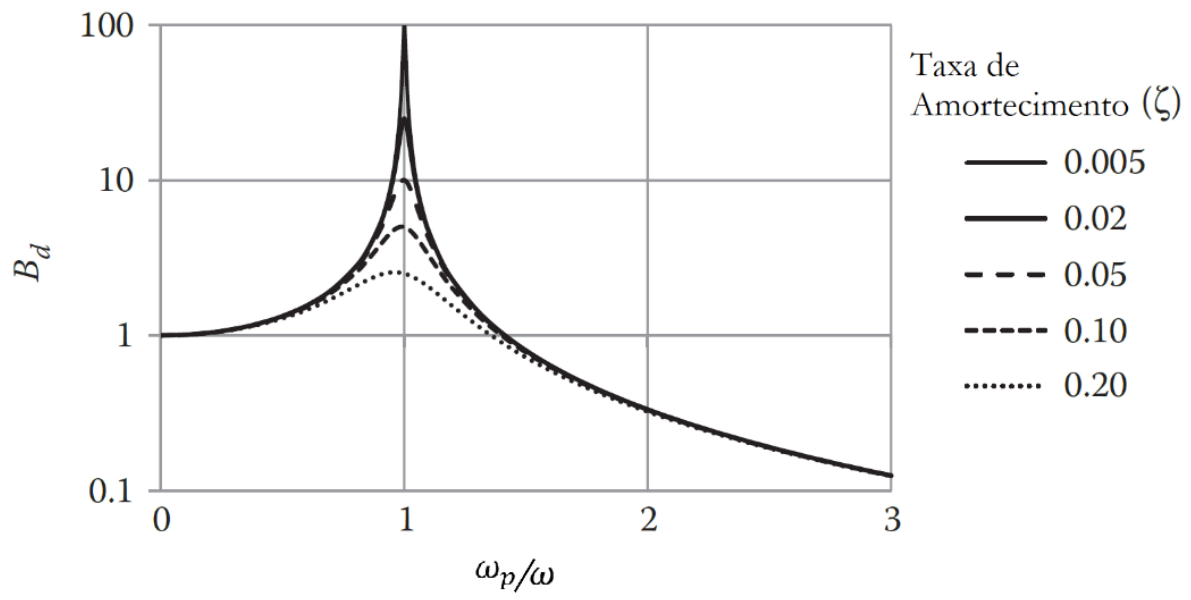

Figura 6: Amplificação dinâmica em função da taxa de amortecimento. Fonte: Fardis (2015).

O gráfico permite concluir que a taxa de amortecimento tem uma influência considerável nos resultados apenas nos casos em que a frequência do carregamento é próxima à frequência natural da estrutura.

Para valores de $\frac{\omega_{p}}{\omega}$ próximos de zero, ou seja, um carregamento com frequência muito inferior à frequência natural da estrutura, o fator de amplificação dinâmica é praticamente igual a um, fazendo com que o sistema tenha uma resposta dinâmica próxima da resposta estática, ou seja, as forças inerciais são irrelevantes e a estrutura responde quase que exclusivamente com os esforços elásticos.

Para valores de $\frac{\omega_{p}}{\omega}$ muito elevados, o coeficiente $B_{d}$ tende a zero, o que significa que os carregamentos externos ficam praticamente equilibrados com as forças inerciais desenvolvidas pela estrutura, produzindo deslocamentos reduzidos e limitando significativamente a participação da rigidez da estrutura.

Quando a frequência do carregamento é ressonante com a da estrutura, $\frac{\omega_{p}}{\omega}=1$, normalmente obtém-se uma amplificação dinâmica elevada, que fica limitada principalmente pela taxa de amortecimento, geralmente pequena para edificações convencionais. Conforme percebido na Figura 6, a ausência de amortecimento, com uma taxa $\xi=0$, permitiria que os deslocamentos aumentassem ilimitadamente. Mesmo para uma taxa de amortecimento de 5\%, comum para edificações de concreto armado, o coeficiente de amplificação dinâmica é bastante elevado (igual a 10 na ressonância).

Um comportamento parecido ocorre quando, ao invés da aplicação de uma força externa, é introduzida uma movimentação harmônica da base de amplitude $x_{g 0}$ e frequência $\omega_{p}$, dada por $x_{g}=x_{g 0} \operatorname{sen}\left(\omega_{p} t\right)$, que é expressa em acelerações por $\ddot{x_{g}}=-x_{g 0} \omega_{p}{ }^{2} \operatorname{sen}\left(\omega_{p} t\right)$. 
Neste caso, a solução homogênea continua dada pela equação (2.14), enquanto a solução particular é definida por:

$$
x(t)=x_{g 0} T_{d} \operatorname{sen}\left[\omega_{p} t-\phi\right]
$$

onde

$$
T_{d}=\left\{\left[1-\left(\frac{\omega}{\omega_{p}}\right)^{2}\right]^{2}+\left(2 \xi \frac{\omega}{\omega_{p}}\right)^{2}\right\}^{-\frac{1}{2}}
$$

Para esta situação, $T_{d}$ representa o fator de resposta relativo da excitação, com valor equivalente à relação entre o deslocamento relativo e o deslocamento imposto na base. A Figura 7 apresenta o gráfico do parâmetro $T_{d}$ em função da relação entre frequência natural da estrutura e da excitação de base, para diferentes níveis de taxa de amortecimento.

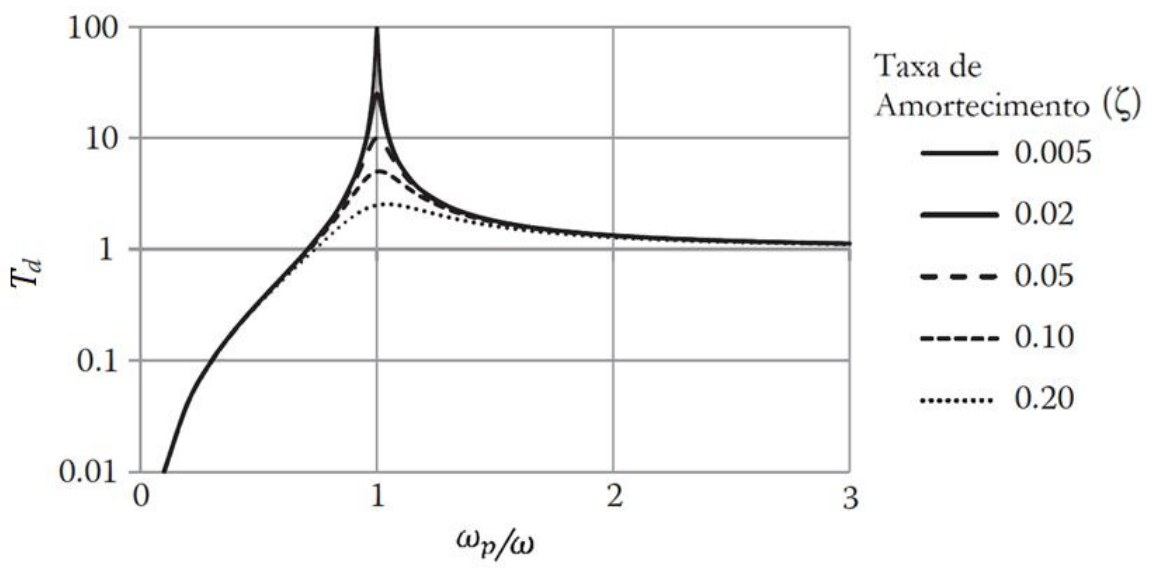

Figura 7: Taxa de deslocamento relativo em função da taxa de amortecimento. Fonte: Fardis (2015).

Valores de $\frac{\omega_{p}}{\omega}$ próximos de zero significam que a frequência de movimentação da base é tão pequena que o sistema se movimenta praticamente como um corpo rígido, sem deformações relativas. Valores elevados de $\frac{\omega_{p}}{\omega}$ representam uma frequência de excitação muito superior à frequência natural do sistema, caso em que as massas ficariam praticamente inativas, produzindo deslocamentos relativos praticamente idênticos ao deslocamento da base. Para valores de $\frac{\omega_{p}}{\omega}$ próximos a um, ocorre um comportamento ressonante análogo ao apresentado anteriormente.

Portanto, uma boa estratégia é tentar evitar que a frequência do carregamento seja ressonante com a frequência da estrutura, o que pode ser obtido por meio do enrijecimento ou da flexibilização dos sistemas estruturais, como é explorado mais adiante neste estudo. 


\subsection{SISTEMAS DE MÚLTIPLOS GRAUS DE LIBERDADE}

Embora alguns casos possam ser representados adequadamente por sistemas de apenas um grau de liberdade, a maioria dos problemas encontrados na engenharia requer modelos de múltiplos graus de liberdade (MGLs).

Evita-se aqui a formulação detalhada das equações de movimento para sistemas de múltiplos graus de liberdade, que pode ser encontrada, por exemplo, em Chopra (1995) e Clough e Penzien (2003). Entretanto, sua forma matricial é bastante similar à equação escalar do SGL, conforme se indica em (2.20):

$$
[M]\{\ddot{x}\}+[C]\{\dot{x}\}+[K]\{x\}=\{p\}-[M]\{\beta\} \ddot{x}_{g}
$$

onde

$[M]$ : matriz de massa

$[C]$ : matriz de amortecimento

$[K]$ : matriz de rigidez

$\{x\},\{\dot{x}\},\{\ddot{x}\}$ : respectivamente os vetores de deslocamento, velocidade e aceleração

$\{p\}$ : vetor de forças externas

$\ddot{x}_{g}$ : aceleração derivada do deslocamento imposto na base (ver item 2.1.2)

$\{\beta\}$ : vetor de influência dos deslocamentos impostos na base

Neste equacionamento, o vetor de influência $\{\beta\}$ é formado apenas por 0 e 1 , onde 1 é aplicado aos graus de liberdade que sofrem influência da aceleração $\ddot{x}_{g}$ imposta e 0 é aplicado aos demais graus de liberdade. No caso das vibrações livres não amortecidas, temse analogamente ao SGL:

$$
[M]\{\ddot{x}\}+[K]\{x\}=0
$$

que possui solução geral

$$
\{x\}=\{\phi\} \operatorname{sen}\left[\omega\left(t-t_{1}\right)\right]
$$

Substituindo-se a expressão (2.22) e sua segunda derivada em (2.21), chega-se a:

$$
\left[[K]-\omega^{2}[M]\right]\{\phi\}=0
$$

que escrita na forma canônica do problema de autovalores e autovetores é dada por:

$$
\left[[M]^{-1}[K]-\lambda[I]\right]\{\phi\}=0
$$

A equação (2.23) possui soluções não triviais se: 


$$
\left|[K]-\omega^{2}[M]\right|=0
$$

O problema clássico de autovetores $(\{\phi\})$ e autovalores $(\lambda)$ da matriz $[M]^{-1}[K]$ apresentado permite determinar os modos naturais de vibração e suas respectivas frequências, obtidos respectivamente pelos autovetores e pela raiz quadrada dos autovalores da expressão (2.25).

O número $n$ de graus de liberdade é equivalente à quantidade de modos e frequências naturais do sistema, sendo que os modos podem ser organizados em uma matriz quadrada $[\Phi]$ de ordem $n$, de forma que cada vetor $\{\phi\}$ ocupe uma de suas colunas. À essa matriz é dado o nome de matriz modal.

A matriz modal possui a propriedade de ortogonalidade com relação às matrizes de massa e rigidez, que pode ser expressa pelas seguintes relações:

$$
\begin{aligned}
{K^{*}}^{*}{ }_{i j}=\{\phi\}_{i}{ }^{T}[K]\{\phi\}_{j}=0 & \text { para } i \neq j \\
M^{*}{ }_{i j}=\{\phi\}_{i}{ }^{T}[M]\{\phi\}_{j}=0 & \text { para } i \neq j
\end{aligned}
$$

Assim, as matrizes $\left[K^{*}\right]$ e $\left[M^{*}\right]$ denominadas de matriz de rigidez modal e matriz de massa modal, respectivamente

$$
\begin{aligned}
& {\left[K^{*}\right]=[\Phi]^{T}[K][\Phi]} \\
& {\left[M^{*}\right]=[\Phi]^{T}[M][\Phi]}
\end{aligned}
$$

são matrizes diagonais, isto é, possuem valores diferentes de zero apenas em suas diagonais principais.

Para as vibrações livres amortecidas, a equação do movimento é caracterizada por:

$$
[M]\{\ddot{x}\}+[C]\{\dot{x}\}+[K]\{x\}=0
$$

Nos casos usuais, considera-se um amortecimento proporcional, onde a matriz de amortecimento $[C]$ é obtida por meio de uma combinação linear das matrizes de massa e de rigidez, que pode ser expressa por:

$$
[C]=a_{0}[M]+a_{1}[K]
$$

a ser devidamente calibrada, mediante a escolha criteriosa dos parâmetros $a_{0}$ e $a_{1}$. Com essa consideração, a taxa de amortecimento para cada modo de vibração fica caracterizada por: 


$$
\xi_{i}=\frac{a_{0}}{2 \omega_{i}}+\frac{a_{1} \omega_{i}}{2}
$$

Dessa expressão, pode-se perceber que cada modo de vibração terá uma taxa de amortecimento diferente. De fato, é possível impor, por exemplo, que os dois primeiros modos de vibração possuam dadas taxas de amortecimento, e resolver o sistema para obtenção dos coeficientes $a_{0}$ e $a_{1}$.

Alternativamente, pode-se obter a matriz $[C]$ de forma que ela satisfaça a seguinte relação:

$$
[\Phi]^{T}[C][\Phi]=\left[C^{*}\right]
$$

sendo a matriz $\left[C^{*}\right]$ diagonal, com termos $C^{*}{ }_{i j}=0$ e $C^{*}{ }_{i i}=2 \xi_{i} \omega_{i} M^{*}{ }_{i i}$, para $i \neq j$. Com essa consideração, conclui-se que:

$$
[C]=[\Phi]^{-T}\left[C^{*}\right][\Phi]^{-1}
$$

onde as matrizes $[\Phi]^{-T}$ e $[\Phi]^{-1}$ podem ser facilmente obtidas a partir de (2.27).

Segundo Fardis (2015), na maior parte dos casos, pode-se obter respostas sem perda considerável de precisão, ao assumir um comportamento não amortecido, proceder a uma análise modal e depois corrigir os resultados a partir de uma redução nas respostas, relativas a uma taxa de amortecimento adotada para cada modo de vibração.

Um conceito similar é apresentado a seguir, no método da superposição modal, a partir da aplicação das matrizes modais de massa $\left[M^{*}\right]$, rigidez $\left[K^{*}\right]$ e amortecimento $\left[C^{*}\right]$.

\subsection{SUPERPOSIÇÃO MODAL}

Para a análise linear, um sistema de múltiplos graus de liberdade pode ser entendido como a combinação de múltiplos sistemas de um grau de liberdade, onde cada SGL é equivalente a um modo de vibração do MGL. Esse conceito é importante pois, como será detalhado no item 3.3, é possível definir espectros de resposta para SGLs que permitam obter, de maneira mais expedita, suas respostas máximas para acelerações e deslocamentos. Assim, pode-se rapidamente obter as respostas de cada SGL que compõe um MGL e então combiná-los, de forma a obter as respostas finais para o sistema desejado.

O equacionamento desse conceito é feito tomando por base a propriedade de ortogonalidade da matriz modal, que permite desacoplar o sistema de $n$ graus de liberdade, utilizando a seguinte transformação de variáveis:

$$
\{x\}=[\Phi]\{y\}
$$


Aplicando-se o novo formato da variável na equação de movimento do MGL dada por (2.36), pode-se escrever:

$$
[M][\Phi]\{\ddot{y}\}+[C][\Phi]\{\dot{y}\}+[K][\Phi]\{y\}=\{p\}-[M]\{\beta\} \ddot{x}_{g}
$$

Admitindo-se a princípio a existência apenas de uma força externa, sem deslocamento imposto na base, isto é, $[M]\{\beta\} \ddot{x}_{g}=0$, pode-se rapidamente converter as matrizes de massa, rigidez e amortecimento, para matrizes modais, multiplicando-se os dois lados da equação por $[\Phi]^{T}$, que resulta em:

$$
\begin{gathered}
{[\Phi]^{T}[M][\Phi]\{\ddot{y}\}+[\Phi]^{T}[C][\Phi]\{\dot{y}\}+[\Phi]^{T}[K][\Phi]\{y\}=[\Phi]^{T}\{p\}} \\
{[M]^{*}\{\ddot{y}\}+[C]^{*}\{\dot{y}\}+[K]^{*}\{y\}=\{p\}^{*}}
\end{gathered}
$$

Consequentemente, para uma análise linear, onde a matriz de amortecimento respeite a propriedade de proporcionalidade expressa em (2.31) ou em (2.33), tem-se todas as matrizes modais diagonais, permitindo-se assumir que o problema inicial de $n$ graus de liberdade seja representado por $n$ problemas de um grau de liberdade, para os quais a equação de cada modo de vibração $j$ é dada por:

$$
M^{*} \ddot{y}_{j}+C^{*} \dot{\mathrm{y}}_{j}+K^{*}{ }_{j} \mathrm{y}_{j}=p^{*}{ }_{j}
$$

Substituindo-se o amortecimento $C^{*}{ }_{j}$ por $2 \xi_{j} \omega_{j} M^{*}{ }_{j}$ e fazendo a divisão de todos os termos por $M^{*}{ }_{j}$, chega-se à equação generalizada do modo $j$, dada por:

$$
\ddot{\mathrm{y}}_{j}+2 \xi_{j} \omega_{j} \dot{\mathrm{y}}_{j}+\omega_{j}{ }^{2} \mathrm{y}_{j}=\frac{p^{*}}{M^{*}}
$$

A conversão da força externa aplicada para excitações impostas na base, para a representação de uma ação sísmica, por exemplo, pode ser feita por:

$$
\frac{p^{*}{ }_{j}(t)}{M^{*}{ }_{j}}=-\ddot{x}_{g}(t) \frac{\left\{\Phi_{j}\right\}^{T}[M]\{\beta\}}{M^{*}{ }_{j}}=-\ddot{x}_{g}(t) L_{j}
$$

Resultando em

$$
\ddot{\mathrm{y}}_{j}+2 \xi_{j} \omega_{j} \dot{\mathrm{y}}_{j}+\omega_{j}^{2} \mathrm{y}_{j}=-\ddot{x}_{g}(t) L_{j}
$$

onde $L_{j}$ é chamado de fator de participação modal e representa a parcela de massa da estrutura participante em cada modo de vibração $j$, em relação à massa total. Esse fator é um importante critério para as análises espectrais, conforme é visto mais adiante. 
A equação (2.41) pode ser resolvida para $\mathrm{y}_{j}(\mathrm{t})$ numericamente, por qualquer método adequado para solucionar equações diferenciais SGL, uma vez que sejam conhecidas as condições iniciais $\mathrm{y}_{j}(0)$ e $\dot{\mathrm{y}}_{j}(0)$. A solução para $\mathrm{y}_{j}(\mathrm{t})$ retorna o resultado parcial dos deslocamentos do sistema, referentes ao modo $j$, na variável transformada, possibilitando a obtenção das respostas finais, na variável original, por meio da superposição dos efeitos de cada modo, dado por:

$$
\{x\}(t)=[\Phi]\{y\}(t)=\sum_{i=1}^{n} \Phi_{i} y_{i}(t)
$$




\section{ANÁLISE SÍSMICA DE EDIFICAÇÕES}

O território brasileiro fica, em grande parte, situado em uma região interna na placa tectônica sul-americana, consideravelmente distante das regiões de contato entre placas, onde as atividades sísmicas são mais frequentes e intensas. De fato, o Brasil possui uma atividade sísmica muito inferior a muitas outras regiões no globo terrestre, entretanto, os efeitos dessas atividades em edificações não devem ser negligenciados. Portanto, é de grande importância que os engenheiros sejam capazes de desenvolver projetos estruturais viáveis que contabilizem corretamente os efeitos desse tipo de carregamento, sendo capazes de resisti-los adequadamente.

A NBR 15421 (2006) apresenta alguns dos critérios mínimos que devem ser atendidos para o dimensionamento de edificações sismo-resistentes. Entretanto, além das provisões serem bastante limitadas em função da baixa sismicidade do território brasileiro, grande parte das informações necessárias para a elaboração de um projeto estrutural não estão presentes, por exemplo: os critérios de detalhamento estrutural em função da classe de ductilidade admitida não são apresentados; é apresentado em detalhe apenas o método das forças laterais equivalentes, que é discutido no item 3.7.1, mas que, em se tratando de um método bastante simplificado, muitas vezes não é o mais indicado para algumas intensidades sísmicas ou configurações estruturais; outros métodos, como a análise espectral ou análise no histórico do tempo são apenas mencionados, ou tratados de forma bastante superficial.

Neste estudo, visando a possibilitar a extensão dos dados analisados para situações com características sísmicas diferentes das encontradas no Brasil e considerando que a norma brasileira não apresenta provisões relativas a estruturas com isolamento de base, é utilizada como referência a norma europeia Eurocódigo 8 (2005) e, eventualmente, a norma americana ASCE/SEI 7 (2016).

\subsection{DETERMINAÇÃO DA AÇÃO SÍSMICA}

O Eurocódigo 8 (2005), assim como a NBR 15421 (2006), define os parâmetros que caracterizam a ação sísmica de projeto em função de um período de retorno de 475 anos, que é equivalente a uma probabilidade de $10 \%$ do sismo de projeto ser excedido em 50 anos. Para as verificações de limitação de danos, feitas em função do deslocamento entre lajes, o período de retorno considerado é de 95 anos, que corresponde a 10\% de probabilidade de superar o sismo de projeto em um período de 10 anos. 
Via de regra, a ação sísmica é caracterizada por acelerações horizontais, originadas por ondas de cisalhamento, denominadas de "tipo S", e por acelerações verticais, geradas por ondas de pressão, denominadas “tipo P”. Segundo Parisenti (2011), as acelerações verticais têm despertado menos o interesse de engenheiros civis, em parte, pois o dimensionamento estático considera coeficientes de ponderação mais conservadores para os carregamentos produzidos pela gravidade, geralmente originando estruturas com fatores de segurança mais elevados para carregamentos na direção vertical. Ainda assim, cuidados devem ser tomados em relação às acelerações verticais, conforme se indica no item 4.3.3.5.2 do Eurocódigo 8 (2005), para evitar o colapso de edificações por esmagamento entre pisos, a exemplo do que se observou no caso do sismo Great Hanshin em 1995 no Japão. Algumas estruturas como barragens e fundações de estruturas superficiais também podem demandar maior atenção a estes carregamentos. Não obstante, neste estudo as acelerações verticais não serão consideradas nas análises.

Um dos principais parâmetros necessários para definição da ação sísmica é o valor de referência para a aceleração máxima na superfície do terreno $\left(a_{g r}\right)$. O anexo nacional de cada país da União Europeia define zonas sísmicas para seu território, onde cada zona possui um valor de $a_{g r}$ constante que é utilizado como referência para determinar o movimento sísmico da região. As ações, em geral, são representadas por um espectro de resposta elástica, que é explanado no item 3.3. A partir desse espectro são obtidas as variáveis necessárias para a aplicação dos diversos métodos de análise que são detalhados no item 3.7. A definição do espectro de resposta elástica é feita a partir do valor de referência da aceleração $a_{g r}$, multiplicada por um coeficiente de importância $\gamma_{f}$, que leva em conta a confiabilidade que se deseja garantir para o dimensionamento de cada tipo de edificação. Assim, o parâmetro que define a aceleração máxima considerada é dado por:

$$
a_{g}=a_{g r} \gamma_{f}
$$

O coeficiente $\gamma_{f}$ possui valores-base fornecidos pelo Eurocódigo 8 (2005). Entretanto, valores diferentes podem ser sugeridos pelo anexo nacional, em função da fiabilidade que se deseja alcançar para determinada região. A Tabela 1 apresenta os valores de $\gamma_{f}$ definidos pelo Eurocódigo 8 e pelo anexo nacional português. 
Tabela 1 - Coeficientes de importância. Fonte: Adaptado de Eurocódigo 8 (2005)

\begin{tabular}{|c|c|c|c|}
\hline $\begin{array}{c}\text { Categoria de } \\
\text { utilização }\end{array}$ & Natureza da ocupação & $\begin{array}{c}\gamma_{f} \\
\text { (Eurocódigo) }\end{array}$ & $\begin{array}{c}\gamma_{f} \\
\text { (Anexo Português) }\end{array}$ \\
\hline I & Edifícios de menor importância (Agrícolas) & 0,8 & 0,65 \\
\hline II & Edifícios comuns & 1 & 1 \\
\hline III & Edifícios mais relevantes (escolas, etc.) & 1,2 & 1,45 \\
\hline IV & Edifícios essenciais (hospitais, quartéis, etc.) & 1,4 & 1,95 \\
\hline
\end{tabular}

\subsection{CLASSIFICAÇÃO DO TERRENO}

As ações sísmicas são transmitidas para as estruturas através do terreno no local de implantação. Portanto, além da ampla caracterização da ação sísmica fornecida pela definição das zonas sísmicas, é necessário considerar a influência específica que cada tipo de terreno pode ter na condução e transmissão das ações, que é feita por meio da aplicação de coeficientes de majoração das acelerações e de parâmetros que alteram a forma do espectro de resposta (ver Figura 17 e Tabela 6). Com esse objetivo, alguns parâmetros para a definição do espectro de resposta elástica são obtidos em função do tipo de terreno, que, por sua vez, é caracterizado em função da velocidade de propagação das ondas de cisalhamento nos 30 metros abaixo da superfície do terreno $\left(v_{s, 30}\right)$. Nos casos em que $v_{s, 30}$ não possa ser obtida, os terrenos podem ser definidos com base em ensaios SPT, conforme as informações fornecidas pela Tabela 2. 
Tabela 2 - Classificação do terreno. Fonte: Eurocódigo 8 (2005)

\begin{tabular}{|c|c|c|c|}
\hline \multirow{2}{*}{$\begin{array}{l}\text { Tipo de } \\
\text { terreno }\end{array}$} & \multirow[b]{2}{*}{ Descrição do perfil estratigráfico } & \multicolumn{2}{|c|}{ Parâmetros } \\
\hline & & $v_{\mathrm{s}, 30}(\mathrm{~m} / \mathrm{s})$ & $\underset{\text { (pancadas } / 30 \mathrm{~cm} \text { ) }}{N_{\mathrm{SPT}}}$ \\
\hline A & $\begin{array}{l}\text { Rocha ou outra formação geológica de tipo } \\
\text { rochoso, que inclua, no máximo, } 5 \mathrm{~m} \text { de } \\
\text { material mais fraco à superfície }\end{array}$ & $>800$ & - \\
\hline B & $\begin{array}{l}\text { Depósitos de areia muito compacta, de seixo } \\
\text { (cascalho) ou de argila muito rija, com uma } \\
\text { espessura de, pelo menos, várias dezenas de } \\
\text { metros, caracterizados por um aumento } \\
\text { gradual das propriedades mecânicas com a } \\
\text { profundidade }\end{array}$ & $360-800$ & $>50$ \\
\hline $\mathrm{C}$ & $\begin{array}{l}\text { Depósitos profundos de areia compacta ou } \\
\text { medianamente compacta, de seixo } \\
\text { (cascalho) ou de argila rija com uma } \\
\text { espessura entre várias dezenas e muitas } \\
\text { centenas de metros }\end{array}$ & $180-360$ & $15-50$ \\
\hline $\mathrm{D}$ & $\begin{array}{l}\text { Depósitos de solos não coesivos de } \\
\text { compacidade baixa a média (com ou sem } \\
\text { alguns estratos de solos coesivos moles), ou } \\
\text { de solos predominantemente coesivos de } \\
\text { consistência mole a dura }\end{array}$ & $<180$ & $<15$ \\
\hline $\mathrm{E}$ & $\begin{array}{l}\text { Perfil de solo com um estrato aluvionar } \\
\text { superficial com valores de } v_{\mathrm{s}} \text { do tipo C ou D } \\
\text { e uma espessura entre cerca de } 5 \mathrm{~m} \text { e } 20 \mathrm{~m} \text {, } \\
\text { situado sobre um estrato mais rígido com } \\
v_{\mathrm{s}}>800 \mathrm{~m} / \mathrm{s}\end{array}$ & & \\
\hline$S_{1}$ & $\begin{array}{l}\text { Depósitos constituídos ou contendo um } \\
\text { estrato com pelo menos } 10 \mathrm{~m} \text { de espessura } \\
\text { de argilas ou siltes moles com um elevado } \\
\text { índice de plasticidade }(\mathrm{PI}>40) \text { e um } \\
\text { elevado teor de água }\end{array}$ & $\begin{array}{c}<100 \\
\text { (indicativo) }\end{array}$ & - \\
\hline$S_{2}$ & $\begin{array}{l}\text { Depósitos de solos com potencial de } \\
\text { liquefacção, de argilas sensíveis ou qualquer } \\
\text { outro perfil de terreno não incluído nos tipos } \\
\text { A - E ou } S_{1}\end{array}$ & & \\
\hline
\end{tabular}

Os terrenos classificados como $S_{1}$ ou $S_{2}$ exigem atenção especial, pois frequentemente apresentam velocidades de propagação muito baixas e amortecimento interno reduzido, podendo gerar amplificações dinâmicas atípicas e interação solo-estrutura imprevisível. Assim, um estudo específico deve ser realizado nesses casos para determinação da ação sísmica a ser considerada.

\subsection{ESPECTRO DE RESPOSTA DE ACELERAÇÕES SÍSMICAS}

No âmbito das análises sísmicas, um espectro de resposta é fundamentalmente o conjunto das respostas máximas de osciladores de um grau de liberdade com períodos naturais varrendo a faixa de valores relevantes, para uma determinada excitação e com uma taxa de amortecimento $\xi$ específica, geralmente no intervalo de zero a quatro segundos. Usualmente na engenharia sísmica, espectros de resposta são expressos por gráficos, em 
termos de pseudoacelerações $\left(S_{a}\right)$, pseudovelocidades $\left(S_{v}\right)$ ou pseudodeslocamentos $\left(S_{d}\right)$, onde, no eixo das abcissas, fica representado o período, em segundos, relativo à frequência natural dos SGLs considerados, enquanto o eixo das ordenadas apresenta os valores do termo desejado, como, por exemplo, das pseudoacelerações, para cada período.

Assim, a elaboração de um espectro de resposta, para $S_{d}$, vem da solução da equação (2.7), onde SGLs, com períodos naturais variando de zero a um período de interesse, são resolvidos para uma taxa de amortecimento definida, por meio de algum método de integração numérica (por exemplo, o método de Newmark, que é explicado no item (3.4), de modo a se obter o máximo deslocamento para cada caso. Os deslocamentos obtidos são, então, representados em um gráfico, em função do período relativo à sua frequência natural $\omega$

A resposta obtida em termos de deslocamentos $(D)$, pode ser facilmente convertida para pseudovelocidades ou pseudoacelerações por meio da seguinte relação:

$$
S_{a}=\omega S_{v}=\omega^{2} D
$$

Uma vez determinado o espectro de resposta e conhecendo-se as propriedades de massa $(m)$ e rigidez $(k)$ do sistema analisado, as forças elásticas máximas também podem ser rapidamente encontradas, através da aplicação de:

$$
F_{\text {máx }}=k D=\omega^{2} m D=m S_{a}
$$

Como pode ser observado em (2.7), a solução do sistema independe das específicas propriedades de massa e rigidez do sistema de um grau de liberdade, dependendo, sim, de sua frequência natural e taxa de amortecimento, ou seja, uma vez gerado o espectro, podese obter imediatamente as respostas máximas para sistemas com quaisquer combinações de massa e rigidez que forneçam um período natural de vibração natural e uma taxa de amortecimento compreendidos entre os valores que definem esse espectro.

A utilização de espectros de resposta é de grande interesse para a engenharia sísmica pois, conforme visto no item 2.3, mesmo estruturas mais complexas, com múltiplos graus de liberdade, geralmente podem ser convertidas em uma combinação de sistemas SGL e, para estes, a solução em termos de deslocamentos e forças elásticas é praticamente imediata.

De fato, não é coerente aplicar um espectro de resposta definido em função de uma única excitação, diretamente na análise de um projeto estrutural genérico, uma vez que ele irá fornecer as respostas específicas para o carregamento utilizado na definição do espectro, 
enquanto que, em geral, visa-se a obter as respostas para um carregamento sísmico probabilístico inicialmente não especificado.

Com o objetivo de adaptar a aplicação desses espectros para análises sísmicas gerais, introduz-se o conceito de espectros de resposta elástica definido no Eurocódigo 8 (2005). Estes espectros são versões mais abrangentes, formuladas a partir de uma envoltória de espectros de respostas, de modo a representar uma gama extensa de terremotos possíveis, baseados na localização, tipo de fundação e fiabilidade da estrutura a ser analisada. A Figura 8 ilustra a diferença entre um único espectro de resposta e a abrangência de um espectro de resposta elástica da norma.

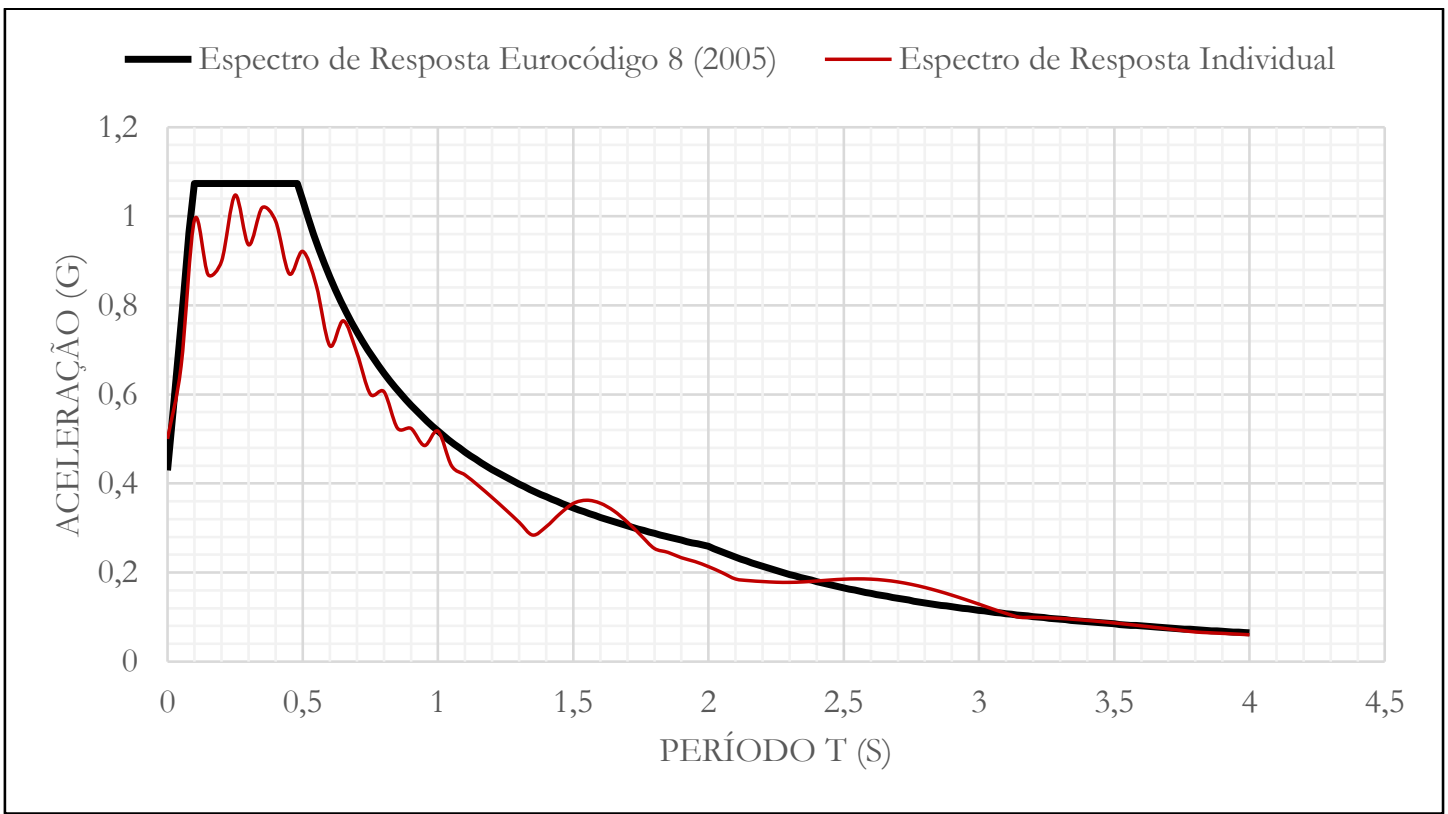

Figura 8: Exemplos de espectros de resposta individual e normativo. Fonte: autor.

Um espectro de resposta elástica de engenharia sísmica, usualmente, fornece a máxima pseudoaceleração, normalizada em relação à aceleração da gravidade, para uma taxa de amortecimento de 5\%. A aplicação destes em análises sísmicas pode ser feita a partir da combinação das respostas máximas para cada modo de vibrar da estrutura, onde cada modo é representado por um SGL. Entretanto, por possuírem períodos variados, as máximas respostas de cada modo de vibração ocorrem em momentos distintos, assim, um simples somatório de todas as respostas máximas forneceria um resultado superestimado. No item 3.7.2 são apresentados alguns métodos de combinação que corrigem esse problema, possibilitando obter respostas mais coerentes. 


\subsection{ACELEROGRAMAS}

Um terremoto, do ponto de vista da análise estrutural, é entendido como uma excitação de suporte, onde um deslocamento é aplicado à base da estrutura. Entretanto, os efeitos causados por um terremoto dependem mais da forma como esse deslocamento é aplicado, do que da própria amplitude do movimento. O carregamento aplicado em uma análise sísmica, conforme equacionado em (2.40) e (2.41), é função da aceleração externa introduzida na base da estrutura. Portanto, para que se possa realizar a análise no domínio do tempo, ou mesmo gerar um espectro de resposta, necessita-se conhecer a variação das acelerações no tempo, impostas pelo terremoto. Ao gráfico que representa a intensidade das acelerações em função do tempo, dá-se o nome de acelerograma.

Usualmente, o eixo das abcissas de um acelerograma apresenta o tempo, em segundos, enquanto o eixo das ordenadas pode apresentar as acelerações em $\mathrm{m} / \mathrm{s}^{2}$, ou normalizada em relação a aceleração da gravidade, com unidade $g$, conforme ilustrado na Figura 9.

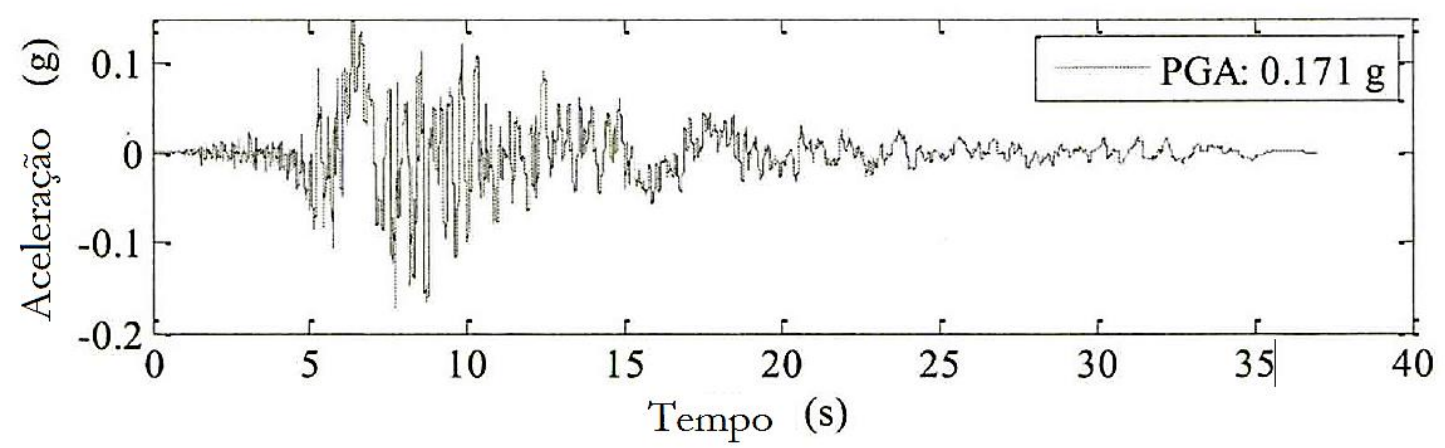

Figura 9: Exemplo de acelerograma - El Centro. Fonte: Sun (2011).

O acelerograma da Figura 9 representa as acelerações do terremoto Imperial V alley de 1979, registrado pela estação 412 El Centro 10 na divisa do México com os Estados Unidos. Pode-se notar no gráfico que a representação normalizada permite identificar facilmente a máxima aceleração atingida (PGA - Peak Ground Acceleration) de 0,171g, que é um dos parâmetros mais importantes para a caracterização da ação sísmica.

Outra importante informação fornecida pelos acelerogramas é a duração do terremoto, que pode influenciar consideravelmente nas respostas estruturais de uma análise sísmica. A Figura 10 apresenta o acelerograma característico do terremoto de Chi-Chi em Taiwan, registrado pela estação TCU031. Pode-se notar que, apesar do PGA de o terremoto de Imperial Valley ser superior ao de Chi-Chi, o tempo de duração deste é praticamente o 
dobro, conferindo-lhe características bastante diferentes do anterior, o que pode produzir respostas desproporcionais à variação do PGA.

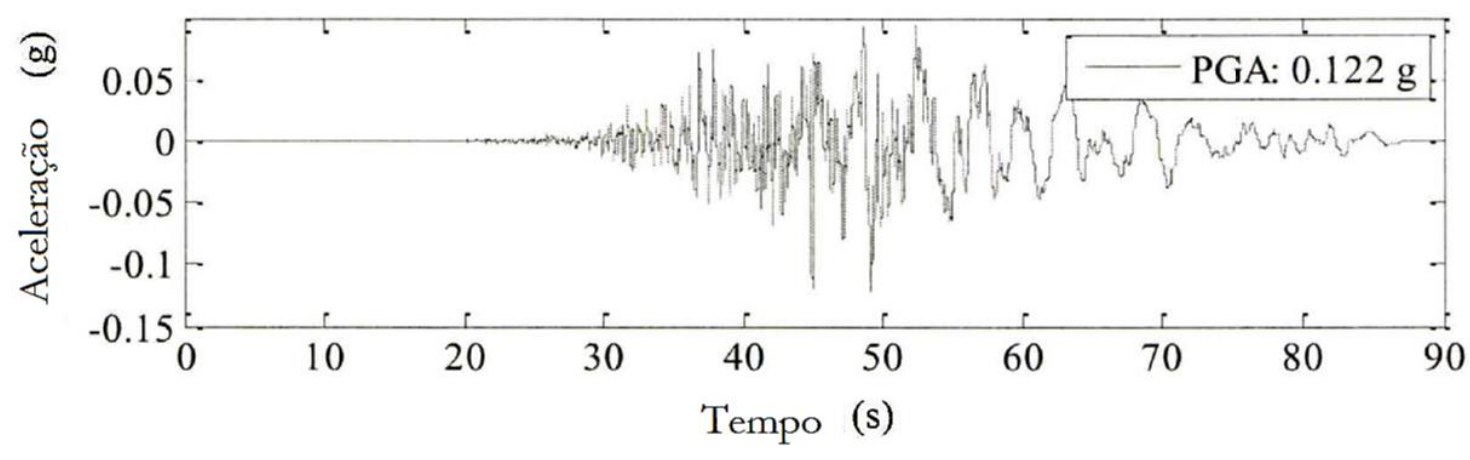

Figura 10: Exemplo de acelerograma - TCU031. Fonte: Sun (2011).

Para aplicações práticas em análises sísmicas, é possível utilizar acelerogramas de terremotos reais, "escalados" de modo a atingir o PGA adequado à localização do projeto a ser analisado. Segundo Quintero (2017), essa abordagem pode não ser a mais adequada, em função da pequena probabilidade de que exista um conjunto suficiente de registros que atenda às características necessárias para que seja aplicado a um local específico.

Uma alternativa possível é a geração de acelerogramas artificiais, estudados no Brasil de forma pioneira por Sergio Hampshire C. Santos (1980), que sejam adequados ao projeto em análise, atendendo às características desejadas e adequando-se aos espectros de resposta definidos nas normas. A geração de acelerogramas artificiais permite controlar melhor a amplitude das acelerações, a duração do evento, as frequências atingidas, a aderência ao espectro de resposta, dentre outras características que se deseja conferir aos carregamentos sísmicos.

Em Quintero (2017) e Rodrigues (2012) encontram-se metodologias para a geração desses acelerogramas artificiais. Postula-se que um acelerograma pode ser modelado por um processo gaussiano estacionário, com densidade espectral derivada do espectro de velocidades. Esse processo estacionário, por sua vez, pode ser bem representado por meio de um sinal de "ruído branco", definido como um processo estacionário de banda larga, com igual contribuição em todas as frequências, com o conteúdo de frequências filtrado por um espectro de potência que the proporcione as características desejadas. Acelerogramas artificiais gerados dessa forma são aceitáveis para boa parte dos estudos sísmicos, entretanto, movimentos sísmicos de longa duração com baixa intensidade exigem representação por meio de um processo não estacionário, considerando os seguintes trechos: inicialmente crescente a partir do repouso, acelerações máximas e atenuação até o 
repouso. Para atribuir essas características, pode-se multiplicar estes acelerogramas por uma função-envoltória, que corrige a intensidade do sinal em função do tempo, imprimindo a estes uma forma desejada. Algumas das diversas funções-envoltória que podem ser aplicadas estão apresentadas na Figura 11:
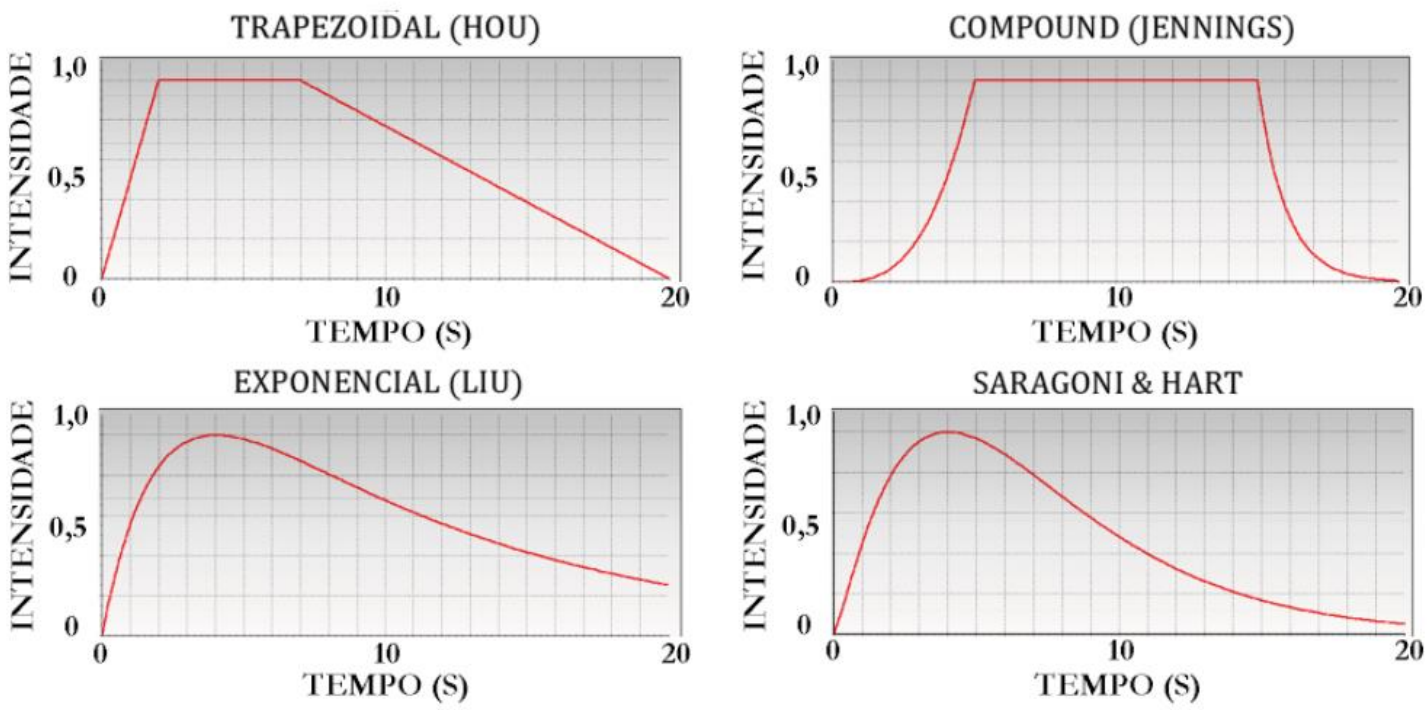

Figura 11: Funções-envoltória. Fonte: Adaptado de SeismoArtif (2018).

Uma vez ajustadas as intensidades das ações em função do tempo, aplica-se um processo iterativo proposto por Levy e Wilkinson (1976), e explicado em Quintero (2017), que consiste em encontrar coeficientes de amplitude para cada período natural, buscando que o acelerograma tenha uma boa aderência ao espectro de resposta elástica.

Exceto em casos específicos, a duração mínima de um acelerograma gerado artificialmente, para aplicação em análises sísmicas, é de 10 segundos.

A viabilidade da utilização de um acelerograma artificialmente gerado pode ser verificada por meio da recuperação do espectro de resposta. Por meio de algum método de integração numérica para sistemas SGL, pode-se resolver a equação do movimento para uma sequência de SGLs, com períodos naturais variando de quase zero a quatro segundos, por exemplo, adotando para as excitações externas as acelerações geradas pelo acelerograma artificial. O método de Newmark, explicado no item 3.4.1, mostra-se adequado para integrar a equação de movimento proposta, além de sua implantação em software como MatLab ou Excel ser bastante simples, sendo assim uma ótima ferramenta para esta verificação. 


\subsubsection{Métodos para solução do SGL}

As respostas dinâmicas dos sistemas SGL podem ser obtidas de diversas formas. Uma delas é realizar a análise no domínio da frequência. Se já for especificado o espectro das acelerações impostas à base em função da frequência, segue-se o procedimento descrito na seção 3.7.2. Entretanto, se tiver sido especificado o acelerograma de projeto, deve-se, preliminarmente, obter-se o espectro das acelerações. Parte-se do princípio de que um carregamento qualquer pode ser entendido como uma série de carregamentos periódicos. A aplicação da transformada discreta de Fourier (DFT) a um carregamento dado pelo acelerograma de projeto gera um espectro que representa a magnitude das acelerações em função da frequência, permitindo antecipar qualitativamente as respostas para um sistema estrutural de interesse. A partir daí, é possível equacionar a resposta dinâmica no domínio da frequência, conforme descrito na seção 3.7.2, obtendo-se os deslocamentos em função da frequência. A Figura 12 e a Figura 13, a seguir, apresentam dois acelerogramas, com seus respectivos espectros de potência, obtidos mediante a aplicação da DFT. Os acelerogramas apresentados são versões do sismo original, “escalados" para uma aceleração máxima de 0,15g. A DF'T do acelerograma permite verificar quais as frequências mais excitadas para determinado sismo, possibilitando qualificar a resposta das estruturas perante tais carregamentos. No exemplo das figuras, espera-se que o sismo de Lexington excite com maior intensidade estruturas menos rígidas, com frequências naturais próximas de $1 \mathrm{~Hz}$, enquanto o sismo de Caucete influencie mais estruturas com frequências entre 2,5 e 9Hz. Este é classificado como um sismo de banda larga, enquanto aquele tem classificação de banda estreita. 

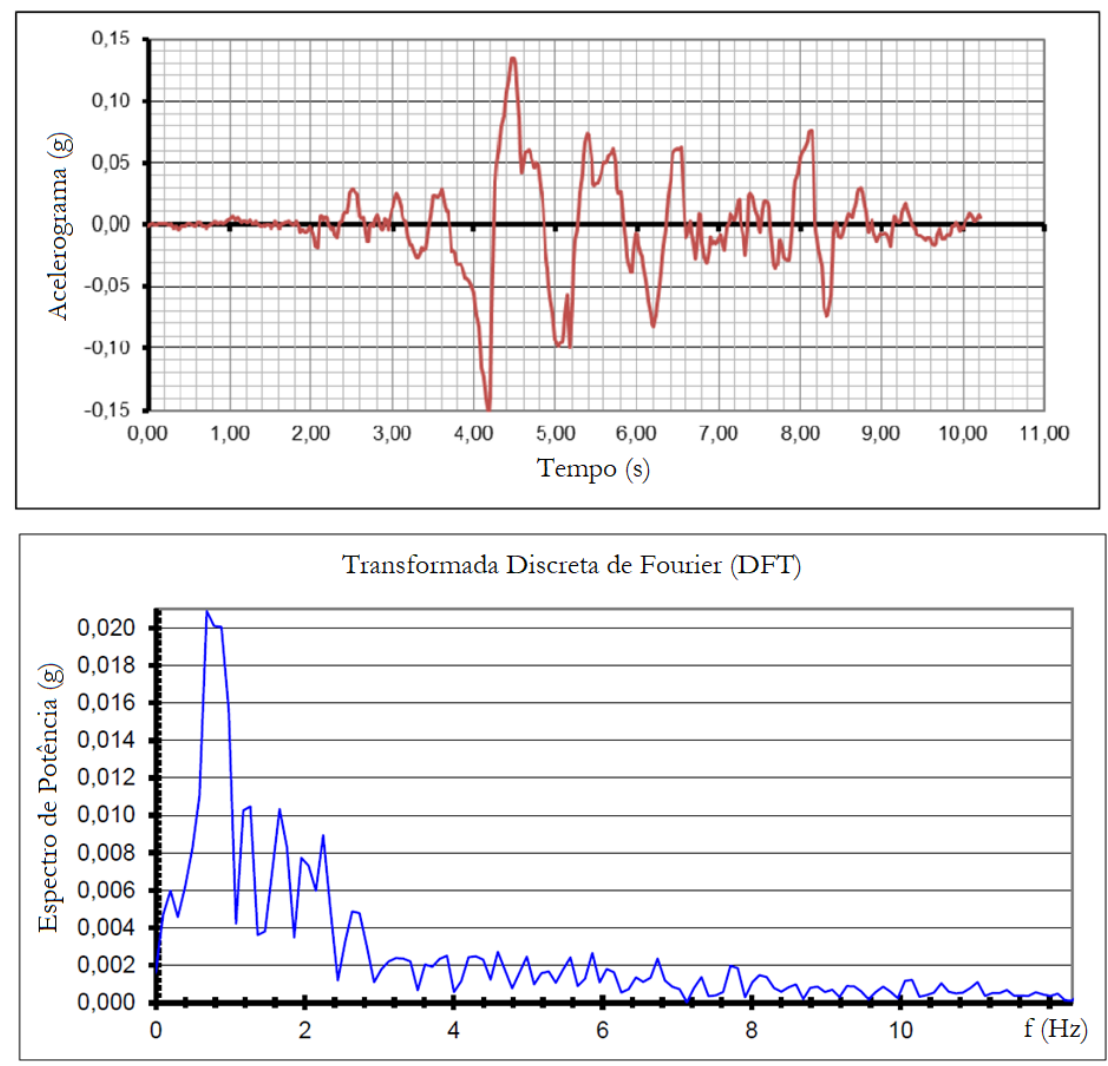

Figura 12: Acelerograma e Espectro de potência - Sismo Lexington. Fonte: Adaptado de Parisenti (2011)
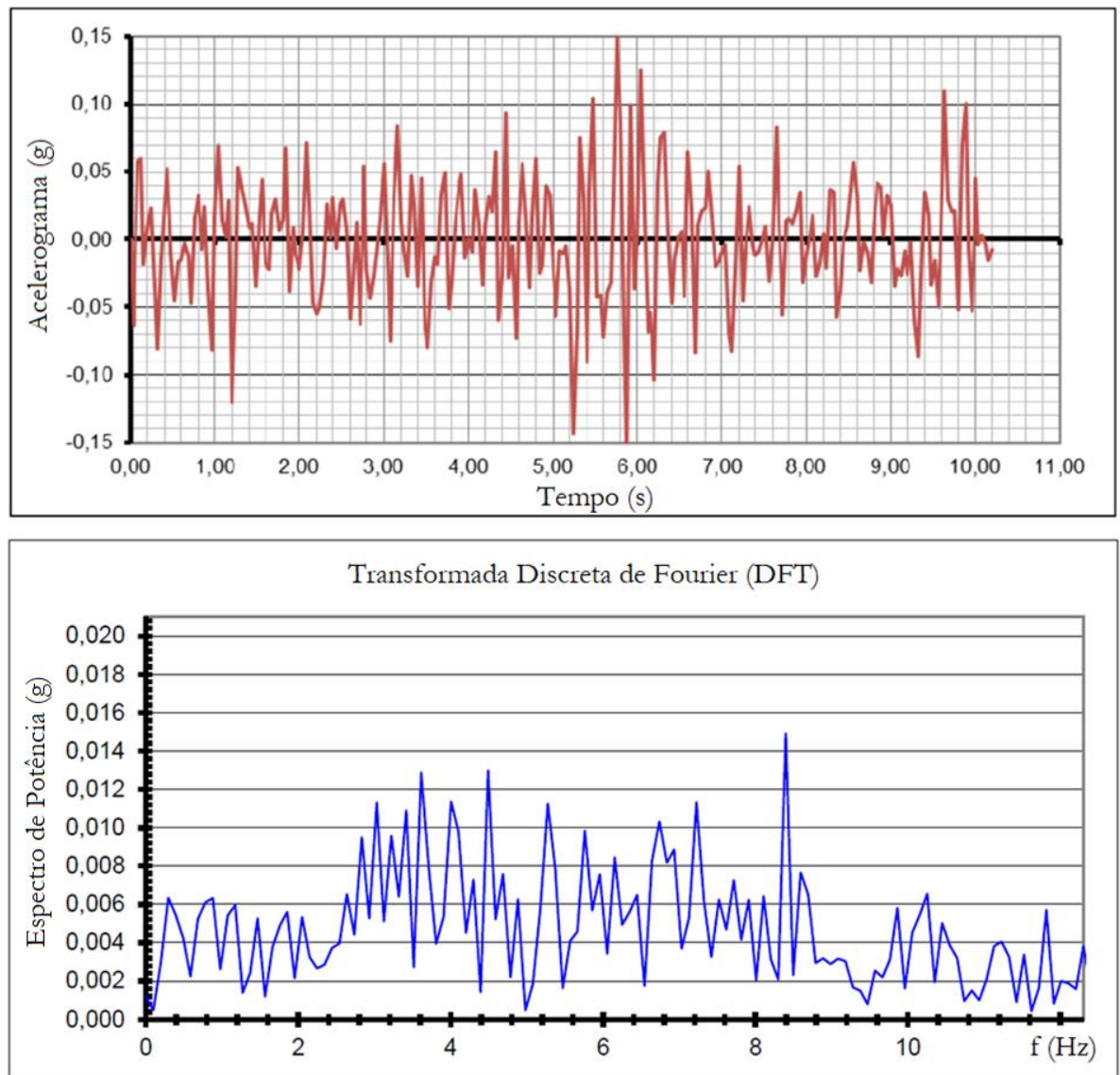

Figura 13: Acelerograma e Espectro de potência - sismo Caucete; Fonte: Adaptado de Parisenti (2011) 
Outra alternativa para analisar a equação do movimento é a integração numérica no domínio do tempo da própria equação do movimento apresentada em (2.6) e (2.7). Neste caso, se o acelerograma de projeto já tiver sido definido, procede-se diretamente como descrito na seção 3.7.3. Caso tenha sido fornecido o espectro de acelerações, ao invés do acelerograma de projeto, será necessário, preliminarmente, gerar um acelerograma artificial, conforme descrito na seção 3.4. Existem diversos métodos para realizar a integração das equações de movimento no domínio do tempo, dentre eles, o método de Runge-Kutta de $4^{\text {a }}$ ordem, o de Newmark e o de Wilson- $\theta$. Apresenta-se a seguir a aplicação do método de Newmark para:

$$
\ddot{x}_{i}+2 \omega \xi \dot{x}_{i}+\omega^{2} x_{i}=\frac{p_{i}}{m}
$$

O método parte do princípio de que sejam conhecidas as condições iniciais de deslocamento e velocidade, dadas respectivamente por $x_{0}$ e $\dot{x}_{0}$, assim como a função de carregamento (por unidade de massa) $\frac{p}{m}$. Por conveniência, discretiza-se a variável tempo em passos $\Delta t$ constantes; assim, procura-se encontrar os deslocamentos, velocidades e acelerações em cada tempo $t_{i}=i \Delta \mathrm{t}$.

De (3.4), pode-se obter a aceleração no tempo inicial $t_{0}$, conforme:

$$
\ddot{x}_{0}=p_{0}-2 \omega \xi \dot{x}_{0}-\omega^{2} x_{0}
$$

A aplicação de (3.5) garante que todas as variáveis da equação sejam conhecidas no tempo inicial. De fato, é necessário conhecer o carregamento em qualquer tempo $t_{i}$. As seguintes expressões são propostas:

$$
\begin{gathered}
\dot{x}_{i+1}=\dot{x}_{i}+(1-\delta) \Delta t \ddot{x}_{i}+\delta \Delta t \ddot{x}_{i+1} \\
x_{i+1}=x_{i}+\dot{x}_{i} \Delta t+\left(\frac{1}{2}-\alpha\right) \Delta t^{2} \ddot{x}_{i}+\alpha \Delta t^{2} \ddot{x}_{i+1}
\end{gathered}
$$

onde $\delta$ e $\alpha$ são constantes arbitrárias, que são discutidas mais adiante.

As equações (3.13) e (3.14) podem ser resolvidas para $\dot{x}_{i+1}$ e $\ddot{x}_{i+1}$, em função de $x_{i+1}$, resultando em:

$$
\begin{gathered}
\ddot{x}_{i+1}=\frac{1}{\alpha \Delta t^{2}}\left(x_{i+1}-x_{i}\right)-\frac{1}{\alpha \Delta t} \dot{x}_{i}-\left(\frac{1}{2 \alpha}-1\right) \ddot{x}_{i} \\
\dot{x}_{i+1}=\dot{x}_{i}+(1-\delta) \Delta t \ddot{x}_{i}+\delta \Delta t \ddot{x}_{i+1}
\end{gathered}
$$

Aplicando-se (3.8) e (3.9) em (3.5), pode-se escrever: 


$$
\hat{k} x_{i+1}=\hat{R}_{i+1}
$$

onde

$$
\begin{gathered}
\hat{k}=\omega^{2}+\frac{1}{\alpha \Delta t^{2}}+\frac{\delta}{\alpha \Delta t} 2 \omega \xi \\
\hat{R}_{i+1}=\frac{p_{i+1}}{m}+\left[\frac{1}{\alpha \Delta t^{2}} x_{i}+\frac{1}{\alpha \Delta t} \dot{x}_{i}+\left(\frac{1}{2 \alpha}-1\right) \ddot{x}_{i}\right] \\
+2 \omega \xi\left[\frac{\delta}{\alpha \Delta t} x_{i}+\left(\frac{\delta}{\alpha}-1\right) \dot{x}_{i}+\left(\frac{\delta}{\alpha}-2\right) \frac{\Delta t}{2} \ddot{x}_{i}\right]
\end{gathered}
$$

Nota-se que, para um $\Delta t$ constante, $\hat{k}$ também é constante. $\widehat{R}_{i+1}$ depende apenas das variáveis conhecidas, portanto, o deslocamento $x_{i+1}$ pode ser obtido em (3.10), o que permite obter a aceleração $\ddot{x}_{i+1}$ em (3.8) e posteriormente, a velocidade $\dot{x}_{i+1} \mathrm{em}$ (3.9). Esse procedimento conclui um passo de integração do método, que pode ser repetido para obtenção dos deslocamentos, velocidades e acelerações seguintes, respectivamente, $x_{i+2}$, $\dot{x}_{i+2}, \ddot{x}_{i+2}$, e assim por diante, até um tempo final $t_{f}$ desejado.

É importante saber que o método de Newmark é incondicionalmente estável apenas para algumas escolhas específicas de valores para as constantes $\delta$ e $\alpha$, a saber: $\delta \geq \frac{1}{2}$ e $\alpha \geq \frac{1}{4}\left(\frac{1}{2}+\delta\right)^{2}$ (Bathe, 1982).

Um caso particular do método de Newmark é o chamado método de Euler-Gauss. Este se baseia em uma aproximação que considera um movimento uniformemente acelerado com aceleração constante em cada intervalo de tempo $\Delta t$, adotando-se para tanto seu valor médio entre $t_{i}$ e $t_{i+1}$, expresso por $\frac{\ddot{x}_{i}+\ddot{x}_{i+1}}{2}$.

Observa-se que a determinação da aceleração média depende da aceleração no final do período. Da aceleração média é possível escrever, para a velocidade, a seguinte equação:

$$
\dot{x}_{i+1}=\dot{x}_{i}+\frac{1}{2}\left(\ddot{x}_{i}+\ddot{x}_{i+1}\right) \Delta t
$$

Os deslocamentos podem ser obtidos integrando-se uma vez (3.13) no tempo:

$$
x_{i+1}=x_{i}+\dot{x}_{i} \Delta t+\frac{1}{4}\left(\ddot{x}_{i}+\ddot{x}_{i+1}\right) \Delta t^{2}
$$


As expressões (3.13)e (3.14) são equivalentes às expressões (3.6) e (3.7), respectivamente, assumindo $\delta=\frac{1}{2}$ e $\alpha=\frac{1}{4}$, o que torna o método incondicionalmente estável, ou seja, sempre irá convergir para a solução.

Com essas considerações, as expressões (3.8) e (3.9) tornam-se, respectivamente:

$$
\begin{gathered}
\ddot{x}_{i+1}=\frac{4}{\Delta t^{2}}\left(x_{i+1}-x_{i}\right)-\frac{4}{\Delta t} \dot{x}_{i}-\ddot{x}_{i} \\
\dot{x}_{i+1}=\dot{x}_{i}+\frac{\Delta t}{2} \ddot{x}_{i}+\frac{\Delta t}{2} \ddot{x}_{i+1}
\end{gathered}
$$

Consequentemente, as expressões (3.11) e (3.12) são respectivamente reescritas como:

$$
\begin{gathered}
\hat{k}=\omega^{2}+\frac{4}{\Delta t^{2}}+\frac{2}{\Delta t} 2 \omega \xi \\
\hat{R}_{i+1}=\frac{p_{i+1}}{m}+\left(\frac{4}{\Delta t^{2}} x_{i}+\frac{4}{\Delta t} \dot{x}_{i}+\ddot{x}_{i}\right)+2 \omega \xi\left(\frac{2}{\Delta t} x_{i}+\dot{x}_{i}\right)
\end{gathered}
$$

Quanto menor for o valor adotado $\Delta t$, melhor será a aproximação obtida, tanto para o método de Newmark, quanto Euler-Gauss. Segundo Mazzilli (2015), é recomendável adotar um valor da ordem de $\frac{T^{*}}{20}$, onde $T^{*}$ representa o menor valor entre o período natural do sistema e o menor período forçante relevante.

A aplicação dos dois métodos apresentados pode ser facilmente convertida de uma aplicação de força externa para uma excitação de suporte, adotando-se em (3.12) ou (3.18), $\frac{p_{i+1}}{m}=-\ddot{x}_{g_{i+1}}$.

Esses métodos podem ser utilizados, conforme se demonstra na Figura 15, para atender ao critério iterativo referido no item 3.4, onde se faz verificar a aderência de um acelerograma gerado artificialmente a um espectro de resposta elástica que se pretende atingir, por meio da recuperação do espectro de resposta do acelerograma. Eventualmente, pode-se também realizar a geração de um espectro de resposta médio entre diversos acelerogramas, baseado na média das respostas obtidas para cada acelerograma.

$\mathrm{Na}$ Figura 14 ilustra-se um acelerograma, arbitrariamente denomidado HT0,20gD, gerado pelo software SeismoArtif (2016), onde foi adotada uma taxa de amortecimento de 5\%, função de envoltória tipo Saragoni \& Hart (ver Figura 11) e espectro de resposta elástica a ser atingido para uma aceleração característica de $0,20 \mathrm{~g}$ em terreno de classificação "D”, com as considerações do Eurocódigo 8 (2005). 


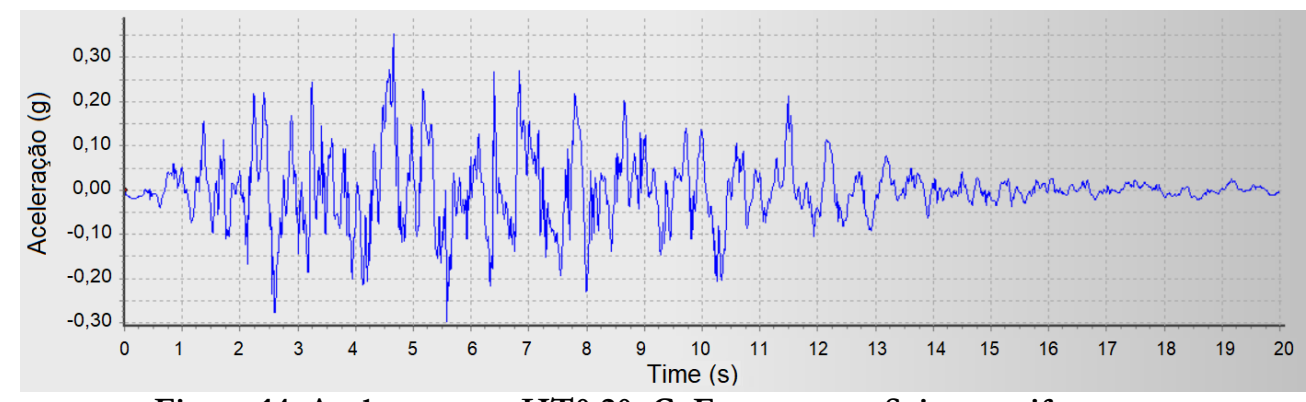

Figura 14: Acelerograma HT0,20gC. Fonte: autor-Seismoartif

A Figura 15 apresenta, em vermelho, três espectros de resposta obtidos para três acelerogramas diferentes, gerados de forma análoga ao apresentado na Figura 14. Os espectros de resposta foram gerados por integração numérica pelo método de Newmark (Euler-Gauss), por meio da implementação, no software Excel, da rotina apresentada em (3.13) a (3.18). Em preto está representado o espectro de resposta elástica original, definido para uma aceleração característica máxima de $0,5 \mathrm{~g}$ e, em cinza, estão representados os limites superiores e inferiores que se buscou respeitar, com desvios de mais e menos 10\% respectivamente. Assim, pode-se perceber que os acelerogramas gerados produziram espectros de resposta coerentes com o espectro de resposta desejado e, portanto, são adequados para aplicação em análises sísmicas.

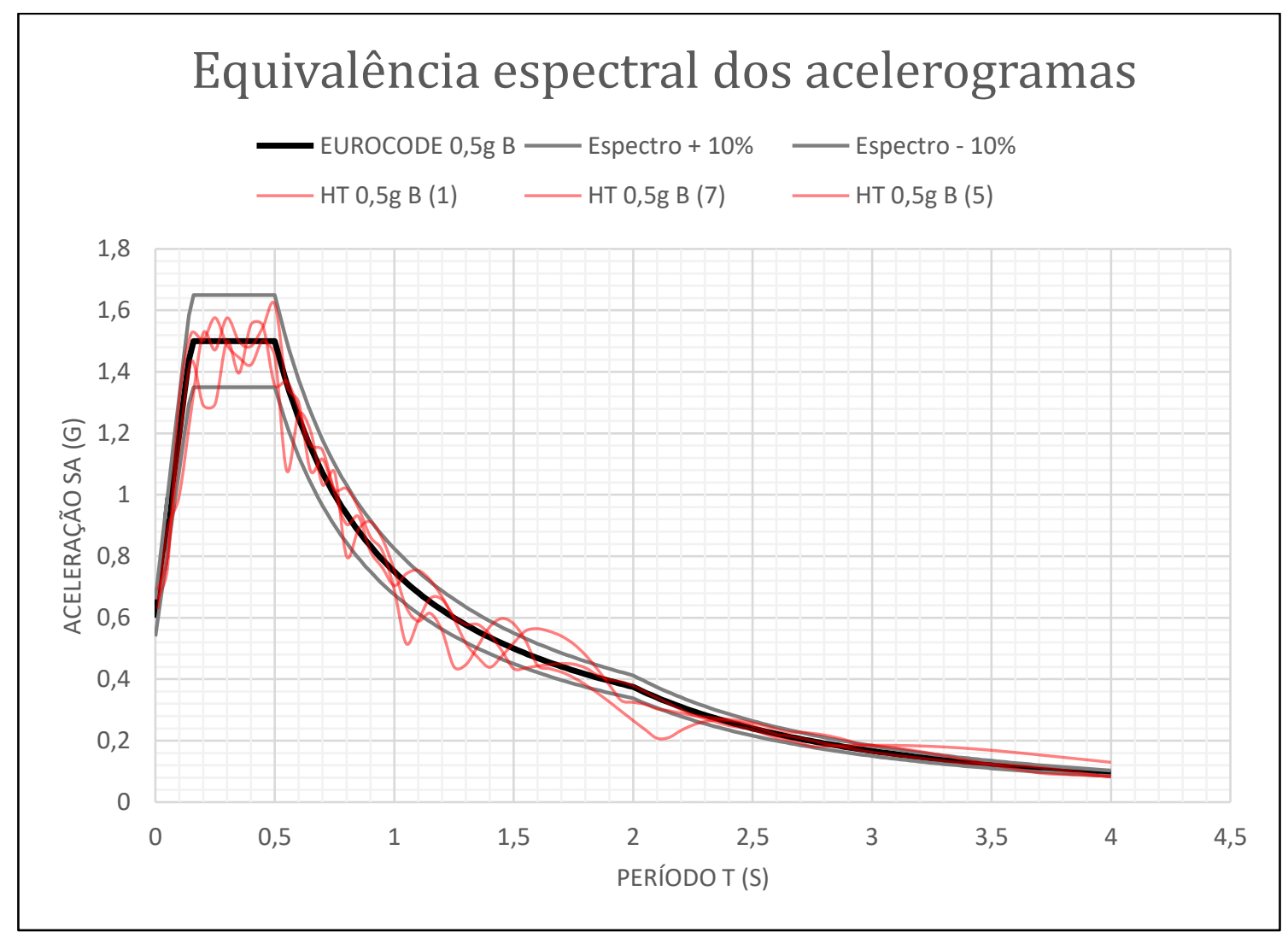

Figura 15: Aderência dos acelerogramas ao espectro elástico. Fonte: autor 


\subsection{CRITÉRIOS E LIMITAÇÕES}

O comportamento das estruturas durante um evento sísmico é bastante complexo, portanto, torna-se consideravelmente difícil a obtenção de resultados precisos com relação a esforços internos e deslocamentos. Alguns métodos e análises não lineares buscam produzir resultados mais realistas, por meio da consideração de alguns fatores como: o comportamento inelástico dos materiais estruturais; formação de rótulas plásticas nas juntas; dissipação de energia por meio de comportamentos histeréticos, dentre outros; entretanto, existe grande dificuldade na definição dos parâmetros e dos efeitos a serem considerados, o que pode gerar muitas incertezas nos resultados. Além disso, a utilização de análises não lineares complexas é muito mais laboriosa, não sendo aplicável, na prática da engenharia de projetos, para grande parte dos projetos desenvolvidos.

Embora, para situações quase-estáticas, uma análise elástica gere resultados bastante razoáveis, é sabido que, por não considerar a grande participação dos efeitos inelásticos na dissipação da energia, esse tipo de abordagem em análises dinâmicas pode produzir esforços exageradamente superiores aos esforços reais produzidos por um evento sísmico. Para contornar tal obstáculo, os regulamentos sugerem a aplicação de coeficientes de modificação da resposta (esforços) e de modificação dos deslocamentos, de modo a compatibilizar as respostas de uma análise elástica com aquelas esperadas para as estruturas sob carregamentos sísmicos.

O Eurocódigo 8 (2005) sugere que seja feita uma análise elástica da estrutura, utilizando um espectro de cálculo $S_{a, d}$, que é, na verdade, um espectro de resposta elástico $S_{a, e}$ com um fator de redução $q$ embutido, denominado fator de comportamento. A norma europeia sugere diversos valores para o fator $q$ em seus vários capítulos, em função do sistema estrutural adotado, da classe de ductilidade assumida, do material utilizado, dentre outras particularidades. Esses valores foram determinados, essencialmente, de maneira empírica e objetivam fornecer uma relação entre a resposta obtida para um sistema totalmente elástico e aquela esperada para a situação real.

A utilização do espectro de cálculo $S_{a, d}$ produz, portanto, esforços mais realistas quando comparado aos obtidos por meio do $S_{d e}$. Entretanto, esse espectro também influencia os deslocamentos. Embora as dissipações de energia devido ao comportamento não linear permitam reduzir consideravelmente os esforços, os deslocamentos não sofrem essa redução, portanto, é necessário fazer uma correção das respostas dos deslocamentos quando o espectro $S_{a, d}$ é utilizado (ver item 3.7.1). Essa correção é feita pela multiplicação 
dos deslocamentos por um coeficiente de majoração, que na norma europeia, é o próprio " $q$ ". Coeficientes com propósitos similares são adotados na norma brasileira, embora sejam especificados fatores distintos para redução dos esforços e recuperação dos deslocamentos, chamados respectivamente de " $R$ " e " $C_{d}$ ".

A tabela a seguir apresenta alguns dos valores sugeridos pelo Eurocódigo 8 (2005) e para a NBR 15421, para algumas estruturas mais comuns.

Tabela 3 - Coeficientes de comportamento. Fonte: autor

\begin{tabular}{|c|c|c|c|c|}
\hline \multirow[b]{2}{*}{ Sistemas estruturais (Pórticos) } & \multicolumn{2}{|c|}{ NBR } & \multicolumn{2}{|c|}{ EUROCÓDIGO } \\
\hline & $\begin{array}{l}\text { Modificação } \\
\text { resposta }(R)\end{array}$ & $\begin{array}{c}\text { Amplificação } \\
\text { deslocamentos } \\
\left(C_{d}\right)\end{array}$ & $\begin{array}{l}\text { Modificação da } \\
\text { resposta e } \\
\text { amplificação dos } \\
\text { deslocamentos }(q)\end{array}$ & $\begin{array}{l}\text { Classe de } \\
\text { ductilidade }\end{array}$ \\
\hline Pórtico de concreto - usual & 3 & 2,5 & $3,0 \alpha_{u} / \alpha_{1}$ & DCM \\
\hline Pórtico de concreto - especial & 8 & 5,5 & $4,5 \alpha_{u} / \alpha_{1}$ & $\mathrm{DCH}$ \\
\hline $\begin{array}{l}\text { Pórtico de aço momento-resistente - } \\
\text { usual }\end{array}$ & 3,5 & 3 & $3,0 \alpha_{u} / \alpha_{1}$ & DCM \\
\hline $\begin{array}{c}\text { Pórtico de aço momento-resistente - } \\
\text { especial }\end{array}$ & 8 & 5,5 & $4,5 \alpha_{u} / \alpha_{1}$ & $\mathrm{DCH}$ \\
\hline Pórtico de aço contraventado - usual & 3,25 & 3,25 & $3,0 \alpha_{u} / \alpha_{1}$ & DCM \\
\hline Pórtico de aço contraventado - especial & 6 & 5 & $4,5 \alpha_{u} / \alpha_{1}$ & $\mathrm{DCH}$ \\
\hline
\end{tabular}

Os valores numéricos apresentados para o coeficiente $q$ levam em consideração a classe de ductilidade, explicada no item 3.5.2, enquanto o parâmetro $\alpha_{u} / \alpha_{1}$ considera a resistência excedente que determinada estrutura geralmente possui, em relação à resistência de projeto exigida. Segundo o Eurocódigo 8 (2005), é possível determinar a relação $\alpha_{u} / \alpha_{1}$ por uma análise estática não linear do tipo Pushover, que basicamente consiste na aplicação iterativa de esforços laterais, até que seja atingido um deslocamento-alvo, definido em função das ações sísmicas admitidas. Contudo, a normativa sugere diversos valores estimados que podem ser utilizados de maneira conservadora, em substituição à realização de uma análise mais elaborada.

\subsubsection{Princípios gerais de um projeto sismo-resistente}

Um projeto deve considerar os efeitos causados por atividades sísmicas, desde o início de sua concepção estrutural, incorporando à concepção arquitetônica a maior quantidade possível de conceitos básicos sismo-resistentes, de modo que a estrutura final possa ser corretamente dimensionada aos carregamentos dinâmicos, de forma economicamente viável, sem prejudicar o desempenho ou o nível de segurança buscado.

Alguns conceitos sismo-resistentes fundamentais, adotados por diversas normas técnicas, dentre elas, a brasileira, a estadunidense e o Eurocódigo 8 (2005), são: simplicidade 
estrutural; uniformidade, simetria e redundância da estrutura; resistência e rigidez em quaisquer direções ortogonais do plano horizontal; resistência e rigidez à torção; ação de diafragma no nível das lajes; fundação adequada.

A simplicidade estrutural é importante porque estruturas com fluxos de esforços bem definidos e contínuos garantem um comportamento estrutural mais previsível, permitindo que a análise e as considerações durante o dimensionamento estrutural sejam mais precisas, trazendo resultados mais confiáveis. Além disso, é mais garantido que a construção de uma estrutura simples fique adequada ao projeto, favorecendo que a edificação real se comporte conforme antecipado em projeto.

A uniformidade, simetria e redundância são importantes tanto para a previsibilidade do comportamento, como para evitar zonas de concentração de tensões indesejadas, que podem levar a uma plastificação excessiva em alguns elementos estruturais, potencializando um colapso prematuro. Arranjos simétricos também minimizam excentricidades do centro de massa em relação ao centro de rigidez da estrutura, evitando que esforços adicionais sejam produzidos por uma configuração muito complicada. Elementos estruturais uniformemente distribuídos contribuem para a melhor redistribuição de esforços, espalhando-os equilibradamente para o restante da estrutura.

A rigidez bidirecional, obtida usualmente por meio de uma distribuição ortogonal dos elementos estruturais em planta, é importante devido ao carregamento sísmico ser caracterizado como um fenômeno bidirecional. Assim, as estruturas devem visar a reduzir esforços e deslocamentos excessivos em quaisquer direções no plano. Similar importância é dada para a rigidez à torção, obtida pela distribuição de contraventamentos nas regiões mais externas da edificação.

O comportamento das lajes como diafragma é relevante pois garante que a distribuição dos esforços horizontais, produzidos pela atividade sísmica, seja transmitida de maneira uniforme para os elementos verticais resistentes. Esse comportamento é particularmente importante quando os pilares e paredes possuem uma disposição mais complexa. Portanto, deve-se tomar cuidado com aberturas de grandes dimensões nas lajes, que possam comprometer a rigidez no seu plano, bem como aberturas próximas a elementos verticais, que impeçam a correta transferência de esforços laterais, dificultando sua contribuição para a rigidez do sistema.

A fundação de uma edificação possui papel fundamental na transferência dos esforços da superestrutura para o terreno e vice-versa. Por isso, é fundamental que seu desempenho 
seja adequado, conforme antecipado em projeto. Sugere-se que os elementos de fundação sejam conectados por vigas ou lajes, de forma a garantir uma distribuição uniforme dos carregamentos sísmicos para todo o sistema estrutural, especialmente no caso de fundações isoladas como sapatas ou estacas. Normalmente, em modelos de análise, admite-se uma conexão rígida entre a superestrutura e a fundação. Trata-se de consideração conservadora, posto que a flexibilidade da fundação e amortecimento do terreno fornecem efeitos favoráveis. Apesar disso, casos em que o terreno seja pouco rígido, ou fundações menos convencionais, podem demandar verificações que envolvam interação solo-estrutura, aumentando substancialmente a complexidade das análises e, consequentemente, do projeto.

O item 4.2.3 do Eurocódigo 8 (2005) define alguns critérios de regularidade estrutural e, para cada critério, especifica o tipo de análise estrutural permitida. As regularidades são divididas em horizontais e verticais, sendo que para edifícios horizontalmente regulares, permite-se a adoção de modelos planos, ao invés de modelos espaciais, exigidos somente na presença de irregularidades em planta. No caso de irregularidades verticais, o Eurocódigo 8 não recomenda a utilização do método das forças laterais equivalentes (descrito no item 3.7.1), devendo-se aplicar o método da análise espectral (descrito no item 3.7.2). Além disso, para este caso, adota-se uma redução de $20 \%$ no valor do coeficiente de comportamento (ver Tabela 4).

A regularidade em planta é garantida, dentre alguns critérios, pela simetria de rigidez lateral e distribuição de massas em duas direções ortogonais. Devem ser evitadas geometrias com cantos reentrantes em planta, que projetem formatos como " $\mathrm{L}$ ", " $\mathrm{H}$ ", "X", "I" e "C", pois elas podem comprometer significativamente o comportamento de diafragma das lajes.

A regularidade vertical é admitida quando os sistemas resistentes verticais (pórticos, paredes e núcleos) são contínuos desde a fundação até o topo do edifício. Adicionalmente, as massas das lajes de cada pavimento devem ser aproximadamente iguais. São admitidos (a) recuos sucessivos simétricos que não excedam $20 \%$ da dimensão da laje em planta, na direção em que o recuo é idealizado; (b) para recuos não simétricos, a soma dos recuos não deve ser superior a 30\% da dimensão do piso de fundação; (c) recuos localizados nos 15\% inferiores da altura da edificação não devem ser superiores a 50\% da dimensão, em planta, do nível inferior. 


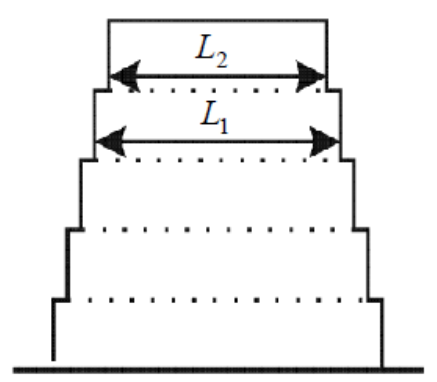

(a): $\frac{L_{1}-L_{2}}{L_{1}} \leq 0,20$

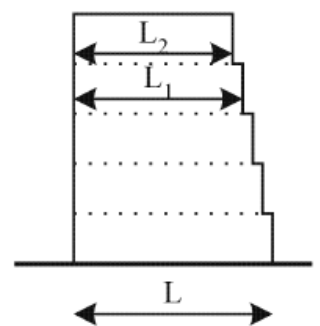

(b) : $\frac{L-L_{2}}{L} \leq 0,30$

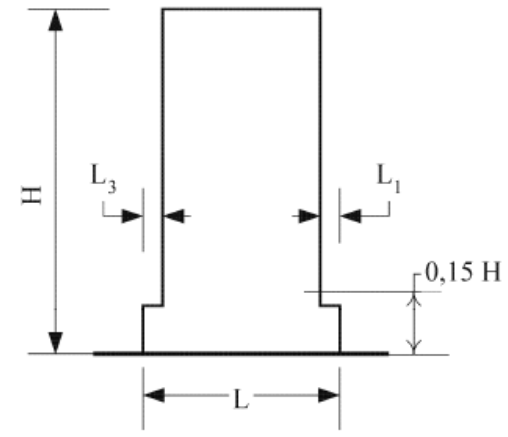

(c): $\frac{L_{3}+L_{1}}{L} \leq 0,50$

Figura 16: Condições para regularidade vertical. Fonte: Adaptado do Eurocódigo 8 (2005).

\subsubsection{Classificação de ductilidade}

É fundamental, dentro de uma análise sísmica, a consideração da plasticidade das estruturas e os ganhos que isso pode trazer em relação aos esforços a serem resistidos. Essa consideração, via de regra, é feita por meio da aplicação dos coeficientes de comportamento apresentados na Tabela 3. A norma brasileira classifica as estruturas em três grupos principais, designadamente, estruturas com detalhamento usual, intermediário e especial. Embora a NBR 15421 (2006) não especifique quais os critérios para que se possa considerar cada tipo de detalhamento, a classificação é bastante semelhante à apresentada pela norma americana ASCE SEI 7 (2016), na qual esses critérios estão especificados detalhadamente. O Eurocódigo 8 (2005), analogamente, subdivide as classes de ductilidade em baixa (Ductility Class Low - DCL); média (Ductility Class Medium - DCM) e alta (Ductility Class High - DCH). Para cada classe, admitem-se coeficientes de comportamento diferentes, sendo mais favoráveis quanto maior for a classe. Contudo, existe uma série de especificações que devem ser atendidas, determinadas na norma europeia para cada tipo de estrutura, para que se possa considerar uma classe de ductilidade superior.

Dentre essas especificações encontram-se limites mínimos de dimensões para seções transversais; taxas máximas e mínimas de armadura; diâmetros mínimos de vergalhões; espaçamentos entre barras de armação; comprimentos de ancoragem; considerações de cálculo para resistência à força cortante; correções na tensão admissível ao escoamento do aço; dentre outras definidas para cada tipo de elemento (vigas, pilares e nós de pórtico) que intentam garantir maior ductilidade e formação de rótulas plásticas. 


\subsubsection{Sistemas estruturais}

No Eurocódigo 8, as edificações são classificadas em alguns sistemas estruturais definidos em função do seu comportamento sob ações sísmicas. Nessa classificação destacam-se os sistemas: de pórticos; mistos de pórticos e paredes; de paredes dúcteis, de paredes de grandes dimensões de concreto fracamente armado; de pêndulo invertido, e torcionalmente flexíveis.

Essa classificação depende do comportamento do edifício perante os carregamentos sísmicos horizontais, de modo que um mesmo edifício pode ter classificações diferentes para cada direção horizontal ortogonal analisada.

O sistema de parede de grande dimensão fracamente armado é assumido quando são atendidos os seguintes requisitos: ao menos duas paredes, com dimensão horizontal superior a $4 \mathrm{~m}$, suportem no mínimo $20 \%$ da carga gravitacional total; as paredes devem ter sua base engastada, sem permitir rotações; devem possuir, individualmente, período fundamental inferior a $0,5 \mathrm{~s}$.

A consideração dos sistemas de pórticos ou paredes é dependente do atendimento aos critérios de rigidez à torção, especificados no item 4.2.3.2 do Eurocódigo 8, que é automaticamente atendido, sem necessidade de verificações adicionais, para edificações com elementos verticais uniformemente distribuídos em planta. Caso a rigidez à torção especificada não possa ser atendida, o sistema deverá ser considerado como torcionalmente flexível. Todas as paredes que não atenderem aos critérios de parede de grande dimensão de concreto fracamente armado, deverão ser consideradas como paredes dúcteis.

Conforme apresentado na Tabela 3, a norma europeia recomenda alguns coeficientes de comportamento em função do tipo de sistema estrutural admitido, que devem ser aplicados conforme a expressão:

$$
\mathrm{q}=\mathrm{q}_{0} \times k_{w} \geq 1,5
$$

onde $\mathrm{q}_{0}$ é o valor-base determinado para o sistema estrutural e $k_{w}$ corrige o parâmetro, consoante ao tipo de ruptura esperado para as paredes, apresentado no item 5.2.2.2 do Eurocódigo 8 (2005). Indica-se, ainda, uma redução de 20\% nos valores do parâmetro q, para sistemas irregulares em altura.

\subsubsection{Deslocamentos globais e relativos}

O deslocamento relativo entre pavimentos é um importante indicador para avaliar o dano potencial em uma edificação. Entretanto, no caso dos esforços obtidos por meio de uma 
análise que considera um sismo com período de retorno de 475 anos, utilizados para prevenir o colapso da estrutura, assumem-se deformações plásticas que provocariam danos bastante elevados à edificação. Para que se possa garantir que sismos de menor intensidade não provoquem danos irreversíveis à estrutura, o regulamento europeu determina um critério de limitação de danos, que leva em consideração os deslocamentos relativos entre pavimentos para um sismo com período de retorno inferior ao de projeto (95 anos), obtido por meio da aplicação de um coeficiente de redução $v$ para os deslocamentos $d_{r}$ obtidos para o sismo de projeto, em que $d_{r}$ é o deslocamento já corrigido pela multiplicação do coeficiente de comportamento $q$.

Assim, limitam-se os deslocamentos relativos para sistemas que possuam elementos não estruturais frágeis, fixos à estrutura, em:

$$
d_{r} v \leq 0,005 h
$$

Para edifícios com elementos não estruturais dúcteis, admite-se:

$$
d_{r} v \leq 0,0075 h
$$

e para edifícios onde os elementos não estruturais não interfiram com a estrutura:

$$
d_{r} v \leq 0,010 h
$$

sendo $h$ a altura entre lajes para os quais se definiu o valor $d_{r}$. O valor mais comumente adotado para o parâmetro redutor $v$ é 0,5 , sugerido pelo Eurocódigo 8, na intenção de equiparar os deslocamentos de um sismo de período de retorno de 475 anos para um de 95.

Esse critério abrange situações usuais, sendo necessárias verificações específicas para eventuais limitações de equipamentos ou condições especiais, como edifícios importantes para a proteção civil.

\subsubsection{Efeitos de torção acidental}

A torção acidental é aquela que pode ocorrer em função da incerteza na distribuição das massas presentes em uma edificação. Para edifícios com distribuição de massa uniforme nas lajes, esses efeitos podem ser considerados de duas maneiras simplificadas. Pode-se adotar uma correção dos esforços em cada elemento estrutural, multiplicando-os por um coeficiente $\delta$, que segundo o Eurocódigo, é dado por:

$$
\delta=1+0,6 \frac{x}{L_{e}}
$$


onde $x$ é a distância medida perpendicularmente à direção da ação sísmica, entre o elemento considerado e o centro de gravidade do edifício, em planta. $L_{e}$ representa a distância entre os dois elementos de contraventamento mais afastados, medida de forma análoga.

Outra forma simplificada de estimar os efeitos de torção em modelos espaciais é por meio da aplicação de torques $M_{a i}$ nos centros de massas de cada laje, que segundo a mesma normativa europeia, são dados pela expressão:

$$
M_{a i}=e_{a i} F_{i}
$$

onde $F_{i}$ é a força horizontal atuante na laje $i$, para cada direção relevante e $e_{a i}$ é a excentricidade acidental, definida pelo valor de $\pm 0,05 L_{i}$, com $L_{i}$ sendo a maior dimensão da laje $i$, em planta, perpendicular à ação sísmica considerada.

Nota-se que, para análises que considerem modelos planos, é permitido adotar a mesma correção proposta em (3.23), substituindo a constante 0,6 por 1,2.

\subsubsection{Efeitos de segunda ordem}

Em análises lineares, os efeitos de segunda ordem são abordados mediante um coeficiente de estabilidade $\theta$. Esse coeficiente mede a influência dos esforços que as cargas verticais aplicam na estrutura, em conjunto com os deslocamentos horizontais apresentados, relativamente aos esforços que as próprias forças horizontais acarretam. Desse modo, o valor de $\theta$ obtido pela expressão (3.25) define se existe a necessidade de considerar efeitos de segunda ordem na análise de determinada estrutura.

$$
\theta=\frac{P_{x} \Delta_{x}}{H_{x} h_{x}}
$$

onde

$P_{x}$ é a força vertical total atuando no pavimento, na situação do projeto sísmico

$\Delta_{x}$ é o deslocamento relativo entre pavimentos

$H_{x}$ é a força cortante atuando no pavimento, na situação do projeto sísmico

$h_{x}$ é a distância entre as elevações correspondentes

Valores de $\theta$ inferiores a 0,1 permitem que os efeitos de segunda ordem sejam negligenciados, sem prejuízo para os resultados da análise. Eventualmente, para valores de $\theta$ superiores a 0,1 , mas que não superem o valor-limite definido no Eurocódigo 8: $\theta_{\text {máx }}=$ 0,2 , os efeitos de segunda ordem podem ser considerados de forma bastante simplificada, realizando a multiplicação de todos os esforços pela relação $\frac{1}{1-\theta}$. Essa consideração implica 
um acréscimo aos esforços na estrutura proporcional ao coeficiente de estabilidade, que é supostamente equivalente ao acréscimo que seria produzido pelos efeitos de segunda ordem, assumindo que, dentro desse limite, não há riscos para a estabilidade estrutural. Para estruturas de concreto armado, raramente os valores de $\theta$ superam esse limite de 0,2. No entanto, quando valores superiores a 0,2 são apresentados, não são permitidas análises lineares, sendo necessário reavaliar o sistema estrutural de forma a reduzir os valores obtidos para o parâmetro, ou adotar um procedimento mais complexo, que leve em conta explicitamente os efeitos de segunda ordem, como, por exemplo, uma análise não linear. A norma brasileira e a americana adotam a mesma consideração a respeito dos efeitos de segunda ordem, com o ajuste de $\theta_{\text {máx }}=0,25$.

\subsection{CARREGAMENTOS E COMBINAÇÕES}

Em geral, considera-se na análise sísmica a combinação de ações em que as cargas permanentes $\left(G_{k, i}\right)$ e as cargas sísmicas $\left(E_{E k}\right)$ são tomadas com seus valores nominais característicos, enquanto as cargas variáveis $\left(Q_{k, i}\right)$ assumem seu valor característico multiplicado pelo coeficiente de ponderação $\psi_{2}$, definido no Eurocódigo EN 1990 (2009).

$$
G_{k, i}+\sqrt{E_{E x}^{2}+E_{E y}^{2}}+\psi_{2} Q_{k, i}
$$

As massas utilizadas para realizar a análise sísmica consideram todas as cargas gravitacionais, entretanto, com coeficientes de ponderação diferentes. Para edificações convencionais, adotam-se as massas relativas às cargas permanentes em seu valor integral, enquanto as massas derivadas das cargas variáveis são tomadas na forma $\psi_{\mathrm{E}} \times Q_{k, i}$. De fato, $\psi_{\mathrm{E}}$ é o coeficiente de ponderação de massas variáveis para o caso sísmico e possui valor igual a 0,3 para sobrecargas na cobertura; 0,15 para sobrecargas nos demais pavimentos. A redução da contribuição das massas das cargas variáveis se dá por dois fatores principais: as cargas variáveis não estão presentes simultaneamente em todas as regiões da estrutura; cargas variáveis usualmente possuem uma conexão não rígida com a estrutura, podendo vibrar em fase diferente desta durante um evento sísmico, reduzindo a contribuição para amplificação dos efeitos dinâmicos.

Quanto à combinação das ações sísmicas, entende-se que estas ocorrem simultaneamente nas duas direções horizontais ortogonais; entretanto, via de regra, as análises são feitas para cada direção de maneira independente. Assim, as respostas obtidas para cada análise 
precisam ser combinadas para que se obtenham os esforços finais. Em virtude de as análises fornecerem as respostas máximas para cada direção, embora essas respostas não necessariamente ocorram no mesmo instante para as duas direções, é feita uma combinação das ações sísmicas que considere essa superposição parcial de efeitos. A combinação é feita pelo método da raiz quadrada da soma dos quadrados, dado por:

$$
E_{E}=\sqrt{E_{E x}^{2}+E_{E y}^{2}}
$$

onde $E_{E}$ são os esforços finais de interesse combinados, enquanto $E_{E x}$ e $E_{E y}$ são os esforços nas direções $x$ e $y$, respectivamente.

Alternativamente, permite-se fazer uma combinação linear para o pior caso entre:

$$
\begin{aligned}
& E_{E}=E_{E x}+0,3 E_{E y} \\
& E_{E}=E_{E y}+0,3 E_{E x}
\end{aligned}
$$

Nota-se que, em alguns casos, a combinação apresentada em (3.27) apresenta valores mais favoráveis do que os encontrados em (3.28) e (3.29), assim como o contrário também acontece. Posto que o Eurocódigo 8 (2005) permite que sejam utilizados qualquer dos métodos, alternativamente, pode-se adotar o caso mais favorável dentre eles.

\subsection{MÉTODOS DE ANÁLISE}

Atualmente, existe uma grande variedade de métodos aplicáveis para análise sísmica estrutural de edificações, que podem ser classificados em dois grupos: métodos estáticos e métodos dinâmicos. Esses métodos podem ainda ser subdivididos em: métodos lineares e métodos não lineares. Em relação à subdivisão, os métodos lineares são, geralmente, mais simples, exigem menos esforço computacional e conseguem abranger a grande maioria dos casos, portanto, são amplamente utilizados. Atualmente, com o desenvolvimento da tecnologia e de software, é viável aplicar métodos dinâmicos lineares com praticamente o mesmo custo computacional da aplicação de métodos estáticos lineares, possibilitando realizar análises sísmicas mais adequadas sem sobrecarregar o desenvolvimento do projeto.

Dentre as análises não lineares, podem ser citadas as análises do tipo pushover, que abordam a não linearidade por meio de uma análise estática, com incrementos iterativos nos esforços laterais, com a respectiva perda de rigidez estrutural, em função dos deslocamentos e esforços desenvolvidos em cada iteração da análise. Outro método é o da análise não linear 
no domínio do tempo (non-linear history response analysis - NLHR), que normalmente não é obrigatória nos regulamentos sísmicos, por isso é aplicado apenas em alguns casos específicos. Entretanto, algumas situações e características somente podem ser corretamente interpretadas por meio de uma análise desse tipo, por exemplo, o comportamento não linear histerético de alguns dispositivos de isolamento de base, que são discutidos no item 4.3. A NLHR é a mais abrangente dentre as disponíveis, contudo, ainda existem muitas incertezas a respeito da sua correta aplicação. Segundo Fardis (2015), não são bem difundidos os melhores procedimentos para representação do comportamento histerético de elementos estruturais sob carregamentos cíclicos de grande amplitude, ou uma forma precisa para a modelagem do amortecimento estrutural em estruturas de concreto armado sob carregamentos sísmicos, de modo que a calibração dos parâmetros necessários para a aplicação da NLHR se torna mais complexa que a dos métodos dinâmicos lineares. Futuramente, é bem possível que o método NLHR seja utilizado como padrão, entretanto, atualmente os métodos lineares são considerados suficientes para obtenção de respostas adequadas e os casos específicos nos quais uma análise não linear se mostra recomendada, podem ser devidamente solucionados por análises do tipo pushover.

A norma brasileira NBR 15421 (2006) define como método principal o método das forças laterais equivalentes (MFE), que é um método estático linear, enquanto o Eurocódigo define o método do espectro de resposta (MER) como fundamental, sendo este um método dinâmico linear. Adicionalmente, conforme apresentado na Tabela 4, o Eurocódigo desaconselha a utilização do MFE quando da existência de irregularidades verticais (na Tabela 4, o MER é referido como "Modal"), consideração que não é feita na NBR.

Tabela 4 - Métodos permitidos. Fonte: Eurocódigo 8 (2005)

\begin{tabular}{|c|c|c|c|c|}
\hline \multicolumn{2}{|c|}{ Regularidade } & \multicolumn{2}{c|}{ Simplificações admitidas } & $\begin{array}{c}\text { Coeficiente de } \\
\text { comportamento }\end{array}$ \\
\hline $\begin{array}{c}\text { Em } \\
\text { planta }\end{array}$ & Em altura & Modelo & Análise elástica linear & (para a análise linear) \\
\hline Sim & Sim & Plano & Força lateral & Valor de referência \\
Sim & Não & Plano & Modal & Valor reduzido \\
Não & Sim & Espacial & Força lateral & Valor de referência \\
Não & Não & Espacial & Modal & Valor reduzido \\
\hline
\end{tabular}

A seguir, apresentam-se, em detalhes, os métodos lineares abordados nesta pesquisa. 


\subsubsection{Método das forças laterais equivalentes (MFE)}

O MFE considera que é possível estimar a força sísmica máxima na base de uma estrutura e então redistribuir essa força em cada pavimento, por meio da aplicação de forças laterais equivalentes que produzam a mesma força total na base, de forma a obter uma aproximação das respostas dinâmicas da estrutura.

A norma europeia define o MFE pelas seguintes expressões:

Força horizontal na base:

$$
H=S_{a, d}(T) W \lambda
$$

onde $T$ é o período fundamental da estrutura em segundos, $S_{a, d}$ é a ordenada referente ao espectro de cálculo adotado (ver 3.7.2) normalizado em relação à aceleração da gravidade, $W$ é o peso total da estrutura e $\lambda=0,85$ caso $T<2 T_{c}$ (definido na Tabela 6 em função do terreno considerado), supondo que o edifício tenha mais de 2 pavimentos; ou $\lambda=1,0$ nos outros casos.

Essa formulação é derivada da análise no domínio da frequência, apresentada em 3.7 .2 e estima os esforços considerando a estrutura como possuindo apenas um grau de liberdade e sua massa concentrada, de modo que o esforço cortante máximo seja dado pelo produto da aceleração horizontal do espectro de resposta considerado (normalizado em relação à gravidade) pelo peso da estrutura. Ao mesmo tempo, o parâmetro $\lambda$ compatibiliza o esforço obtido, admitindo que para uma estrutura com período fundamental inferior a $2 T_{c}$ e mais de dois pavimentos, a participação de massa do modo de vibração fundamental seja aproximadamente $85 \%$ da massa total. Essa consideração se mostra razoável para estruturas regulares e com distribuição de massa uniformemente distribuída entre os pavimentos, entretanto, pode destoar consideravelmente caso a estrutura seja irregular em altura ou possua concentrações de massa em determinados pavimentos.

O período $T$ refere-se ao primeiro modo de vibrar na direção analisada, que segundo este método, pode ser estimado pela simplificação a seguir:

$$
T=C_{t} h^{x}
$$

onde $h$ é a altura em metros da estrutura acima da base, com os parâmetros " $C_{t}$ " e " $\chi$ " definidos pela Tabela 5 . 
Tabela 5 - Coeficientes " $C_{t}$ " e " $x$ ". Fonte: Adaptado de Eurocódigo 8 (2005)

\begin{tabular}{|c|c|c|}
\hline \multirow{2}{*}{ Tipo de estrutura } & \multicolumn{2}{|c|}{ EUROCÓDIGO 8 } \\
\cline { 2 - 3 } & $C_{t}$ & $x$ \\
\hline Pórtico de aço momento-resistente & 0,085 & 0,75 \\
\hline Pórtico de concreto & 0,075 & 0,75 \\
\hline Pórtico de aço contraventado & 0,075 & 0,75 \\
\hline Outras estruturas & 0,05 & 0,75 \\
\hline
\end{tabular}

Alternativamente, permite-se definir o período fundamental $T$ por:

$$
T=2 \sqrt{d}
$$

com $d$ sendo o deslocamento lateral no topo do edifício, em metros, referente às forças da gravidade atuando na direção horizontal.

A força horizontal total na base $(H)$ é distribuída verticalmente, entre as várias elevações “ $x$ " da estrutura, conforme a expressão abaixo:

$$
F_{x}=H \frac{s_{x} m_{x}}{\sum s_{i} m_{i}}
$$

onde:

$m_{x}=$ massa do pavimento da elevação " $x$ "

$m_{i}=$ massa do pavimento da elevação "i"

Os parâmetros $s_{x}$ e $s_{i}$ podem ser tomados respectivamente a uma distribuição linear em função da altura do edifício, onde:

$s_{x}=$ altura do pavimento da elevação " $x$ " em relação à base

$s_{i}=$ altura do pavimento da elevação " $i$ " em relação à base

Alternativamente, pode-se adotar estes parâmetros relativos ao deslocamento das massas no modo fundamental de vibrar da estrutura, onde:

$s_{x}=$ deslocamento relativo do pavimento da elevação " $x$ "

$s_{i}=$ deslocamento relativo do pavimento da elevação " $i$ "

Os deslocamentos obtidos por este método devem ser multiplicados pelo coeficiente de amplificação dos deslocamentos “q”, apresentado na Tabela 3, para que retornem aos seus valores nominais, após a aplicação do espectro de cálculo.

A distribuição dos esforços e a obtenção das forças cortantes na base consideram apenas o modo fundamental de vibração da estrutura, de modo que este método se mostra adequado para análises de sistemas cujas respostas não sejam significativamente alteradas pela contribuição de modos de vibração superiores ao fundamental. Neste último caso, a 
aplicação de uma análise mais complexa, como a espectral, fornece resultados mais confiáveis.

\subsubsection{Método do espectro de resposta (MER)}

O MER baseia-se na definição de um espectro de resposta elástica $S_{a, e}$, conforme discutido no item 3.3. Cada regulamento apresenta uma sequência de formulações que visam a obter um espectro adequado, em conjunto com uma série de parâmetros que adequam o modelo matemático do espectro para cada região considerada. No Eurocódigo 8 (2005) a seguinte formulação é apresentada:

Para $0 \leq T \leq T_{B}$

$$
S_{a, e}(T)=a_{g} S\left[1+\frac{T}{T_{B}}(2,5 \eta-1)\right]
$$

Para $T_{B} \leq T \leq T_{C}$

$$
S_{a, e}(T)=2,5 a_{g} S \eta
$$

Para $T_{C} \leq T \leq T_{D}$

$$
S_{a, e}(T)=2,5 a_{g} S \eta \frac{T_{C}}{T}
$$

Para $T \geq T_{D}$

$$
S_{a, e}(T)=2,5 a_{g} S \eta \frac{T_{C} \times T_{D}}{T^{2}}
$$

sendo $S, T_{B}, T_{C}$ e $T_{D}$ definidos nos quadros 3.2 e 3.3 do Eurocódigo 8 (2005), apresentados na Tabela 6 , em função do terreno, e $a_{g}$ a aceleração da gravidade de cálculo à superfície. $\mathrm{O}$ parâmetro $\eta$ permite corrigir o espectro em função da taxa de amortecimento viscoso $\xi(\%)$ desejada, sendo tomado usualmente igual à unidade, para $\xi=5 \%$. Para outras taxas de amortecimento, a seguinte expressão permite definir $\eta$ :

$$
\eta=\sqrt{10 /(5+\xi)} \geq 0,55
$$

O espectro de resposta elástica $S_{a, e}$, definido pela norma europeia, apresenta a seguinte forma:

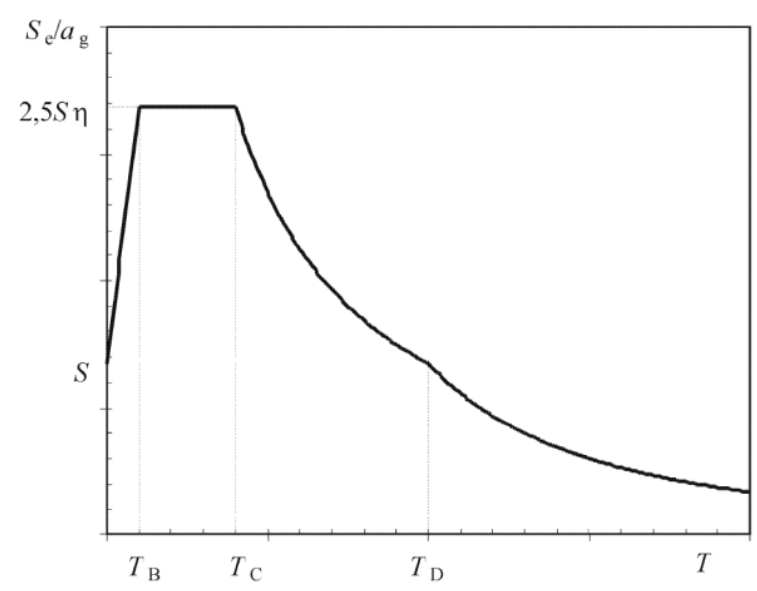

Figura 17: Forma do espectro de resposta elástica $S_{a, e}$. Fonte: Eurocódigo 8 (2005). 
Considerando que a Europa se encontra em uma região com ocorrências sísmicas de fontes variadas, o Eurocódigo define dois espectros de resposta típicos, segundo Arai (2013): Tipo 1 para regiões de terremotos com magnitudes superiores a 5,5 na escala Richter e Tipo 2 para regiões de terremotos com magnitudes inferiores a 5,5.

Tabela 6 - Parâmetros para espectro de resposta. Fonte: Adaptado de Eurocódigo 8 (2005)

\begin{tabular}{|c|c|c|c|c|c|c|c|c|}
\hline \multirow{2}{*}{$\begin{array}{c}\text { Classe do terreno } \\
\left(v_{S}\right)\end{array}$} & \multicolumn{7}{|c|}{ Tipo 1} & \multicolumn{5}{|c|}{ Tipo 2} \\
\cline { 2 - 10 } & $S$ & $T_{B}$ & $T_{C}$ & $T_{D}$ & $S$ & $T_{B}$ & $T_{C}$ & $T_{D}$ \\
\hline & 1 & 0,15 & 0,4 & 2 & 1 & 0,05 & 0,25 & 1,2 \\
\hline$v_{S}>800$ & 1,2 & 0,15 & 0,5 & 2 & 1,35 & 0,05 & 0,25 & 1,2 \\
\hline$v_{S}>370$ & 1,15 & 0,2 & 0,6 & 2 & 1,5 & 0,1 & 0,25 & 1,2 \\
\hline$v_{S}>180$ & 1,35 & 0,2 & 0,8 & 2 & 1,8 & 0,1 & 0,3 & 1,2 \\
\hline$v_{S}<180$ & \multicolumn{10}{|c|}{} \\
\hline
\end{tabular}

Para a proposição do espectro de cálculo $S_{a, d}$, o Eurocódigo leva em consideração o coeficiente de modificação da resposta $q$, apresentado na Tabela 3, já embutido nas expressões:

$$
\begin{array}{ll}
\text { Para } 0 \leq T \leq T_{B} & S_{a, d}(T)=a_{g} S\left[\frac{2}{3}+\frac{T}{T_{B}}\left(\frac{2,5}{q}-\frac{2}{3}\right)\right] \\
\text { Para } T_{B} \leq T \leq T_{C} & S_{a, d}(T)=a_{g} S\left(\frac{2,5}{q}\right) \\
\text { Para } T_{C} \leq T \leq T_{D} & S_{a, d}(T)=a_{g} S\left(\frac{2,5}{q}\right) \frac{T_{C}}{T} \geq 0,2 a_{g} \\
\text { Para } T \geq T_{D} & S_{a, d}(T)=a_{g} S\left(\frac{2,5}{q}\right) \frac{T_{C} T_{D}}{T^{2}} \geq 0,2 a_{g}
\end{array}
$$

Ressalta-se, todavia, que o espectro de cálculo não deverá ser utilizado para estruturas com isolamento de base. Nesses casos, o espectro elástico $S_{a, e}$ deverá ser adotado e, no caso de edificações convencionais em concreto armado, o coeficiente de comportamento $q$ deverá ser aplicado diretamente aos esforços resultantes.

Uma vez definido o espectro, a análise espectral é feita por meio da superposição modal dos resultados obtidos para cada modo de vibração natural do sistema analisado, devendose utilizar uma quantidade de modos que garanta ao menos $90 \%$ de participação de massa. A combinação das respostas pode ser feita por meio da soma da raiz quadrada da soma dos quadrados (Square Root of the Sum of the Squares - SRSS) sempre que a diferença entre o período de dois modos de vibração adjacentes for superior a 10\%. Para casos em que os 
períodos de modos adjacentes sejam muito próximos, deve-se adotar métodos de combinação mais precisos, como o da combinação quadrática completa ${ }^{2}$ (CQC).

Para períodos naturais de até quatro segundos, as respostas em termos de deslocamentos $S_{D e}$ podem ser obtidas a partir da seguinte expressão:

$$
S_{D e}(T)=S_{a, e}(T)\left[\frac{T}{2 \pi}\right]^{2}
$$

A partir do deslocamento $S_{D e}$ de cada modo de vibração, juntamente com o método da superposição modal, pode-se encontrar, para cada modo de vibração, o deslocamento de cada grau de liberdade do modelo, conforme apresentado em (2.42). Em seguida, torna-se possível obter os esforços em cada elemento estrutural, relacionando a força com o produto do deslocamento pela rigidez de cada elemento.

A utilização do espectro de cálculo, ao invés do elástico, fornece resultados de esforços com valores de cálculo. Entretanto, em função da aplicação do coeficiente de comportamento $q$, os deslocamentos apresentam-se reduzidos, devendo ser corrigidos por meio da multiplicação pelo coeficiente $q$, para que retornem a valores mais realistas.

\subsubsection{Método do histórico no tempo (MHT)}

O método de análise do histórico no tempo utiliza a integração numérica direta das equações diferenciais do movimento, utilizando como ação externa acelerogramas que representem adequadamente o movimento do terreno em situação de projeto.

Para modelar corretamente o espectro de resposta elástica definido, são necessários pelo menos três acelerogramas distintos. Nesse caso, a resposta mais desfavorável obtida para cada situação deverá ser adotada. Alternativamente, ao utilizar um mínimo de sete acelerogramas, permite-se adotar como resposta a média das respostas obtidas para cada acelerograma. Os acelerogramas podem ser fornecidos de duas formas principais: acelerogramas de sismos reais, "escalados" de forma a atender ao espectro elástico definido para a situação sendo analisada; acelerogramas gerados artificialmente, fundamentados no espectro elástico, conforme apresentado no item 3.4.

A utilização de acelerogramas reais fica limitada aos registros existentes, sendo necessário que sejam compatíveis com o tipo de solo e com a distância do foco dentre as demais propriedades que caracterizam a atividade sísmica, para que então se possa "escalar" essas

\footnotetext{
${ }^{2}$ Wilson, E.L. et al. (1981)
} 
acelerações para o atendimento ao espectro de resposta elástica. A utilização de acelerogramas gerados artificialmente permite um maior controle do tipo de excitação que se deseja impor, permitindo definir a duração da ocorrência, as frequências mais excitadas, o tipo de banda, etc., tornando-os mais interessantes para aplicação neste tipo de análise. 


\section{ISOLAMENTO SÍSMICO DE BASE}

O conceito de isolamento sísmico tem sido estudado há muito tempo, entretanto, foi somente a partir da década de 1980 que esses sistemas começaram a ter uma participação mais significativa nas grandes construções civis. Atualmente, segundo Konrad Eriksen, presidente da Dynamic Isolation Systems Inc., informou para a Engineering News-Record (ENR), o Japão coloca o isolamento sísmico como uma das primeiras opções a serem consideradas na proteção sísmica de construções. Entretanto, aplicações frequentes ainda ficam restritas a países com larga experiência nesses sistemas. Outros países como os Estados Unidos, por exemplo, usualmente utilizam outras formas de proteção sísmica, que apesar de protegerem edificações contra perda de vida humana, muitas vezes não possuem uma das grandes vantagens do isolamento de base, que é a garantia de operacionalidade imediatamente após um evento sísmico.

\subsection{FUNDAMENTOS DO ISOLAMENTO DE BASE}

O princípio básico do isolamento de base é reduzir a transmissão dos esforços sísmicos produzidos pelo terreno para a estrutura. Esse objetivo é atingido por meio da flexibilização da estrutura, no nível da base, de tal forma que o período natural desta fique enquadrado no trecho do espectro de resposta onde as acelerações transmitidas são menores. Além de reduzir a transmissão dos esforços, um bom isolamento sísmico também tenta acrescentar, no nível do isolamento, um mecanismo de dissipação de energia, aumentando o amortecimento estrutural e assim, controlando melhor o comportamento dinâmico do sistema em respeito aos esforços e deslocamentos atingidos.

Um sistema estrutural sismo-resistente convencional, quando atingido por fortes acelerações sísmicas, faz uso de sua capacidade dissipativa para poder resistir aos esforços sem colapsar. Entretanto, nessas estruturas, a dissipação de energia ocorre mediante a formação de fraturas no concreto, do escoamento dos elementos dúcteis e da formação de rótulas plásticas. Muito embora a estrutura não entre necessariamente em colapso, geralmente fica condenada, necessitando de grandes reparos para que possa voltar a ser utilizada com segurança. Já nas estruturas sismicamente isoladas, a dissipação de energia, bem como os maiores deslocamentos, ficam quase totalmente contidos nos dispositivos de isolamento, fazendo com que os demais elementos estruturais permaneçam em regime elástico, mesmo durante acelerações sísmicas de grande magnitude. Esse comportamento possibilita que a estrutura possa exercer sua função mesmo que imediatamente após um 
evento sísmico intenso. Isso explica o fato de estruturas de maior importância como hospitais, quarteis, corpo de bombeiros, dentre outros, muitas vezes serem protegidas por meio desses sistemas.

Por outro lado, edificações ordinárias muitas vezes deixam de aplicar esse tipo de solução, em virtude do elevado custo dos dispositivos de isolamento. A consideração desse custo de forma isolada, entretanto, pode levar a decisões inconvenientes, pois a utilização desse conceito, conforme se demonstra no decorrer deste estudo, permite que a estrutura seja solicitada por esforços bastante reduzidos, dispensando a utilização de detalhamentos sismo-resistentes específicos. Esses fatores podem possibilitar a construção de uma edificação mais esbelta, com detalhamento comum, o que potencialmente reduziria o custo com materiais e mão de obra para a construção. Além disso, o custo com a manutenção após um evento sísmico relevante também seria muito inferior, fator este que poderia contribuir positivamente na escolha do isolamento sísmico, mesmo quando considerados apenas critérios financeiros. Inclusive, segundo Skinner, et al. (1993), apud SUN (2011), na Nova Zelândia, verificou-se uma redução de 5 a 10\% no custo estrutural de estruturas com isolamento de base.

\subsection{CONCEITOS GERAIS}

A vantagem de estruturas mais rígidas é a redução dos deslocamentos diferenciais entre pavimentos, com a desvantagem de ter que resistir a maiores esforços em função de sua maior rigidez. A vantagem das estruturas mais flexíveis é justamente o oposto, sua menor rigidez faz com que o sistema estrutural absorva acelerações menores, reduzindo os esforços a serem resistidos; entretanto, os deslocamentos relativos tornam-se mais elevados. Estruturas com isolamento beneficiam-se das vantagens dos dois sistemas anteriores, pois a flexibilização da estrutura faz com que esta receba uma parcela reduzida de esforços a serem resistidos, enquanto os grandes deslocamentos produzidos ficam contidos no dispositivo de isolamento, com o comportamento da superestrutura se assemelhando ao de um corpo rígido, com pequenos deslocamentos diferenciais.

Idealmente, uma estrutura com isolamento de base deveria desacoplar completamente a base da estrutura das movimentações sísmicas laterais do terreno, sem perder capacidade de suporte vertical. Isso garantiria que todos os esforços sísmicos laterais ficassem contidos no dispositivo isolador. Entretanto, essa idealização torna-se difícil de ser implementada por diversos motivos: limitações dos materiais e dispositivos existentes, limitações e restrição 
de movimentação lateral da estrutura e até mesmo comprometimento do comportamento da estrutura perante outros esforços laterais, como o do vento.

Portanto, a forma como o isolamento de base é implementado atualmente visa a desacoplar parcialmente a estrutura das movimentações sísmicas laterais, de modo a transferir o mínimo possível de energia cinética para a superestrutura, sem deixar de atender aos requisitos normativos e limitações dos diversos sistemas do conjunto.

O local para implantação dos dispositivos de isolamento sísmico é definido com base em diversos fatores, como: tipo de construção; tipo de fundação; caso seja uma construção nova ou a reabilitação de uma estrutura existente, o acesso para manutenção; dentre outros. Entretanto, idealmente, visa-se a inserir os dispositivos o mais próximo possível do terreno, para que toda a superestrutura possa ser isolada. Eventualmente, em construções nas quais as paredes do subsolo façam também a contenção do terreno, não é possível implantar os dispositivos na base, pois com as paredes em contato com o terreno, não seria possível garantir a devida folga para movimentações laterais, necessárias para estruturas isoladas. Nesses casos, pode-se fazer um isolamento na elevação do piso térreo; entretanto, a estrutura do subsolo não estaria protegida pelo sistema, então se deveria tomar os devidos cuidados no dimensionamento dessa fundação, de modo a garantir que esta possa absorver tanto os esforços produzidos pela movimentação da superestrutura nos apoios isoladores como os provenientes da movimentação do terreno. Em qualquer dos casos, procura-se sempre ter uma malha de vigas ou uma laje estrutural no nível do isolamento, de forma que todos os aparelhos de apoio sofram aproximadamente as mesmas deformações, ou seja, o nível do isolamento deve operar similarmente a um diafragma rígido, evitando que um aparelho sofra esforços ou deslocamentos muito superiores aos demais, uma vez que o dimensionamento é feito de forma a abranger grupos de aparelhos isoladores, ao invés de considerá-los individualmente.

Em virtude dos expressivos deslocamentos que ocorrem no nível do isolamento, é muito importante que os sistemas eletromecânicos da edificação possuam conexões flexíveis na interface com o nível de isolamento, projetados de forma que possam absorver esses deslocamentos sem comprometer a operacionalidade. A Figura 18 exemplifica uma conexão de tubulação flexível. 


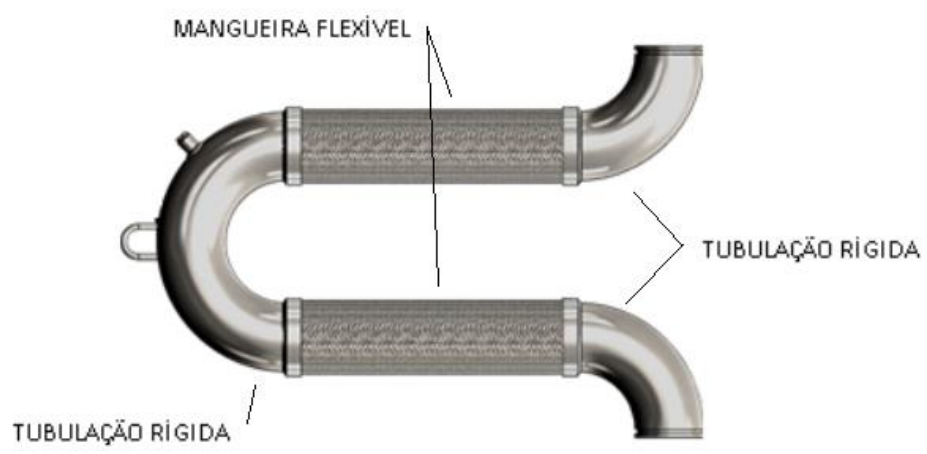

Figura 18: Exemplo de conexão flexível. Fonte: Adaptado de Arsen em www.arsenflex.com (2019).

A viabilidade de um sistema de isolamento sísmico para determinada edificação depende de uma série de fatores, dentre eles a intensidade sísmica, o tipo de fundação, o propósito da edificação, os custos diretos e indiretos envolvidos. Entretanto, em geral, um sistema de isolamento é mais eficiente quando a edificação está fundada em terreno mais rígido, possuindo uma rigidez consideravelmente elevada, de modo que a frequência do modo de vibração fundamental da estrutura seja pelo menos três vezes superior à do modo de vibração da estrutura dotada de isolamento. Isso ocorre pois quando esse critério de relação é atendido, os esforços e deslocamentos ficam mais contidos dentro do primeiro modo de vibração, enquanto a superestrutura responde quase como um corpo rígido. Entretanto, quando essa relação não é respeitada, ocorre maior participação dos outros modos de vibração, compactuando com uma maior transferência das ações sísmicas para a superestrutura. Essa relação, inclusive, é uma boa ferramenta para medir o nível de eficiência potencial de um sistema de isolamento para determinada estrutura, podendo ser descartadas situações onde essa relação seja muito inferior a três. Em relação aos terrenos, segundo Figueiredo (2007), nos casos em que existam ações sísmicas com predominância de frequências muito baixas, solos muito moles que são caracterizados por possuírem frequências naturais baixas, podem potencializar essas ações, manifestando respostas superiores às que seriam produzidas em sistemas não isolados. Ademais, solos menos rígidos podem apresentar deslocamentos diferenciais significativos, comprometendo o funcionamento do conjunto de isolamento da base, dificultando a previsibilidade e a consistência de seu comportamento, uma vez que eles são dimensionados para possuírem um mesmo deslocamento no conjunto inteiro.

\subsubsection{Critérios de modelagem para estruturas com isolamento de base}

Devido às incertezas inerentes à modelagem e ao comportamento dos sistemas de isolamento, exige-se uma confiabilidade maior para evitar episódios indesejados nesses 
componentes. Usualmente, essa maior confiabilidade é garantida por meio da amplificação dos deslocamentos envolvidos no dimensionamento desses sistemas, multiplicando-os por um coeficiente $\gamma_{x}$. O Eurocódigo sugere a adoção do valor 1,2 para esse coeficiente. Além dos dispositivos de isolamento, redes de tubulações também deverão ser dimensionadas para absorver esses deslocamentos majorados.

Os isoladores deverão, sempre que houver risco considerável, serem protegidos de efeitos perigosos, como incêndios, ataques químicos dentre outros. Considera-se que os dispositivos de isolamento poderão atingir sua capacidade última, enquanto que a superestrutura deverá permanecer em regime elástico. Portanto, não é permitido considerar as dissipações de energia mais elevadas que ocorrem quando uma edificação adentra o regime plástico. Assim, a análise de estruturas com isolamento deve ser realizada com base no espectro de resposta elástica $S_{a, e^{3}}$, permitindo-se a redução dos esforços de cada elemento estrutural por um coeficiente de comportamento (q) não superior a 1,5.

O centro de rigidez e de amortecimento do sistema de isolamento sísmico deverá ser disposto o mais próximo possível da projeção do centro de massa da edificação no plano do isolamento, para que se tenha uma maior previsibilidade do comportamento dinâmico da estrutura isolada, evitando por exemplo efeitos de torção. Usualmente, portanto, faz-se uma distribuição da rigidez e amortecimento do sistema de isolamento de modo proporcional à ação vertical descarregada em cada aparelho de apoio. O modelo de análise deve traduzir de forma suficientemente precisa a disposição espacial dos isoladores adotados, ou seja, independentemente da existência ou ausência de irregularidades na construção, é recomendada a utilização de um modelo tridimensional para realizar as análises de edificações com isolamento de base.

A seguir, apresentam-se os tipos de análise que podem ser realizadas para sistemas estruturais com isolamento de base, com suas devidas limitações.

\subsubsection{Análise linear equivalente}

Basicamente, a análise linear equivalente consiste na aplicação do MFE nos casos em que o sistema atenda aos requisitos para que possa ser considerado de comportamento linear. Este é um dos métodos mais simplificados dentre as metodologias dispostas no Eurocódigo 8, entretanto, com as facilidades da computação atual, métodos mais aprimorados como o MER e o MHT possuem quase o mesmo nível de dificuldade para

\footnotetext{
${ }^{3}$ Ver item 3.7.2, equações (3.34) a (3.37)
} 
serem implementados, têm um custo computacional bastante próximo e produzem resultados mais confiáveis.

Para que os dispositivos de isolamento possam ser considerados com comportamento linear equivalente, eles deverão ser constituídos por apoios de elastômero, ou apoios elastoplásticos que possuam um comportamento histerético bilinear, além de atender às seguintes condições:

a) A rigidez efetiva do sistema de isolamento para o deslocamento de projeto $\left(d_{d c}\right)$ deve ser superior a $50 \%$ da rigidez efetiva para um deslocamento de $0,2 d_{d c}$.

b) A taxa de amortecimento efetiva do sistema de isolamento $\xi_{\text {eff }}$ deve ser inferior a $30 \%$, sendo aplicado apenas no primeiro modo de vibração, enquanto os demais modos devem considerar a taxa de amortecimento natural da superestrutura de base fixa.

c) A relação força-deslocamento do sistema de isolamento não deve variar mais de $10 \%$ em função da velocidade de carregamento ou do valor das cargas verticais.

d) O aumento da força de restituição no sistema de isolamento, para deslocamentos entre $0,5 d_{d c}$ e $d_{d c}$, não deve ser inferior a $2,5 \%$ do peso atuante acima do sistema de isolamento.

A Figura 19 retrata a relação bilinear esperada entre força e deslocamento dos dispositivos de isolamento, com as rigidezes das fases elástica e plástica sendo representadas, respectivamente, por $K_{1}$ e $K_{2}$. Apresenta-se também a relação linearizada, conforme os critérios supramencionados, onde a rigidez equivalente efetiva $K_{\text {eff }}$ dos dispositivos é dada pela rigidez secante referente a um deslocamento de projeto $d_{d c}$. A dissipação de energia, que no comportamento bilinear é representada pela área interna do paralelogramo que descreve o ciclo histerético, deverá ser traduzida por um amortecimento viscoso equivalente, relativo a uma taxa de amortecimento efetivo $\xi_{\text {eff }}{ }^{4}$, que graficamente é expressa pela área interna da elipse que descreve um ciclo de vibração. A rigidez efetiva $K_{\text {eff }}$ e o amortecimento equivalente efetivo $\xi_{\text {eff }}$ de cada tipo de dispositivo de isolamento deverão ser obtidos por métodos que possam representá-los de forma adequada, conforme se demonstra no item 4.3.1.

\footnotetext{
${ }^{4}$ A relação entre a taxa de amortecimento equivalente $\xi_{\text {eff }}$ e a área da elipse que descreve o ciclo histerético
} será mostrada no item 4.3.1 

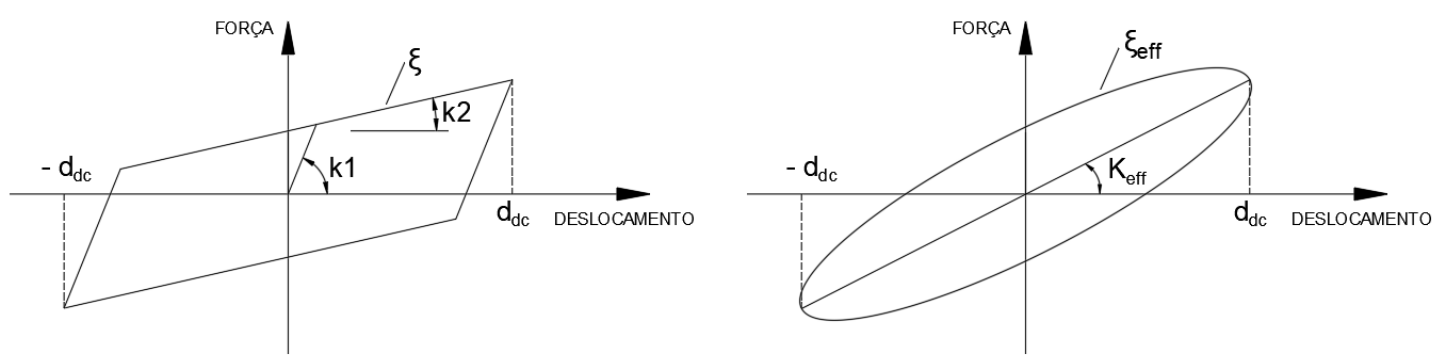

Figura 19: Comportamento histerético e rigidez efetiva de um dispositivo. Fonte: autor.

O MFE deverá ser aplicado, considerando, ao invés das acelerações sísmicas do espectro de resposta de cálculo $S_{a, d}(T)$, as acelerações do espectro de resposta elástico efetivo $S_{a, e}\left(T_{\text {eff }}\right)$, definido por (3.34) a (3.37), adotando-se como período fundamental $T$, o período efetivo $T_{e f f}$ obtido em função da rigidez efetiva $K_{e f f}$, e realizando a correção para o nível de amortecimento dos aparelhos de apoio, por meio da aplicação da equação (3.38) com um amortecimento efetivo $\xi_{\text {eff }}$.

Essas definições permitem que a rigidez e amortecimento dos dispositivos de isolamento sejam aplicados como apoio elásticos nos elementos sismo-resistentes verticais do modelo de cálculo, que em conjunto com a aplicação das ações sísmicas consideradas, possibilita processar, de forma análoga ao sistema com base fixa, as acelerações, esforços e deslocamentos de resposta do modelo estrutural.

Adicionalmente, nos tipos de aparelho em que a rigidez efetiva $K_{\text {eff }}$ seja dependente do deslocamento de projeto $d_{d c}$ suposto, após a realização da análise sísmica, o deslocamento de resposta $d_{r}$ obtido deve ser comparado com o $d_{d c}$, respeitando a seguinte proporção:

$$
\left|d_{d c}-d_{r}\right| \leq 0,05 d_{d c}
$$

Ou seja, o deslocamento obtido da análise deve ter um desvio inferior a 5\% em relação ao deslocamento assumido no projeto, de forma a garantir que a rigidez efetiva do sistema seja compatível com os deslocamentos obtidos. Caso essa relação não seja respeitada, deve-se realizar uma nova iteração de análise, com uma nova consideração nos parâmetros do sistema de isolamento ou no deslocamento de projeto admitido, até que a solução convirja.

\subsubsection{Análise linear simplificada}

Para alguns sistemas, admite-se ainda uma análise mais simplificada, na qual o sistema estrutural é considerado como um sólido rígido em translação acima do sistema de isolamento. Nesses sistemas, os esforços a serem aplicados na superestrutura e os deslocamentos no nível do isolamento são obtidos por formulações bastante simplificadas, 
que levam em consideração duas direções horizontais ortogonais sobrepondo-se os efeitos de torção apresentados no item 3.5.5.

Para que uma análise linear simplificada possa ser realizada, segundo o Eurocódigo 8, as seguintes condições devem ser atendidas:

1) O sistema de isolamento deverá ser compatível com as condições de um sistema amortecido linear equivalente apresentado no item 4.2.2;

2) A excentricidade total, incluindo a excentricidade acidental de (3.24), deve ser inferior a 7,5\% do comprimento da estrutura na direção horizontal perpendicular à ação sísmica sendo considerada. Desse modo, pode-se desprezar os efeitos de torção dinâmicos em relação ao eixo vertical da estrutura;

3) O local da estrutura deverá estar a uma distância superior a $15 \mathrm{~km}$ de qualquer falha geológica com potencial para gerar atividade sísmica de magnitude de onda de superfície na escala Richter $M_{s}>6,5$;

4) A estrutura deve ter sua maior dimensão horizontal inferior a $50 \mathrm{~m}$;

5) A fundação e o terreno deverão ser rígidos o suficiente para que os deslocamentos diferenciais sejam desprezíveis em relação aos deslocamentos no nível do isolamento.

6) Todos os dispositivos isoladores devem estar dispostos acima dos elementos da fundação que suportam as cargas verticais;

7) O período efetivo natural $T_{\text {eff }}$ do sistema estrutural isolado, em segundos, deverá satisfazer à seguinte relação com o período $T_{f}$ do sistema considerado com base fixa:

$$
3 T_{f} \leq T_{e f f} \leq 3 \mathrm{~s}
$$

8) O sistema de contraventamento deverá estar disposto regular e simetricamente a dois eixos horizontais principais da estrutura;

9) A rigidez vertical do sistema de isolamento deverá ser ao menos 150 vezes superior à rigidez horizontal;

10) $O$ período fundamental vertical $T_{v}$ deverá satisfazer à seguinte expressão, em função da massa $M$ e da rigidez vertical $K_{v}$ da estrutura: 


$$
0,1 s>T_{v}=2 \pi \sqrt{\frac{M}{K_{v}}}
$$

Com todas essas condições atendidas, os deslocamentos $d_{d c}$ no nível do isolamento poderão ser obtidos mediante a seguinte expressão:

$$
d_{d c}=\frac{M S_{a, e}\left(T_{e f f}\right)}{K_{e f f}}
$$

Sendo $M$ a massa considerada acima do sistema de isolamento e $S_{a, e}\left(T_{e f f}\right)$ e $K_{\text {eff }}$ respectivamente as acelerações sísmicas e a rigidez efetiva consideradas, conforme exposto no item 4.2.2.

Os esforços a serem aplicados horizontalmente na superestrutura devem ser obtidos pela seguinte expressão:

$$
f_{i}=m_{i} S_{a, e}\left(T_{e f f}\right)
$$

onde $f_{i}$ representa o esforço horizontal no pavimento de elevação $i$ e $m_{i}$ a massa desse pavimento.

Além desses esforços, devem ser somados os esforços estáticos devidos à torção, que podem ser obtidos conforme o item 3.5.5, adotando a excentricidade como a soma da excentricidade acidental e a excentricidade do centro de rigidez dos aparelhos de apoio em relação ao centro de massa da superestrutura.

Os efeitos de torção nos aparelhos de apoio poderão ser verificados por meio da multiplicação dos deslocamentos pelo coeficiente $\delta_{x i}$, obtido pela seguinte expressão:

$$
\delta_{x i}=1+\frac{e_{t o t, y}}{r_{y}^{2}} y_{i}
$$

em que:

$\delta_{x i}$ é o coeficiente de majoração do deslocamento do isolador $i$ considerado, na direção x; $y_{i}$ é a distância do isolador ao centro de rigidez do sistema de isolamento;

$e_{t o t, y}$ é a excentricidade total na direção $y$;

$r_{y}{ }^{2}$ é o quadrado do raio de torção do sistema de isolamento na direção $y$, obtido por:

$$
r_{y}{ }^{2}=\frac{\sum\left(x_{i}{ }^{2} K_{y i}+y_{i}{ }^{2} K_{x i}\right)}{\sum K_{x i}}
$$

onde $K_{x i}$ e $K_{y i}$ são as rigidezes de um isolador $i$, respectivamente nas direções $x$ e $y$. 


\subsubsection{Análise linear modal por espectro de resposta}

A análise linear por espectro de resposta para um sistema estrutural com isolamento de base é feita de forma muito similar à análise para um sistema com a base fixa, explicado em 3.7.2. Para tanto, os dispositivos isoladores devem ser compatíveis com a análise linear equivalente expressa no item 4.2.2.

Analogamente ao método linear equivalente, o MER deverá ser aplicado, considerando, ao invés das acelerações sísmicas do espectro de resposta de cálculo $S_{a, d}(T)$, as acelerações do espectro de resposta elástico efetivo $S_{a, e}(\mathrm{~T})$, definido por (3.34) a (3.37). Para o primeiro modo de vibração (modo do isolamento), deverá ser aplicada a correção para o nível de amortecimento dos aparelhos de apoio, por meio da aplicação da equação (3.38) com um amortecimento efetivo $\xi_{\text {eff }}$. Já os demais modos deverão ser analisados com base no espectro elástico para a taxa de amortecimento convencional de 5\%. A Figura 20 apresenta o espectro a ser adotado, no caso de uma análise com isolamento de base, para um sismo de intensidade $0,2 \mathrm{~g}$ em solo de classe $\mathrm{D}$, em que o período do primeiro modo de vibração (modo do isolamento) seja superior a 2 s e para os demais modos inferior a $2 \mathrm{~s}$.

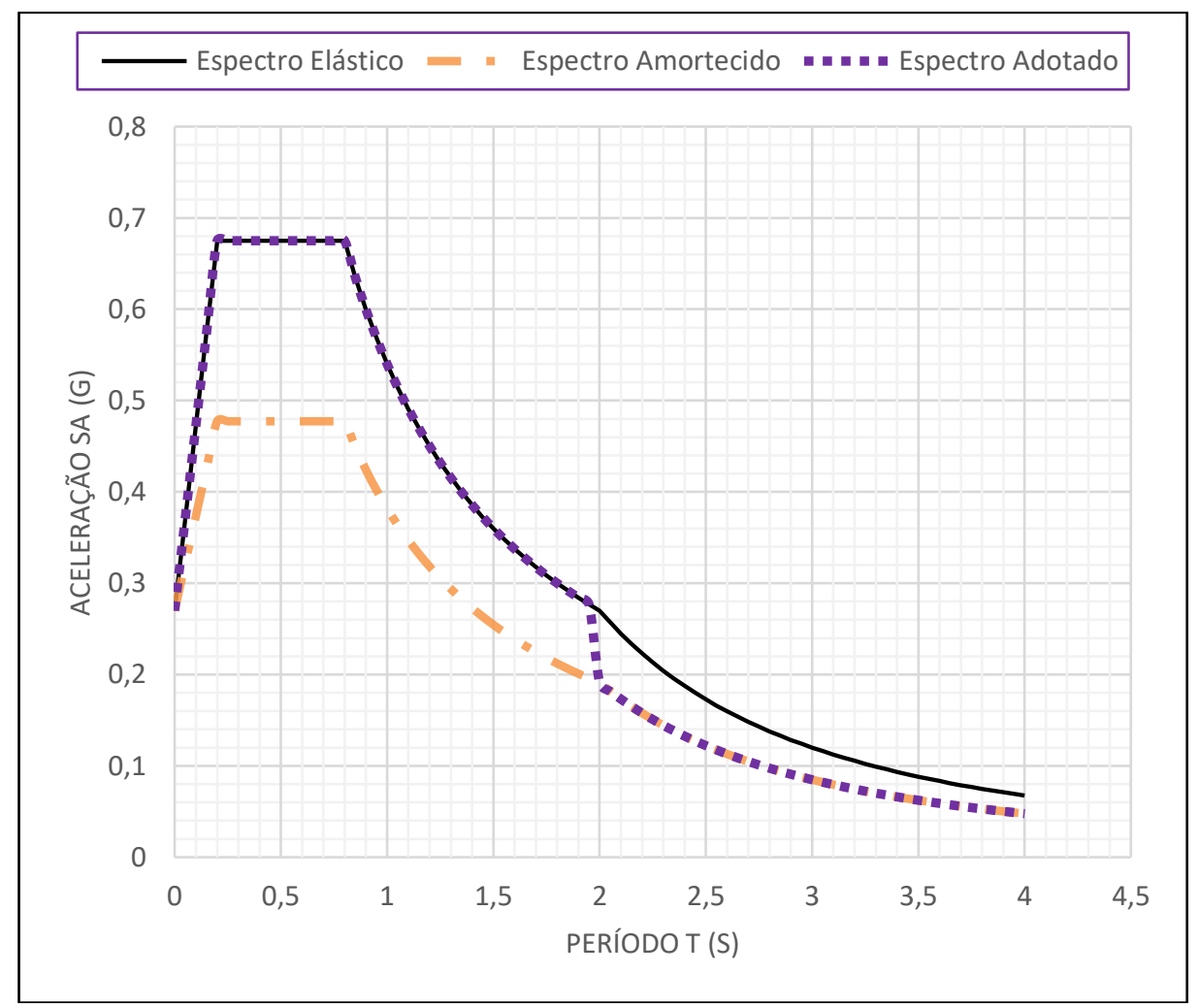

Figura 20: Espectro de Resposta para aplicação do MER em estruturas com isolamento sísmico de base. Fonte: autor 
O modelo estrutural deverá considerar, na conexão dos elementos sismo-resistentes verticais com a fundação, a rigidez horizontal e vertical dos aparelhos de apoio aplicados, de modo que o período fundamental do sistema estrutural fique compatível com o isolamento adotado.

\subsubsection{Análise no domínio do tempo}

A análise no domínio do tempo configura-se como a mais completa dentre as estudadas e é certamente a mais apropriada para o caso das estruturas com isolamento de base, uma vez que permite considerar o comportamento não linear, presente em alguns tipos de dispositivos isoladores. Aliás, sempre que não for possível caracterizar um dispositivo para uma análise linear equivalente, seguindo os critérios do item 4.2.2, deve-se recorrer a uma análise no domínio do tempo.

A análise no domínio do tempo deve ser realizada conforme os fundamentos apresentados no item 3.7.3 e pode ser realizada em regime linear ou não linear. Usualmente, realiza-se uma análise linear modal no domínio do tempo, que basicamente decorre da integração direta da equação do movimento de cada modo de vibração do sistema estrutural com a subsequente superposição das respostas de cada modo, obtidos em cada instante de tempo. No SAP2000, existe ainda uma análise nomeada de Fast Nonlinear Analysis (FNA), na qual se definem alguns elementos específicos com comportamento não linear (link-elements) e então, realiza-se uma análise linear modal, com as respostas internas dos link-elements sendo obtidas por um processo iterativo de modo a convergir para satisfazer o equilíbrio. Essencialmente, o software interpreta a não linearidade dos aparelhos de apoio modificando a contribuição de acelerações que é transferida para a superestrutura, que em seguida é computada por meio de uma análise linear modal convencional. Esse método permite que algumas características, como a relação força-deslocamento e os amortecimentos concentrados, possam ser contabilizados internamente nesses elementos de link, tornando este o método mais eficiente para analisar uma estrutura sismicamente isolada.

A utilização da FNA, com os dispositivos isoladores sendo implementados como linkelements, permite desconsiderar as alíneas a), b), c) e d) do item 4.2.2, pois as propriedades não lineares dos isoladores são inseridas diretamente no modelo de análise. Desse modo, ampliam-se as possibilidades de dimensionamento destes dispositivos. Entretanto, é necessário verificar cuidadosamente o comportamento estrutural, pois desprezando essas 
limitações, alguns esforços menos previsíveis podem ocorrer, como é verificado no estudo de caso desta pesquisa.

Mais relevante ainda, a adoção da análise FNA desobriga das iterações necessárias para atendimento à equação (4.1), uma vez que a dependência da rigidez efetiva em relação ao deslocamento é considerada explicitamente na análise. Isso simplifica bastante o procedimento de convergência no dimensionamento do dispositivo de isolamento.

\subsection{SISTEMAS DE ISOLAMENTO}

Dentre os sistemas de isolamentos mais comumente utilizados, pode-se destacar os dispositivos de elastômeros comuns (Rubber Bearing - RB), os dispositivos de elastômeros de alto amortecimento (High Damping Rubber Bearing - HDRB), os elastômeros com núcleo de chumbo (Lead Rubber Bearing - LRB) e os dispositivos de pêndulo de fricção (Friction Pendulum System - FPS).

Os sistemas de elastômeros comuns $\mathrm{RB}$ são os mais simples disponíveis e de fácil fabricação. Eles consistem basicamente de camadas de elastômeros vulcanizados posicionadas alternadamente a finas chapas metálicas de reforço, de forma similar aos aparelhos de apoio de vigas de pontes, o que garante uma maior confiabilidade, uma vez que já são largamente utilizados com essa função alternativa. $O$ sistema funciona basicamente com o elastômero garantindo a flexibilização horizontal da estrutura, enquanto as chapas metálicas impedem que as camadas de borracha embarriguem nas extremidades, conforme ilustrado na Figura 21.

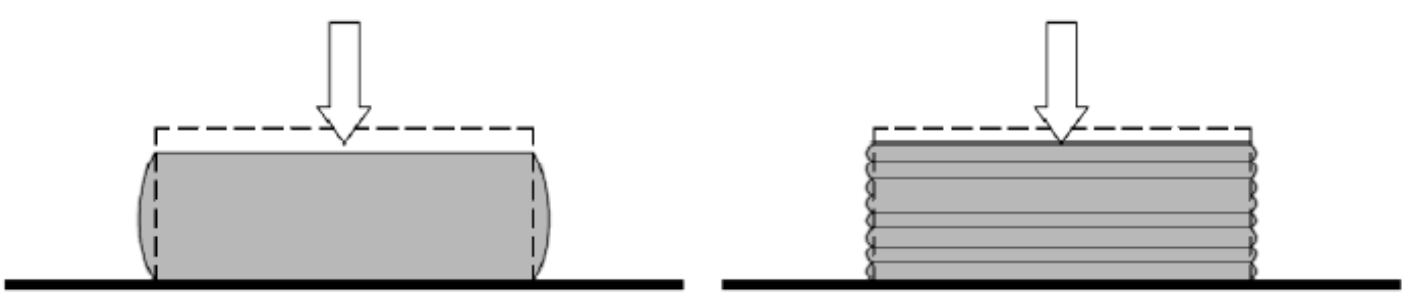

Figura 21: Rubber Bearing - RB. Fonte: Figueiredo (2007)

As camadas de borracha possuem, usualmente, espessura de 8 a $20 \mathrm{~mm}$, conforme a especificação de cada fabricante, enquanto as chapas de aço podem ter espessuras variando de 3 a $5 \mathrm{~mm}$. Nas faces inferior e superior, os dispositivos possuem chapas metálicas grossas, de aproximadamente $20 \mathrm{~mm}$, para fixação do dispositivo na fundação e na estrutura. 
A Figura 22 representa o comportamento básico do RB. Em virtude desses dispositivos elevarem consideravelmente o período do primeiro modo de vibração da estrutura, as respostas da análise dependem quase que totalmente do primeiro modo de vibração, que é condicionado quase que exclusivamente pelo deslocamento dos dispositivos de isolamento, com o restante da estrutura respondendo de forma praticamente rígida. Esse tipo de sistema possui a força de restituição garantida pelo próprio elastômero, que após deformado, tende a retornar para sua posição original. Ainda assim, após um evento sísmico com aceleração característica próxima à de projeto, faz-se necessário realizar a inspeção, manutenção e eventual substituição dos dispositivos de isolamento, uma vez que não se pode garantir a inexistência de comportamento histerético diferencial entre os isoladores. A principal fonte de amortecimento provém da capacidade de dissipação de energia do elastômero utilizado. Desse modo, as taxas de amortecimento não são muito elevadas, limitando-se a aproximadamente 5\% do amortecimento crítico e por vezes levando a amplos deslocamentos. Segundo Kelly (1986), é possível aplicar esses dispositivos em conjunto com elementos dissipativos para aumentar o amortecimento do sistema, entretanto, nesses casos pode haver respostas significativas nos modos de vibração mais elevados, o que dificulta a aplicação de análises mais simplificadas como o Método das Forças Laterais Equivalentes, conforme é explorado mais detalhadamente no item 5.
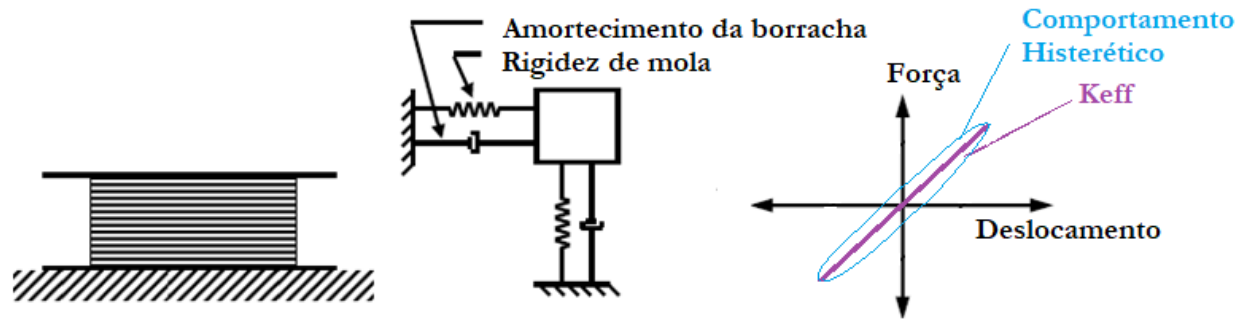

Figura 22: Comportamento do RB. Fonte: Adaptado de Wiles (2008).

A partir dos mesmos conceitos de isolamento, os estudos sobre dispositivos de isolamento foram avançando, e uma evolução do RB foi desenvolvida, substituindo-se os elastômeros convencionais por elastômeros de alto amortecimento, visando a obter basicamente as mesmas propriedades do RB, acrescentando uma maior parcela de dissipação de energia. Diferentemente dos elastômeros comuns, os elastômeros de alto amortecimento possuem um comportamento diferente em sua fase de carregamento e descarregamento, originando um comportamento histerético diverso do RB, conforme pode ser observado na Figura 23, na qual a área interna do ciclo histerético representa a quantidade de energia dissipada por ciclo. Esses dispositivos são chamados de HDRB, que apesar de muito similares aos RB, 
podem chegar a uma taxa de amortecimento de 10 a $15 \%$ do amortecimento crítico, segundo Infanti e Castellano (2004), citado por Figueiredo (2007).

RB

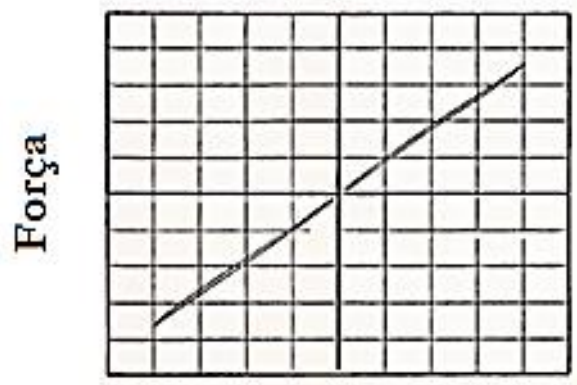

HDRB

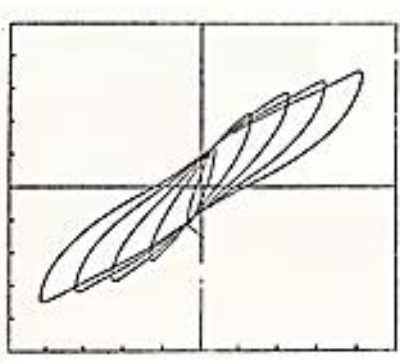

Deslocamento

Figura 23: Comparativo dos comportamentos histeréticos RB, HDRB e LRB. Fonte: Raufaste (1992)

O LRB é um outro tipo de dispositivo que foi desenvolvido com princípios muito similares ao RB e HDRB e configura, segundo Figueiredo (2007), como um dos dispositivos mais aplicados na atualidade. Seu desenvolvimento foi impulsionado em função da disponibilidade de materiais disponíveis para fabricação de isoladores de elastômeros na região da Austrália e Nova Zelândia, que não atendiam aos critérios desejados quanto à dissipação de energia. Portanto, a adoção de elastômeros comuns, similares ao RB, foi combinada com um núcleo confinado de chumbo, de modo que as deformações produzidas no aparelho fossem equivalentes no elastômero e no núcleo, conforme ilustrado na Figura 24. A adição do núcleo de chumbo traz três vantagens principais: a primeira é, de fato, o acréscimo na dissipação de energia por ciclo histerético, garantido por meio do escoamento do núcleo de chumbo durante deformações acentuadas, que pode atingir um nível muito superior ao obtido pelos dispositivos HDRB, levando a uma taxa de amortecimento superior a $25 \%$, muito embora nem sempre taxas de amortecimento tão elevadas configurem um bom projeto, como é verificado no item 5; a segunda é o acréscimo de rigidez vertical, melhorando o suporte estrutural do dispositivo; e a terceira é uma maior rigidez horizontal inicial, que antecipa o escoamento do núcleo de chumbo, reduzindo significativamente a sensibilidade de deslocamentos perante carregamentos horizontais de menor intensidade, como é potencialmente o caso para carregamento de vento em edificações de até dez pavimentos. 


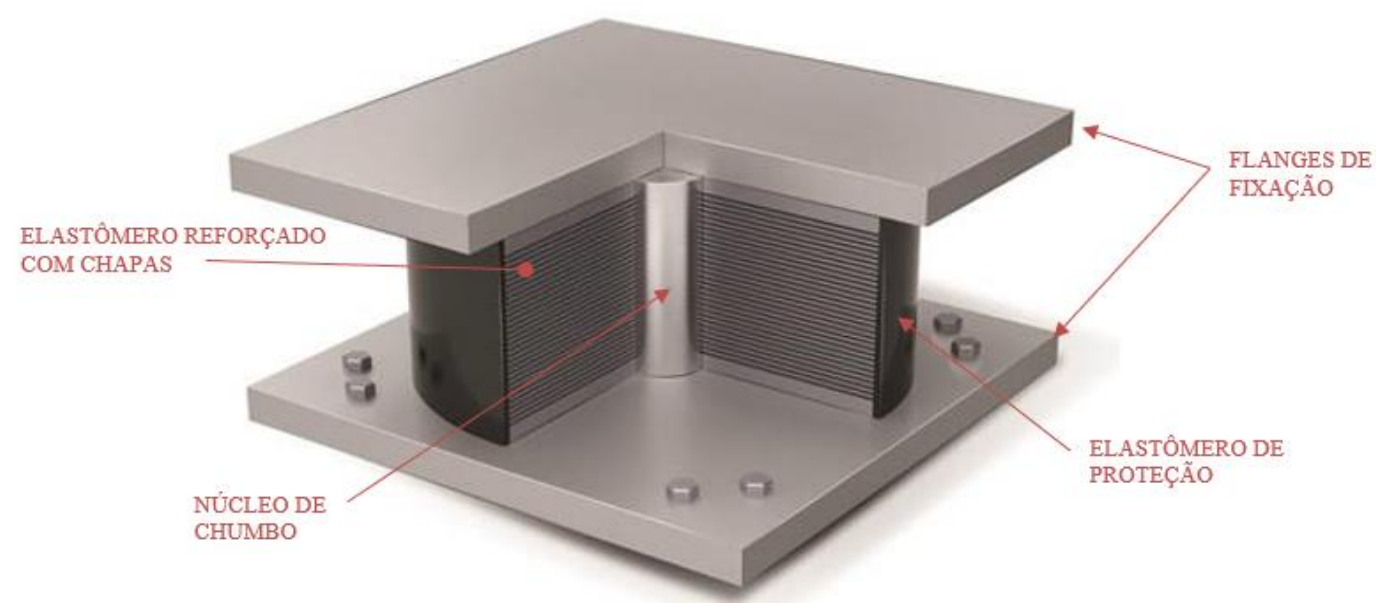

Figura 24: Seção transversal LRB. Fonte: Adaptado de Jingtong em www.bearing-pad.com (2019)

O chumbo é especificamente adotado como material no núcleo desses dispositivos por possuir algumas propriedades importantes: baixa tensão tangencial de plastificação (usualmente entre 8 a $10 \mathrm{MPa}$ ), garantindo que mesmo uma seção com diâmetro considerável - entre 15 a 30\% do diâmetro do dispositivo - escoe sob os esforços de projeto; um comportamento elastoplástico, com boa resistência à fadiga, permitindo que, em seu escoamento, trabalhe como um amortecedor viscoelástico, mantendo as propriedades mecânicas originais, mesmo após sofrer ações cíclicas; além disso é um material que possui grande ductilidade, o que facilita seu funcionamento conjunto no dispositivo, ainda que diante das grandes distorções que ocorrem durante eventos sísmicos.

A Figura 25 representa as considerações e o comportamento da curva de forçadeslocamento dos dispositivos LRB.
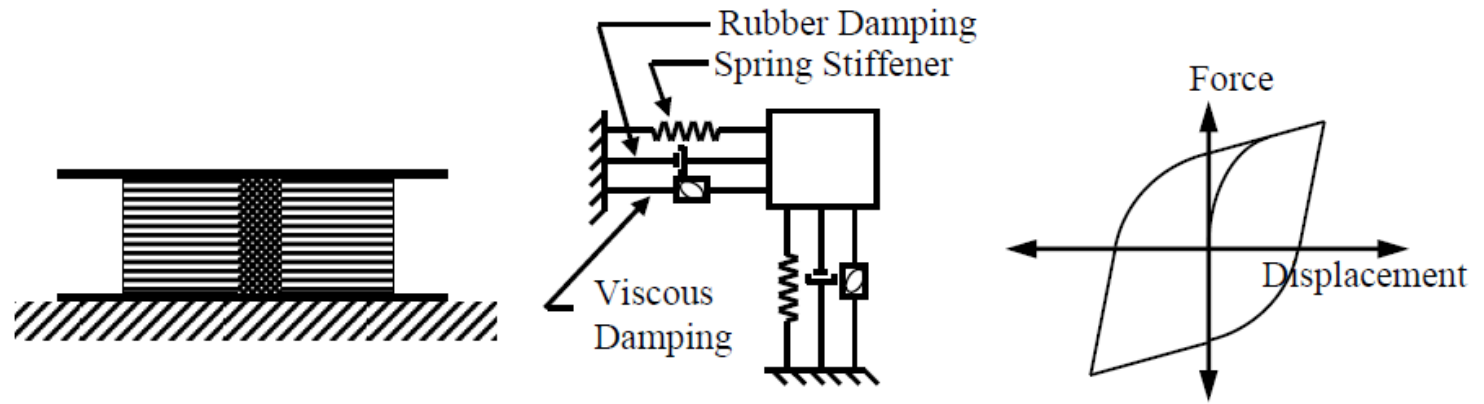

Figura 25: Comportamento do LRB. Fonte: Adaptado de Wiles (2008).

O desempenho do núcleo de chumbo no dispositivo está diretamente vinculado à sua deformação por corte puro, de forma que alguns cuidados construtivos devem ser levados em conta. Os flanges de fixação devem ser fabricados em preciso contato com o núcleo de 
chumbo e com o elastômero, de modo a impedir a rotação das faces superior e inferior desses elementos, quando em funcionamento. A fretagem - chapas metálicas de reforço entre camadas de elastômero - deve possuir um espaçamento pequeno (até $20 \mathrm{~mm}$ ) para evitar deformações por flexão nas regiões entre chapas. O núcleo de chumbo deve ser fabricado com um volume aproximadamente 1\% superior ao nicho onde será instalado, de forma que toda sua superfície fique pressionada contra o elastômero fretado e as chapas de fixação.

Além dos dispositivos constituídos por elastômeros, existem ainda os aparelhos isoladores constituídos por pêndulos de fricção, conforme representado na Figura 26.

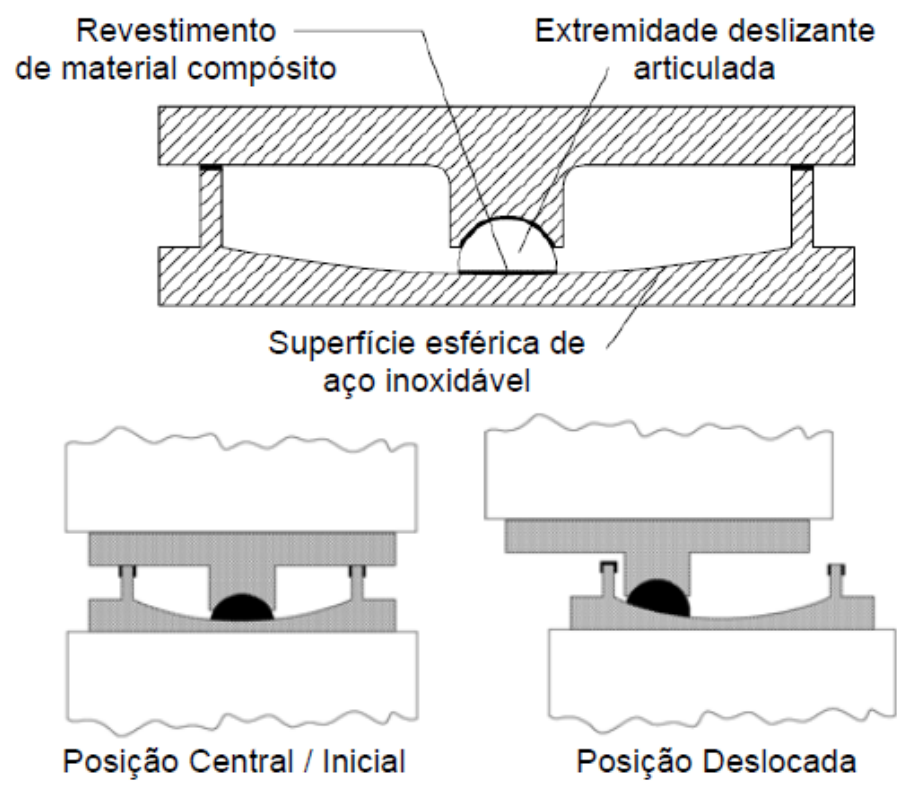

Figura 26: Dispositivos de fricção. Fonte: Figueiredo (2007)

Esses dispositivos são baseados nos princípios da movimentação pendular, onde a extremidade fixada à fundação possui uma superfície convexa e a extremidade fixada na superestrutura possui uma superfície côncava, que ficam interligadas de forma articulada por um elemento deslizante com mesmo raio de curvatura nos contatos, revestido por um material de baixo atrito. Desse modo, a movimentação diferencial da fundação em relação à superestrutura imprime um movimento pendular internamente no dispositivo, que garante a flexibilização horizontal do sistema, enquanto o atrito produzido entre as superfícies de deslizamento assegura a dissipação de energia necessária para redução das respostas e controle dos deslocamentos, que pode chegar a níveis similares aos obtidos pelos apoios LRB, de 25\% do amortecimento crítico.

A restauração da posição inicial da edificação, diferentemente dos apoios com elastômeros, é promovida pela própria geometria interna do dispositivo, em conjunto com a atuação do 
peso próprio da edificação, que tende a posicionar o elemento deslizante de apoio na região mais baixa e central da superfície convexa da base do dispositivo, de forma similar à atuação de um pêndulo.

Uma das grandes vantagens dos apoios pendulares de fricção é sua altura bastante compacta, usualmente até $30 \mathrm{~cm}$, o que facilita muito sua instalação na restauração de edificações existentes, evitando a necessidade de grandes alterações arquitetônicas. Por outro lado, existe a necessidade de manutenções mais regulares nas superfícies de atrito, para que sejam removidos detritos indesejáveis que possam comprometer o correto funcionamento do dispositivo.

Neste estudo, serão abordados com mais profundidade somente os dispositivos LRB. A seguir apresentam-se as formulações e definições específicas para o dimensionamento e aplicação desses dispositivos em análises sísmicas.

\subsubsection{Dimensionamento do Lead Rubber Bearing (LRB)}

A implementação dos aparelhos isoladores em modelos de análise, sejam estes RB, HDRB, LRB ou apoios de fricção, baseia-se, quase que em sua totalidade, em sua relação de forçadeslocamento. Uma vez que essa relação esteja definida, pode-se inseri-la nos nós de apoio do modelo matemático, de forma a computar seu comportamento na análise dinâmica. Após a obtenção das respostas dessa análise, deve-se fazer a verificação das deformações obtidas nos dispositivos, garantindo que estejam de acordo com as premissas do dimensionamento, validando desse modo sua aplicação.

No caso dos LRB, essa relação pode ser definida de duas formas principais: por um modelo bilinear, bastante similar ao apresentado na Figura 27, onde a rigidez inicial e após o escoamento do núcleo de chumbo são representadas, cada uma, por uma reta com inclinação distinta, formando um "paralelogramo", no qual sua área interna representa a dissipação de energia por ciclo histerético de carregamento e descarregamento; ou por um modelo linearizado, que apresenta a rigidez equivalente por uma única reta, conectando os dois extremos de máxima força-deslocamento e mínima força-deslocamento, enquanto a dissipação viscoelástica equivalente é obtida de forma a possuir uma área equivalente à do modelo bilinear. Os dois modelos usualmente adotados podem ser verificados a seguir. 


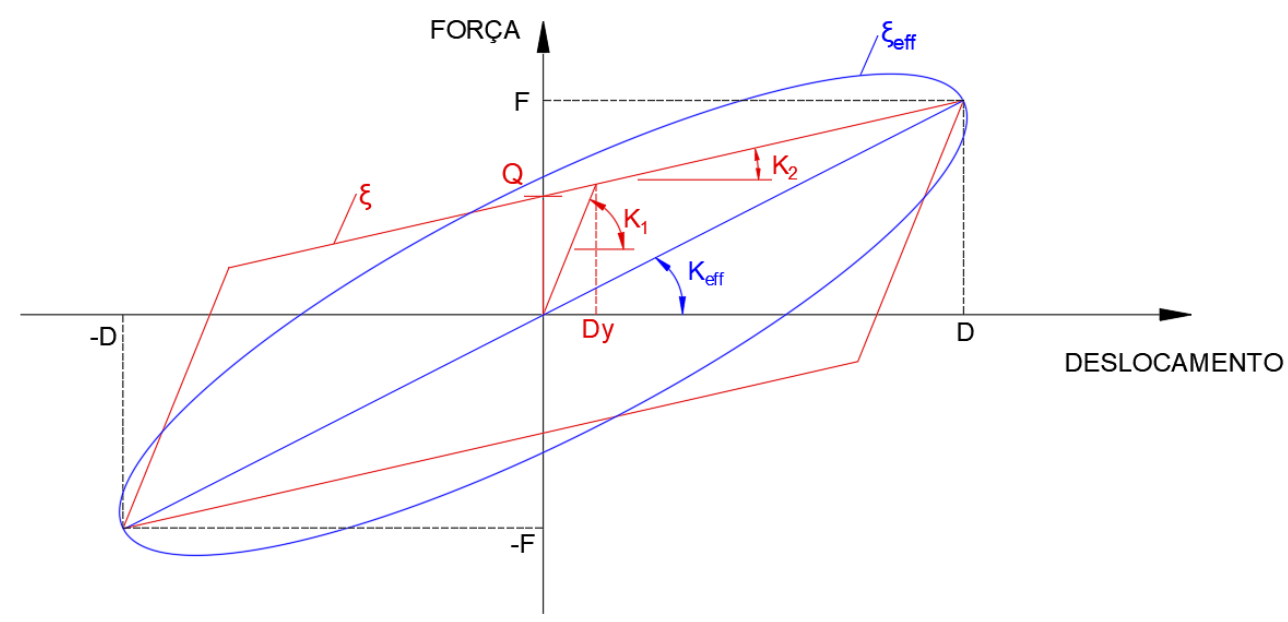

Figura 27: Modelo histerético bilinear do LRB (em vermelho) e modelo histerético linearizado do LRB (em azul). Fonte: autor.

$\mathrm{Na}$ Figura 27, $K_{1}$ e $K_{2}$ representam respectivamente a rigidez elástica e a rigidez pós escoamento do núcleo de chumbo, $K_{\text {eff }}$ representa a rigidez equivalente linearizada e $\mathrm{F}$ representa a força máxima resistida pelo isolamento quando é atingido o deslocamento máximo $D$. Além desses parâmetros, no caso do modelo bilinear, $Q$ representa a força característica do aparelho, definida por:

$$
\mathrm{Q}=\mathrm{F}_{\mathrm{y}}\left(1-\frac{\mathrm{K}_{2}}{\mathrm{~K}_{1}}\right)
$$

sendo $\mathrm{F}_{\mathrm{y}}$ a força de escoamento do núcleo de chumbo do aparelho, expressa por:

$$
\mathrm{F}_{\mathrm{y}}=\frac{1}{\varphi} f_{y l} \frac{\pi \Phi_{L}^{2}}{4}
$$

onde $f_{y l}$ é a tensão de escoamento do chumbo, de aproximadamente 8 a $10 \mathrm{MPa}, \Phi_{L}$ o diâmetro do núcleo e $\varphi$ o fator de fluência do chumbo, que, para carregamentos dinâmicos, é igual à unidade.

A rigidez $K_{2}$, pós-plastificação do núcleo, é análoga a uma associação em paralelo entre a rigidez do elastômero e uma contribuição residual da rigidez do núcleo de chumbo, definida quase que exclusivamente pelas propriedades do elastômero, com o chumbo desempenhado um papel bastante reduzido, que pode ser contabilizado por um acréscimo de $10 \%$ na rigidez do elastômero puro, desse modo:

$$
\mathrm{K}_{2}=1,1 \frac{\mathrm{GA}_{\mathrm{b}}}{\mathrm{h}}
$$


onde $\mathrm{G}$ é o modulo de cisalhamento do elastômero, $\mathrm{A}_{\mathrm{b}}$ é a área da seção transversal de elastômero e h, a altura efetiva de elastômero no dispositivo.

A rigidez elástica $K_{1}$ pode ser definida por uma relação em função da rigidez $K_{2}$, em que se recomenda, segundo Naeim e Kelly (1999), $\frac{\mathrm{K}_{2}}{\mathrm{~K}_{1}}=\frac{1}{10}$ a $\frac{1}{21}$, para os aparelhos LRB. Muitos dos estudos de referência adotam a relação $\frac{1}{10}$, entretanto, neste estudo, em vez de adotar o extremo inferior do intervalo, optou-se por um valor intermediário de $\frac{1}{13}$, assim:

$$
\mathrm{K}_{1}=13 \mathrm{~K}_{2}
$$

A dissipação de energia $E$ pode ser calculada pela seguinte expressão:

$$
\mathrm{E}=4 \mathrm{Q}\left(\mathrm{D}-\mathrm{D}_{y}\right)
$$

com:

$$
\mathrm{D}_{y}=\frac{\mathrm{Q}}{\mathrm{K}_{1}-\mathrm{K}_{2}}
$$

A partir dessas definições, é possível aplicar uma adaptação do método desenvolvido por Naeim e Kelly (1999), utilizando alguns parâmetros conhecidos e outros estimados, para definir todas as propriedades necessárias para aplicação do LRB na análise sísmica, tanto para o modelo bilinear, quanto para o modelo linearizado. O método adota as seguintes formulações para linearização do modelo do LRB:

$$
\mathrm{T}_{e f f}=2 \pi \sqrt{\frac{\mathrm{M}}{K_{e f f}}}
$$

onde $\mathrm{T}_{\text {eff }}$ é o período equivalente efetivo da estrutura isolada, $\mathrm{M}$ é a massa contabilizada na análise sísmica e $K_{\text {eff }}$ é a rigidez equivalente efetiva linearizada do isolamento, que também pode ser determinada por:

$$
K_{e f f}=\frac{\mathrm{F}}{\mathrm{D}}=\frac{\mathrm{Q}+\mathrm{K}_{2} \mathrm{D}}{\mathrm{D}}
$$

A energia dissipada pelo amortecimento viscoso equivalente $E_{v}$, com valor equivalente à área da elipse da Figura 27, segundo a formulação de Jacobsen (1930), é dada por:

$$
E_{v}=2 \pi K_{e f f} \mathrm{D}^{2} \xi_{e f f}
$$

onde $\xi_{\text {eff }}$ é a taxa de amortecimento equivalente. 
Portanto, após as definições das características sísmicas que irão configurar a análise, como local, espectro de resposta elástica e tipo da estrutura, o dimensionamento do LRB inicia-se com a determinação do deslocamento horizontal estimado $\mathrm{D}$, que pode ser obtido diretamente da resposta de um sistema de um grau de liberdade, que, de forma similar à expressão (3.43), é dado por:

$$
\mathrm{D}=S_{e f f}\left[\frac{\mathrm{T}_{e f f}}{2 \pi}\right]^{2}
$$

onde $S_{e f f}$ é a aceleração sísmica em $\mathrm{m} / \mathrm{s}^{2}$, tomada em relação ao espectro de resposta elástica corrigido para uma taxa de amortecimento $\xi_{\text {eff }}$, para um sistema com período efetivo $\mathrm{T}_{\text {eff }}$.

O período $\mathrm{T}_{e f f}$ é escolhido de tal forma a satisfazer à expressão (4.2), sendo que, quanto mais distante do período $\mathrm{T}_{f}$ da estrutura com base fixa, mais eficiente se torna o sistema de isolamento. Assim, usualmente, adotam-se valores próximos de três, para análises dinâmicas em regime linear. A taxa de amortecimento $\xi_{\text {eff }}$ é escolhida inicialmente entre os valores $10 \%$ a $30 \%$, sendo que deverá satisfazer às alíneas 1) a 7) do item 4.2.2, no caso de uma análise linear. Além disso, valores muito superiores a 10\% podem gerar excitações em modos superiores ao primeiro, produzindo esforços cortantes superiores aos basais internamente na estrutura, conforme se mostra no estudo de caso. Verificou-se também que valores superiores a 30\% podem não garantir convergência na obtenção dos demais parâmetros do método.

Com o valor de $\mathrm{T}_{\text {eff }}$ escolhido, pode-se determinar $K_{\text {eff }}$ da expressão (4.14). O amortecimento equivalente $E_{v}$, definido em (4.16) deve possuir valor igual à dissipação de energia (4.12). Portanto, igualando-se as duas expressões e rearranjando o resultado, podese chegar a:

$$
\mathrm{Q}=\frac{\pi K_{e f f} \mathrm{D}^{2} \xi_{e f f}}{2\left(\mathrm{D}-\mathrm{D}_{y}\right)}
$$

Aqui, inicia-se um procedimento iterativo, para obtenção dos demais parâmetros do isolamento:

1) Determina-se a primeira iteração de $Q$, negligenciando $D_{y}$ na expressão (4.18);

2) Utiliza-se o valor de $Q$ para obter $K_{2}$, rearranjando a expressão (4.15) em $\mathrm{K}_{2}=K_{e f f}-\frac{\mathrm{Q}}{\mathrm{D}}$ 
3) $\mathrm{K}_{1}$ é obtido de (4.11);

4) $\mathrm{D}_{y}$ é obtido de (4.11) e (4.13);

5) Recalcula-se $\mathrm{Q}$ a partir de (4.18), agora se incluindo a parcela $\mathrm{D}_{y}$;

6) Repetem-se os passos 2) a 5), até que a solução convirja.

$\mathrm{O}$ valor final de $\mathrm{D}_{y}$ é utilizado para calcular a força de escoamento $\mathrm{F}_{\mathrm{y}}$, aplicando-se a expressão (4.13) em (4.8) e rearranjando para:

$$
\mathrm{F}_{\mathrm{y}}=\mathrm{K}_{1} \mathrm{D}_{y}
$$

Finalmente, os valores finais de $\mathrm{K}_{2}$ e $\mathrm{F}_{\mathrm{y}}$ podem ser utilizados para determinar as dimensões do elastômero e do núcleo de chumbo do LRB, respectivamente por meio das expressões (4.10) e (4.9). Para tanto, deve-se considerar que a área de elastômero $A_{b}$ é dada pela área da seção transversal do dispositivo, descontada da área do núcleo de chumbo; e que a altura de elastômero h deve ser fixada de modo que atenda aos critérios de distorção admitidos para um bom funcionamento do dispositivo.

Segundo os estudos realizados em Raufaste (1992), os dispositivos LRB atendem a distorções bastante superiores a 100\%, portanto, para satisfazer com segurança os critérios de distorção, levando em consideração o coeficiente normativo $\gamma_{x}$, apresentado no item 4.2.1, pode-se definir a altura $h$ pela seguinte expressão:

$$
\mathrm{h} \cong 1,5 \mathrm{D}
$$

No caso de uma análise linear, após a definição dos parâmetros e dimensões do LRB, devese verificar se as alíneas do item 4.2.2 estão atendidas e se as respostas da análise atendem à expressão (4.1). Caso algum dos critérios não seja atendido, os devidos ajustes devem ser feitos em um novo estudo, para que a análise possa ser devidamente validada.

A aplicação dos parâmetros do LRB no SAP2000 é feita por meio dos link-elements, adotando elementos do tipo rubber isolator, no qual, para o caso de uma análise linear, informa-se a rigidez equivalente efetiva $K_{e f f}$, e o coeficiente de amortecimento efetivo $c_{e f f}$, relativo à taxa de amortecimento efetivo $\xi_{\text {eff }}{ }^{5}$, que pode ser obtido ao rearranjar as expressões (2.4) e (2.13) para:

\footnotetext{
${ }^{5}$ Para aplicação do coeficiente de amortecimento efetivo $c_{\text {eff }}$ nos isoladores, a taxa de amortecimento $\xi_{\text {eff }}$ deve ser subtraída de 5\%, relativo à taxa de amortecimento já considerada na análise do SAP2000.
} 


$$
c_{e f f}=2 \sqrt{K_{e f f} M} \xi_{e f f}
$$

Para as análises do tipo FNA, informa-se a rigidez elástica $K_{1}$ do aparelho, a força de escoamento $\mathrm{F}_{\mathrm{y}}$, a relação $\frac{\mathrm{K}_{2}}{\mathrm{~K}_{1}}$ e a posição da deformação cortante $\mathrm{D}_{y}$. 


\section{ESTUDO DE CASO}

A seguir, apresenta-se a aplicação dos fundamentos de análise sísmica estudados, em alguns modelos de interesse, permitindo-se analisar comparativamente as respostas dos diferentes métodos e conceitos apresentados. A princípio, os métodos de análise estudados (MFE, MER e MHT) são aplicados a três modelos numéricos de base fixa, que serão chamados neste estudo de modelos 1A, 1B e 1C, sendo $1 \mathrm{~A}$ o modelo de referência e, os outros dois, modelos derivados do primeiro com algumas alterações em sua rigidez, que são detalhadas a seguir. São comparadas as respostas obtidas por cada método para um mesmo modelo, assim como a influência que as alterações no modelo causam no comparativo. Em seguida, são analisados modelos derivados dos modelos 1A, 1B e 1C, com a base isolada, que serão chamados respectivamente de $2 \mathrm{~A}, 2 \mathrm{~B}$ e $2 \mathrm{C}$. Um novo estudo comparativo é feito com base nas respostas dos modelos de base isolada, com respeito às suas contrapartes de base fixa.

\subsection{GENERALIDADES SOBRE OS MODELOS}

O modelo de referência 1A, consiste em um edifício regular de classe de importância II (comum), de 8 pavimentos, sendo 6 pavimentos acima do nível térreo e dois subsolos. O pavimento térreo é o único com quatro metros de altura; os demais pavimentos, inclusive os subsolos, possuem três metros de altura cada. Foram consideradas lajes de 18 centímetros de espessura, apoiadas em vigas de 30 centímetros de base por 50 centímetros de altura. Os pilares periféricos possuem seção de $30 \mathrm{x} 70 \mathrm{~cm}$, com pilares internos de $50 \mathrm{x}$ $50 \mathrm{~cm}$. A continuação dos pilares periféricos no subsolo adota um ligeiro engrossamento com seção de $40 \times 70 \mathrm{~cm}$. Paredes de seções 400 x 30cm foram dispostas em duas laterais opostas do edifício, assim como um núcleo rígido composto de duas paredes de $400 \mathrm{x}$ $25 \mathrm{~cm}$ fazendo a caixa de descida da escada somadas a um pilar-parede de seção "C" com dimensões 360 × 180 × 25 cm, conforme representado nas Figura 28, Figura 29 e Figura 30. Para o subsolo, no perímetro da edificação, foi considerada uma parede de contenção com $30 \mathrm{~cm}$ de espessura, atuando como uma viga de fundação profunda, apoiada em uma fundação direta convencional. A princípio, todos os elementos estruturais verticais foram considerados engastados em suas bases na fundação.

Foi adotado concreto C25/30 para os elementos estruturais, com $f_{c k}=27,6 \mathrm{MPa}$, módulo de elasticidade $E=31000 \mathrm{MPa}$. O peso específico do concreto armado foi considerado aproximadamente $25 \mathrm{kN} / \mathrm{m}^{3}$. 
Foram considerados os carregamentos permanentes devidos ao peso próprio da estrutura, somados a uma carga permanente de $2 \mathrm{kN} / \mathrm{m}^{2}$ referente a acabamentos e fechamentos.

Adicionalmente, foi considerada uma sobrecarga de $2 \mathrm{kN} / \mathrm{m}^{2}$ em cada pavimento, referente aos carregamentos variáveis de utilização em um edifício residencial.

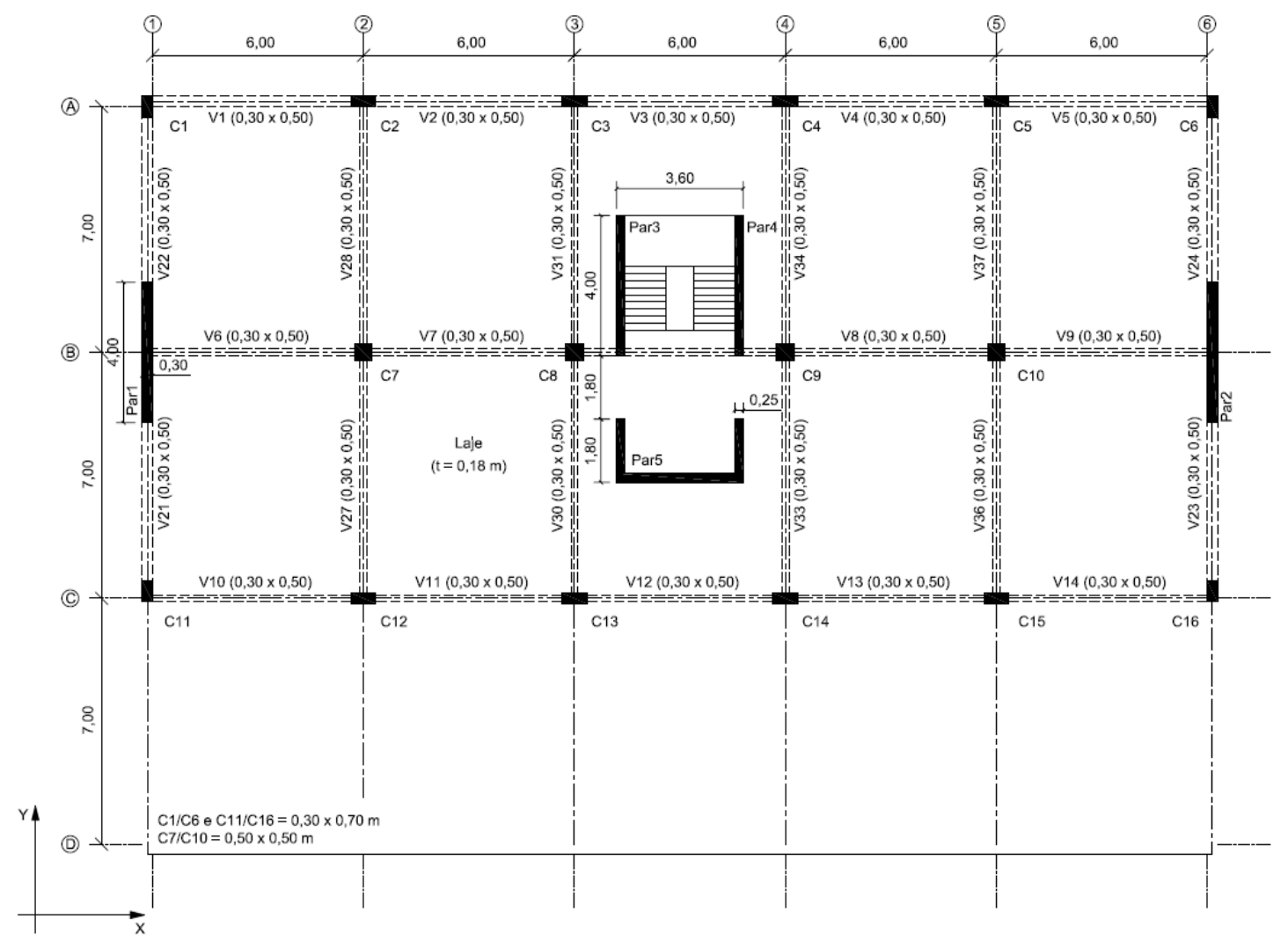

Figura 28: Planta dos pavimentos acima do piso térreo. Fonte: autor 


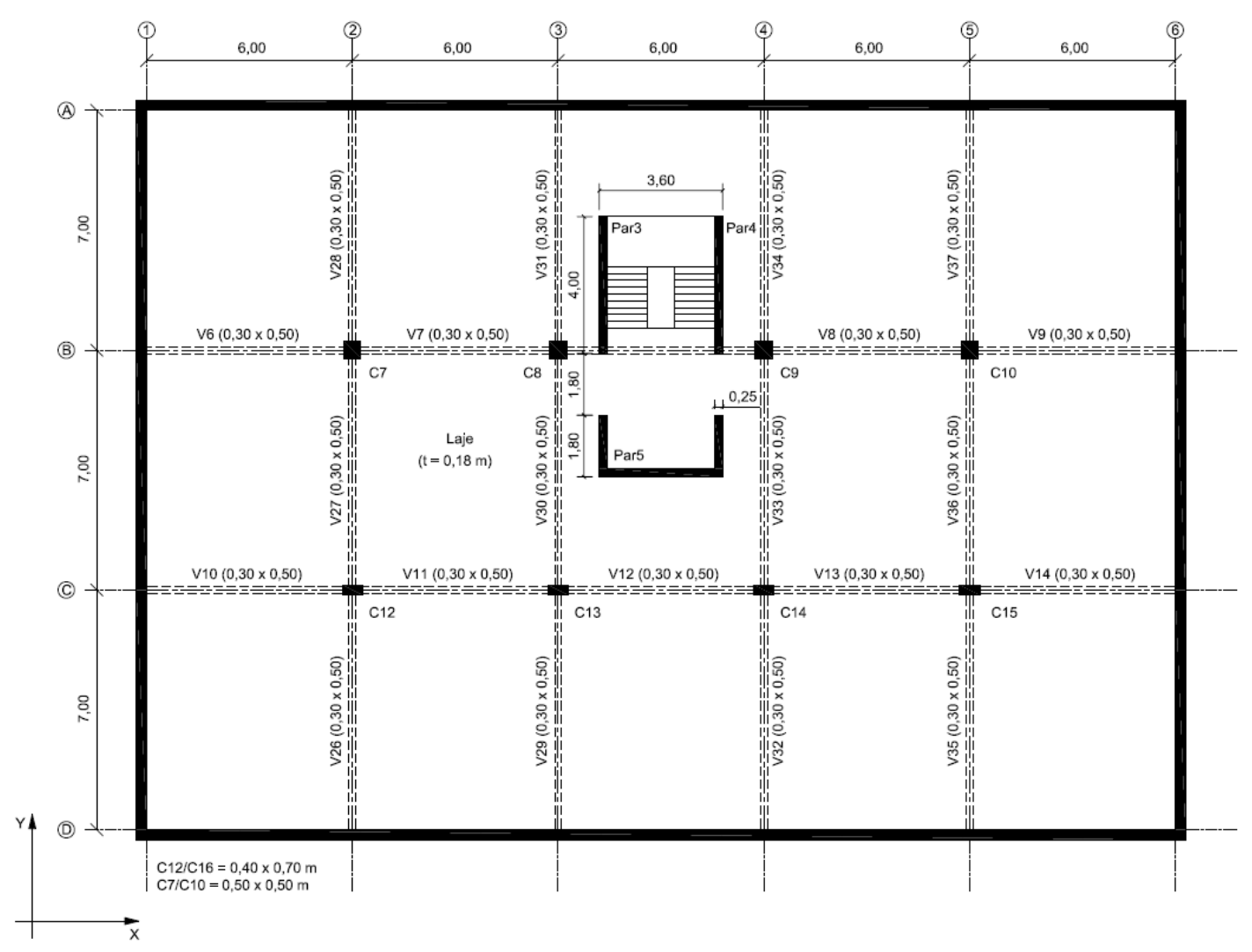

Figura 29: Planta dos subsolos. Fonte: autor 


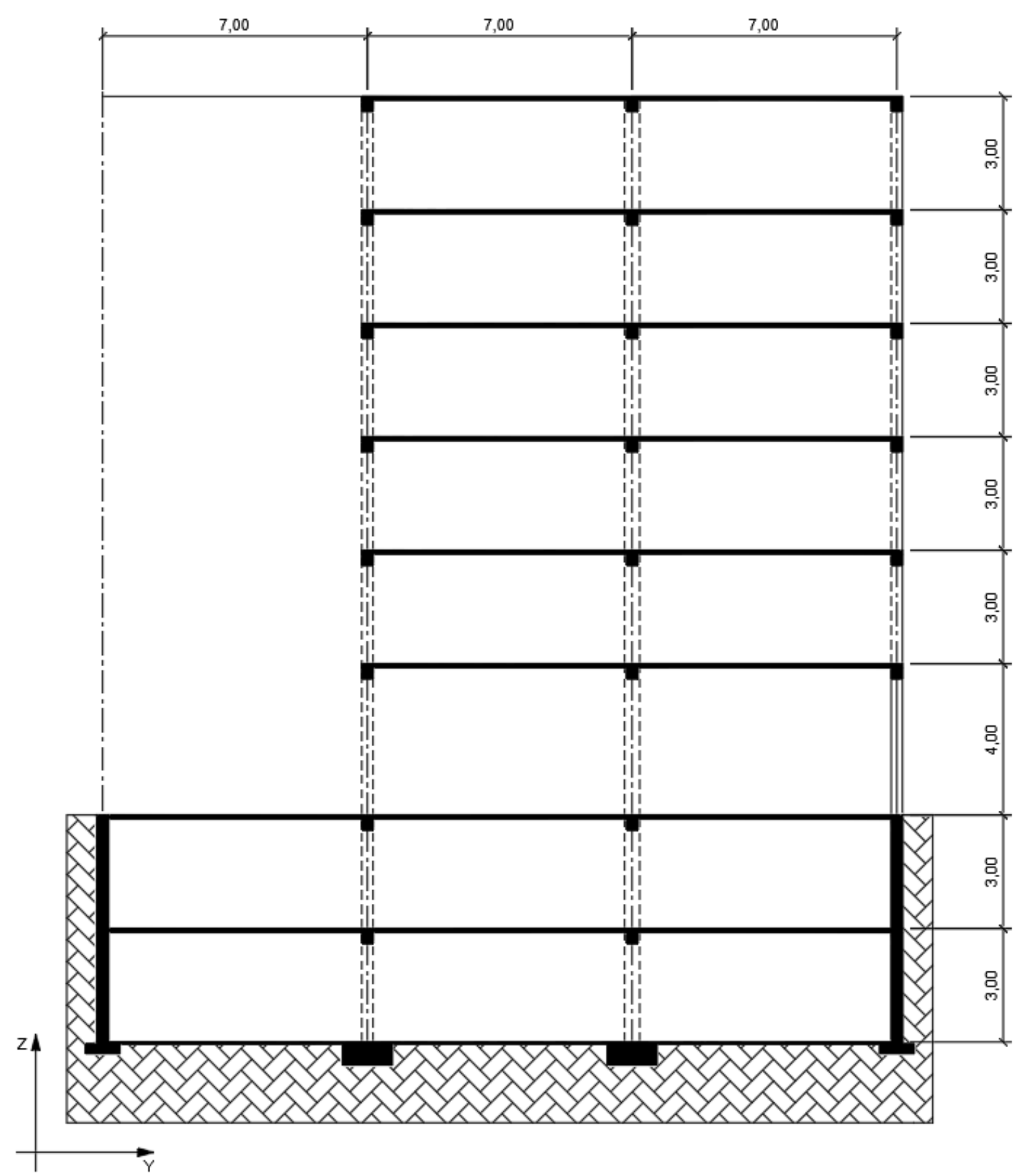

Figura 30: Elevação lateral típica. Fonte: autor

Para os carregamentos sísmicos, foi considerada uma aceleração de projeto $a_{g}=0,2 g$, já considerando o fator de correção em função da classe de importância $\left(\gamma_{f}=1,00\right)$. Foi considerado um sismo de espectro tipo 1 do Eurocódigo 8 (2005), em um solo de classificação "D". A estrutura foi considerada com detalhamento convencional, portanto, foram adotados na análise os parâmetros referentes a estruturas do tipo DCM.

O modelo de referência foi adaptado do modelo apresentado em Fardis et al. (2015). As adaptações consistiram em alterações nas seções de alguns elementos estruturais, adoção de uma diferente aceleração de projeto e do tipo de solo na fundação. Foi adotada uma 
metodologia ligeiramente diferente na modelagem das paredes de contenção no subsolo e na distribuição das massas concentradas, conforme apresentado no item 5.2. Incluíram-se também as respostas obtidas pelo MHT e as análises com a base isolada. Neste estudo, não se consideraram as acelerações verticais, nem a interação solo-estrutura na fundação.

\subsection{MODELAGEM}

O modelo estrutural foi elaborado com auxílio do software SAP2000 v.20 (2018). Todos os elementos estruturais foram modelados com elementos lineares (frames), com engaste elástico nas juntas. As lajes não foram modeladas, portanto, sua influência foi considerada por meio da aplicação de diafragmas rígidos em cada pavimento, além de as vigas terem sido modeladas de forma a considerar a parcela colaborante da laje em sua rigidez. As seções das vigas com laje colaborante foram definidas conforme sugerido pela norma europeia Eurocódigo 2 e estão apresentadas na Figura 31.
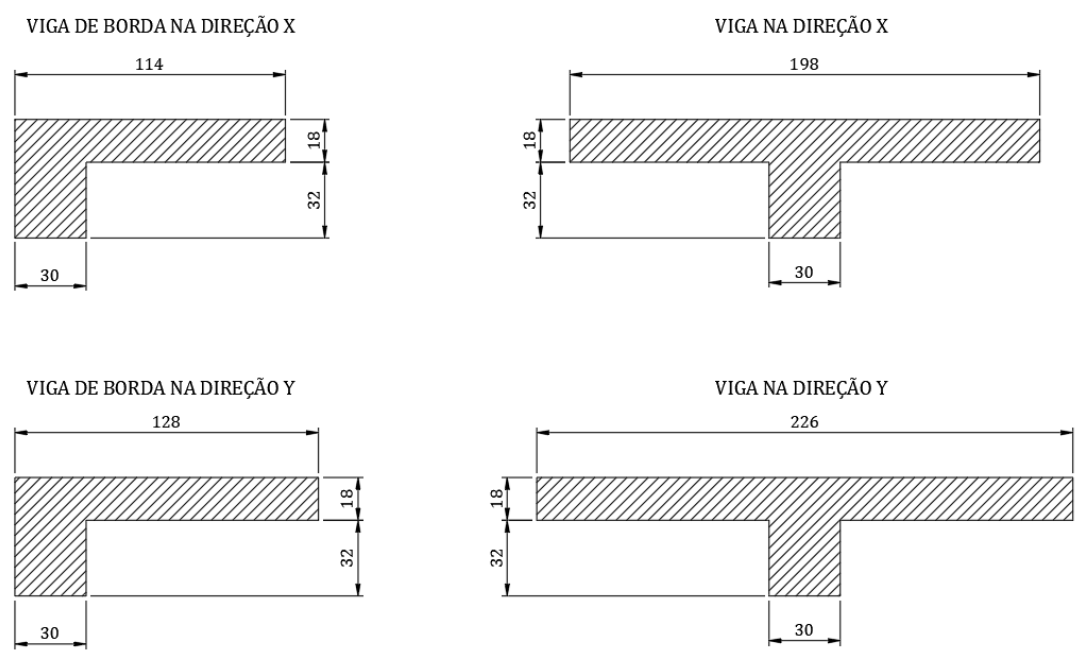

Figura 31: Seção transversal das vigas. Fonte: autor

Os carregamentos e o peso próprio da laje foram aplicados uniformemente distribuídos nas vigas mais próximas ou concentrados nos elementos verticais do núcleo rígido, considerando a área de influência aproximada de cada um desses elementos. Para a análise dinâmica, as massas foram consideradas concentradas nos nós dos pavimentos ao invés de concentradas no centro de massa da laje, em função da distribuição dos carregamentos adotados e do peso próprio dos elementos estruturais.

As massas foram computadas de acordo com as prescrições do código europeu. Foram consideradas $100 \%$ das massas referentes aos carregamentos permanentes, 30\% referentes aos carregamentos acidentais na cobertura e 15\% referentes aos carregamentos acidentais nos demais pavimentos. Para garantir um melhor entendimento da participação de massa 
em cada modo de vibração, não foram consideradas as massas do subsolo, pois, devido à limitação dos deslocamentos em função da grande rigidez das paredes de contenção, não influenciam significativamente os resultados que serão analisados. De fato, para manter a coerência das comparações, são analisadas apenas as respostas acima do pavimento térreo.

Tabela 7 - Somatório de carregamentos e massas por pavimento - 1A. Fonte: autor

\begin{tabular}{|c|c|c|c|c|}
\hline Pavimento & altura $(\mathrm{m})$ & Carregamento $(\mathrm{kN})$ & Massa $(\mathrm{t})$ & M.I. Massa $\left(\mathrm{t} . \mathrm{m}^{2}\right)$ \\
\hline 6 & 25 & 3576 & 365 & 33319 \\
\hline 5 & 22 & 3814 & 389 & 35532 \\
\hline 4 & 19 & 3814 & 389 & 35532 \\
\hline 3 & 16 & 3814 & 389 & 35532 \\
\hline 2 & 13 & 3814 & 389 & 35532 \\
\hline 1 & 10 & 4174 & 425 & 38884 \\
\hline 0 & 6 & - & - & - \\
\hline-1 & 3 & - & - & - \\
\hline \multicolumn{2}{|c|}{ Somatório } & 23006 & 2345 & 214333 \\
\hline
\end{tabular}

Conforme determinado na norma europeia, os elementos sismo-resistentes em condição fissurada foram tomados com rigidez à flexão e ao cisalhamento equivalente a $50 \%$ da rigidez do elemento não fissurado. No SAP2000 essa consideração foi feita reduzindo-se em $50 \%$ o momento de inércia e a área de cisalhamento dos elementos fissurados. A rigidez torcional desses elementos também foi reduzida, substituindo-se o momento de inércia à torção dos elementos por 10\% do seu valor nominal. Essa compatibilização é feita apenas na análise considerando a base fixa, pois quando o isolamento da base é aplicado, considera-se que a superestrutura acima do isolamento permaneça em regime elástico, sem perdas tão expressivas em sua rigidez.

A parede de contenção no subsolo foi modelada por elementos lineares verticais em continuação a cada elemento vertical que se apoia sobre esta. Valendo-se da simetria e uniformidade da estrutura, foram adotados seis pilares de mesma seção na direção x e quatro pilares de mesma seção na direção y, com rigidez à flexão para um pilar com base engastada equivalente à rigidez transversal das paredes nas direções x e y respectivamente. A rigidez ao cisalhamento das paredes foi obtida por $\frac{G \times t}{H}$, onde $G$ é o módulo de rigidez transversal do material (concreto), $t$ a espessura da parede e $H$ seu comprimento em planta. Os pilares-parede equivalentes têm seis metros de comprimento $(L)$, da fundação até o pavimento térreo, seção transversal com base $(b)$ igual $30 \mathrm{~cm}$ e altura $(h)$ dimensionada de forma a obter uma rigidez à flexão $\frac{3 E I}{L^{3}}$ equivalente à rigidez transversal da parede, onde $E$ é 
o modulo de elasticidade do material (concreto) e $I$ é o momento de inércia à flexão da seção do pilar.

Consequentemente, foram adotados pilares-parede com seções de 30x $712 \mathrm{~cm}$ na direção x, e 30x750 cm na direção y. Para contabilizar a rigidez horizontal garantida pela parede de contenção, o topo dos pilares do nível térreo foram conectados, entre si, por elementos lineares horizontais, rígidos exclusivamente na translação da direção axial.

Quando às derivações do modelo de referência, o modelo 1B é basicamente o mesmo que o modelo $1 \mathrm{~A}$, com a remoção dos dois pavimentos superiores, constituindo, assim, um edifício de 6 pavimentos, sendo dois deles subsolos. Praticamente todas as considerações do modelo 1A são aplicáveis, com exceção das massas e carregamentos que passam a ser:

Tabela 8 - Somatório de carregamentos e massas por pavimento - 1B. Fonte: autor

\begin{tabular}{|c|c|c|c|c|}
\hline Pavimento & altura $(\mathrm{m})$ & Carregamento $(\mathrm{kN})$ & Massa $(\mathrm{t})$ & M.I. Massa $\left(\mathrm{t} . \mathrm{m}^{2}\right)$ \\
\hline 4 & 19 & 3576 & 365 & 33319 \\
\hline 3 & 16 & 3814 & 389 & 35532 \\
\hline 2 & 13 & 3814 & 389 & 35532 \\
\hline 1 & 10 & 4174 & 425 & 38884 \\
\hline 0 & 6 & - & - & - \\
\hline-1 & 3 & - & - & - \\
\hline \multicolumn{2}{|r|}{ Somatório } & 15378 & 1568 & 143268 \\
\hline
\end{tabular}

O modelo 1C possui a mesma quantidade de pavimentos do modelo $1 \mathrm{~A}$, entretanto, o núcleo rígido foi removido e substituído pela continuação das vigas na direção $\mathrm{x}$, e as paredes laterais foram substituídas por pilares de seção 30x100cm. Os carregamentos foram mantidos, havendo apenas a redução de peso em função da redução de seção de alguns elementos, que resultou em um peso total de aproximadamente $19300 \mathrm{kN}$.

A seguir apresentam-se ilustrações tridimensionais dos modelos de análise.
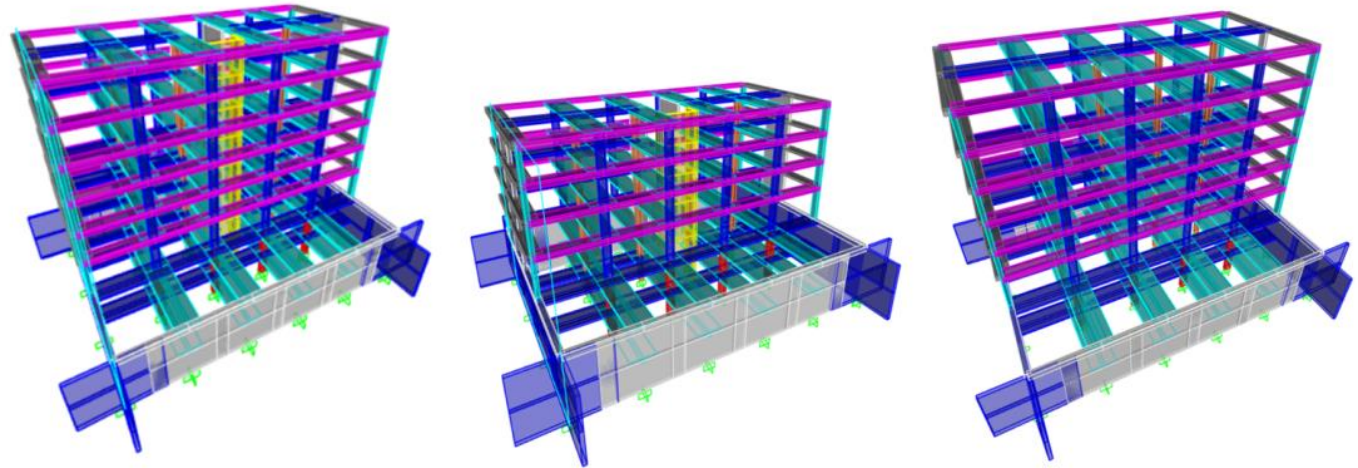

Figura 32: Vistas isométricas dos modelos de análise. Da esquerda para a direita, modelo 1A, 1B e 1C. Fonte: autor, SAP2000. 

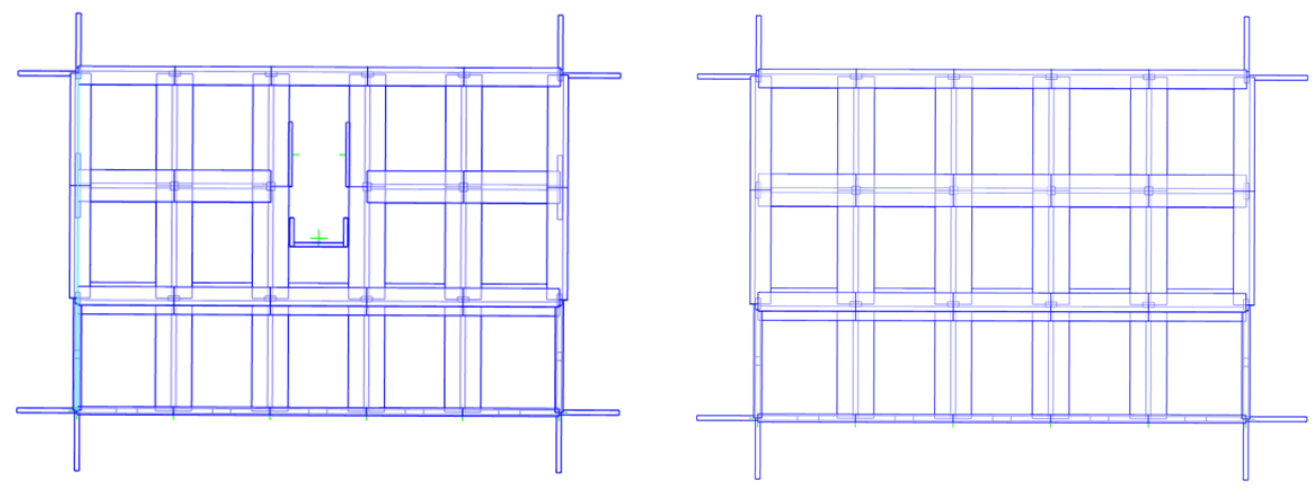

Figura 33: Plantas dos modelos de análise. Da esquerda para a direita, modelo 1A/1B e 1C. Fonte: autor, SAP2000.

\subsection{ANÁLISE COM BASE FIXA}

A partir da análise modal, foram obtidos os modos de vibração e períodos naturais do modelo de referência, necessários para realizar a análise sísmica pelos métodos apresentados. Para efeito comparativo, foram feitas duas análises, uma considerando as massas distribuídas nos elementos estruturais, conforme apresentado no item 5.2 e outra considerando as massas concentradas no centro de massa de cada laje, conforme simplificação permitida pelo Eurocódigo 8 (2005). A Tabela 9 apresenta os resultados obtidos para os nove primeiros modos de cada estrutura, além do somatório final de participação de massa modal para o máximo número de modos considerados em cada caso. Apresentam-se apenas as translações nas direções X e Y e a rotação em torno do eixo Z, que determinam as características de maior interesse para as análises propostas aos modelos.

Tabela 9-Análise modal - 1A. Fonte: autor

\begin{tabular}{|c|c|c|c|c|c|c|c|c|c|}
\hline \multirow{3}{*}{ Modo } & \multicolumn{4}{|c|}{ Modelo 1A - Massa Concentrada } & & \multicolumn{4}{|c|}{ Modelo 1A - Massa Distribuída } \\
\hline & \multirow{2}{*}{ Período (s) } & \multicolumn{3}{|c|}{ Participação de massa modal } & \multirow{2}{*}{ Modo } & \multirow{2}{*}{ Período (s) } & \multicolumn{3}{|c|}{ Participação de massa modal } \\
\hline & & $\mathrm{X}$ & $\mathrm{Y}$ & RZ & & & $\mathrm{X}$ & $\mathrm{Y}$ & RZ \\
\hline 1 & 0,89 & $80,2 \%$ & $0,0 \%$ & $0,3 \%$ & 1 & 0,88 & $78,9 \%$ & $0,0 \%$ & $0,3 \%$ \\
\hline 2 & 0,70 & $0,0 \%$ & $76,1 \%$ & $0,0 \%$ & 2 & 0,69 & $0,0 \%$ & $75,1 \%$ & $0,0 \%$ \\
\hline 3 & 0,53 & $0,3 \%$ & $0,0 \%$ & $74,1 \%$ & 3 & 0,56 & $0,3 \%$ & $0,0 \%$ & $73,0 \%$ \\
\hline 4 & 0,22 & $15,1 \%$ & $0,0 \%$ & $0,2 \%$ & 4 & 0,22 & $14,5 \%$ & $0,0 \%$ & $0,2 \%$ \\
\hline 5 & 0,15 & $0,0 \%$ & $19,3 \%$ & $0,0 \%$ & 5 & 0,15 & $0,0 \%$ & $19,0 \%$ & $0,0 \%$ \\
\hline 6 & 0,11 & $0,2 \%$ & $0,0 \%$ & $19,3 \%$ & 6 & 0,12 & $0,2 \%$ & $0,0 \%$ & $18,8 \%$ \\
\hline 7 & 0,10 & $3,2 \%$ & $0,0 \%$ & $0,2 \%$ & 7 & 0,12 & $0,0 \%$ & $0,0 \%$ & $0,0 \%$ \\
\hline 8 & 0,06 & $0,8 \%$ & $0,0 \%$ & $0,0 \%$ & 8 & 0,12 & $0,0 \%$ & $0,0 \%$ & $0,0 \%$ \\
\hline 9 & 0,06 & $0,0 \%$ & $3,8 \%$ & $0,0 \%$ & 9 & 0,10 & $3,2 \%$ & $0,0 \%$ & $0,1 \%$ \\
\hline \multicolumn{2}{|c|}{ Somatório } & $99,8 \%$ & $99,2 \%$ & $94,0 \%$ & \multicolumn{2}{|c|}{ Somatório } & $97,1 \%$ & $94,0 \%$ & $92,4 \%$ \\
\hline \multicolumn{2}{|c|}{$\begin{array}{l}\text { Somatório } \\
18 \text { modos }\end{array}$} & $100,0 \%$ & $100,0 \%$ & $100,0 \%$ & \multicolumn{2}{|c|}{$\begin{array}{l}\text { Somatório } \\
30 \text { modos }\end{array}$} & $98,2 \%$ & $97,9 \%$ & $97,1 \%$ \\
\hline
\end{tabular}


As massas concentradas foram inseridas apenas com respeito às translações $\mathrm{X}$ e $\mathrm{Y}$ e rotação $\mathrm{Z}$ desejadas, enquanto as massas distribuídas, geradas em função da distribuição dos elementos e dos carregamentos, consideraram adicionalmente parâmetros para translação em Z e rotações em torno dos eixos X e Y. Conforme se pode notar ao observar os dados da Tabela 9 e a Figura 34, a análise com massas distribuídas necessita de uma maior quantidade de modos para que a participação de massa modal se aproxime de 100\%, enquanto a análise com massas concentradas atinge 100\% de participação com apenas 18 modos. Isso ocorre porque a distribuição de massa proposta permite que alguns pontos quase indeslocáveis concentrem uma pequena parcela da massa dos pilares. Além disso, no modelo com massa distribuída são calculados alguns modos de vibração da massa das lajes em translação segundo o eixo Z (vertical), fazendo com que seja necessário um maior número de modos analisados para aumentar a participação de massa nas translações em X e Y.

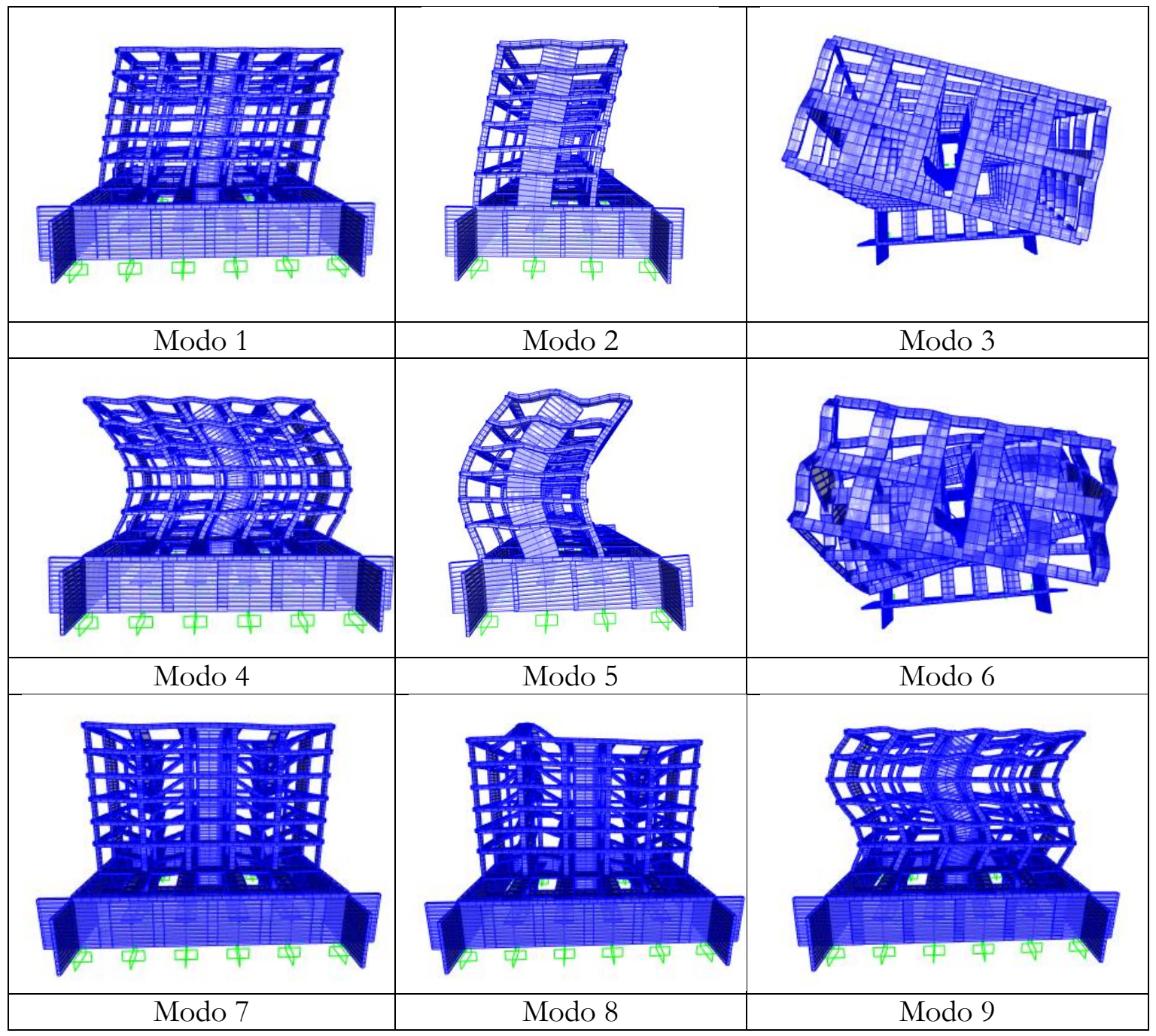

Figura 34: Geometria dos modos de vibração de 1A com massas distribuídas. Fonte: autor, SAP2000. 
Apesar das pequenas diferenças encontradas entre os períodos e participações de massa modal para os modelos com massa concentrada ou distribuída, é possível perceber que qualquer uma das duas representa de forma bastante próxima as características dinâmicas da estrutura e, portanto, são consideradas adequadas. Neste estudo de caso, será adotada a distribuição da massa para os demais modelos analisados.

As características dinâmicas dos modelos 1B e 1C foram obtidas de forma análoga à adotada para o modelo 1A, e os resultados obtidos estão apresentados na Tabela 10.

Tabela 10 - Análise modal - 1B e 1C. Fonte: autor

\begin{tabular}{|c|c|c|c|c|c|c|c|c|c|}
\hline \multirow{3}{*}{ Modo } & \multicolumn{4}{|c|}{ Modelo 1B } & & & \multirow{2}{*}{\multicolumn{3}{|c|}{$\begin{array}{c}\text { Modelo 1C } \\
\text { Participação de massa modal }\end{array}$}} \\
\hline & \multirow{2}{*}{$\begin{array}{l}\text { Período } \\
\text { (s) }\end{array}$} & \multicolumn{3}{|c|}{ Participação de massa modal } & \multirow{2}{*}{ Modo } & \multirow{2}{*}{$\begin{array}{l}\text { Período } \\
\text { (s) }\end{array}$} & & & \\
\hline & & $\mathrm{X}$ & $\mathrm{Y}$ & RZ & & & $\mathrm{X}$ & $\mathrm{Y}$ & $\mathrm{RZ}$ \\
\hline 1 & 0,57 & $81,6 \%$ & $0,0 \%$ & $0,3 \%$ & 1 & 1,21 & $0,0 \%$ & $85,2 \%$ & $0,0 \%$ \\
\hline 2 & 0,41 & $0,0 \%$ & $79,4 \%$ & $0,0 \%$ & 2 & 1,12 & $87,9 \%$ & $0,0 \%$ & $0,1 \%$ \\
\hline 3 & 0,33 & $0,4 \%$ & $0,0 \%$ & $76,6 \%$ & 3 & 0,99 & $0,1 \%$ & $0,0 \%$ & $83,7 \%$ \\
\hline 4 & 0,13 & $13,4 \%$ & $0,0 \%$ & $0,2 \%$ & 4 & 0,37 & $0,0 \%$ & $9,4 \%$ & $0,0 \%$ \\
\hline 5 & 0,09 & $0,0 \%$ & $0,0 \%$ & $0,0 \%$ & 5 & 0,35 & $8,1 \%$ & $0,0 \%$ & $0,0 \%$ \\
\hline 6 & 0,09 & $0,0 \%$ & $0,0 \%$ & $0,0 \%$ & 6 & 0,30 & $0,0 \%$ & $0,0 \%$ & $9,9 \%$ \\
\hline 7 & 0,09 & $0,0 \%$ & $17,1 \%$ & $0,0 \%$ & 7 & 0,20 & $0,0 \%$ & $2,9 \%$ & $0,0 \%$ \\
\hline 8 & 0,07 & $0,1 \%$ & $0,0 \%$ & $16,9 \%$ & 8 & 0,20 & $2,1 \%$ & $0,0 \%$ & $0,0 \%$ \\
\hline 9 & 0,07 & $0,0 \%$ & $0,0 \%$ & $0,0 \%$ & 9 & 0,16 & $0,0 \%$ & $0,0 \%$ & $3,3 \%$ \\
\hline \multicolumn{2}{|c|}{ Somatório } & $95,5 \%$ & $96,4 \%$ & $94,0 \%$ & \multicolumn{2}{|c|}{ Somatório } & $98,1 \%$ & $97,5 \%$ & $97,0 \%$ \\
\hline \multicolumn{2}{|c|}{$\begin{array}{c}\text { Somatório } 30 \\
\text { modos }\end{array}$} & $97,4 \%$ & $98,3 \%$ & $95,0 \%$ & \multicolumn{2}{|c|}{$\begin{array}{l}\text { Somatório } 30 \\
\text { modos }\end{array}$} & $99,0 \%$ & $99,0 \%$ & $98,3 \%$ \\
\hline
\end{tabular}

A maior rigidez de $1 \mathrm{~B}$, referente à redução do número dos pavimentos, modifica ligeiramente a participação de massa modal em cada modo, fazendo com que os primeiros modos tenham uma participação de massa inclusive maior do que em 1A. Entretanto, essa maior rigidez faz com que o período de alguns modos de translação em Z supere períodos de modos de translação em X e de rotação em torno de Z, produzindo uma participação de massa final, nessas direções, levemente inferior às obtidas para $1 \mathrm{~A}$, quando considerados 30 modos. De fato, a utilização de uma quantidade maior de modos poderia aproximar a participação de massa de 100\%, entretanto, o número de modos utilizados já se mostra suficiente, uma vez que a participação em todas as direções de interesse supera 90\%.

Curiosamente, a menor rigidez de 1C também produz participação de massa modal, nos primeiros modos, superior à obtida para o modelo de referência. Por outro lado, essa menor rigidez gera períodos de vibração consideravelmente mais elevados para as direções de maior interesse, fazendo com que os períodos de translação em $Z$ fiquem mais afastados na escala modal, acarretando um somatório final da participação de massa para translação 
em $\mathrm{X}$ e $\mathrm{Y}$ e rotação em $\mathrm{Z}$ bastante próximos à unidade, sendo superiores aos obtidos para os modelos $1 \mathrm{~A}$ e 1B. Nota-se também que a remoção do núcleo rígido e paredes laterais inverteu a posição de todos os modos de translação em X com os de translação em $\mathrm{Y}$, mostrando a grande influência desses elementos no comportamento global dinâmico das edificações.

\subsubsection{Parâmetros MFE}

O sistema estrutural do edifício considerado se resume a um pórtico estrutural de concreto armado, com detalhamento convencional de armação; portanto, da Tabela 3 pode-se definir o coeficiente de comportamento por 3,0 $\alpha_{u} / \alpha_{1}$. Foi admitido valor de 1,3 para o parâmetro $\alpha_{u} / \alpha_{1}$, estimado com auxílio do item 5.2.2.2(5) do Eurocódigo 8 (2005). Assim, adotou-se o coeficiente de comportamento com valor $q=3,6$. O coeficiente de importância $I$ foi tomado com valor igual à unidade, por esta ser considerada uma edificação comum.

Para garantir uma maior coerência nas comparações, foram adotados os períodos fundamentais da análise modal da estrutura em cada direção ortogonal, para aplicação do método das forças laterais equivalentes, ou seja, $T=0,88 s$ na direção $x$ e $T=0,69 s$ na direção $y$. A utilização da simplificação permitida para obtenção do período natural fundamental, dada em (3.29), resultaria em $T=0,84 \mathrm{~s}$ para as duas direções. Esta seria adequada para aplicação do método na direção $x$, entretanto, por ser determinada apenas em função do tipo estrutural e da altura do edifício, não seria suficientemente aproximada para utilização na direção y.

O peso de cada pavimento e o peso total do edifício foram os mesmos definidos para a análise modal de cada modelo. Todos os modelos possuem períodos naturais inferiores a $2 T_{c}$, com $T_{c}$ fornecido na Tabela 6 , em função do tipo de solo adotado; portanto, permitese a redução de $15 \%$ da força total na base, aplicada por meio do parâmetro $\lambda=0,85$.

A Tabela 11 apresenta o resumo dos parâmetros de cada modelo, juntamente com os parâmetros em função do tipo de solo e dos respectivos resultados para a força total na base, obtidos conforme (3.30). 
Tabela 11 - Parâmetros para o MFE. Fonte: autor

\begin{tabular}{|c|l|c|c|c|c|c|c|c|c|c|c|c|c|}
\cline { 2 - 14 } \multicolumn{1}{c|}{} & Classe solo & $q$ & $I$ & $T(s)$ & $W(k N)$ & $\lambda$ & $a_{g}$ & $S$ & $T_{B}$ & $T_{C}$ & $T_{D}$ & $S_{d}$ & $H(k N)$ \\
\hline \multirow{2}{*}{ 1A } & $0,20 \mathrm{~g}$ Dx & 3,6 & 1 & 0,88 & 23000 & 0,85 & 0,2 & 1,35 & 0,20 & 0,8 & 2 & 0,1705 & 3332 \\
\cline { 2 - 15 } & $0,20 \mathrm{~g}$ Dy & 3,6 & 1 & 0,69 & 23000 & 0,85 & 0,2 & 1,35 & 0,20 & 0,8 & 2 & 0,1875 & 3665 \\
\hline \multirow{2}{*}{$1 \mathrm{~B}$} & $0,20 \mathrm{~g}$ Dx & 3,6 & 1 & 0,57 & 15378 & 0,85 & 0,2 & 1,35 & 0,20 & 0,8 & 2 & 0,1875 & 2451 \\
\cline { 2 - 14 } & $0,20 \mathrm{~g}$ Dy & 3,6 & 1 & 0,41 & 15378 & 0,85 & 0,2 & 1,35 & 0,20 & 0,8 & 2 & 0,1875 & 2451 \\
\hline \multirow{2}{*}{ 1C } & $0,20 \mathrm{~g}$ Dx & 3,6 & 1 & 1,12 & 19300 & 0,85 & 0,2 & 1,35 & 0,20 & 0,8 & 2 & 0,1339 & 2197 \\
\cline { 2 - 14 } & $0,20 \mathrm{~g}$ Dy & 3,6 & 1 & 1,21 & 19300 & 0,85 & 0,2 & 1,35 & 0,20 & 0,8 & 2 & 0,1240 & 2034 \\
\hline
\end{tabular}

As forças $H$ na base foram distribuídas em cada pavimento, segundo a expressão (3.33), e aplicadas no modelo estrutural elaborado com auxílio do SAP2000. Os resultados estão apresentados a seguir, no item 5.3.4.

A Tabela 12 apresenta as forças laterais aplicadas a cada pavimento do modelo 1A, nas duas direções ortogonais consideradas. Os modelos 1B e 1C tiveram suas respectivas forças determinadas analogamente.

Tabela 12 - Forças laterais equivalentes - 1A. Fonte: autor

\begin{tabular}{|c|c|c|c|c|c|c|c|c|}
\hline \multirow{8}{*}{ 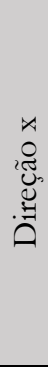 } & Pavimento & $h(m)$ & $W(k N)$ & $h \times W$ & $F(k N)$ & $H(k N)$ & $5 \% L$ & $M_{a}(k N m)$ \\
\hline & 6 & 19 & 3576 & 67944 & 871 & 870,55 & 1,5 & 1305,82 \\
\hline & 5 & 16 & 3814 & 61024 & 782 & 1652,43 & 1,5 & 1172,83 \\
\hline & 4 & 13 & 3814 & 49582 & 635 & 2287,71 & 1,5 & 952,92 \\
\hline & 3 & 10 & 3814 & 38140 & 489 & 2776,39 & 1,5 & 733,02 \\
\hline & 2 & 7 & 3814 & 26698 & 342 & 3118,47 & 1,5 & 513,11 \\
\hline & 1 & 4 & 4174 & 16696 & 214 & 3332,39 & 1,5 & 320,88 \\
\hline & 0 & 0 & - & - & - & - & - & - \\
\hline \multirow{8}{*}{ 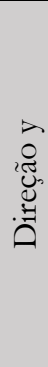 } & Pavimento & $h(m)$ & $W(k N)$ & $h \times W$ & $F(k N)$ & $H(k N)$ & $5 \% L$ & $M_{a}(k N m)$ \\
\hline & 6 & 19 & 3576 & 67944 & 958 & 957,60 & 1,5 & 1436,40 \\
\hline & 5 & 16 & 3814 & 61024 & 860 & 1817,68 & 1,5 & 1290,11 \\
\hline & 4 & 13 & 3814 & 49582 & 699 & 2516,48 & 1,5 & 1048,21 \\
\hline & 3 & 10 & 3814 & 38140 & 538 & 3054,03 & 1,5 & 806,32 \\
\hline & 2 & 7 & 3814 & 26698 & 376 & 3430,31 & 1,5 & 564,42 \\
\hline & 1 & 4 & 4174 & 16696 & 235 & 3665,63 & 1,5 & 352,97 \\
\hline & 0 & - & - & - & - & - & - & - \\
\hline
\end{tabular}

\subsubsection{Parâmetros MER}

O espectro de resposta elástica foi definido com base nas equações (3.34) a (3.37), considerando a zona sísmica e o tipo de solo, conforme previamente apresentados. Foi assumido um amortecimento de 5\%, conforme especificado pelo Eurocódigo. Esse espectro foi posteriormente corrigido pelas expressões (3.39) a (3.42), com base no coeficiente de comportamento $q=3,6$.

A Figura 35 apresenta o espectro de resposta elástica e o espectro corrigido utilizados na análise sísmica dos três modelos. 


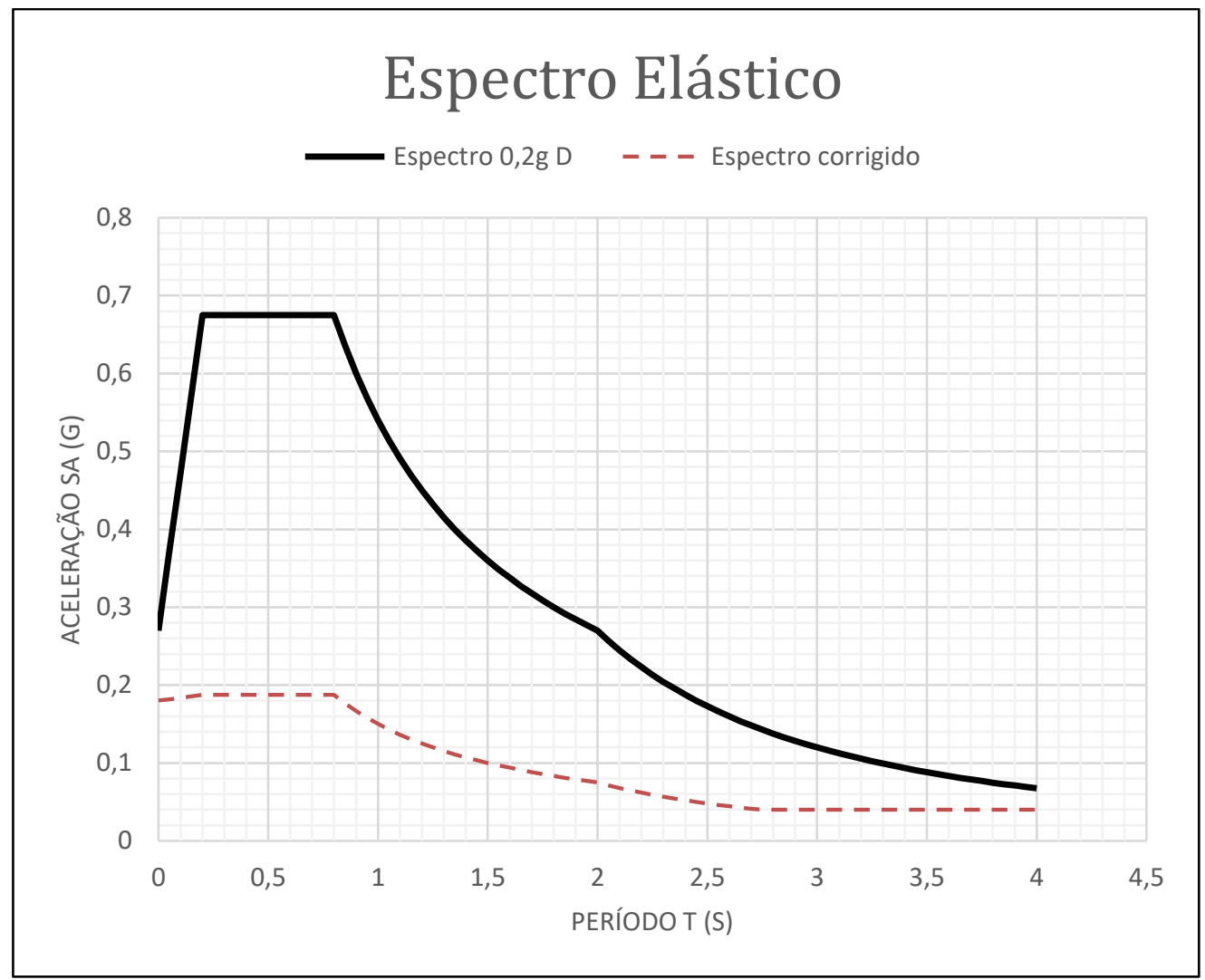

Figura 35: Espectros de resposta. Fonte: autor.

Conforme apresentado na análise modal, foram utilizados 18 modos naturais para a estrutura com massas concentradas e 30 modos para a estrutura com massas distribuídas. Os resultados, apresentados no item 5.3.4, consideraram a combinação de resposta de cada modo pelo método SRSS.

\subsubsection{Parâmetros MHT}

Neste estudo, optou-se pela utilização de acelerogramas gerados artificialmente. Foram gerados, com auxílio do software SeismoArtif, sete acelerogramas com base no espectro de resposta elástica apresentado, para que se pudesse adotar a média dos resultados obtidos. Para estes, aplicou-se a função de envoltória Saragoni \& Hart, limitando as respostas do espectro para um período de quatro segundos. Foram gerados acelerogramas com um tempo total de 15 segundos, superior aos 10 segundos que segundo o Eurocódigo 8 (2005), é o tempo mínimo exigido para acelerogramas artificiais. As figuras a seguir apresentam os acelerogramas utilizados neste estudo. 


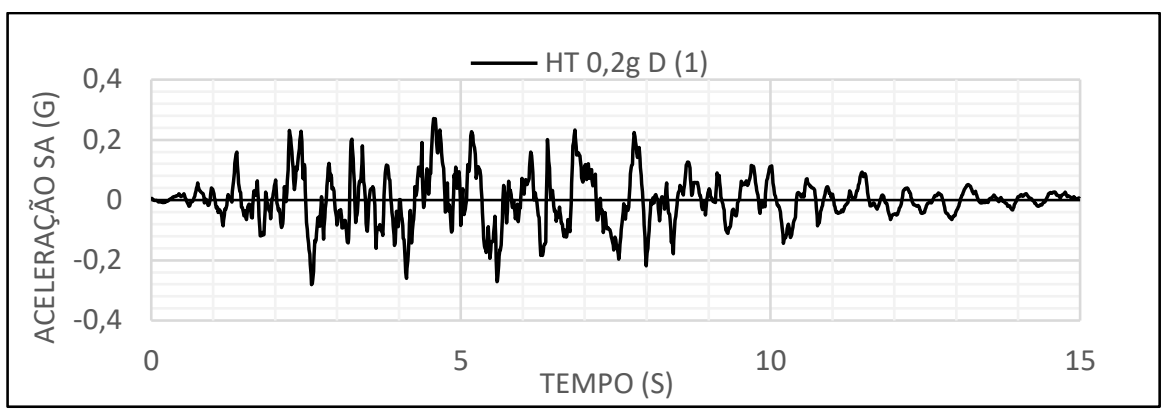

Figura 36: Acelerograma HT0,2gD (1). Fonte: autor.

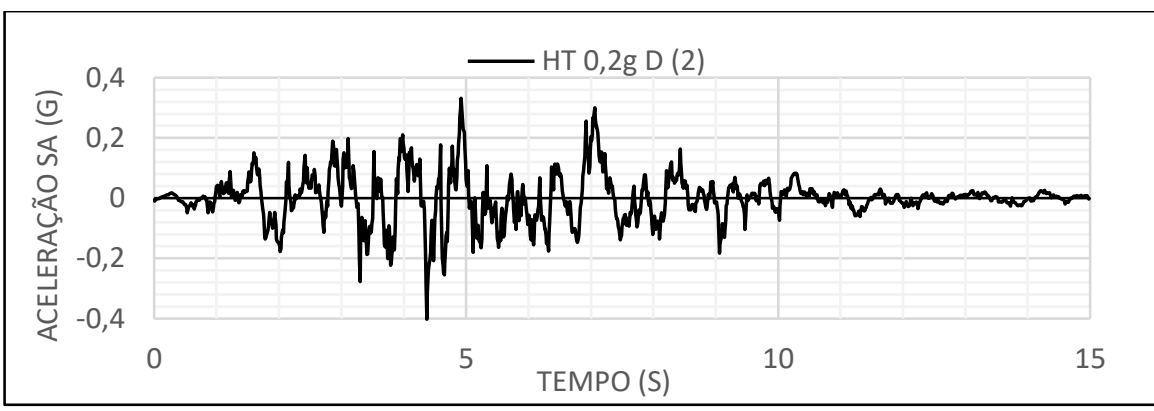

Figura 37: Acelerograma HT0,2gD (2). Fonte: autor.

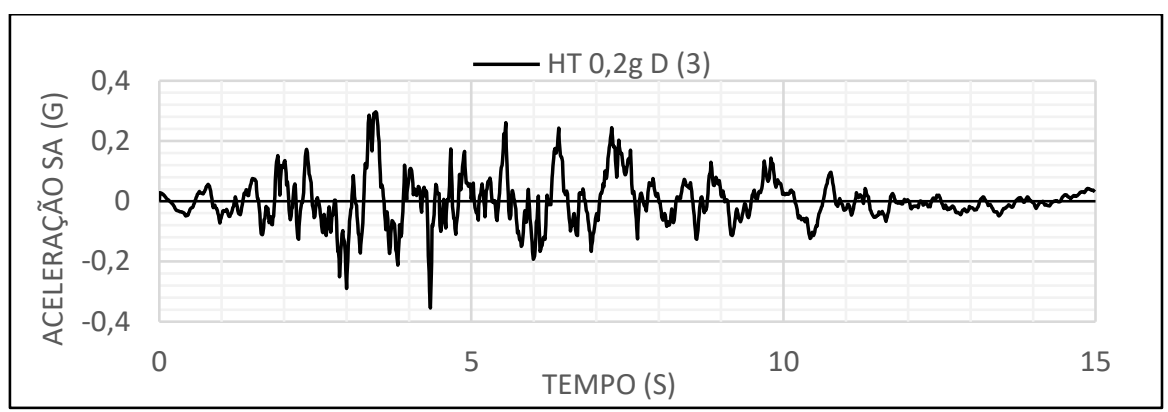

Figura 38: Acelerograma HT0,2gD (3). Fonte: autor.

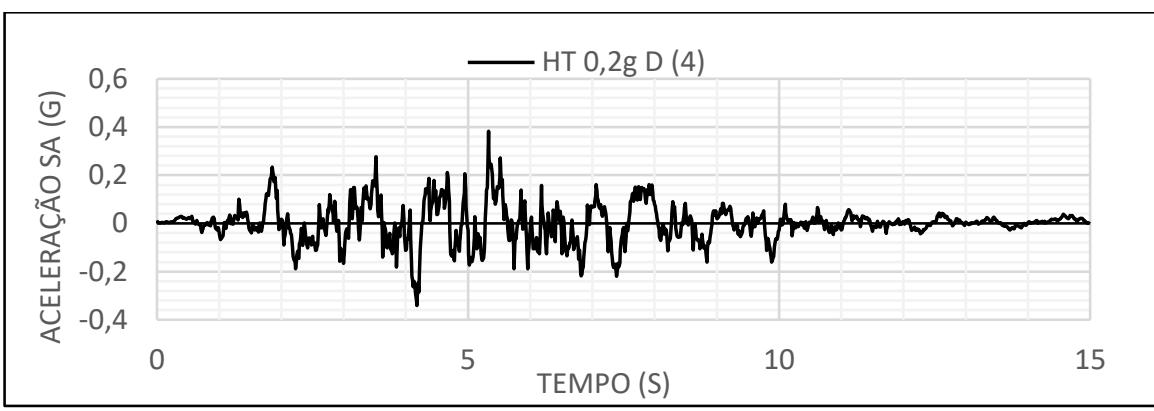

Figura 39: Acelerograma HT0,2gD (4). Fonte: autor. 


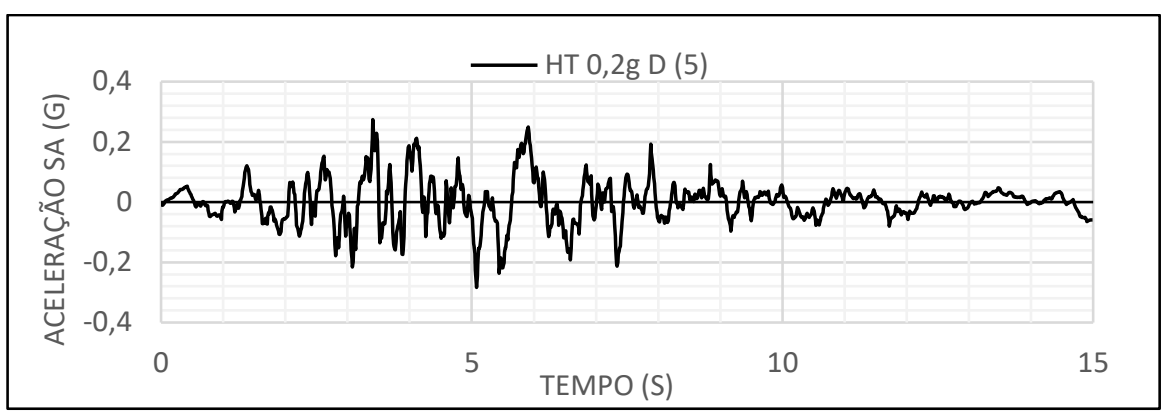

Figura 40: Acelerograma HT0,2gD 5(). Fonte: autor.

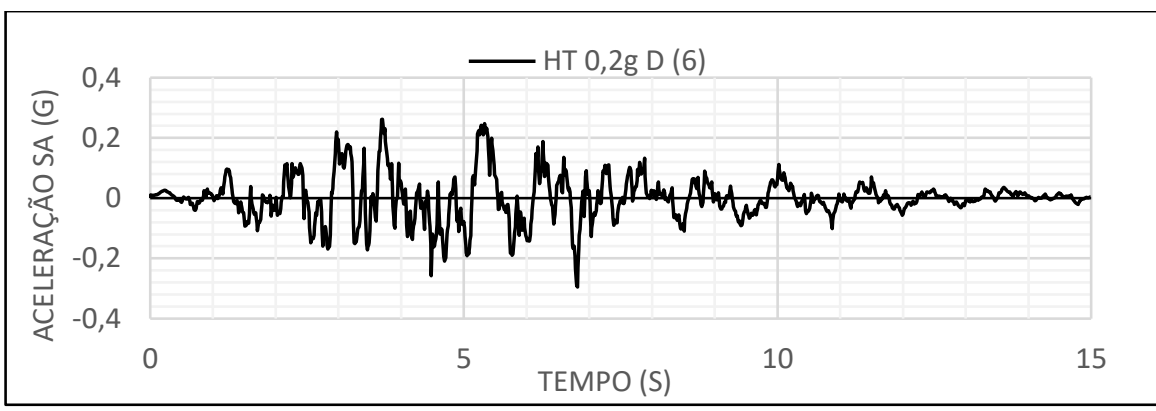

Figura 41: Acelerograma HT0,2gD (6). Fonte: autor.

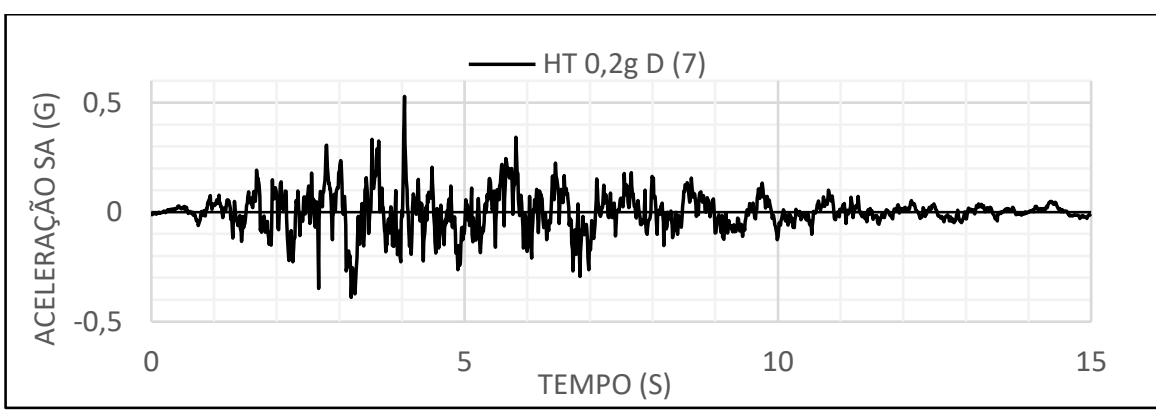

Figura 42: Acelerograma HT0,2gD (7). Fonte: autor.

Os acelerogramas gerados foram, posteriormente, verificados quanto à aderência ao espectro de resposta, utilizando o método de Newmark, apresentado no item 3.4.1. Os resultados decorrentes da integração para os sete acelerogramas estão apresentados na Figura 43. Também foram representados o espectro de resposta elástica utilizado como referência e as margens de $10 \%$ positivas e negativas que devem ser respeitadas. Nota-se que em alguns trechos, alguns acelerogramas fornecem respostas inferiores à margem inferior adotada, assim como em outros, as respostas superam a margem superior. Entretanto, a utilização de múltiplos acelerogramas adequados garante que a média das respostas esteja enquadrada dentro dos limites aceitáveis. 


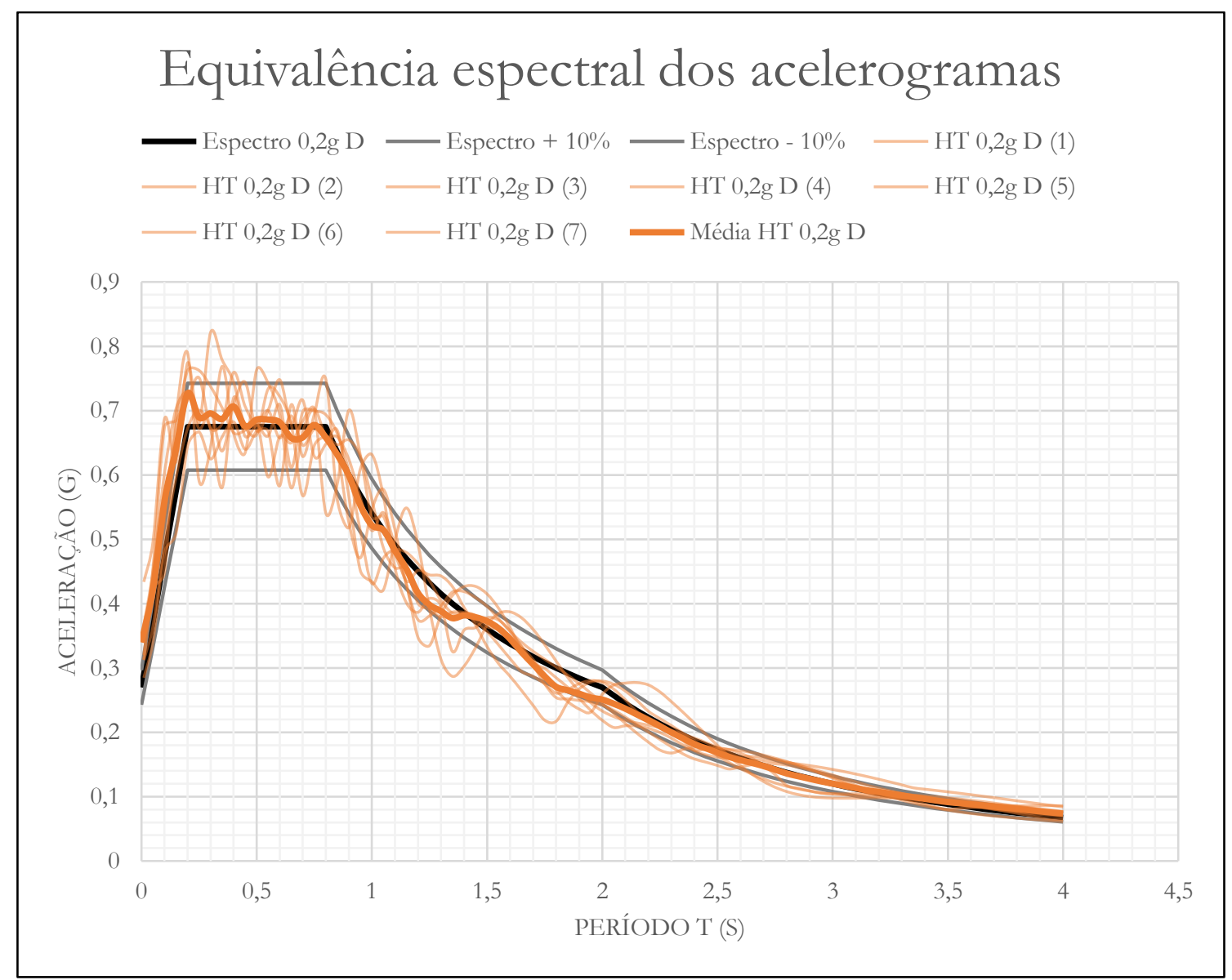

Figura 43: Acelerograma HT0,2gD (7). Fonte: autor.

A partir dos acelerogramas gerados, foi feita uma análise dinâmica pelo histórico no tempo, com auxílio do software SAP2000. Os resultados, apresentados no item 5.3.4, consideraram a combinação de resposta de cada modo pelo método SRSS.

\subsubsection{Resultados comparativos}

Com base nas características referentes ao comportamento perante sismos de cada modelo e nos respectivos parâmetros de cada método, foram obtidos os resultados abaixo, com auxílio do software SAP2000, que serão apresentados de forma comparativa para os métodos e modelos estudados.

\section{Força cortante na base.}

Inicialmente, são apresentadas as máximas forças cortantes na base, obtidas pelos três métodos estudados, com respeito ao modelo $1 \mathrm{~A}$ com as massas concentradas e distribuídas em cada direção ortogonal. Foram consideradas as combinações de carregamentos sísmicos dadas por (3.28) e (3.29). Para o MHT, estão apresentadas as médias dos resultados de cada acelerograma empregado. 

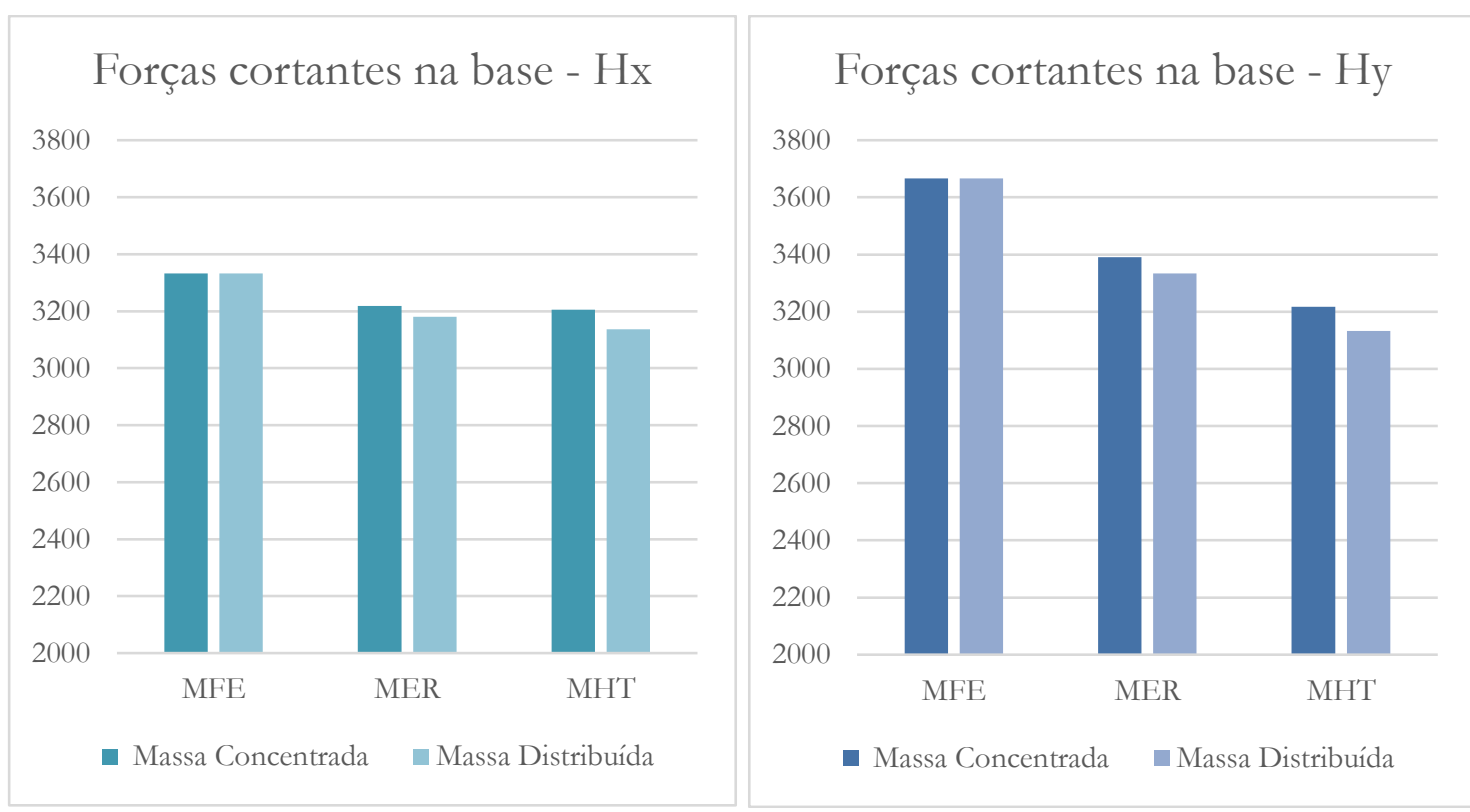

Figura 44: Forças cortantes na base - Hx e Hy - Modelo 1A. Fonte: autor.

Observa-se que, para o modelo analisado, o MFE é o que apresenta as maiores forças cortantes na base, condizente com a proposta do método, fundamentada em uma simplificação que permite obter respostas mais conservadoras, com menor custo computacional. O MHT, embora mais complexo, não possui um custo computacional tão mais elevado que os demais métodos e apresenta resultados mais favoráveis, entretanto exige uma quantidade maior de parâmetros. O desvio dos resultados do MER e MHT em relação ao MFE foi de aproximadamente 3,4\% e 3,8\% respectivamente para a consideração de massas concentradas e 4,5\% e 5,9\% respectivamente para massas distribuídas, na direção x. Na direção y, as diferenças com massas concentradas foram de 7,5\% e 12,2\% respectivamente em relação ao MER e MHT, e 9,0\% e 14,6\% considerando as massas distribuídas.

A utilização de massas concentradas ou distribuídas não causa nenhum efeito na aplicação do MFE pois, uma vez que as forças equivalentes estejam calculadas, a análise é feita em função da rigidez estática da estrutura ao invés de suas propriedades dinâmicas. Por outro lado, em análises dinâmicas como o MER ou MHT, a concentração das massas pode, em alguns casos, como no exemplo analisado, levar a resultados menos favoráveis. Ainda assim, neste modelo, o método utilizado na análise causa maior influência do que o tipo de distribuição de massa adotado. A utilização de massas concentradas, para qualquer método de análise aplicado, resultou em uma diferença inferior a 3\% em relação às massas distribuídas. 
A Figura 45 e a Figura 46 apresentam respectivamente as forças cortantes na base nas direções x e y, para cada um dos sete acelerograma artificiais gerados. Considerou-se na análise o modelo 1A com massas distribuídas.

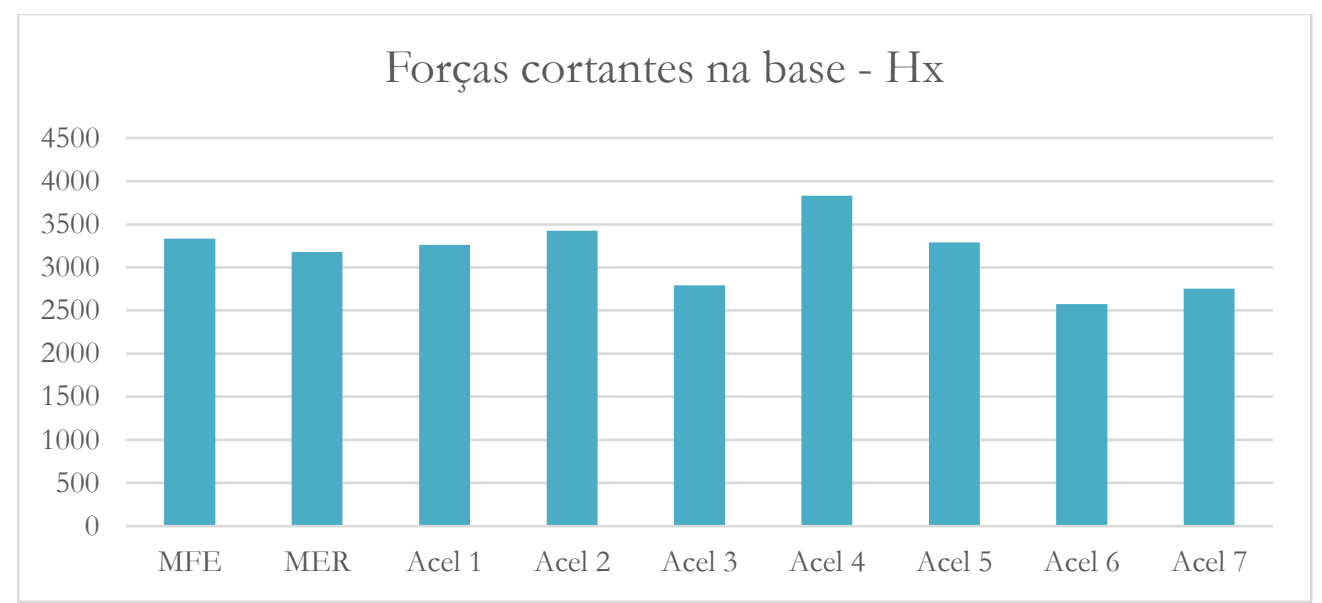

Figura 45: Forças cortantes na base - Hx - Modelo 1A. Fonte: autor.

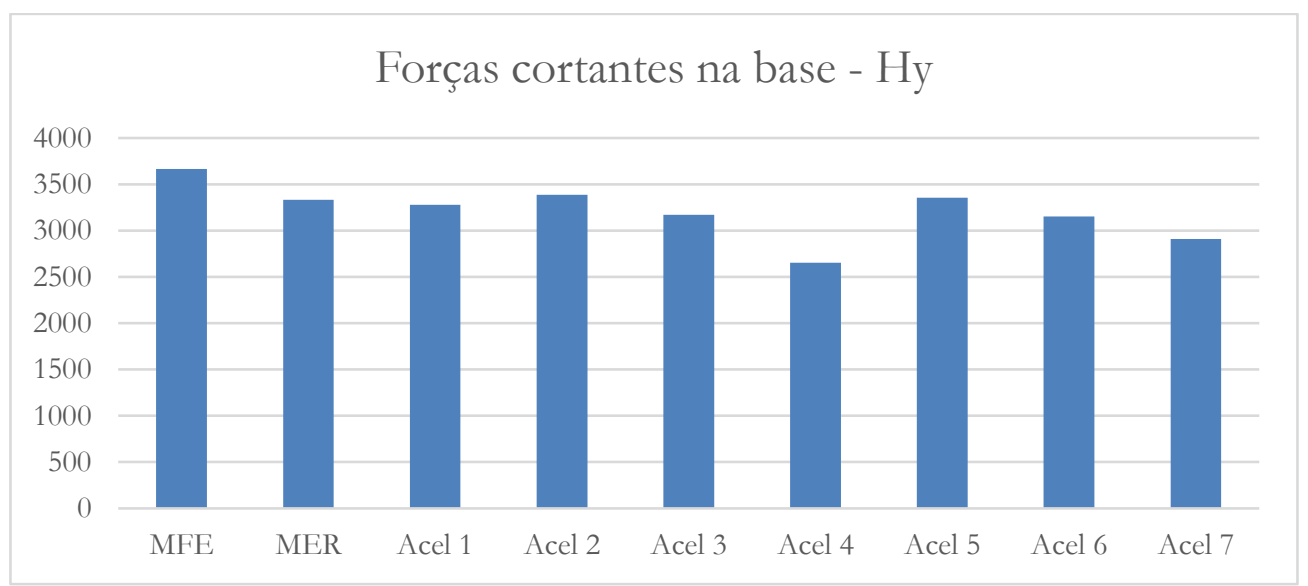

Figura 46: Forças cortantes na base - Hy - Modelo 1A. Fonte: autor.

Das figuras acima, observa-se que a utilização de uma quantidade reduzida de acelerogramas artificiais poderia produzir resultados muito diferentes do esperado. Por exemplo, na direção x, o acelerograma 6 apresenta esforço cortante na base 18\% menor, se comparado com a média obtida pelos sete acelerogramas. No outro extremo, o acelerograma 4 apresenta esforços que superam em até $22 \%$ os obtidos pela média dos acelerogramas. Assim, quanto maior a quantidade de acelerogramas utilizados, mais confiável se torna a média dos resultados. No exemplo analisado, foram utilizados acelerogramas artificiais gerados de modo bastante parecido. A utilização de acelerogramas com diferentes funções de envoltória, durações e espectros de potências variados, com base no mesmo espectro de resposta, produziria resultados ainda mais abrangentes. 
A seguir, apresentam-se as forças cortantes na base, com respeito aos modelos 1A, 1B e 1C, obtidas pelos três métodos estudados, nos quais foram consideradas as respostas médias para o MHT e as massas distribuídas.

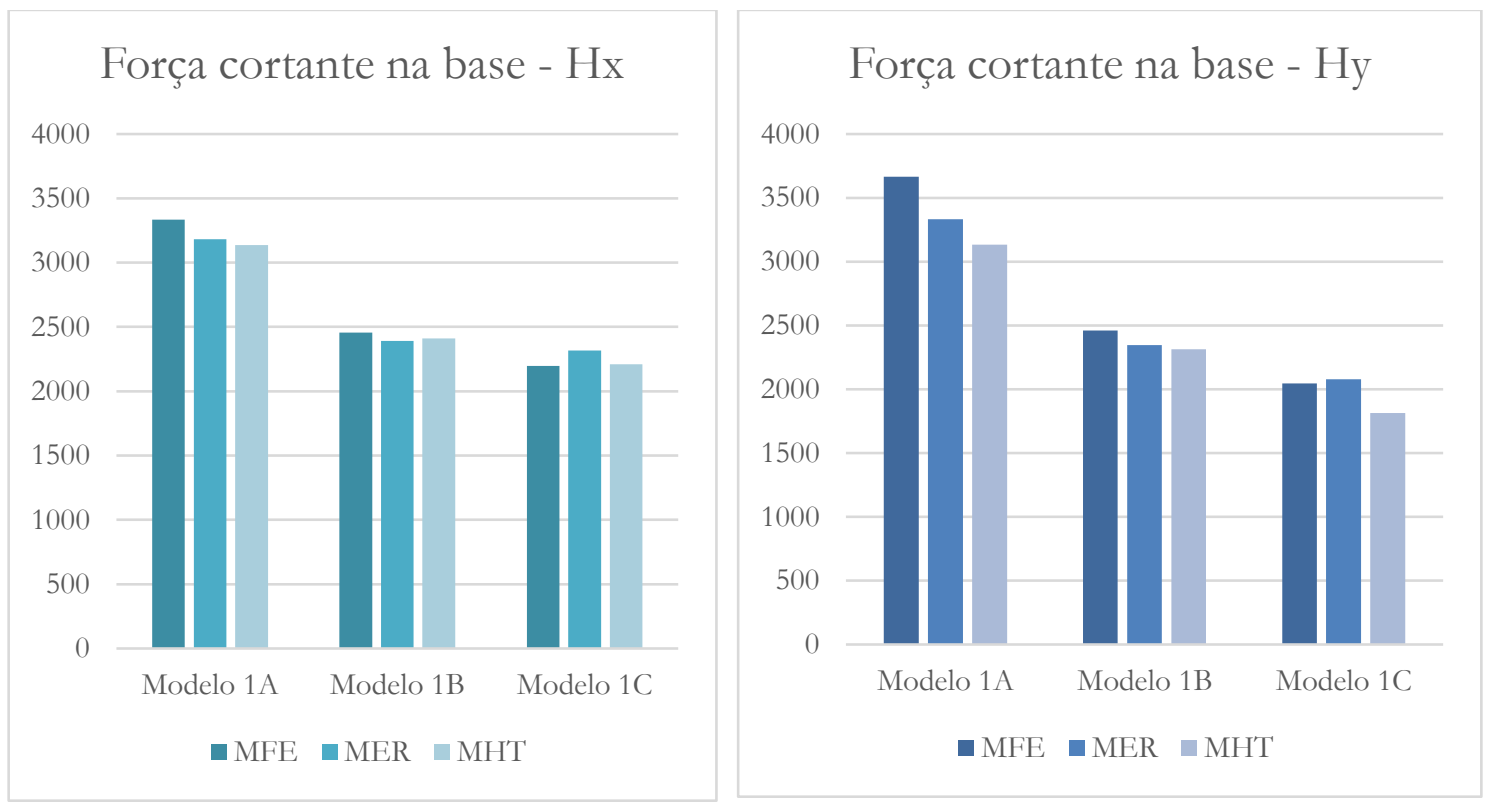

Figura 47: Forças cortantes na base - Modelos 1A, 1B e 1C. Fonte: autor.

Para o modelo 1B, devido à maior rigidez do sistema estrutural que consequentemente possui período natural fundamental reduzido, o MFE produz forças na base iguais, tanto para a direção x como para a direção y, sendo independentes da variação de rigidez do modelo em cada direção. Já os métodos dinâmicos sofrem maior influência da rigidez da estrutura, respondendo mais adequadamente, com variações na resposta em cada direção.

O modelo 1C, mais flexível dentre os três analisados, foi o único em que as respostas do MER foram superiores às respostas do MFE, sugerindo que, para modelos mais flexíveis, o método simplificado das forças equivalentes pode produzir resultados contra a segurança, quando comparado a métodos dinâmicos mais fidedignos.

Apesar das diferenças encontradas entre as respostas de cada método, as variações não são demasiadamente expressivas aqui, o que permite intuir que para edificações regulares como os modelos analisados, os três métodos são capazes de determinar as forças cortantes na base da estrutura. Ainda assim, a avaliação estrutural por métodos dinâmicos é mais apropriada e pode por vezes garantir certa vantagem econômica em relação ao MFE.

Deslocamentos e efeitos de segunda ordem.

A seguir, analogamente às analises anteriores, apresentam-se os deslocamentos obtidos para o modelo 1A, considerando as massas concentradas (MC) e distribuídas (MD) em cada 
direção ortogonal. Considerou-se a média das respostas para os sete acelerogramas considerados, juntamente com a combinação das respostas sísmicas sugeridas em (3.28) e (3.29).

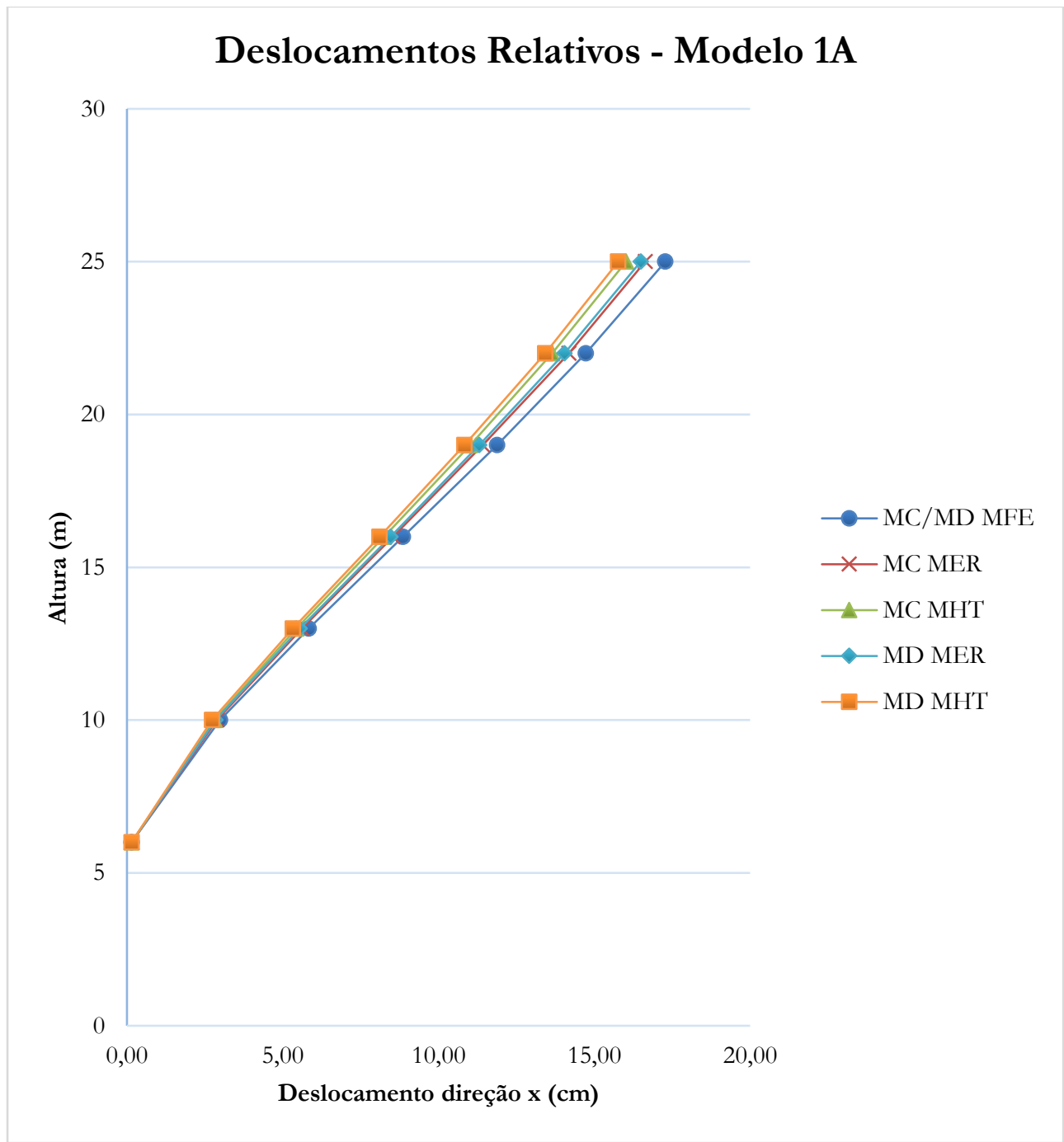

Figura 48: Deslocamentos relativos - direção x - Modelo 1A. Fonte: autor.

Tabela 13 - Deslocamentos relativos - direção x - Modelo 1A. Fonte: autor

\begin{tabular}{|c|c|c|c|c|c|c|}
\hline \multirow{2}{*}{$\begin{array}{c}\text { Altura } \\
\text { pavimento } \\
(\mathrm{m})\end{array}$} & \multicolumn{5}{|c|}{ Massa concentrada } & \multicolumn{3}{c|}{ Massa distribuída } \\
\cline { 2 - 7 } & MC MFE & MC MER & MC MHT & MD MFE & MD MER & MD MHT \\
\hline 25 & 17,28 & 16,63 & 16,02 & 17,28 & 16,49 & 15,77 \\
\hline 22 & 14,72 & 14,18 & 13,64 & 14,72 & 14,04 & 13,43 \\
\hline 19 & 11,88 & 11,41 & 11,02 & 11,88 & 11,30 & 10,84 \\
\hline 16 & 8,86 & 8,53 & 8,24 & 8,86 & 8,46 & 8,10 \\
\hline 13 & 5,83 & 5,62 & 5,44 & 5,83 & 5,54 & 5,33 \\
\hline 10 & 2,99 & 2,88 & 2,81 & 2,99 & 2,84 & 2,74 \\
\hline 6 & 0,14 & 0,14 & 0,14 & 0,14 & 0,14 & 0,14 \\
\hline
\end{tabular}




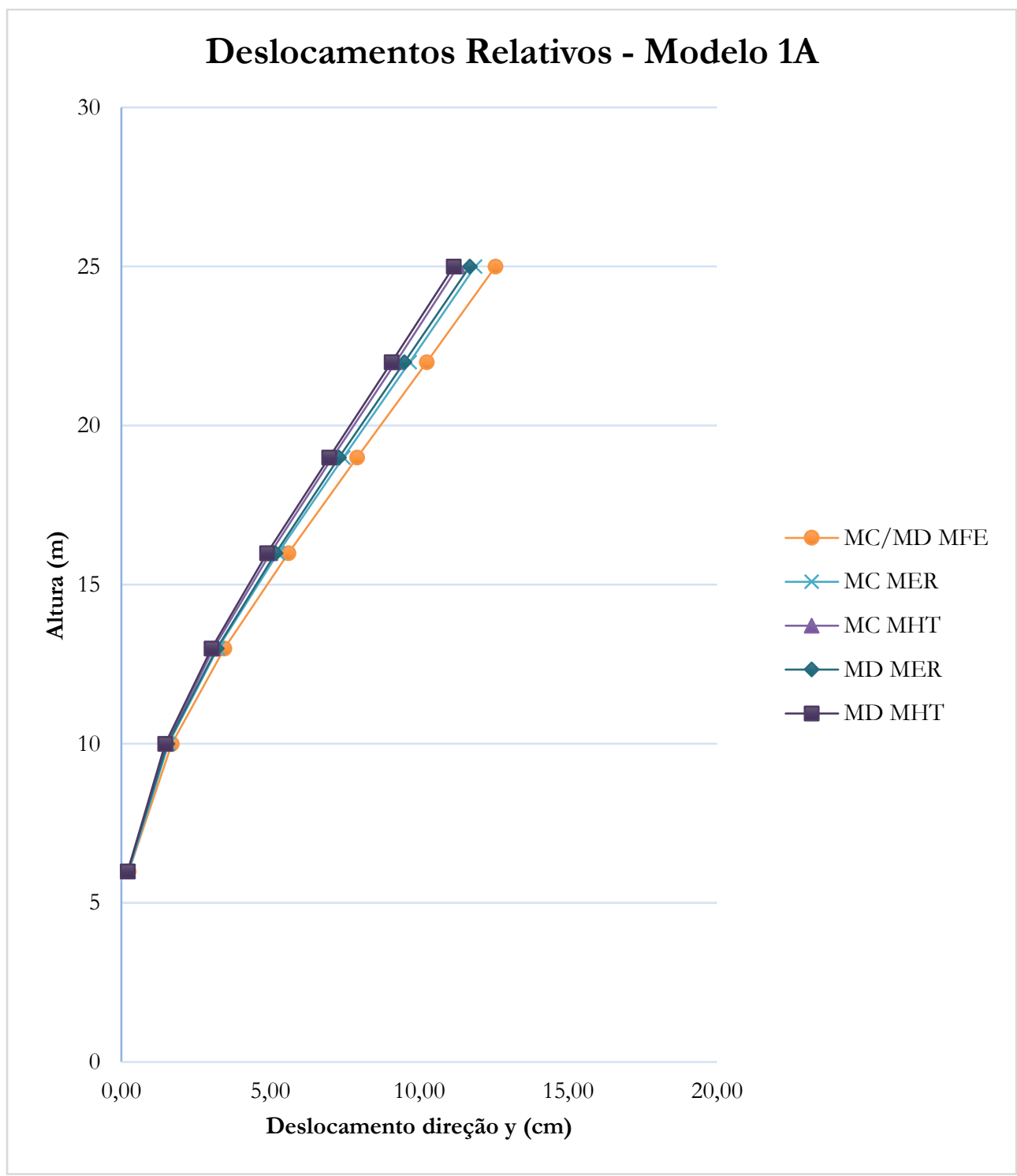

Figura 49: Deslocamentos relativos - direção y - Modelo 1A. Fonte: autor.

Tabela 14 - Deslocamentos relativos - direção y - Modelo 1A. Fonte: autor

\begin{tabular}{|c|c|c|c|c|c|c|}
\hline \multirow{2}{*}{$\begin{array}{c}\text { Altura } \\
\text { pavimento } \\
(\mathrm{m})\end{array}$} & \multicolumn{5}{|c|}{ Massa concentrada } & \multicolumn{3}{c|}{ Massa distribuída } \\
\cline { 2 - 7 } & MC MFE & MC MER & MC MHT & MD MFE & MD MER & MD MHT \\
\hline 25 & 12,56 & 11,88 & 11,30 & 12,56 & 11,70 & 11,16 \\
\hline 22 & 10,26 & 9,68 & 9,22 & 10,26 & 9,50 & 9,07 \\
\hline 19 & 7,92 & 7,45 & 7,09 & 7,92 & 7,31 & 6,98 \\
\hline 16 & 5,62 & 5,26 & 5,00 & 5,62 & 5,18 & 4,90 \\
\hline 13 & 3,46 & 3,24 & 3,10 & 3,46 & 3,20 & 3,02 \\
\hline 10 & 1,69 & 1,58 & 1,51 & 1,69 & 1,55 & 1,48 \\
\hline 6 & 0,25 & 0,25 & 0,22 & 0,25 & 0,22 & 0,22 \\
\hline
\end{tabular}


De fato, assim como para as forças cortantes na base, o MFE é o que apresenta os maiores valores de deslocamentos, por sinal idênticos, independentemente da consideração de massas concentradas ou distribuídas. A consideração de massas concentradas ou distribuídas influencia muito pouco nos resultados do modelo analisado, sendo as maiores variações percebidas quando da utilização de métodos mais complexos, como o MER ou MHT. Ainda assim, os deslocamentos percebidos com as massas distribuídas foram ligeiramente menores para o modelo analisado.

Nota-se que existe uma boa coerência entre o comparativo dos métodos tanto para as forças cortantes na base quanto para os deslocamentos, com as reduções podendo chegar a 6,5\% e 14,3\% para o MER e MHT respectivamente, em relação ao MFE.

A seguir apresentam-se os deslocamentos nas direções x e y, para cada um dos sete acelerogramas artificiais gerados. Considerou-se na análise o modelo $1 \mathrm{~A}$ com massas distribuídas.

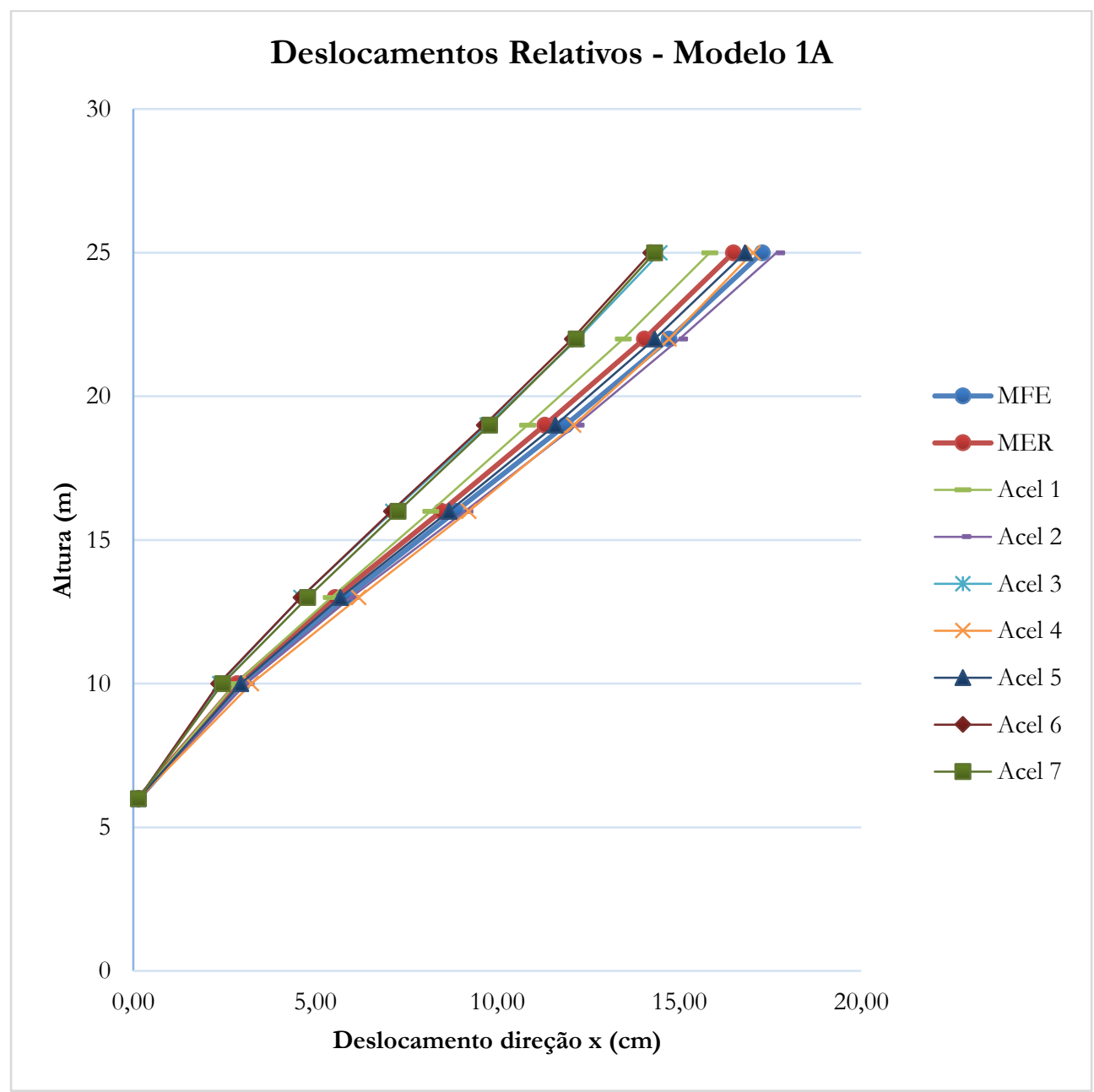

Figura 50: Deslocamentos em x - Modelo 1A. Fonte: autor. 


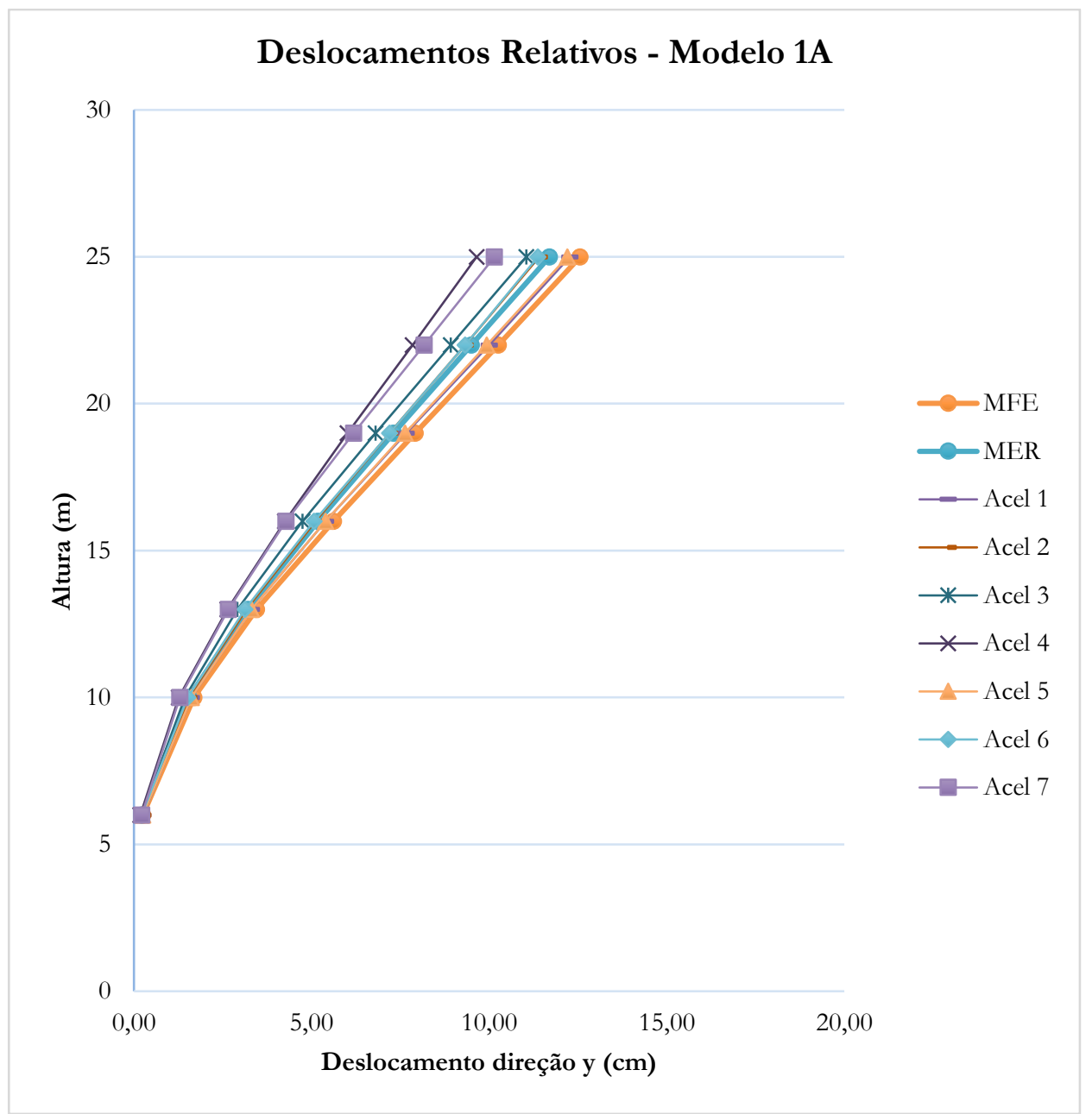

Figura 51: Deslocamentos em y - Modelo 1A. Fonte: autor.

Dos gráficos, observa-se a importância na utilização de uma quantidade adequada de acelerogramas, pois no caso analisado, se fossem consideradas apenas as respostas do acelerograma 4 para os deslocamentos na direção y, seriam obtidos resultados demasiadamente reduzidos e, portanto, contra a segurança. No exemplo analisado, o acelerograma 4 produziu um deslocamento no topo do edifício $23,2 \%$ inferior ao deslocamento produzido pelo MFE. Já a média dos acelerogramas considerados gerou um desvio de apenas 13\% em relação ao MFE e aproximadamente 5\% em relação ao MRE.

A seguir, apresentam-se os deslocamentos no topo dos edifícios 1A, 1B e 1C, segundo os três métodos estudados, nos quais foram consideradas as respostas médias para o MHT e as massas distribuídas. 


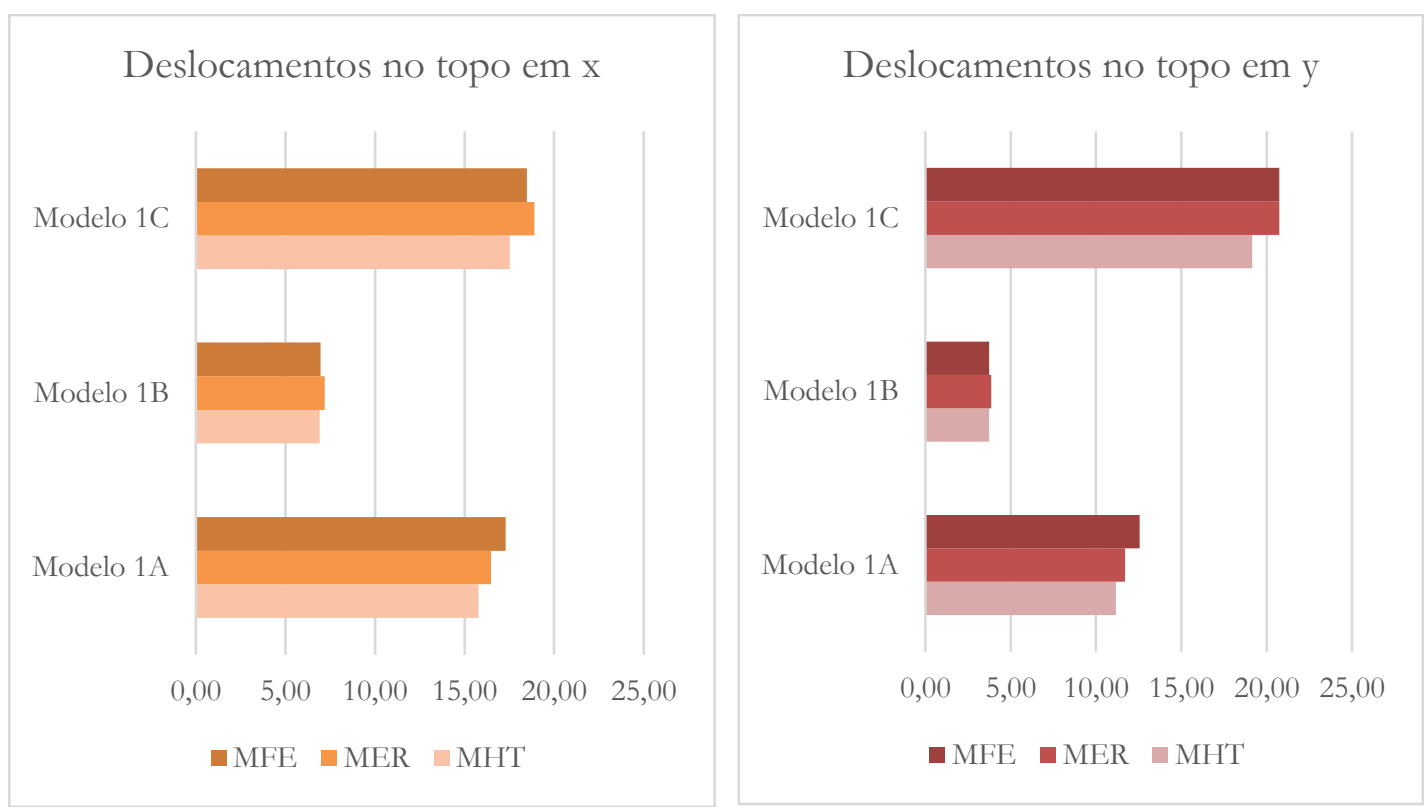

Figura 52: Deslocamentos no topo nas direções x e y - Modelos 1A, 1B e 1C. Fonte: autor.

Os deslocamentos estão dados para o ponto situado no topo do edifício, entre eixos B e 6 , escolhido arbitrariamente. Analisando os deslocamentos no gráfico é possível perceber que o modelo 1C possui um período fundamental na direção y superior ao período fundamental na direção $\mathrm{x}$, pois apresenta maiores deslocamentos nessa direção. Isso é devido à remoção do núcleo rígido e das paredes laterais desse modelo, fato que não ocorre para os modelos $1 \mathrm{~A}$ e $1 \mathrm{~B}$.

$\mathrm{Na}$ abrangência dos dados analisados, o MHT é o que apresenta os menores deslocamentos no topo, enquanto o MER e o MFE alternam entre si as maiores respostas, em função da direção e da rigidez do modelo analisado.

Assim como verificado na análise das forças cortantes na base, as variações encontradas entre as respostas de cada método não são demasiadamente expressivas, o que permite generalizar que para edificações regulares como os modelos analisados, os três métodos são capazes de estimar adequadamente os deslocamentos no topo da estrutura. De fato, a avaliação por métodos dinâmicos é mais apropriada e pode por vezes garantir certa vantagem econômica em relação ao MFE, além do fato de algumas propriedades histeréticas somente serem adequadamente capturadas pelos métodos mais sofisticados.

A Tabela 15, a seguir, apresenta os deslocamentos e esforços em cada laje, juntamente com o coeficiente de estabilidade $\theta$, calculado conforme (3.25) a partir dos resultados obtidos da análise pelo MHT. Analogamente, a Tabela 16 e a Tabela 17 apresentam os resultados para os modelos $1 \mathrm{~B}$ e $1 \mathrm{C}$, respectivamente. 
Nas tabelas, $P_{i}$ é o somatório de forças gravitacionais atuantes no pavimento, $H_{x, i}$ e $H_{y, i}$ são as forças cortantes totais no pavimento, $\Delta_{x, i}$ e $\Delta_{y, i}$ são os deslocamentos relativos entre pavimentos, obtidos pela diferença entre o deslocamento do centro de gravidade do pavimento analisado e do pavimento imediatamente inferior, já considerando a correção por meio da multiplicação pelo coeficiente de comportamento $q$, conforme apresentado no item 3.5. O parâmetro $h_{i}$ representa a altura entre os pavimentos que definem $\Delta_{x, i}$ e $\Delta_{y, i}$.

Tabela 15 - Coeficiente de análise de $2^{\mathrm{a}}$ ordem - direções x e y - Modelo 1A. Fonte: autor

\begin{tabular}{|c|c|c|c|c|c|c|c|c|}
\hline Pavimento & $P_{i}$ & $H_{x, i}(k N)$ & $H_{y, i}(k N)$ & $\Delta_{x, i}(\mathrm{~cm})$ & $\Delta_{y, i}(\mathrm{~cm})$ & $h_{i}(\mathrm{~cm})$ & $\theta_{x, i}$ & $\theta_{y, i}$ \\
\hline 6 & 3872 & 929 & 972 & 2,3400 & 2,0880 & 300,00 & 0,033 & 0,028 \\
\hline 5 & 7639 & 1677 & 1756 & 2,5920 & 2,0880 & 300,00 & 0,039 & 0,030 \\
\hline 4 & 11406 & 2179 & 2303 & 2,7360 & 2,0880 & 300,00 & 0,048 & 0,034 \\
\hline 3 & 15173 & 2543 & 2675 & 2,7720 & 1,8720 & 300,00 & 0,055 & 0,035 \\
\hline 2 & 18940 & 2886 & 2961 & 2,5920 & 1,5480 & 300,00 & 0,057 & 0,033 \\
\hline 1 & 22947 & 3135 & 3132 & 2,5920 & 1,2600 & 400,00 & 0,047 & 0,023 \\
\hline 0 & 22947 & 3135 & 3132 & 0,1440 & 0,2160 & 300,00 & 0,004 & 0,005 \\
\hline
\end{tabular}

Tabela 16 - Coeficiente de análise de $2^{\mathrm{a}}$ ordem - direções x e y - Modelo 1B. Fonte: autor

\begin{tabular}{|c|c|c|c|c|c|c|c|c|}
\hline Pavimento & $P_{i}$ & $H_{x, i}(k N)$ & $H_{y, i}(k N)$ & $\Delta_{x, i}(\mathrm{~cm})$ & $\Delta_{y, i}(\mathrm{~cm})$ & $h_{i}(\mathrm{~cm})$ & $\theta_{x, i}$ & $\theta_{y, i}$ \\
\hline 4 & 3787 & 823 & 841 & 1,5480 & 1,0080 & 300,00 & 0,024 & 0,015 \\
\hline 3 & 7574 & 1485 & 1512 & 1,7280 & 0,9720 & 300,00 & 0,029 & 0,016 \\
\hline 2 & 11360 & 2018 & 1979 & 1,6920 & 0,8640 & 300,00 & 0,032 & 0,017 \\
\hline 1 & 15378 & 2410 & 2315 & 1,8360 & 0,7560 & 400,00 & 0,029 & 0,013 \\
\hline 0 & 15378 & 2410 & 2315 & 0,1080 & 0,1440 & 300,00 & 0,002 & 0,003 \\
\hline
\end{tabular}

Tabela 17 - Coeficiente de análise de $2^{\mathrm{a}}$ ordem - direções x e y - Modelo 1C. Fonte: autor

\begin{tabular}{|c|c|c|c|c|c|c|c|c|}
\hline Pavimento & $P_{i}$ & $H_{x, i}(k N)$ & $H_{y, i}(k N)$ & $\Delta_{x, i}(\mathrm{~cm})$ & $\Delta_{y, i}(\mathrm{~cm})$ & $h_{i}(\mathrm{~cm})$ & $\theta_{x, i}$ & $\theta_{y, i}$ \\
\hline 6 & 3000 & 642 & 615 & 1,0440 & 1,6200 & 300,00 & 0,016 & 0,026 \\
\hline 5 & 6200 & 1115 & 1029 & 1,7640 & 2,4480 & 300,00 & 0,033 & 0,049 \\
\hline 4 & 9400 & 1475 & 1388 & 2,5560 & 3,1320 & 300,00 & 0,054 & 0,071 \\
\hline 3 & 12600 & 1763 & 1622 & 3,2040 & 3,7080 & 300,00 & 0,076 & 0,096 \\
\hline 2 & 15800 & 2028 & 1746 & 3,7800 & 1,8720 & 300,00 & 0,098 & 0,056 \\
\hline 1 & 19300 & 2210 & 1815 & 5,1120 & 6,3000 & 400,00 & 0,112 & 0,167 \\
\hline 0 & 19300 & 2210 & 1815 & 0,0720 & 0,0720 & 300,00 & 0,002 & 0,003 \\
\hline
\end{tabular}

Os dados apresentados permitem concluir que o modelo de referência $1 \mathrm{~A}$ é estável e não necessita de nenhuma correção devido a efeitos de $2^{\mathrm{a}}$ ordem, pois tanto para a direção $\mathrm{X}$ como para a $\mathrm{Y}$, os coeficientes $\theta$ ficaram abaixo de 0,1 . De fato, sendo o modelo $1 \mathrm{~B}$ mais rígido que o anterior, era esperado que também não sofresse efeitos de $2^{\mathrm{a}}$ ordem, como foi comprovado pela avaliação do parâmetro $\theta$, que se mostrou bastante inferior inclusive aos 
apresentados pelo modelo $1 \mathrm{~A}$. Já o modelo $1 \mathrm{C}$, consideravelmente mais flexível que os anteriores, apresenta nas duas direções ortogonais, valores de $\theta$ superiores ao limite de 0,1 , mostrando a necessidade de amplificar os esforços obtidos conforme sugerido no item 3.5.6. Embora a correção nos esforços de 1C seja necessária, nenhum valor de $\theta$ superou o limite de 0,2 , portanto, conclui-se que, mesmo para o edifício mais flexível, não são esperados problemas de estabilidade durante um evento sísmico.

A seguir, verificam-se os deslocamentos relativos quanto ao atendimento aos critérios de limitação de danos, apresentados em (3.20) a (3.22). Nas tabelas, o deslocamento relativo $\Delta_{i}$, em cada direção, considera a redução pelo parâmetro $v=0,5$ sugerida no item 3.5 .4 e está apresentado já normalizado em relação à altura entre lajes $\left(\Delta_{i} / h_{i}\right)$, sendo os critérios apresentados em (3.20) a (3.22) reinterpretados, respectivamente, por:

$$
\begin{aligned}
& \frac{d_{r} v}{h} \leq 0,50 \% \text { para elementos frágeis fixos à estrutura } \\
& \frac{d_{r} v}{h} \leq 0,75 \% \text { para elementos dúcteis fixos à estrutura } \\
& \frac{d_{r} v}{h} \leq 1,00 \% \text { limite, sem elementos fixos à estrutura }
\end{aligned}
$$

Tabela 18 - Critério de limitação de danos - direções x e y - Modelos 1A, 1B e 1C. Fonte: autor

\begin{tabular}{|c|c|c|c|c|c|c|}
\cline { 2 - 7 } \multicolumn{1}{c|}{} & \multicolumn{2}{c|}{ Modelo 1A } & \multicolumn{2}{c|}{ Modelo 1B } & \multicolumn{2}{c|}{ Modelo 1C } \\
\hline Pavimento & $\Delta_{x, i} / h_{i}(\%)$ & $\Delta_{y, i} / h_{i}(\%)$ & $\Delta_{x, i} / h_{i}(\%)$ & $\Delta_{y, i} / h_{i}(\%)$ & $\Delta_{x, i} / h_{i}(\%)$ & $\Delta_{y, i} / h_{i}(\%)$ \\
\hline 6 & $0,39 \%$ & $0,35 \%$ & - & - & $0,17 \%$ & $0,27 \%$ \\
\hline 5 & $0,43 \%$ & $0,35 \%$ & - & - & $0,29 \%$ & $0,41 \%$ \\
\hline 4 & $0,46 \%$ & $0,35 \%$ & $0,26 \%$ & $0,17 \%$ & $0,43 \%$ & $0,52 \%$ \\
\hline 3 & $0,46 \%$ & $0,31 \%$ & $0,29 \%$ & $0,16 \%$ & $0,53 \%$ & $0,62 \%$ \\
\hline 2 & $0,43 \%$ & $0,26 \%$ & $0,28 \%$ & $0,14 \%$ & $0,63 \%$ & $0,31 \%$ \\
\hline 1 & $0,32 \%$ & $0,16 \%$ & $0,23 \%$ & $0,09 \%$ & $0,64 \%$ & $0,79 \%$ \\
\hline 0 & $0,02 \%$ & $0,04 \%$ & $0,02 \%$ & $0,02 \%$ & $0,01 \%$ & $0,01 \%$ \\
\hline
\end{tabular}

O processamento dos resultados apresentado pela Tabela 18 permite constatar que o modelo $1 \mathrm{~A}$ atende a todos os critérios de limitação de danos sugeridos pelo Eurocódigo 8 (2005), mesmo para situações com materiais frágeis não estruturais fixos à estrutura. Obviamente, por se tratar de um modelo bastante mais rígido, 1B também atende aos mesmos critérios, inclusive com uma margem consideravelmente maior. Já o modelo 1C não atende ao critério mais conservador referente aos materiais frágeis fixos à estrutura, e 
no primeiro pavimento não atende inclusive ao critério intermediário com elementos dúcteis fixos à estrutura, para a direção y.

\subsection{ANÁLISE COM BASE ISOLADA}

O modelo 1A do estudo de caso foi analisado considerando o isolamento de base do tipo LRB. Foram dimensionados dispositivos considerando níveis de amortecimento distintos e condições sísmicas variadas, visando a obter resultados que permitissem uma compreensão mais abrangente do comportamento dos LRB's para diferentes situações de projeto.

Optou-se por posicionar o sistema de isolamento no nível térreo, logo acima dos dois subsolos, por dois motivos principais: Os subsolos apresentavam, em seu contorno, paredes de contenção do terreno que, por estarem em contato entre si, não garantiam o espaço mínimo de deslocamento livre necessário para aplicar o isolamento; além disso, como a análise com base fixa considerou principalmente as massas e respostas da superestrutura, acima da fundação e subsolos, o comparativo com o sistema isolado feito dessa forma mostrou-se mais coerente.

Para realizar a análise da estrutura considerando o sistema de isolamento sísmico na base, é necessário, inicialmente, realizar sua análise com a base fixa, pois precisa-se conhecer algumas informações do sistema estrutural sem isolamento, para que seja possível definir alguns parâmetros iniciais da análise com isolamento de base. Primeiramente, é necessário conhecer o período natural fundamental da estrutura com a base fixa, para então definir qual o período que se deseja considerar para a estrutura com isolamento. Essa primeira investigação, feita por meio da expressão (4.2), permite inclusive verificar se a estrutura possui as características necessárias para que seja possível projetar um sistema de isolamento eficaz, especialmente dentro de um regime de análise linear.

Para o modelo 1A deste estudo de caso, temos os seguintes limites para os períodos fundamentais nas direções " $\mathrm{x}$ " e " $y$ ", obtidos em função dos resultados apresentados na Tabela 9:

$$
\begin{aligned}
& 3 T_{x}=3 \times 0,88 s \therefore 2,64 s \leq T_{x, e f f} \leq 3 s \\
& 3 T_{y}=3 \times 0,69 s \therefore 2,07 s \leq T_{y, e f f} \leq 3 s
\end{aligned}
$$

Portanto, para valores de $T_{\text {eff }}$ entre 2,64 e 3,0 segundos, a estrutura satisfaz as condições exigidas para um isolamento de base eficiente, mesmo que analisado por métodos lineares. Adotou-se para este estudo de caso um $\mathrm{T}_{\text {eff }}$ de $2,7 \mathrm{~s}$. 
Além do período alvo, para aplicar o método de dimensionamento do sistema de isolamento segundo o item 4.3.1, também é necessário definir a taxa de amortecimento $\xi_{\text {eff }}$, que irá influenciar diretamente na obtenção do deslocamento estimado no nível do isolamento, por meio de (4.17), que adota a aceleração sísmica $S_{\text {eff }}$ referente ao espectro de resposta elástica corrigido por $\xi_{\text {eff }}$. Para a primeira análise comparativa, foram definidas as taxas de amortecimento de 15\% e 30\%, que, para este estudo de caso, representam aproximadamente a máxima taxa de amortecimento para um apoio linear equivalente e a máxima taxa de amortecimento para um LRB, respectivamente. Assim, foram produzidos dois sistemas de isolamento com características distintas, que serão analisados segundo dois dos métodos de análise no domínio do tempo permitidos pelo SAP2000, mencionados no item 4.2.5, sendo estes o método linear (LN) e o Fast Nonlinear Analysis (FNA). Os sistemas de isolamento foram nomeados conforme apresentado na Tabela 19:

Tabela 19 - Sistemas de Isolamento - Análise 1. Fonte: autor

\begin{tabular}{|c|c|c|}
\hline Nomenclatura & Método de análise & Taxa de amortecimento \\
\hline LN1-15 & Linear & $15 \%$ \\
\hline LN1-30 & Linear & $30 \%$ \\
\hline FNA1-15 & FNA & $15 \%$ \\
\hline FNA1-30 & FNA & $30 \%$ \\
\hline
\end{tabular}

A princípio, os isolamentos LN1-15 e FNA-15 possuem um dimensionamento idêntico, assim como os isolamentos LN1-30 e FNA1-30. A diferença existe no momento da aplicação dos dispositivos no SAP2000, em que o primeiro entra com as propriedades linearizadas enquanto o segundo entra com as propriedades bilineares.

Em seguida, aplica-se a expressão (4.17), utilizando o espectro corrigido para cada taxa de amortecimento considerada, conforme apresentado na Figura 20:

$$
\begin{gathered}
\mathrm{D}_{15 \%}=S_{\text {eff }}\left[\frac{\mathrm{T}_{e f f}}{2 \pi}\right]^{2}=1,01 \times\left[\frac{2,7}{2 \pi}\right]^{2}=0,187 m \\
\mathrm{D}_{30 \%}=S_{\text {eff }}\left[\frac{\mathrm{T}_{e f f}}{2 \pi}\right]^{2}=0,785 \times\left[\frac{2,7}{2 \pi}\right]^{2}=0,145 m
\end{gathered}
$$

Os valores de deslocamento obtidos configuram os valores mínimos que devem ser aplicados no dimensionamento do sistema de isolamento. Eles deverão ser utilizados para balizar os deslocamentos adotados no dimensionamento dos isoladores, de modo a obter análises cujos resultados no nível do isolamento apresentem períodos fundamentais e deslocamentos compatíveis com as premissas adotadas. Os deslocamentos e períodos 
resultantes das análises são, usualmente, superiores às estimativas iniciais, em função da flexibilidade do próprio edifício e das deformações por torção. Neste estudo, foram adotados os deslocamentos calculados acrescidos de 10\%, de forma que, após algumas iterações, foram obtidos resultados compatíveis com o critério apresentado na expressão (4.1):

$$
\begin{aligned}
& D_{15 \%}=0,205 m \\
& D_{30 \%}=0,160 m
\end{aligned}
$$

A rigidez horizontal $K_{\text {eff }}$ do sistema, para atender ao período $\mathrm{T}_{e f f}$ adotado, vem da expressão (4.14), conhecendo a massa $m$ do edifício dado na Tabela 7:

$$
K_{e f f}=\frac{4 \pi^{2} m}{\mathrm{~T}_{e f f}^{2}}=\frac{4 \pi^{2} \times 2345000}{2,7^{2}}=12.699 .161 \mathrm{~N} \cong 12,699 \mathrm{kN}
$$

Nota-se que a $K_{\text {eff }}$ é igual para as duas taxas de amortecimento adotadas, uma vez que independe dos deslocamentos ou acelerações impostos, sendo exclusivamente resolvido em função da massa e do período fundamental da estrutura analisada.

O amortecimento equivalente linear é dado, segundo (4.16), por:

$$
\begin{aligned}
& E_{v, 15 \%}=2 \pi \times 12699 \times 0,205^{2} \times 0,15=505 \mathrm{kN} . \mathrm{s} / \mathrm{m} \\
& E_{v, 30 \%}=2 \pi \times 12699 \times 0,188^{2} \times 0,30=612 \mathrm{kN} . \mathrm{s} / \mathrm{m}
\end{aligned}
$$

Obtidos $K_{e f f}, \mathrm{D}, \xi_{e f f}$ e $E_{v}$, torna-se possível iniciar o procedimento iterativo descrito no item 4.3.1, para dimensionar o LRB.

A Tabela 20 apresenta os resultados da metodologia para o caso com taxa de amortecimento de 15\%, nomeadamente LN1-15 e FNA1-15.

Tabela 20 - Dimensionamento Iterativo LRB 15\%. Fonte: autor

\begin{tabular}{|c|c|c|c|c|}
\hline Iterações & $\mathbf{Q}(\boldsymbol{k N})$ & $\mathbf{K}_{\mathbf{2}}(\boldsymbol{k N} / \boldsymbol{m})$ & $\mathbf{K}_{\mathbf{1}}(\boldsymbol{k N} / \boldsymbol{m})$ & $\mathbf{D}_{\boldsymbol{y}}(\boldsymbol{m})$ \\
\hline iteração 0 & 614,72 & 9706,99 & 126190,90 & 0,00528 \\
\hline iteração 1 & 630,92 & 9628,10 & 125165,36 & 0,00546 \\
\hline iteração 2 & 631,50 & 9625,29 & 125128,73 & 0,00547 \\
\hline iteração 3 & 631,52 & 9625,19 & 125127,41 & 0,00547 \\
\hline iteração 4 & 631,52 & 9625,18 & 125127,36 & 0,00547 \\
\hline iteração 5 & 631,52 & 9625,18 & 125127,36 & 0,00547 \\
\hline
\end{tabular}

A partir desses resultados, define-se $\mathrm{F}_{\mathrm{y}}$ pela expressão (4.19): 


$$
\mathrm{F}_{\mathrm{y}, 15 \%}=125127,36 \mathrm{kN} / \mathrm{m} \times 0,00547 \mathrm{~m}=684,15 \mathrm{kN}
$$

Os valores de $E_{v}, \mathrm{Q}, \mathrm{K}_{1}, \mathrm{~K}_{2}$ e $\mathrm{F}_{\mathrm{y}}$ obtidos permitem caracterizar o sistema de isolamento global, em conjunto com as propriedades linearizadas $K_{\text {eff }}$ e $\xi_{\text {eff }}$. Esse sistema necessita, em seguida, ser dividido entre os pontos de apoio escolhidos no modelo estrutural. Visando a manter o centro de rigidez horizontal do sistema de isolamento o mais próximo possível do centro de massa da estrutura, essa divisão foi feita proporcionalmente à carga gravitacional suportada por cada elemento vertical sismo-resistente, obtida da análise com base fixa. A Tabela 21 apresenta as cargas verticais suportadas em cada pilar e parede da estrutura, em ordem crescente, onde cada elemento vertical está nomeado conforme apresentado na Figura 28. Foram considerados dois pontos de isolamento para cada parede de modo a evitar isoladores com dimensões muito grandes, em função das altas cargas verticais apresentadas por esses elementos.

Tabela 21 - Cargas verticais nos pontos de isolamento definidos para o modelo 1A. Fonte: autor

\begin{tabular}{|c|c|c|c|}
\hline Elemento & Cargas Verticais (kN) & Elemento & Cargas Verticais (kN) \\
\hline Par3.1 & 475 & Par1.2 & 816 \\
\hline Par3.2 & 475 & Par2.1 & 816 \\
\hline Par4.1 & 475 & Par2.2 & 816 \\
\hline Par4.2 & 475 & C12 & 1014 \\
\hline C1 & 558 & C15 & 1014 \\
\hline C6 & 558 & C2 & 1032 \\
\hline C11 & 570 & C5 & 1032 \\
\hline C16 & 570 & Par5.1 & 1041 \\
\hline C3 & 778 & Par5.2 & 1041 \\
\hline C4 & 778 & C8 & 1141 \\
\hline C13 & 778 & C9 & 1141 \\
\hline C14 & 778 & C7 & 1984 \\
\hline Par1.1 & 816 & C10 & 1984 \\
\hline
\end{tabular}

Em seguida, os pontos de apoio definidos foram agrupados em três tipos de isoladores, com base na faixa de carga suportada por cada apoio. A média de carga vertical de cada grupo foi utilizada para distribuir as propriedades do sistema de isolamento global para cada tipo de dispositivo. A divisão adotada está apresentada na Tabela 22 e sua representação gráfica na Figura 53.

Tabela 22 - Cargas verticais nos pontos de isolamento definidos para o modelo 1A. Fonte: autor

\begin{tabular}{|c|c|c|c|}
\hline Isolamento & quantidade & Faixa de Carga (kN) & Média dos Apoios (kN) \\
\hline Tipo 1 & 8 & 0 a 600 & 520 \\
\hline Tipo 2 & 16 & 601 a 1200 & 930 \\
\hline Tipo 3 & 2 & 1201 a 2000 & 1984 \\
\hline
\end{tabular}




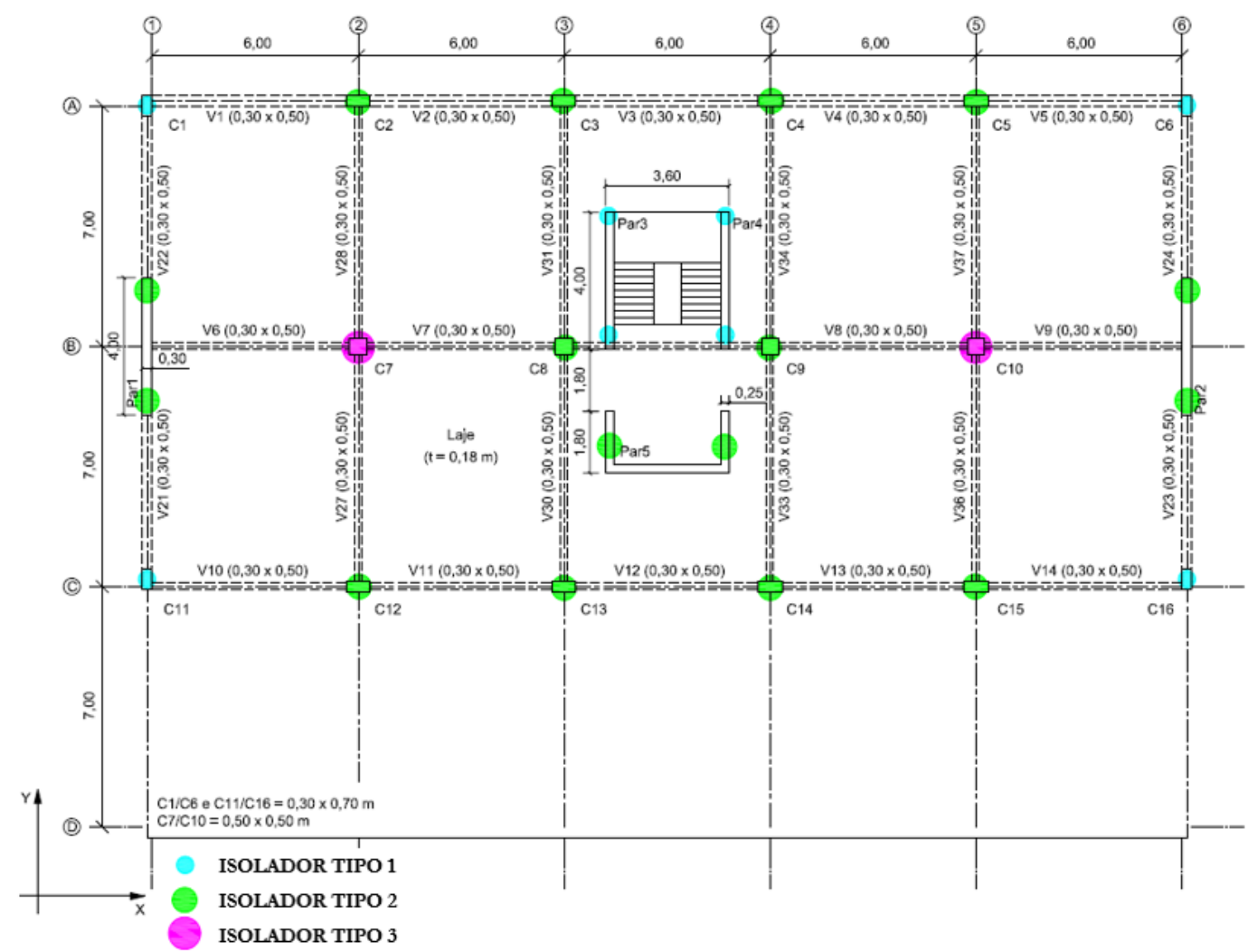

Figura 53: Tipos de Isolamento e Localização - Modelo 1A. Fonte: autor.

A distribuição dos parâmetros de isolamento para cada tipo de isolador foi obtida dividindo-se as propriedades do sistema global pelo somatório de carga dos elementos verticais considerados, que depois foram multiplicados pela média de carga de cada tipo de isolador. Em seguida, as propriedades de cada isolador foram utilizadas para determinar sua altura $\mathrm{h}$, seu diâmetro de elastômero $\Phi_{b}$, relativo à área $A_{b}$, e seu diâmetro de chumbo $\Phi_{L}$, por meio das expressões (4.20), (4.10) e (4.9), respectivamente. Adotou-se para o módulo de cisalhamento do elastômero $440 \mathrm{kN} / \mathrm{m}^{2}$, compatível com as especificações do fabricante Dynamic Isolation Systems (DIS). A Tabela 23 apresenta os três tipos de isoladores resultantes para LN1-15 e FNA1-15.

Finalmente, as dimensões obtidas foram compatibilizadas com as dimensões usualmente fornecidas pelos fabricantes de dispositivos de isolamento. Também foram feitos pequenos ajustes nos diâmetros de elastômero e de chumbo para os três tipos de isoladores, visando a atender aos critérios de linearização requisitados no item 4.2.2. Os isoladores foram então configurados no SAP2000, onde se procedeu à análise do modelo com base isolada. Com os resultados da análise, pequenos ajustes iterativos foram realizados novamente em suas 
dimensões, na intenção de compatibilizar os deslocamentos obtidos com os deslocamentos de projeto, conforme proposto pela expressão (4.1).

Para os isoladores LN1-30 e FNA1-30, o mesmo procedimento descrito foi adotado; entretanto, para as taxas de amortecimento de 30\%, não foi possível atender aos critérios de linearização descritos no item 4.2.2, ou seja, estes isoladores não satisfazem aos critérios para que possam ser implementados em análises lineares. Desse modo, apenas a análise com o isolador FNA1-30 poderia ser considerada, tendo que ser descartada a análise para o LN1-30. Ainda assim, para efeito de comparação dos resultados, foram mantidas as respostas obtidas para o LN1-30.

A Tabela 24 apresenta os parâmetros finais considerados para os isoladores, aplicados nas análises indicadas na Tabela 19.

Tabela 23 - Propriedade iniciais de cada tipo de isolamento. Fonte: autor

\begin{tabular}{|c|c|}
\hline \multicolumn{2}{|c|}{ Isolador Tipo 1} \\
\hline $\mathrm{G}\left(\mathrm{kN} / \mathrm{m}^{2}\right)$ & 440,0 \\
\hline Média Carga $(\mathrm{kN})$ & 520,0 \\
\hline $\mathrm{K}_{\text {eff }}(\mathrm{kN} / \mathrm{m})$ & 287,4 \\
\hline$E_{\boldsymbol{v}}(\mathrm{kN} . \mathrm{s} / \mathrm{m})$ & 24,6 \\
\hline$\xi_{1}$ & 0,15 \\
\hline $\mathrm{h}(\mathrm{cm})$ & 30,0 \\
\hline$F_{y}(\mathrm{kN})$ & 15,5 \\
\hline$\Phi_{L}(\mathrm{~cm})$ & 5,1 \\
\hline $\mathrm{K}_{2}(\mathrm{kN} / \mathrm{m})$ & 217,8 \\
\hline $\mathrm{K}_{1}(\mathrm{kN} / \mathrm{m})$ & 2831,3 \\
\hline$\Phi_{b}(\mathrm{~cm})$ & 42,0 \\
\hline
\end{tabular}

\begin{tabular}{|c|c|}
\hline \multicolumn{2}{|c|}{ Isolador Tipo 2} \\
\hline $\mathrm{G}\left(\mathrm{kN} / \mathrm{m}^{2}\right)$ & 440,0 \\
\hline Média Carga $(\mathrm{kN})$ & 930 \\
\hline $\mathrm{K}_{\text {eff }}(\mathrm{kN} / \mathrm{m})$ & 512,8 \\
\hline$E_{v}(\mathrm{kN} . \mathrm{s} / \mathrm{m})$ & 44,0 \\
\hline$\xi_{1}$ & 0,15 \\
\hline $\mathrm{h}(\mathrm{cm})$ & 30,0 \\
\hline$F_{y}(\mathrm{kN})$ & 27,6 \\
\hline$\Phi_{L}(\mathrm{~cm})$ & 7,20 \\
\hline $\mathrm{K}_{2}(\mathrm{kN} / \mathrm{m})$ & 388,71 \\
\hline $\mathrm{K}_{1}(\mathrm{kN} / \mathrm{m})$ & 5053,18 \\
\hline$\Phi_{b}(\mathrm{~cm})$ & 56,00 \\
\hline
\end{tabular}

\begin{tabular}{|c|c|}
\hline \multicolumn{2}{|c|}{ Isolador Tipo 3 } \\
\hline $\mathrm{G}\left(\mathrm{kN} / \mathrm{m}^{2}\right)$ & 440,0 \\
\hline Média Carga $(\mathrm{kN})$ & 1984 \\
\hline $\mathrm{K}_{\text {eff }}(\mathrm{kN} / \mathrm{m})$ & 1097,4 \\
\hline$E_{\boldsymbol{v}}(\mathrm{kN} . \mathrm{s} / \mathrm{m})$ & 94,2 \\
\hline$\xi_{1}$ & 0,15 \\
\hline $\mathrm{h}(\mathrm{cm})$ & 30,0 \\
\hline$F_{y}(\mathrm{kN})$ & 59,1 \\
\hline$\Phi_{L}(\mathrm{~cm})$ & 10,1 \\
\hline $\mathrm{K}_{2}(\mathrm{kN} / \mathrm{m})$ & 831,8 \\
\hline $\mathrm{K}_{1}(\mathrm{kN} / \mathrm{m})$ & 10813,0 \\
\hline$\Phi_{b}(\mathrm{~cm})$ & 82,0 \\
\hline
\end{tabular}

Tabela 24 - Propriedades dos Isolamento para taxas de amortecimento de $15 \%$ e $30 \%$. Fonte: autor

\begin{tabular}{|c|c|c|c|c|c|c|c|}
\hline \multirow{7}{*}{ 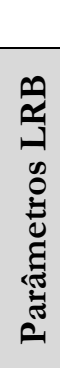 } & & \multicolumn{2}{|c|}{ Isolador tipo 1} & \multicolumn{2}{|c|}{ Isolador tipo 2} & \multicolumn{2}{|c|}{ Isolador tipo 3} \\
\hline & $\xi$ & $15 \%$ & $30 \%$ & $15 \%$ & $30 \%$ & $15 \%$ & $30 \%$ \\
\hline & $\mathrm{h}(\mathrm{cm})$ & 30,0 & 30,0 & 30,0 & 30,0 & 30,0 & 30,0 \\
\hline & $\Phi_{L}(\mathrm{~cm})$ & 5,5 & 7,0 & 7,1 & 10,0 & 10,1 & 14,0 \\
\hline & $\Phi_{\boldsymbol{b}}(\mathrm{cm})$ & 46,0 & 35,0 & 60,0 & 50,0 & 85,0 & 70,0 \\
\hline & $\mathrm{K}_{2}(\mathrm{kN} / \mathrm{m})$ & 264,3 & 149,0 & 449,8 & 304,1 & 902,6 & 596,0 \\
\hline & $\mathrm{Q}(\mathrm{kN})$ & 17,5 & 28,4 & 29,2 & 58,0 & 59,2 & 113,7 \\
\hline \multirow{2}{*}{ Z } & $\mathrm{K}_{\text {eff }}(\mathrm{kN} / \mathrm{m})$ & 349,7 & 337,3 & 592,1 & 588,7 & 1190,5 & 1214,3 \\
\hline & $c_{e f f}(\mathrm{kN} . \mathrm{s} / \mathrm{m})$ & 27,6 & 71,7 & 46,8 & 109,0 & 98,0 & 242,6 \\
\hline \multirow{3}{*}{$\underset{Z}{\mathbb{Z}}$} & $D_{y}(\mathrm{~cm})$ & 0,553 & 1,686 & 0,542 & 1,219 & 0,546 & 1,363 \\
\hline & $\left.\mathrm{K}_{1}(\mathrm{kN} / \mathrm{m})\right)$ & 3436 & 1932 & 5847 & 3990 & 11733 & 7793 \\
\hline & $F_{y}(\mathrm{kN})$ & 19,0 & 32,6 & 31,7 & 48,7 & 64,1 & 106,2 \\
\hline
\end{tabular}


Os parâmetros da Tabela 24 consistem nos valores finais aplicados ao SAP2000, no modelo 1A, para realização da Análise 1 (indicada a seguir) e obtenção das respostas estruturais que são comparadas com os resultados do modelo com base fixa no item 5.4.1.

\subsubsection{Resultados comparativos}

Inicialmente, a Tabela 25 apresenta os períodos e participação de massa modal da análise com isolamento de base. A análise modal é feita sempre considerando os parâmetros lineares equivalentes, portanto os mesmos períodos e fatores de participação de massa modal são válidos tanto para a análise linear quanto para a análise do tipo FNA.

Tabela 25 - Análise modal - 1A. Fonte: autor

\begin{tabular}{|c|c|c|c|c|c|c|c|c|c|}
\hline \multirow{3}{*}{ Modo } & \multicolumn{4}{|c|}{ LN1-15 / FNA1-15 } & & \multicolumn{4}{|c|}{ LN1-30 / FNA1-30 } \\
\hline & \multirow{2}{*}{ Período (seg) } & \multicolumn{3}{|c|}{ Participação de massa modal } & \multirow{2}{*}{ Modo } & \multirow{2}{*}{ Período (seg) } & \multicolumn{3}{|c|}{ Participação de massa modal } \\
\hline & & $\mathrm{X}$ & $\mathrm{Y}$ & $\mathrm{RZ}$ & & & $\mathrm{X}$ & $\mathrm{Y}$ & $\mathrm{RZ}$ \\
\hline 1 & 2,732 & $0,0 \%$ & $99,6 \%$ & $0,0 \%$ & 1 & 2,727 & $0,0 \%$ & $99,6 \%$ & $0,0 \%$ \\
\hline 2 & 2,691 & $99,4 \%$ & $0,0 \%$ & $0,5 \%$ & 2 & 2,686 & $99,4 \%$ & $0,0 \%$ & $0,4 \%$ \\
\hline 3 & 2,619 & $0,4 \%$ & $0,0 \%$ & $99,4 \%$ & 3 & 2,614 & $0,4 \%$ & $0,0 \%$ & $99,4 \%$ \\
\hline 4 & 0,448 & $0,0 \%$ & $0,4 \%$ & $0,0 \%$ & 4 & 0,448 & $0,0 \%$ & $0,4 \%$ & $0,0 \%$ \\
\hline 5 & 0,386 & $0,2 \%$ & $0,0 \%$ & $0,0 \%$ & 5 & 0,386 & $0,2 \%$ & $0,0 \%$ & $0,0 \%$ \\
\hline 6 & 0,331 & $0,0 \%$ & $0,0 \%$ & $0,1 \%$ & 6 & 0,331 & $0,0 \%$ & $0,0 \%$ & $0,1 \%$ \\
\hline \multicolumn{2}{|c|}{ Somatório } & $100,0 \%$ & $100,0 \%$ & $100,0 \%$ & \multicolumn{2}{|c|}{ Somatório } & $100,0 \%$ & $100,0 \%$ & $100,0 \%$ \\
\hline
\end{tabular}

Assim, como se objetivava alcançar, os períodos fundamentais nas direções x e y são bastante parecidos e adequadamente próximos do valor considerado de 2,7 segundos, que também não difere muito do período alcançado para o terceiro modo de vibração, referente ao primeiro modo de torção. Além disso, os fatores de participação de massa atingem valores superiores à $99 \%$ nos primeiros modos de vibrar de cada movimento considerado, ou seja, translação em relação ao eixo x, translação em relação ao eixo y e rotação em relação ao eixo vertical z. Tanto para os isoladores com taxa de amortecimento de $15 \%$ quanto para os de $30 \%$, os períodos e fatores de participação de massa foram equivalentes, em consequência do método de dimensionamento dos dispositivos que buscou justamente atingir esses resultados.

$\mathrm{Na}$ sequência, os resultados obtidos das análises do modelo com a base isolada, realizadas com auxílio do software SAP2000, com base nos parâmetros definidos em 5.4, estão apresentados de forma comparativa aos resultados obtidos para o modelo 1A (base fixa), do item 5.3.

Força cortante na base - Análise 1.

As forças cortantes máximas na base estão apresentadas na Figura 54. 

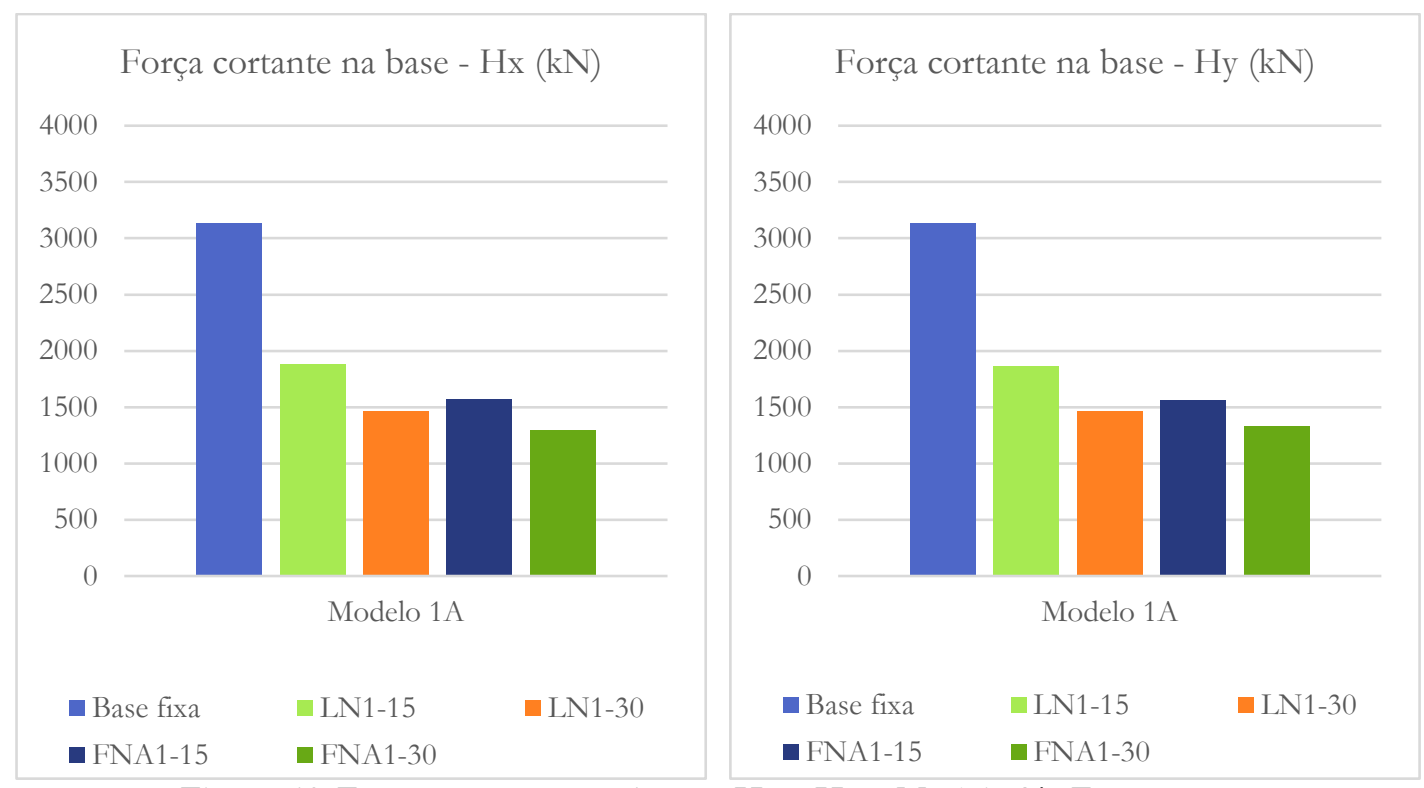

Figura 54: Forças cortantes na base - $\mathrm{Hx}$ e $\mathrm{Hy}-$ Modelo 1A. Fonte: autor.

Conforme esperado, a utilização do sistema de isolamento garante uma redução considerável nos esforços cortantes máximos na base do edifício, sendo que as análises que adotaram os parâmetros linearizados, LN1-15 e LN1-30, obtiveram reduções da ordem de $40 \%$ e 50\%, respectivamente, em relação aos esforços do modelo sem isolamento; Analogamente, as análises bilineares FNA1-15 e FNA1-30 conseguiram reduções da ordem de $50 \%$ e $60 \%$, respectivamente.

Nota-se que tanto nas análises linearizadas quanto nas bilineares, o aumento da taxa de amortecimento resulta em uma redução de aproximadamente $10 \%$ nos esforços cortantes máximos na base. As análises bilineares conseguem, adicionalmente, uma redução de $10 \%$ em relação às análises lineares equivalentes.

A Figura 55 apresenta o esforço cortante máximo obtido em cada pavimento do modelo, para as direções x e y, permitindo avaliar a distribuição desses esforços em relação às elevações da estrutura. 

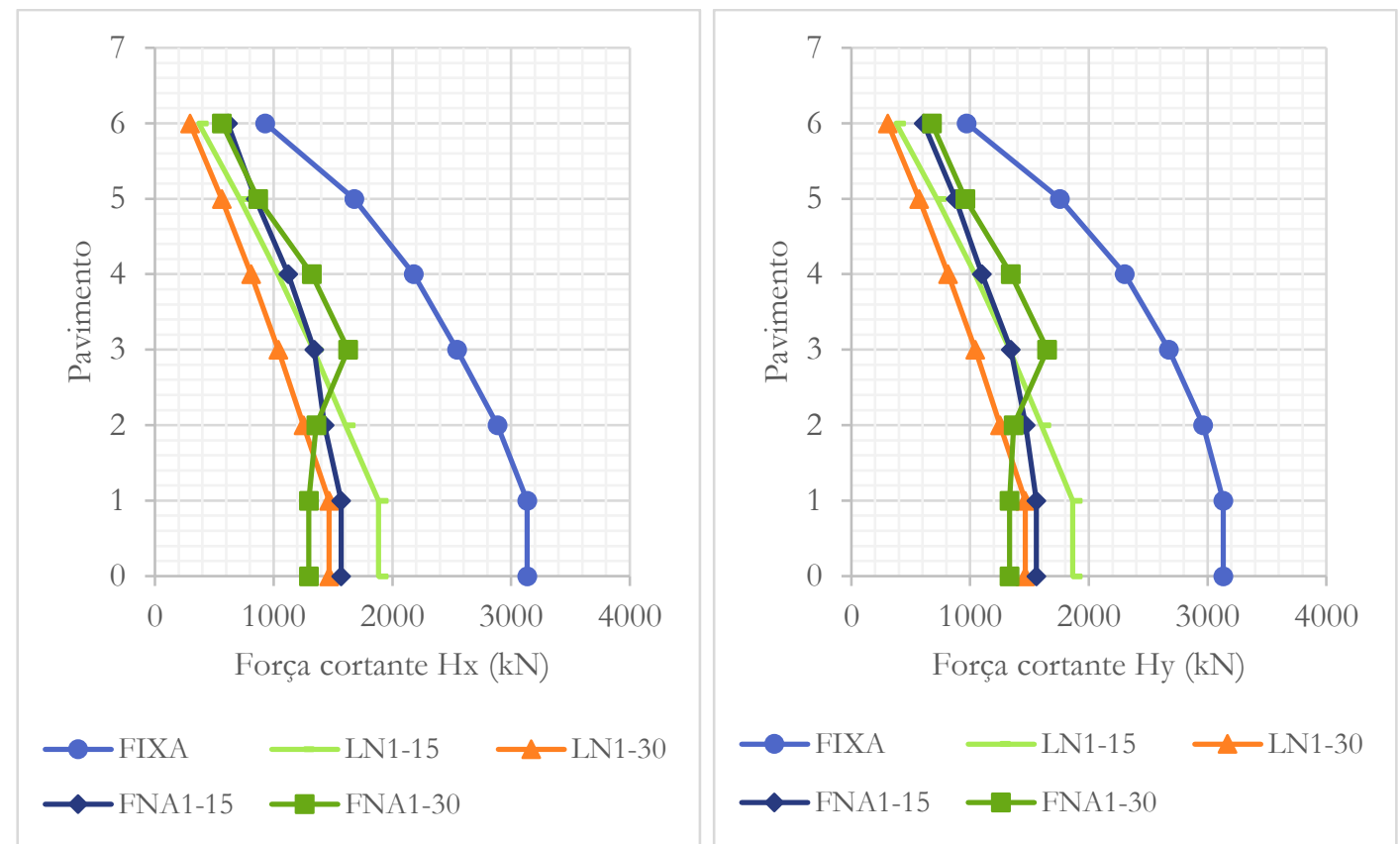

Figura 55: Forças cortantes por pavimento - Hx e Hy - Modelo 1A. Fonte: autor.

Neste comparativo, é possível notar que, apesar da análise com o isolador FNA1-30 apresentar os menores esforços cortantes na base, esforços superiores aos basais ocorrem em pavimentos superiores, mostrando que a utilização de taxas de amortecimento elevadas pode excitar modos de vibração superiores ao fundamental, de tal modo que os esforços cortantes basais deixam de ser os mais críticos para a estrutura. Inclusive, os esforços cortantes no terceiro pavimento para FNA1-30 superam os maiores esforços cortantes apresentados pela análise FNA1-15. Curiosamente, nota-se que as respostas de LN1-30, que utiliza uma análise linearizada para isoladores que intencionalmente não respeitam todas as condições de linearização, não captura essa intensificação de esforços em pavimentos superiores. Esse fato mostra a necessidade de se respeitar os critérios de linearização apresentados em 4.2.2, dado que, neste caso específico, os esforços cortantes basais para LN1-30 foram inferiores aos máximos esforços encontrados em FNA1-30.

Deslocamentos e efeitos de segunda ordem - Análise 1.

Em seguida, são avaliados os deslocamentos e parâmetros de estabilidade para os mesmos casos apresentados na Tabela 19. A princípio, apresentam-se na Figura 56 os deslocamentos relativos obtidos para as direções x e y em função da elevação em metros. 


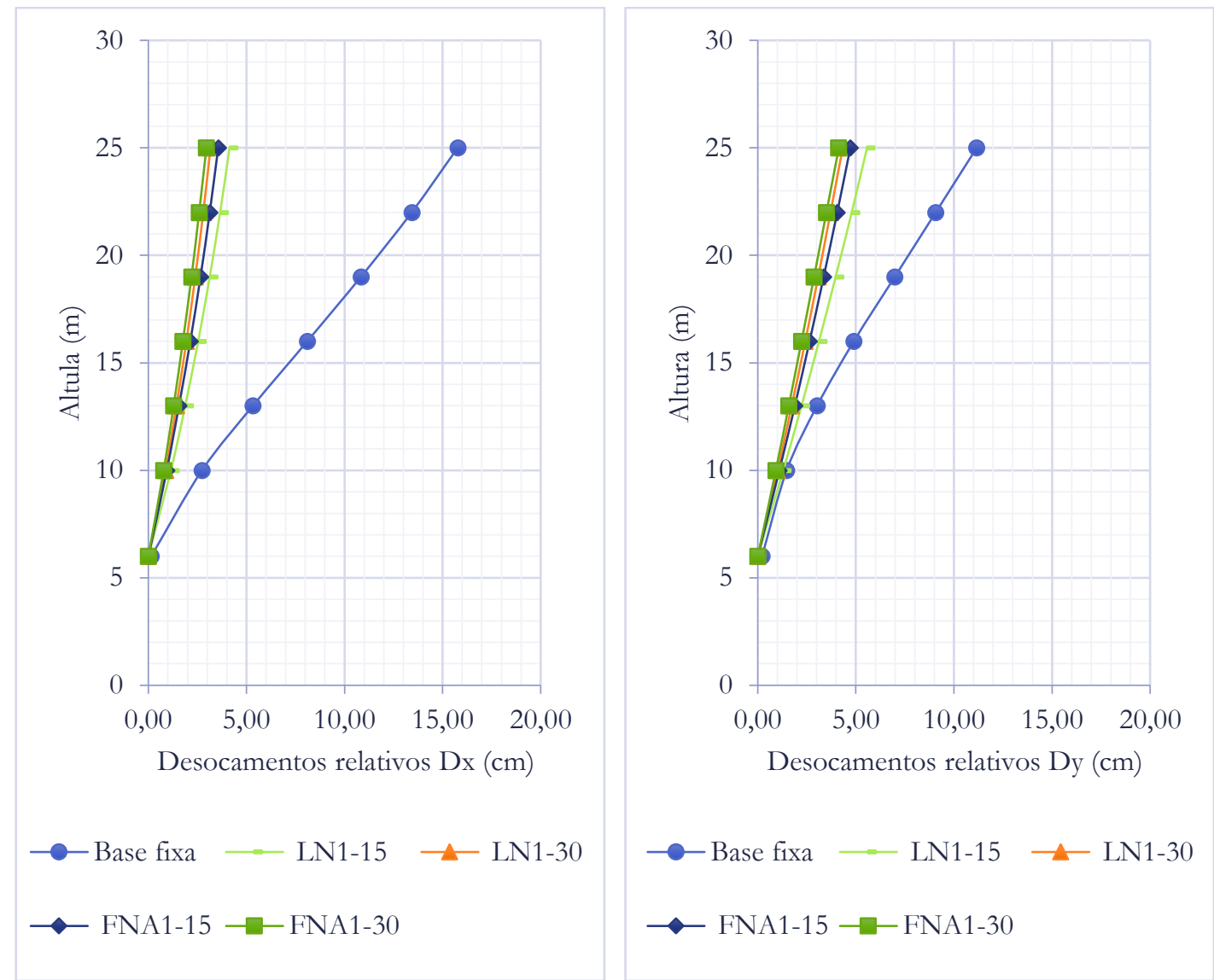

Figura 56: Deslocamentos relativos com isolamento - Dx e Dy - Modelo 1A. Fonte: autor.

Assim como no comparativo de esforços, nota-se uma considerável redução nos deslocamentos relativos obtidos para os modelos com isolamento de base, em relação ao modelo com base fixa. Embora os deslocamentos sejam maiores na direção $\mathrm{x}$ do que na $\mathrm{y}$ para a consideração de base fixa, a relação se inverte quando consideramos o isolamento de base, apresentado deslocamentos superiores na direção y. Ainda assim, de uma forma generalizada, os deslocamentos das análises bilineares FNA mostram-se inferiores aos obtidos nas análises linearizadas.

A seguir, a Figura 57 apresenta os deslocamentos relativos quanto ao atendimento aos critérios de limitação de danos, apresentados em (3.20) a (3.22). Nas figuras, o deslocamento relativo $\Delta_{\mathrm{i}}$, em cada direção, considera a redução pelo parâmetro $v=0,5$ sugerida no item 3.5.4 e está apresentado já normalizado em relação à altura entre lajes $\left(\Delta_{i} / h_{i}\right)$, permitindo sua interpretação segundo (5.1), (5.2) e (5.3). 


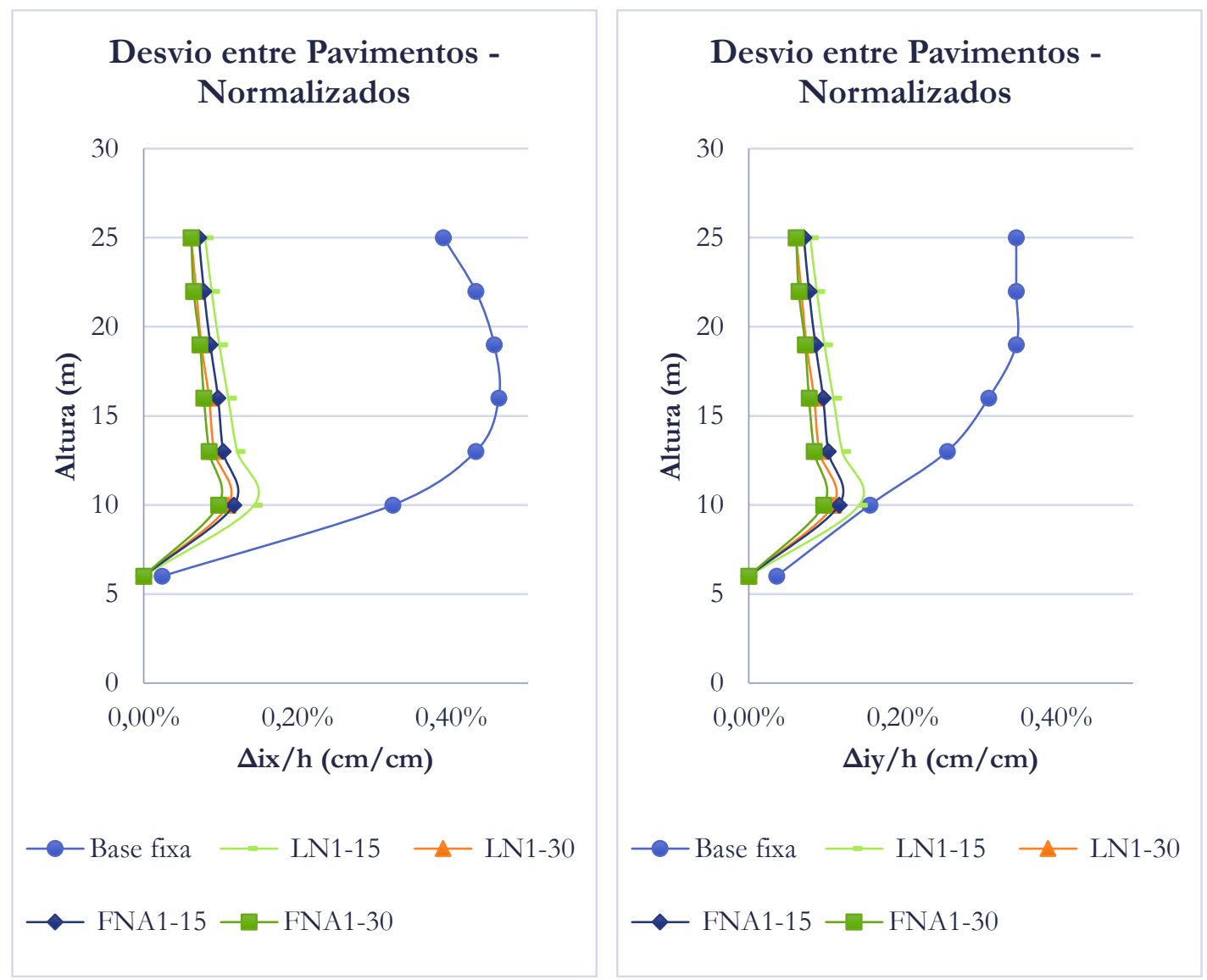

Figura 57: Desvio entre pavimentos normalizados - Modelo 1A. Fonte: autor.

Uma das grandes vantagens da aplicação do sistema de isolamento pode ser observada por este comparativo. As respostas apresentadas mostram claramente o melhor desempenho estrutural dos casos com isolamento, que apresentam riscos muito inferiores de sofrer algum dano, comparado ao modelo de base fixa, especialmente na direção x. Além disso, as respostas com isolamento são muito próximas nas duas direções ortogonais, devido à grande influência que este tem no desempenho da estrutura. Para a intensidade sísmica considerada, mesmo o modelo com base fixa apresenta resultados aceitáveis em relação à limitação de danos, entretanto, como veremos adiante, para intensidades maiores, o ganho de desempenho com isolamento de base pode fazer com que estruturas que não atendam ao critério passem a responder de forma bastante satisfatória.

Em complemento aos desvios analisados, mostra-se na Figura 58 o comparativo dos parâmetros de estabilidade $\theta$, obtidos analogamente aos apresentados na Tabela 15 . 


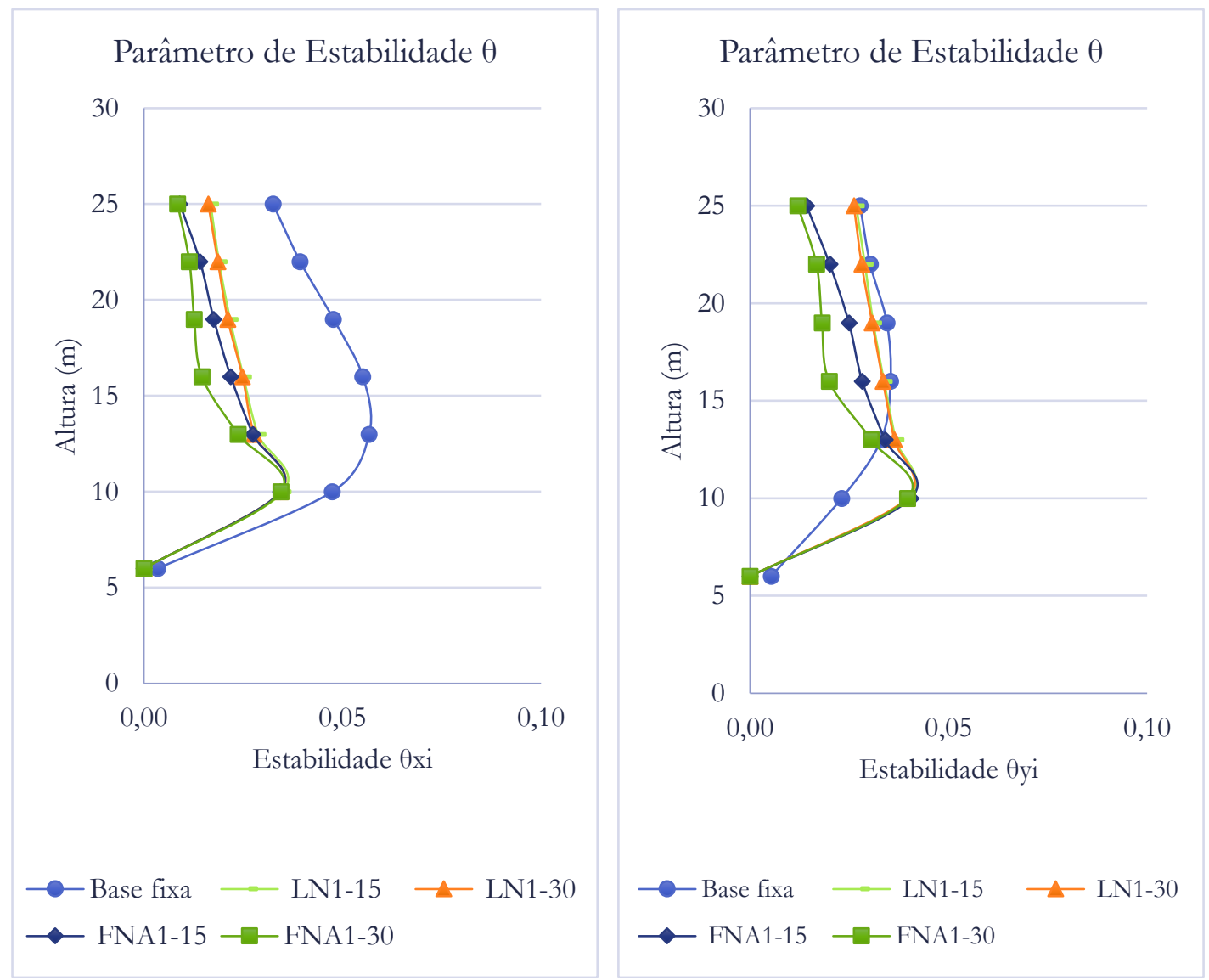

Figura 58: Parâmetro de estabilidade $\theta$ - Modelo 1A. Fonte: autor.

Conclui-se para esta análise, portanto, que a despeito da significativa redução nos esforços laterais quando utilizado o isolamento sísmico, o melhor comportamento proporcionado em relação aos deslocamentos garante que a segurança referente à estabilidade seja superior (direção x), ou ao menos equivalente (direção y), aos obtidos na análise considerando a base fixa, apresentando, neste modelo, apenas uma piora relativa na elevação $10 \mathrm{~m}$, mas sempre com valor inferior ao limite admissível para $\theta$, não exigindo nenhuma consideração adicional em relação aos esforços obtidos. Assim, é possível se beneficiar dos menores esforços, dos menores deslocamentos relativos e do menor risco de danos ao edifício com isolamento, sem prejudicar o atendimento aos demais critérios de segurança.

As acelerações absolutas máximas desenvolvidas no modelo podem ser verificadas na Figura 59, normalizadas em relação à aceleração da gravidade e, portanto, apresentadas em unidade $g$. Conforme esperado, o aumento no período fundamental da estrutura e o acréscimo no coeficiente de amortecimento, produzidos pela aplicação dos isoladores sísmicos, faz com que a estrutura absorva menos acelerações, consequentemente incidindo em menores esforços cortantes e deslocamentos relativos. 

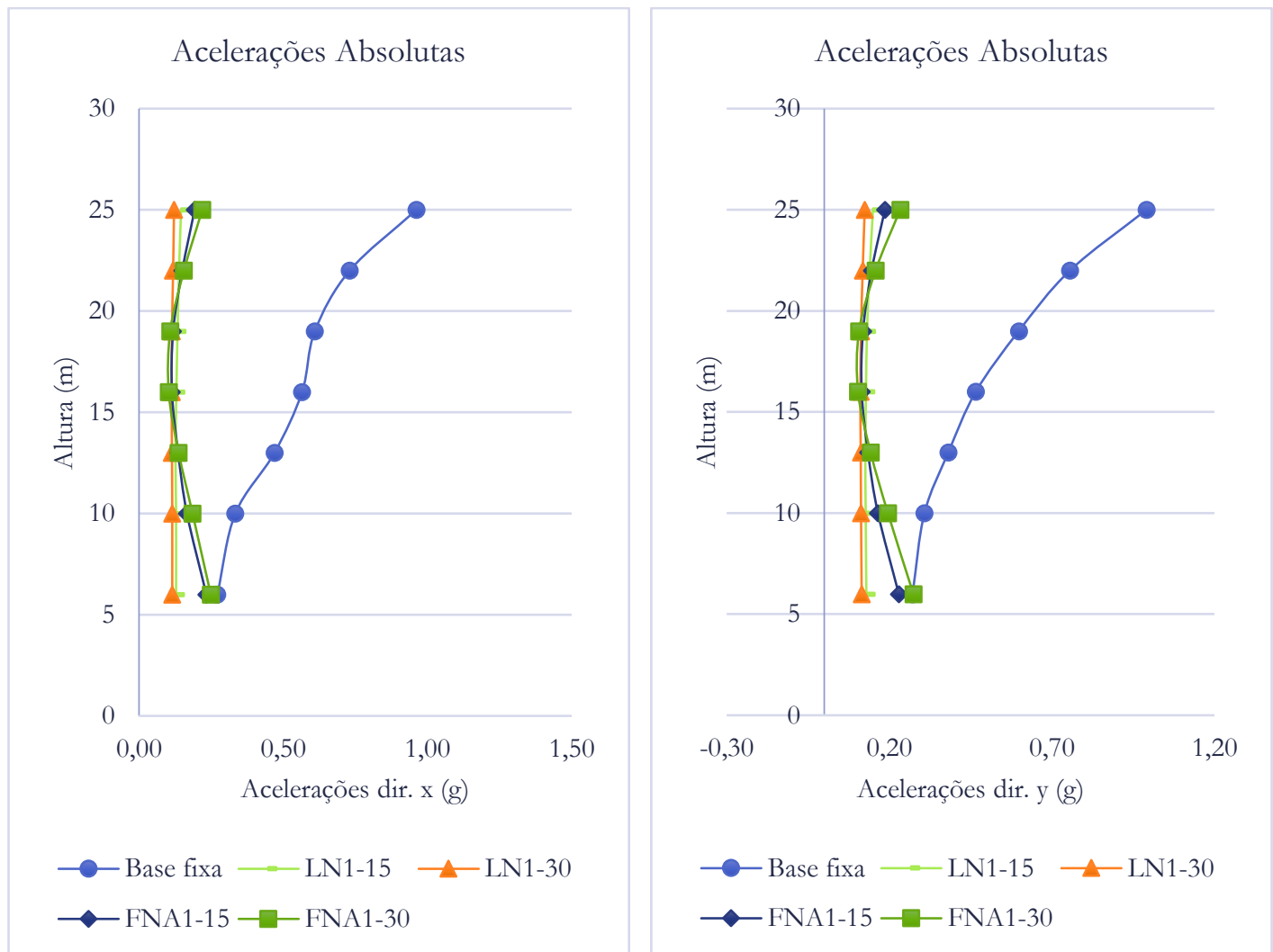

Figura 59: Acelerações - Modelo 1A. Fonte: autor.

Nota-se que as análises linearizadas devolvem resultados mais lineares, enquanto as bilineares apresentam acelerações maiores nos pavimentos extremos da estrutura e acelerações menores nos pavimentos intermediários. Para os dois casos, no entanto, as acelerações capturadas são bastante inferiores às máximas apresentadas pela análise com base fixa, conforme se esperava alcançar com a aplicação do sistema de isolamento.

Em geral, as estruturas são dimensionadas para as máximas intensidades sísmicas de projeto de uma determinada região; no entanto, muitas vezes essas estruturas são submetidas a acelerações sísmicas consideravelmente inferiores às máximas de projeto. Logo, manifesta-se o interesse em saber se dispositivos isoladores dimensionados para intensidades sísmicas mais altas teriam um desempenho coerente mesmo quando submetidos a intensidades inferiores às de projeto. Nessa intenção, dois novos isoladores LN2-15 e FNA2-15 - foram dimensionados utilizando os mesmos critérios e métodos adotados para dimensionar os isoladores LN1-15 e FNA1-15; entretanto, neste dimensionamento considerou-se um espectro de resposta para uma aceleração característica de 0,4g em terreno de classificação D. Esses parâmetros, de fato, produzem isoladores com dimensões consideravelmente maiores que as anteriores, em função dos maiores deslocamentos horizontais esperados no nível do isolamento, que consequentemente exigem uma maior altura de elastômero. Em seguida, procedeu-se à 
aplicação de LN2-15 e FNA2-15 no SAP2000, e a Análise 2 foi computada considerando as mesmas intensidades sísmicas da Análise 1, ou seja, aceleração característica de 0,2g em terreno de classificação D. A Tabela 26 apresenta as propriedades dos isoladores implementados na Análise 2.

Tabela 26 - Propriedades do Isolamento para a Análise 2 - FNA2-15. Fonte: autor

\begin{tabular}{|c|c|c|c|c|}
\hline & Isolador tipo 1 & Isolador tipo 2 & Isolador tipo 3 \\
\hline \multirow{6}{*}{ 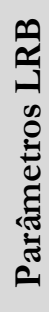 } & $\xi$ & $15 \%$ & $15 \%$ & $15 \%$ \\
\hline & $\mathrm{h}(\mathrm{cm})$ & 60 & 60 & 60 \\
\hline & $\Phi_{L}(\mathrm{~cm})$ & 7,2 & 9,5 & 14 \\
\hline & $\Phi_{\boldsymbol{b}}(\mathrm{cm})$ & 65 & 85 & 120 \\
\hline & $\mathrm{K}_{2}(\mathrm{kN} / \mathrm{m})$ & 264,4 & 452,0 & 899,9 \\
\hline & $\mathrm{Q}(\mathrm{kN})$ & 30,0 & 52,3 & 113,7 \\
\hline \multirow{2}{*}{ Z } & $\mathrm{K}_{e f f}(\mathrm{kN} / \mathrm{m})$ & 339,8 & 583,4 & 1185,1 \\
\hline & $c_{e f f}(\mathrm{kN} . \mathrm{s} / \mathrm{m})$ & 23,6 & 42,2 & 97,1 \\
\hline \multirow{3}{*}{$\underset{Z}{\overleftrightarrow{Z}}$} & $D_{y}(\mathrm{~cm})$ & 0,948 & 0,965 & 1,05 \\
\hline & $\left.\mathrm{K}_{1}(\mathrm{kN} / \mathrm{m})\right)$ & 3437 & 5876 & 11698 \\
\hline & $F_{y}(\mathrm{kN})$ & 32,57 & 56,7 & 123,2 \\
\hline
\end{tabular}

Observa-se que, embora os diâmetros de elastômero e de chumbo sejam expressivamente maiores nestes isoladores, a maior altura $\mathrm{h}$ exigida faz com que os parâmetros de rigidez fiquem bastante próximos aos parâmetros encontrados para a Análise 1. O benefício dos isoladores de maior dimensão reside na maior dissipação de energia derivada dos núcleos de chumbo maiores e, naturalmente, da possibilidade de lidar com deslocamentos superiores no nível do isolamento. Os resultados da Análise 2 estão apresentados a seguir.

Força cortante na base - Análise 2.

Inicialmente, as forças cortantes máximas na base, obtidas da aplicação de LN2-15 e FNA2-15, estão apresentadas na Figura 60 em comparação com a análise FNA1-15 e com o modelo de base fixa. A Figura 61, em seguida, apresenta a distribuição dos esforços cortantes nos pavimentos da estrutura. 

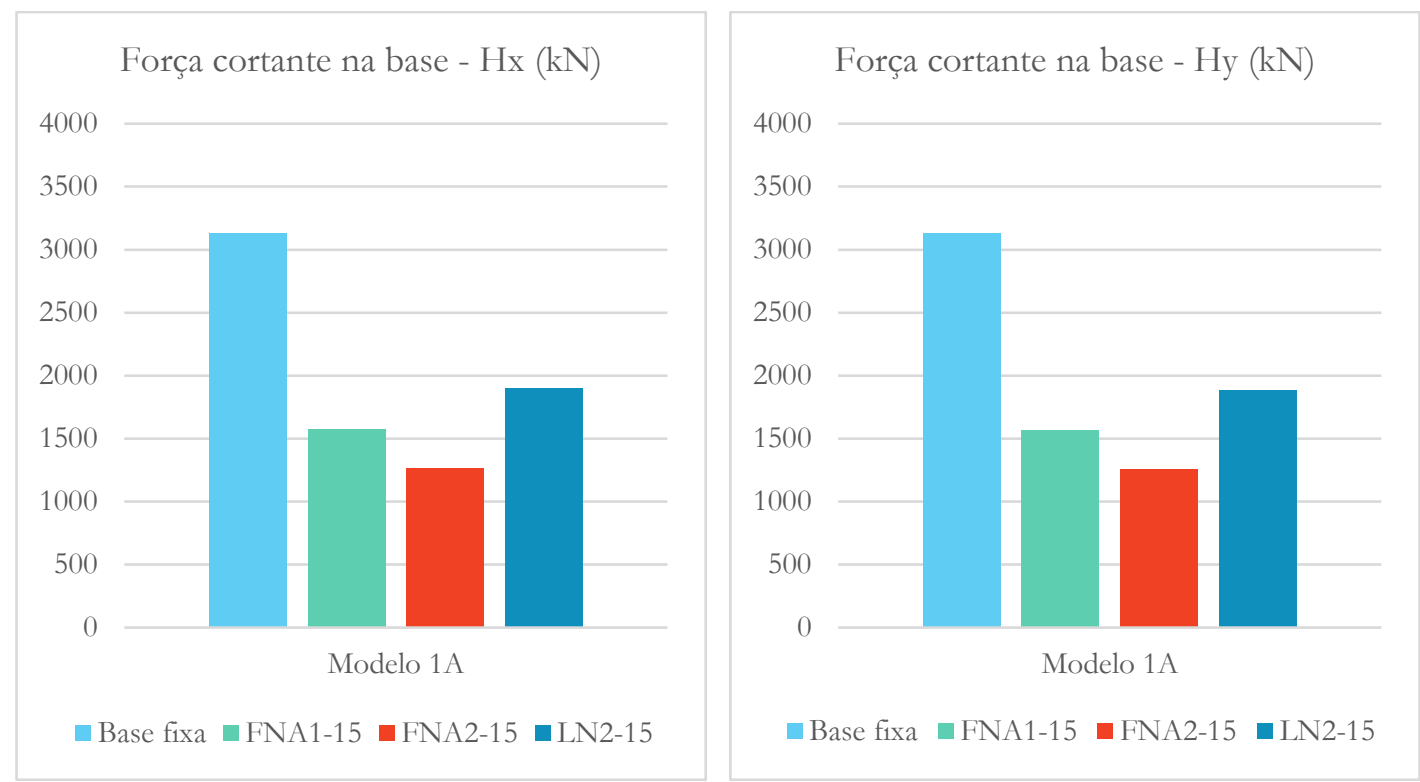

Figura 60: Forças cortantes na base - Hx e $\mathrm{Hy}$ - Análise 2. Fonte: autor.
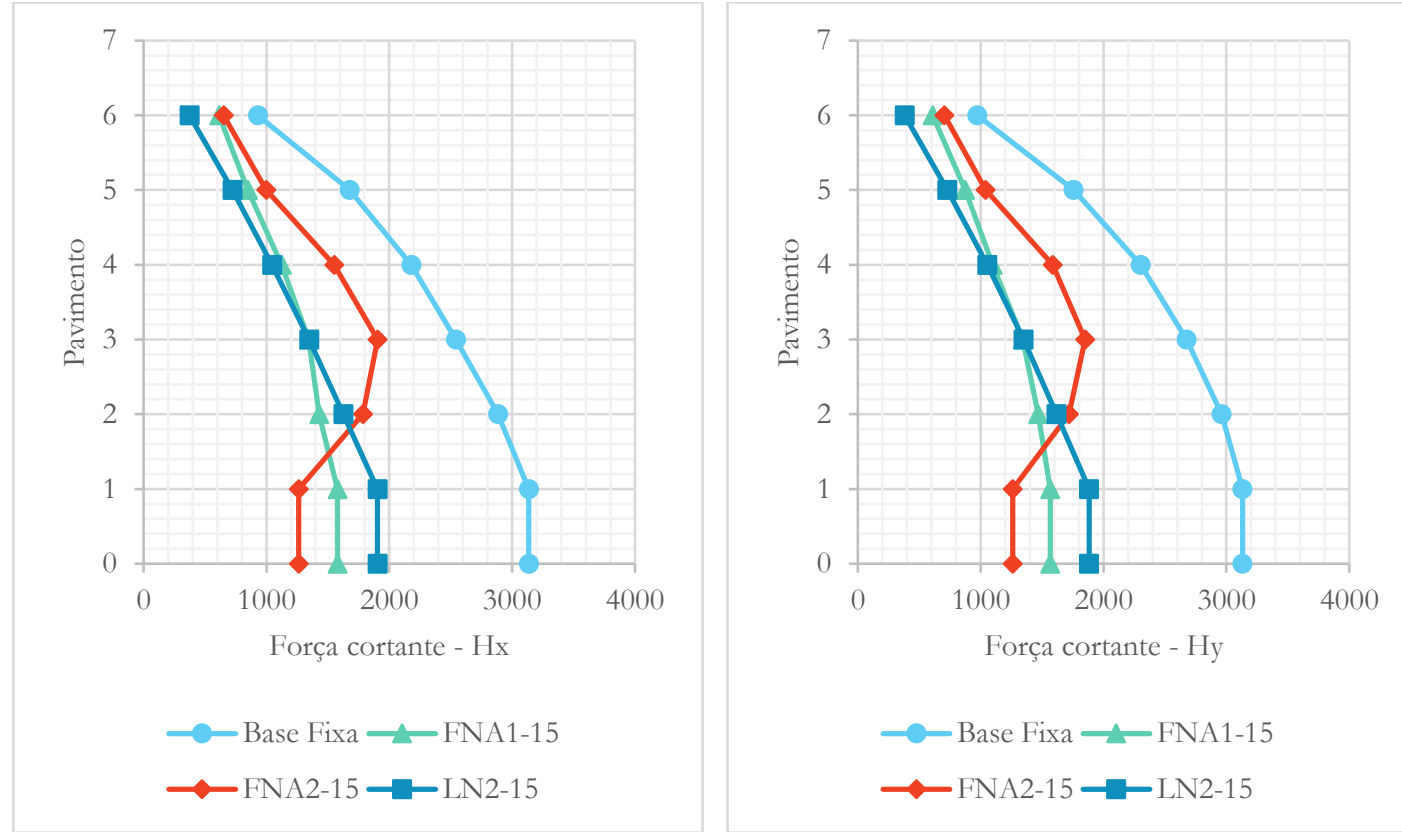

Figura 61: Forças cortantes por pavimento - Hx e Hy - Análise 2. Fonte: autor.

Percebe-se que o comportamento bilinear de isoladores maiores - FNA2-15 - em análises com acelerações características inferiores às de projeto, produzem uma distribuição de esforço cortante com intensidades maiores em pavimentos intermediários do que na base, semelhante ao obtido pelo isolador FNA1-30 na Análise 1. Isso ocorre em função das maiores dimensões do núcleo de chumbo necessárias em FNA2-15, conforme a aplicação do método de dimensionamento do LRB, que se assemelha com as dimensões obtidas para FNA1-30. Como o núcleo de chumbo trabalha baseado fundamentalmente nas deformações por cisalhamento, a altura final do LRB não tem tanta influência em suas 
propriedades, fazendo com que o comportamento de FNA2-15 seja parecido com o comportamento de FNA1-30.

Ainda assim, os máximos esforços cortantes encontrados para a análise FNA2-15 são aproximadamente $40 \%$ inferiores aos encontrados pela análise com base fixa, o que demonstra que o sistema ainda se comporta de forma adequada. A análise linearizada LN2-15 - que neste caso atende a todos os critérios de linearização, também apresentou respostas bem próximas das obtidas pela análise de referência - FNA1-15 - mostrando que mesmo a análise linearizada apresenta comportamento coerente, apesar de não capturar com tanta precisão os esforços cortantes nos pavimentos intermediários.

Deslocamentos e efeitos de segunda ordem - Análise 2.

Os deslocamentos e desvios entre pavimentos obtidos da Análise 2 ficaram muito próximos aos obtidos pela Análise 1, conforme se apresenta na Figura 62 e na Figura 63, mostrando que os deslocamentos sofrem ainda menor influência do que os esforços cortantes, em relação à proporção das dimensões dos isoladores.
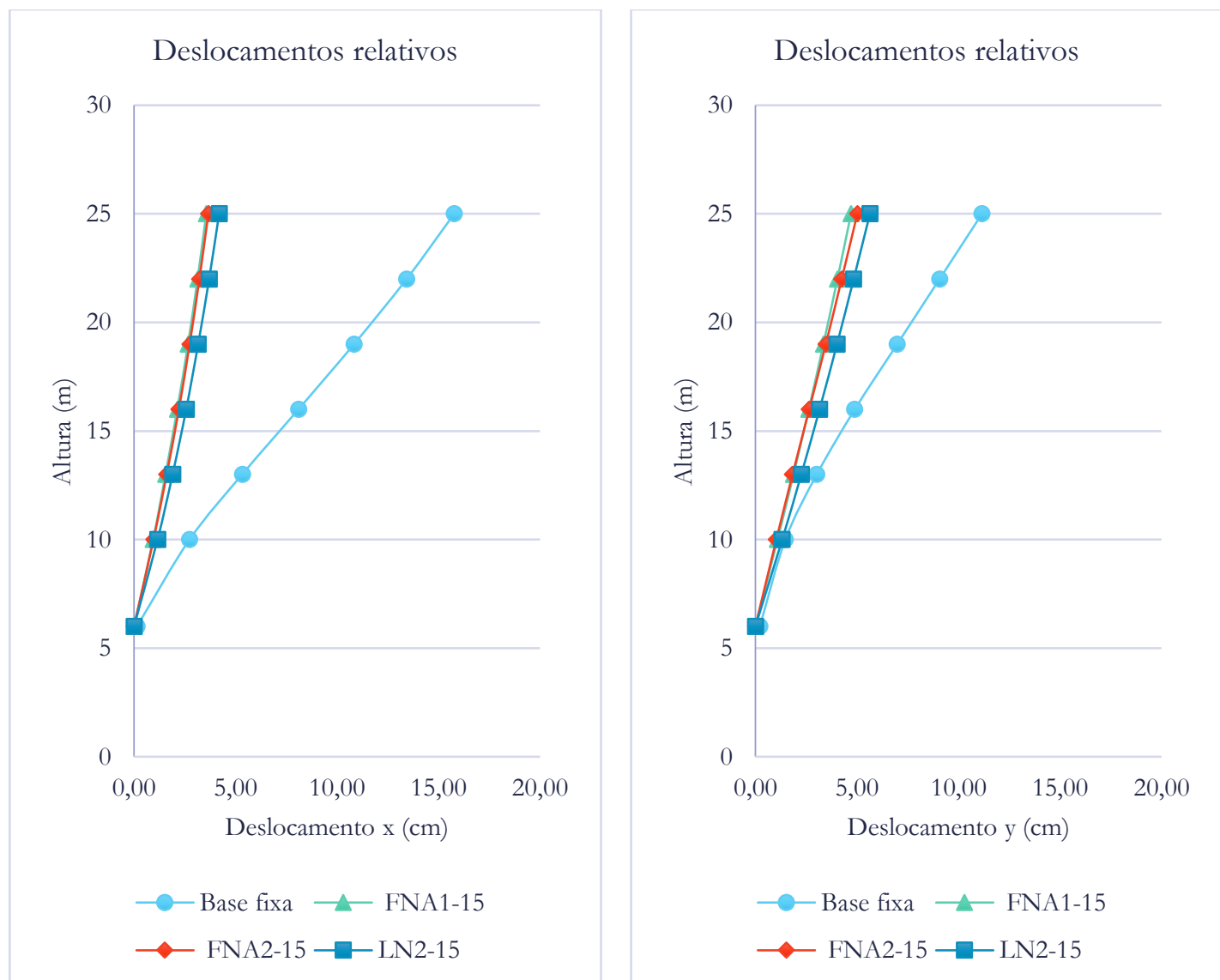

Figura 62: Deslocamentos relativos - Hx e $\mathrm{Hy}$ - Análise 2. Fonte: autor. 

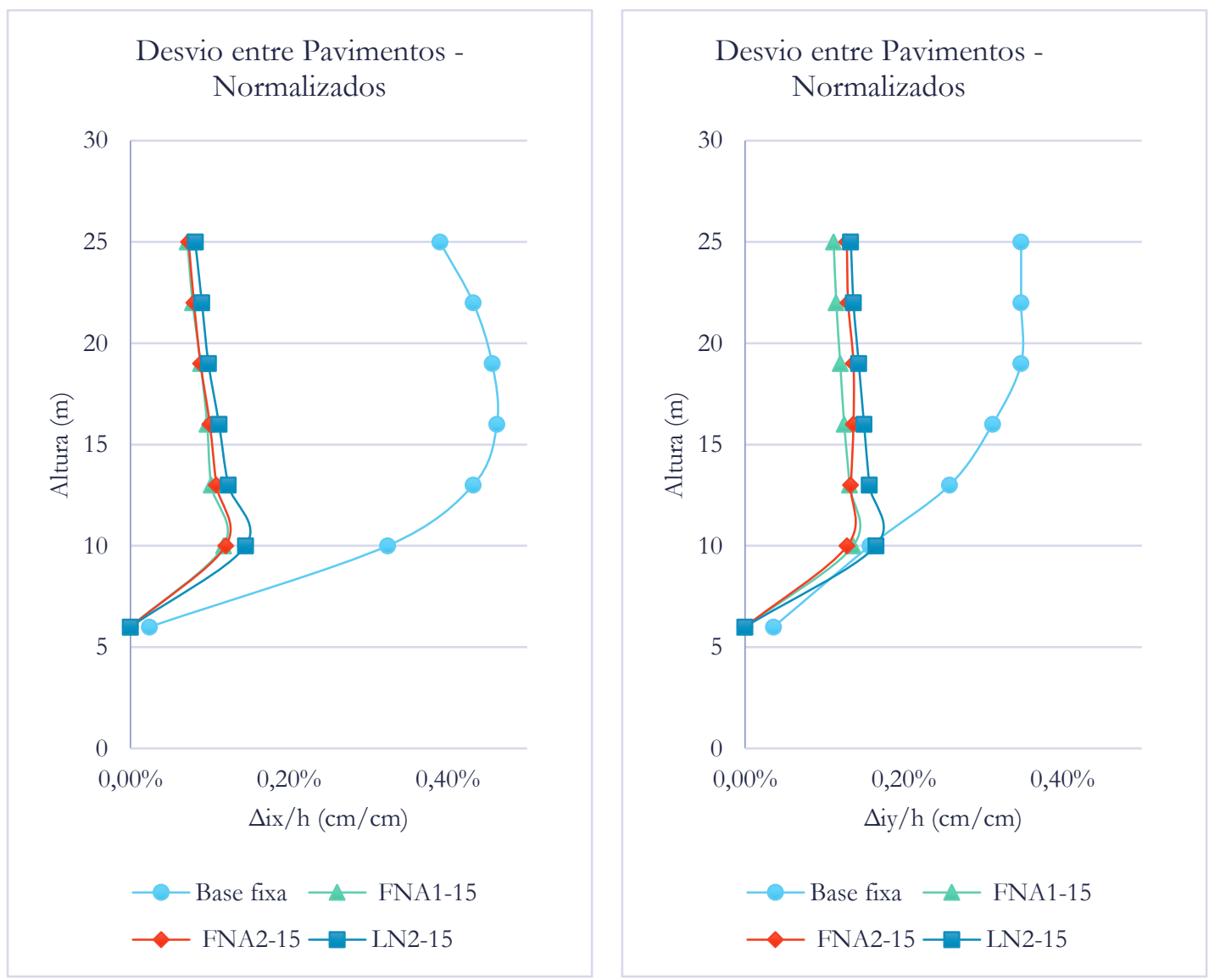

Figura 63: Desvios entre pavimentos - Hx e Hy - Análise 2. Fonte: autor.

Por fim, os parâmetros de estabilidade, apresentados na Figura 64, mostram um comportamento bastante similar ao apresentado na Análise 1, com as respostas de FNA215 bastante próximas das obtidas anteriormente por FNA1-30 e a análise linear com resultados praticamente iguais aos da LN1-15. 

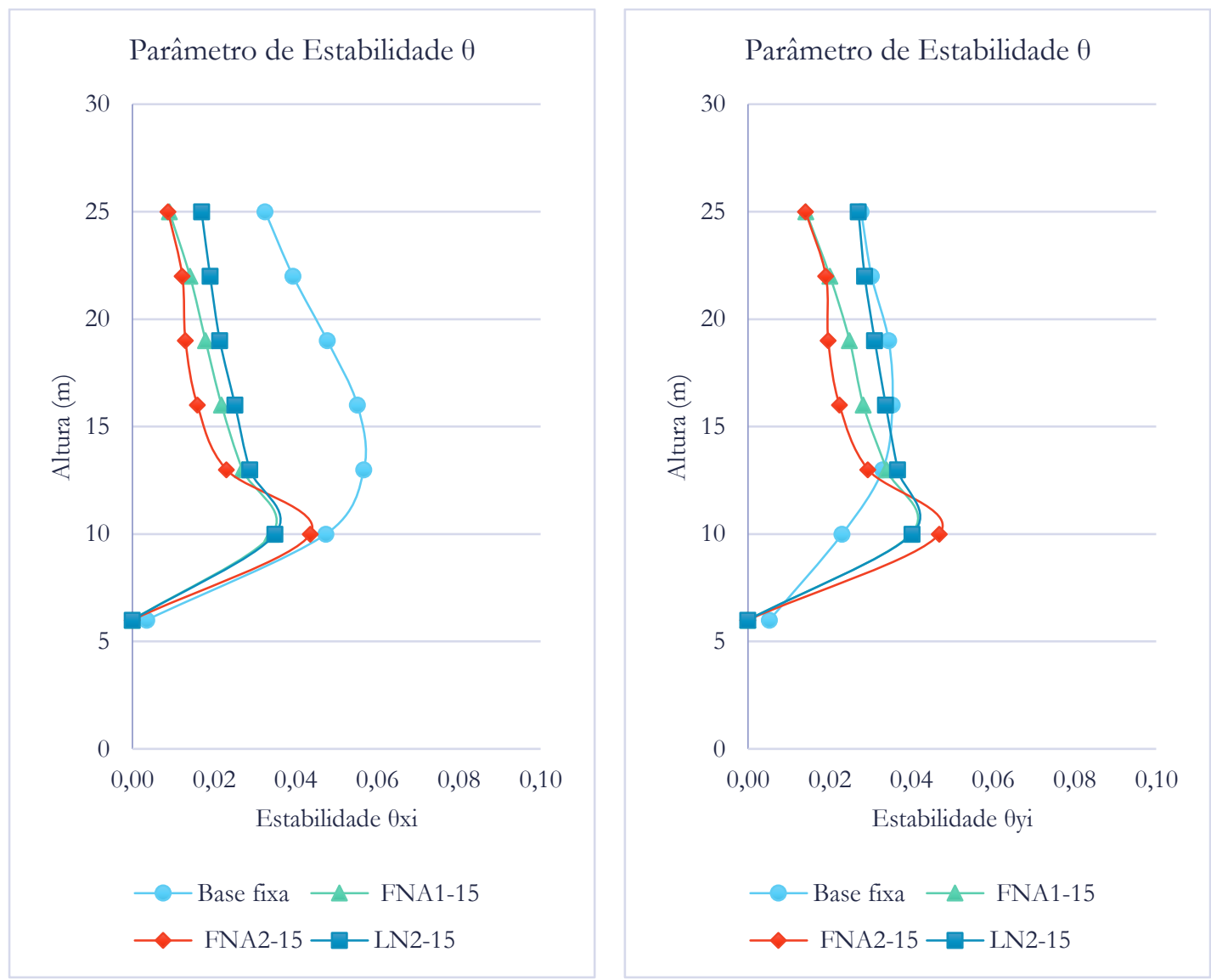

Figura 64: Parâmetro de estabilidade - Análise 2. Fonte: autor.

Esses resultados reafirmam o desempenho adequado deste sistema com isolamento de base, mesmo quando submetido a ações sísmicas menores do que as consideradas no dimensionamento. De fato, as intensidades das respostas são diretamente influenciadas pelas ações sísmicas, entretanto, qualitativamente o comportamento se mostra compatível e adequado, desde que o dimensionamento e as análises não firam os critérios limitantes dos métodos aplicados.

\subsubsection{Análise das taxas de amortecimento}

A ocorrência de esforços cortantes em pavimentos intermediários superiores aos basais, na análise FNA1-30 e FNA2-15, traz o interesse em verificar como ocorrem as distribuições de esforço cortante em função da taxa e do coeficiente de amortecimento adotados no aparelho de isolamento. Portanto, um novo estudo foi realizado, com base na mesma estrutura de $1 \mathrm{~A}$, de modo a permitir verificar o comportamento de diferentes taxas de amortecimento nos isoladores, para uma intensidade sísmica diferente da estudada na Análise 1.

Utilizando os mesmos princípios e critérios aplicados para o estudo com base fixa e para realização da Análise 1, uma Análise 3 foi processada, considerando tanto para o modelo de 
base fixa quanto para os casos com isoladores, uma aceleração característica de $0,5 \mathrm{~g}$ em um terreno de classificação B. Para essa análise, sete novos acelerogramas foram produzidos pelo software Seismoartif, utilizando essas novas características sísmicas, que então foram utilizados para processar as respostas das análises.

Os modelos com base isolada fizeram uso de cinco novos sistemas de isolamento, nomeados de FNA3-10 a FNA3-30, dimensionados pelos mesmos procedimentos adotados para a Análise 1, mas considerando as novas características sísmicas, de forma a obter taxas de amortecimento variando de 10 a 30\% respectivamente, conforme se apresenta na Tabela 27. 
Tabela 27 - Propriedades dos Isolamento - taxas de amortecimento de $10 \%$ a $30 \%$. Fonte: autor

\begin{tabular}{|c|c|c|c|c|c|c|}
\hline \multicolumn{7}{|c|}{ Isolador tipo 1} \\
\hline \multicolumn{2}{|c|}{ Taxa de Amortecimento $\xi$} & $10 \%$ & $15 \%$ & $20 \%$ & $25 \%$ & $30 \%$ \\
\hline \multirow{5}{*}{ 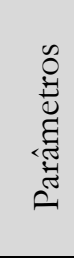 } & $\mathrm{h}(\mathrm{cm})$ & 50 & 50 & 40 & 40 & 40 \\
\hline & $\Phi_{L}(\mathrm{~cm})$ & 5,1 & 6,1 & 7 & 7,2 & 8 \\
\hline & $\Phi_{b}(\mathrm{~cm})$ & 60 & 55 & 50 & 45 & 40 \\
\hline & $\mathrm{K}_{2}(\mathrm{kN} / \mathrm{m})$ & 271,7 & 227,2 & 232,9 & 187,5 & 146,0 \\
\hline & $\mathrm{Q}(\mathrm{kN})$ & 15,09 & 21,58 & 28,42 & 30,07 & 37,12 \\
\hline \multirow{2}{*}{ Z } & $\mathrm{K}_{\text {eff }}(\mathrm{kN} / \mathrm{m})$ & 319,0 & 301,8 & 342,6 & 313,3 & 315,3 \\
\hline & $c_{e f f}(\mathrm{kN} . \mathrm{s} / \mathrm{m})$ & 11,2 & 26,1 & 39,3 & 49,3 & 66,9 \\
\hline \multirow{3}{*}{$\underset{Z}{Z}$} & $D_{y}(\mathrm{~cm})$ & 0,00463 & 0,00792 & 0,01017 & 0,01336 & 0,02119 \\
\hline & $\left.\mathrm{K}_{1}(\mathrm{kN} / \mathrm{m})\right)$ & 3532,3 & 2953,0 & 3028,0 & 2437,7 & 1897,6 \\
\hline & $\mathrm{h}(\mathrm{cm})$ & 16,3 & 23,4 & 30,8 & 32,6 & 40,2 \\
\hline \multicolumn{7}{|c|}{ Isolador tipo 2} \\
\hline \multicolumn{2}{|c|}{ Taxa de Amortecimento $\xi$} & $10 \%$ & $15 \%$ & $20 \%$ & $25 \%$ & $30 \%$ \\
\hline \multirow{5}{*}{ 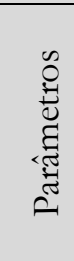 } & $\mathrm{h}(\mathrm{cm})$ & 50 & 50 & 40 & 40 & 40 \\
\hline & $\Phi_{L}(\mathrm{~cm})$ & 7,2 & 8,3 & 9 & 9,5 & 10 \\
\hline & $\Phi_{b}(\mathrm{~cm})$ & 80 & 75 & 65 & 62 & 55 \\
\hline & $\mathrm{K}_{2}(\mathrm{kN} / \mathrm{m})$ & 482,6 & 422,4 & 393,8 & 356,7 & 278,0 \\
\hline & $\mathrm{Q}(\mathrm{kN})$ & 30,07 & 39,96 & 46,98 & 52,34 & 58,00 \\
\hline \multirow{2}{*}{ 贡 } & $\mathrm{K}_{\text {eff }}(\mathrm{kN} / \mathrm{m})$ & 576,9 & 560,7 & 575,2 & 575,6 & 542,6 \\
\hline & $c_{e f f}(\mathrm{kN.s} / \mathrm{m})$ & 24,5 & 47,3 & 66,7 & 83,8 & 106,8 \\
\hline \multirow{3}{*}{$\mathbb{Z}_{I}$} & $D_{y}(\mathrm{~cm})$ & 0,00519 & 0,00788 & 0,00994 & 0,01223 & 0,01739 \\
\hline & $\left.\mathrm{K}_{1}(\mathrm{kN} / \mathrm{m})\right)$ & 6274,2 & 5491,4 & 5119,6 & 4637,5 & 3613,6 \\
\hline & $\mathrm{h}(\mathrm{cm})$ & 32,6 & 43,3 & 50,9 & 56,7 & 62,8 \\
\hline \multicolumn{7}{|c|}{ Isolador tipo 3} \\
\hline \multicolumn{2}{|c|}{ Taxa de Amortecimento $\xi$} & $10 \%$ & $15 \%$ & $20 \%$ & $25 \%$ & $30 \%$ \\
\hline \multirow{5}{*}{ 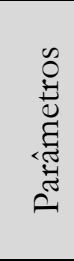 } & $\mathrm{h}(\mathrm{cm})$ & 50 & 50 & 40 & 40 & 40 \\
\hline & $\Phi_{L}(\mathrm{~cm})$ & 10 & 12 & 13 & 14 & 15 \\
\hline & $\Phi_{b}(\mathrm{~cm})$ & 115 & 110 & 90 & 90 & 80 \\
\hline & $\mathrm{K}_{2}(\mathrm{kN} / \mathrm{m})$ & 997,8 & 909,0 & 753,7 & 751,1 & 586,8 \\
\hline & $\mathrm{Q}(\mathrm{kN})$ & 58,00 & 83,52 & 98,02 & 113,68 & 130,50 \\
\hline \multirow{2}{*}{ Z } & $\mathrm{K}_{\text {eff }}(\mathrm{kN} / \mathrm{m})$ & 1179,8 & 1198,0 & 1132,1 & 1226,5 & 1182,2 \\
\hline & $c_{e f f}(\mathrm{kN} . \mathrm{s} / \mathrm{m})$ & 45,6 & 98,0 & 147,3 & 183,0 & 238,1 \\
\hline \multirow{3}{*}{$\underset{Z}{\breve{Z}}$} & $D_{y}(\mathrm{~cm})$ & 0,00484 & 0,00766 & 0,01084 & 0,01261 & 0,01853 \\
\hline & $\left.\mathrm{K}_{1}(\mathrm{kN} / \mathrm{m})\right)$ & 12972,0 & 11816,7 & 9798,2 & 9764,8 & 7628,8 \\
\hline & $\mathrm{h}(\mathrm{cm})$ & 62,8 & 90,5 & 106,2 & 123,2 & 141,4 \\
\hline
\end{tabular}


A seguir, apresentam-se os comparativos dos resultados encontrados para as cinco condições de isolamento propostas, permitindo verificar como a distribuição de esforços cortantes ocorre no modelo do estudo de caso, além da influência que a modificação dos parâmetros dos LRB produz tanto nos esforços como nos deslocamentos da estrutura.

Força cortante por pavimento - Análise 3.

As distribuições de esforço cortante obtidas das análises estão ilustradas na Figura 65 e na Figura 66.

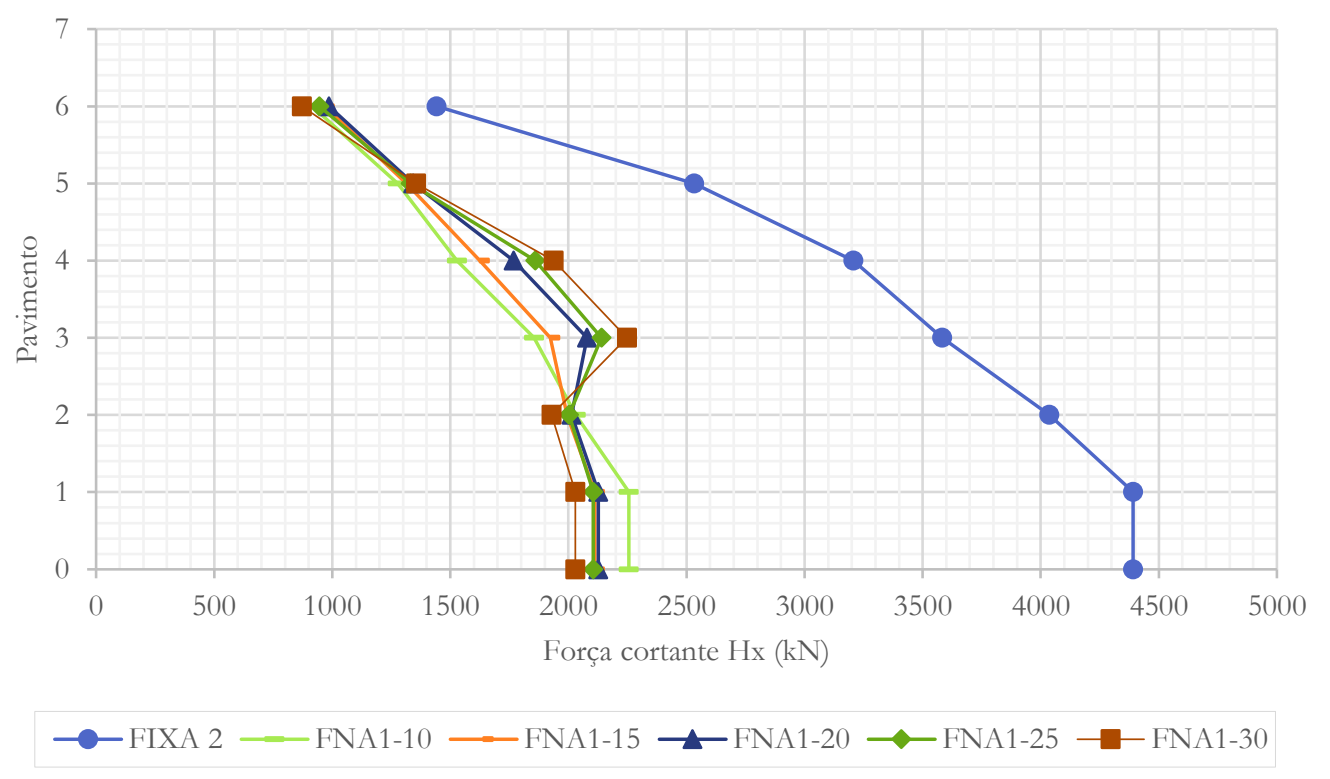

Figura 65: Distribuição de força cortante em $x$ - Análise 3. Fonte: autor.

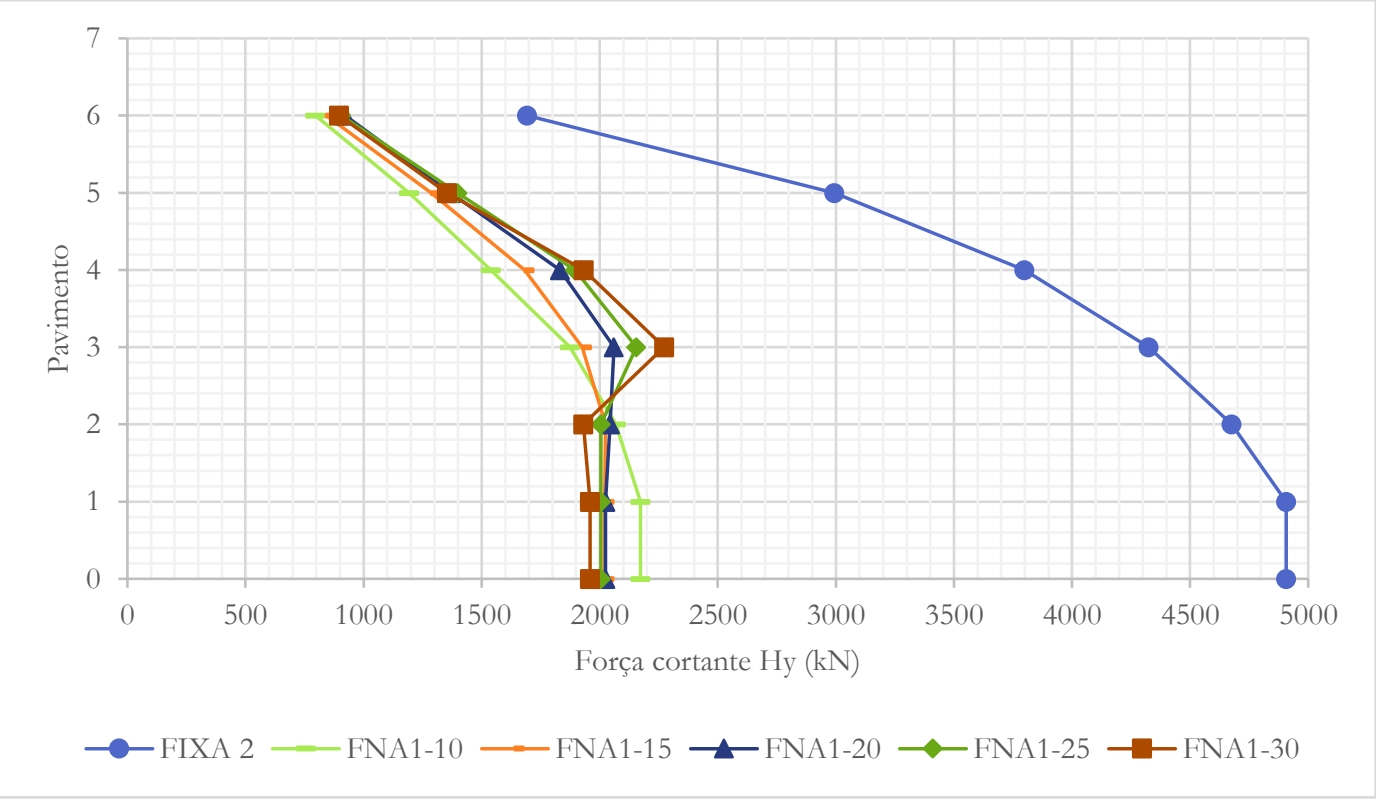

Figura 66: Distribuição de força cortante em y - Análise 3. Fonte: autor. 
Inicialmente, nota-se que para a direção y, foi possível obter reduções de até $60 \%$ nos máximos esforços cortantes na base da estrutura, em relação ao modelo com base fixa. $\mathrm{Na}$ direção x, foi obtida uma proporção de redução de aproximadamente $50 \%$, próxima das obtidas nas análises anteriores.

Em seguida, podemos notar que até uma taxa de amortecimento próxima de $20 \%$ nos isoladores, os esforços cortantes são máximos na base da estrutura e vão decaindo nos pavimentos superiores, assim como ocorre para o modelo com base fixa. Já para taxas superiores a $20 \%$, alguns pavimentos superiores apresentam valores de esforço cortante superiores aos apresentados em pavimentos inferiores. Inclusive, os máximos esforços cortantes obtidos para as análises com taxas de amortecimento de 25\% e 30\% chegam a superar os maiores esforços apresentados na análise com taxa de $20 \%$, mostrando que essas taxas mais elevadas podem inclusive prejudicar o comportamento estrutural.

Deslocamentos e efeitos de segunda ordem - Análise 3.

A análise dos deslocamentos relativos, desvios entre pavimentos e parâmetro de estabilidade, apresentados respectivamente na Figura 67, Figura 68 e Figura 69, permite concluir que não existe uma grande vantagem em utilizar taxas de amortecimento superiores a $20 \%$, uma vez que, para o modelo analisado, as taxas de 15 a $20 \%$ já produzem as maiores reduções nos esforços cortantes, enquanto geram resultados bastante satisfatórios em termos de deslocamentos. Ou seja, taxas de amortecimento maiores podem produzir esforços cortantes maiores na estrutura, ao mesmo tempo em que não trazem praticamente nenhuma vantagem em relação aos deslocamentos. 

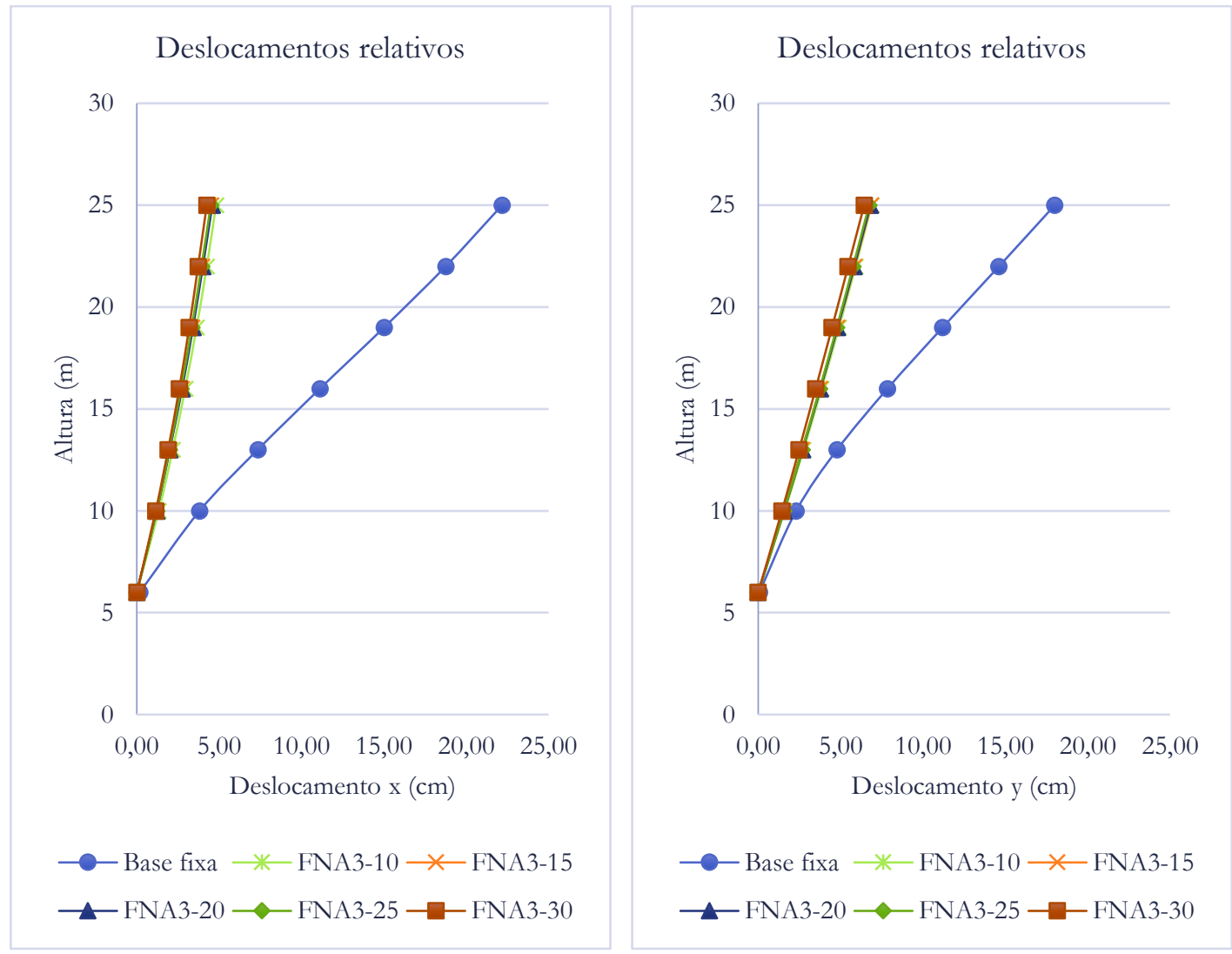

Figura 67: Deslocamentos Relativos - Análise 3. Fonte: autor.
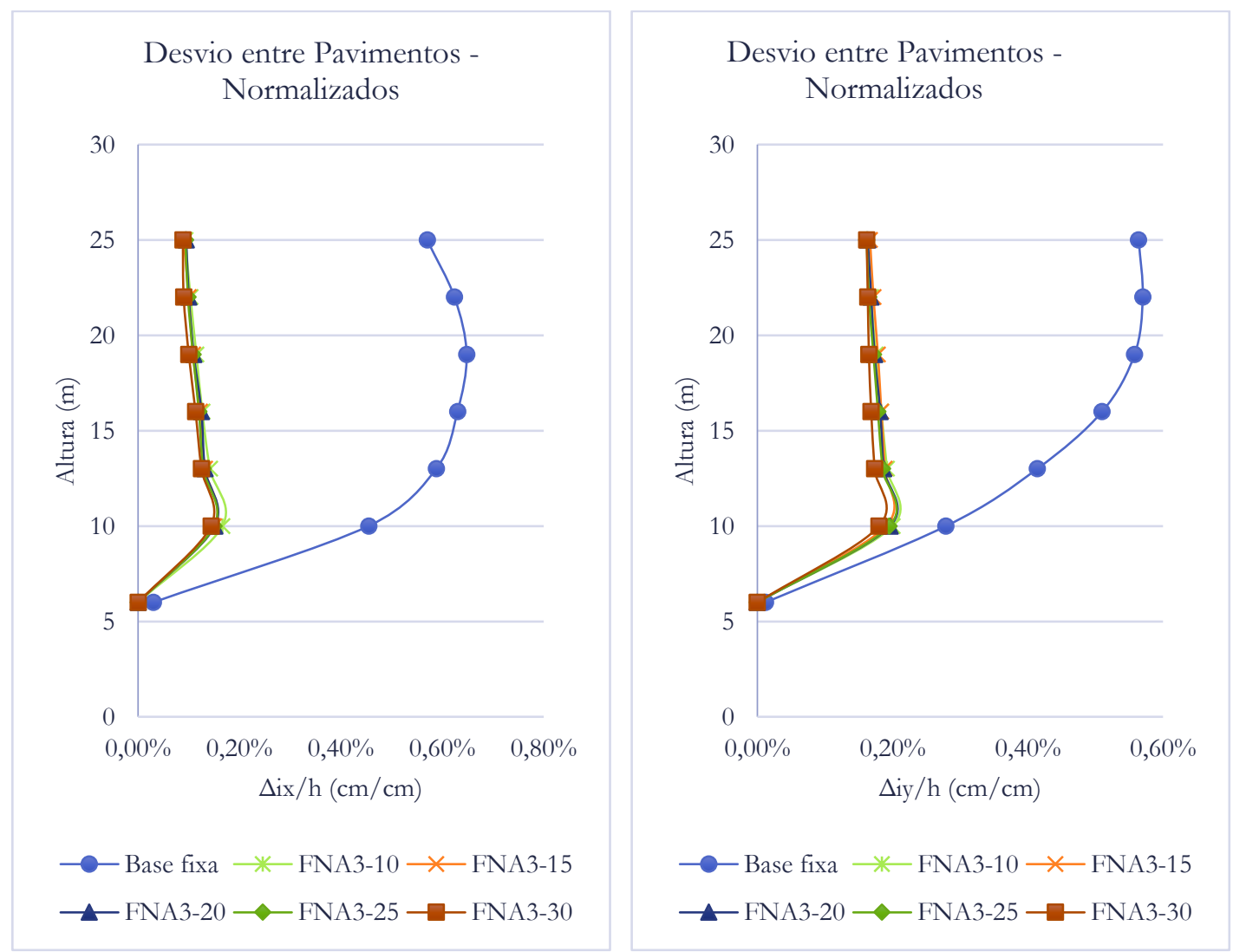

Figura 68: Desvio entre pavimentos - Análise 3. Fonte: autor. 

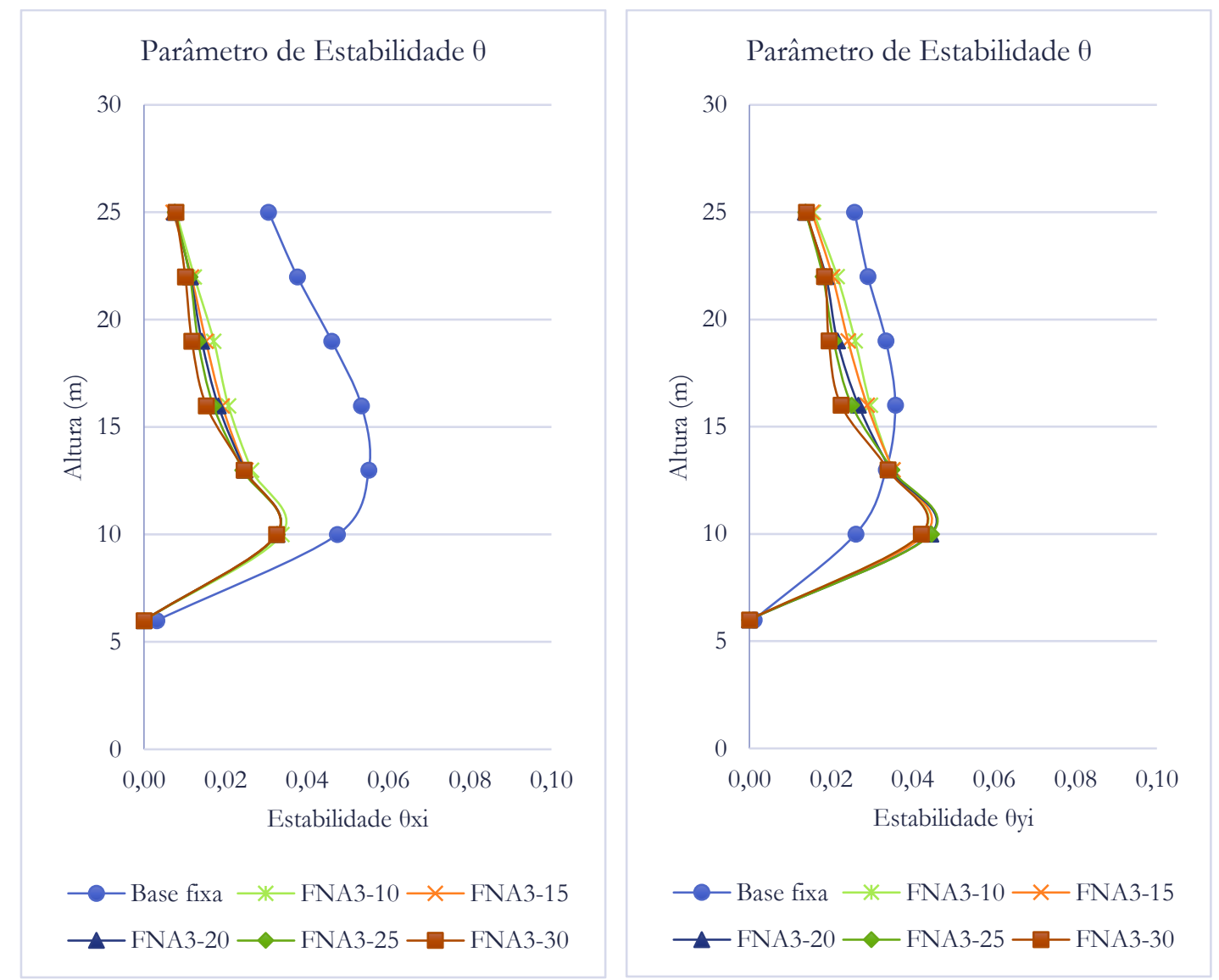

Figura 69: Parâmetro de estabilidade - Análise 3. Fonte: autor.

$\mathrm{Na}$ Figura 68 observa-se que, para esta intensidade de ações sísmicas, as deformações na estrutura com base fixa superam os critérios de limitação de danos propostos na expressão (5.1), indicando que a estrutura já iria apresentar alguns danos estruturais, além de danos não estruturais significativos. Já para os casos com isolamento de base, as deformações se mostram muito reduzidas, atendendo facilmente aos critérios mais severos de limitação de danos, indicando que a estrutura estaria em perfeitas condições após o evento sísmico.

Esta comprovação representa outra das grandes vantagens da aplicação do sistema de isolamento, onde a manutenção estrutural após um evento sísmico fica quase que restrita ao sistema de isolamento, além de permitir que estruturas essenciais, como hospitais e quarteis, continuem em perfeita operação mesmo que imediatamente após o evento sísmico. 


\section{CONCLUSÕES}

Este trabalho apresentou alguns dos conceitos e metodologias mais eficientes e práticos para aplicações em análises sísmicas de edificações. Os resultados obtidos pela aplicação destes métodos, em um modelo estrutural específico, foram comparados permitindo compreender as diferenças, dificuldades e melhorias que um método possui em relação aos demais.

Uma abordagem geral da implementação do isolamento sísmico de base também foi feita, apresentando as características, limitações e diferenças deste conceito em relação ao método tradicional de análise com base fixa. Foram indicados alguns tipos de isoladores de base aplicados na atualidade, realizando-se em seguida um estudo mais aprofundado do dispositivo LRB, para o qual se ilustrou o método de dimensionamento e sua implementação na análise computacional do modelo estrutural adotado.

Os resultados obtidos das análises com isolamento de base foram comparados com os da análise com base fixa, permitindo compreender as vantagens deste método em relação ao tradicional.

\subsection{QUANTO AO COMPARATIVO ENTRE MÉTODOS}

Da análise comparativa entre métodos, as seguintes conclusões puderam ser extraídas:

Para um edifício com geometria e comportamento regulares, foi possível obter resultados aceitáveis pelos três métodos de análise propostos, nomeadamente o MFE, MER e MHT. Entretanto, os métodos dinâmicos MER e MHT são, de fato, intrinsecamente mais coerentes para este tipo de aplicação, uma vez que o sismo imprime um carregamento dinâmico na estrutura, sendo essencial a devida consideração dos decorrentes efeitos inerciais, bem como dos decorrentes do amortecimento da estrutura e dos isoladores.

Apesar disso, o MFE é o método padrão definido pela norma brasileira. Ele é proposto na intenção de requerer uma implementação simplificada e de responder com valores usualmente mais conservadores em termos de esforços estruturais, em relação aos demais métodos de análise, muito embora, em alguns casos, essa expectativa possa não se garantir, como se verificou no estudo de caso. Além disso, o MFE possui uma série de limitações em relação à regularidade da edificação e somente é recomendado para estruturas em que as respostas dos modos de vibração superiores ao fundamental não tenham muita influência. 
A aplicação do MFE considerando as simplificações normativas para obtenção do período fundamental da estrutura pode trazer resultados bastante díspares dos obtidos pelas análises dinâmicas. Assim, faz-se necessário aplicar uma análise modal da estrutura previamente à aplicação do MFE. Essa necessidade faz o custo computacional e complexidade da aplicação do método ficar muito próxima da aplicação do MER, que é um método de análise dinâmica e, portanto, muito mais fidedigno à aplicação em questão.

A maior diferença entre a aplicação do MER e do MHT, em análises lineares, está na geração dos acelerogramas para utilização do último. Entretanto, existem softwares específicos que auxiliam na obtenção desses acelerogramas, tornando a tarefa bastante rápida. O mesmo ocorre para o tempo de processamento dos métodos dinâmicos, que, podendo contar com o desenvolvimento computacional atual, são bastante reduzidos e de fácil aplicação. De fato, o MER é válido somente para análises lineares, enquanto o MHT pode ser implementado, também, em análises não lineares. Em relação aos resultados, as maiores diferenças entre o MER e o MHT foram encontradas proporcionalmente à diferença apresentada entre o espectro de resposta da norma e o espectro de resposta da média dos acelerogramas utilizados, mostrando que os dois métodos possuem uma comparação muito boa de resultados para análises lineares, com superposição modal, desde que a diferença entre o período de dois modos de vibração adjacentes seja superior a $10 \%$.

Com isso, conclui-se que os métodos dinâmicos são mais eficientes e possuem um acréscimo de complexidade e custo computacional mínimo em relação ao método das forças laterais equivalentes, podendo substituí-lo em praticamente todas as situações com vantagens.

\subsection{COMENTÁRIOS QUANTO À UTILIZAÇÃO DO ISOLAMENTO DE BASE}

A técnica de isolamento sísmico de edificações ainda não é tão difundida e estudada em âmbito nacional, fato que de certa forma é justificado pela falta de proximidade com tais eventos no Brasil. Contudo, essa técnica já tem sido utilizada há bastante tempo em alguns países, apresentando resultados bastante satisfatórios, o que evidencia que, em projetos internacionais, onde as acelerações sísmicas desempenham um papel expressivo, o isolamento de base deva ser considerado como uma alternativa válida e segura para garantir um comportamento estruturalmente adequado.

Neste trabalho, após dissertar resumidamente sobre os diversos sistemas de isolamentos de base, procedeu-se ao dimensionamento detalhado do dispositivo do tipo LRB. Esse tipo de 
isolamento de base possui um comportamento histerético bilinear, que pode ser aplicado diretamente na análise computacional ou a partir de parâmetros linearizados.

O dimensionamento do LRB não é muito complexo, mas por vezes carece de um processo iterativo, tanto para a definição de suas propriedades como para validação das respostas obtidas após a análise linearizada. Ainda assim, com auxílio de softwares de processamento de dados, como o Microsoft Excel, é possível chegar a um projeto adequado após poucas iterações, atingindo um nível satisfatório de convergência.

O comparativo das análises com isolamento mostra que a flexibilização horizontal, garantida pelos dispositivos de isolamento, faz com que a estrutura absorva acelerações de origem sísmica bastante reduzidas. Consequentemente, para o modelo adotado, foi possível obter uma redução nos esforços cortantes máximos na estrutura da ordem de 50 a 60\% em relação às análises com base fixa. Em termos de deslocamentos relativos, as reduções são ainda mais expressivas, com a superestrutura sobre o isolamento atuando de forma semelhante a um corpo rígido, podendo atingir reduções superiores a 70\%. Essas características permitiram verificar que, em intensidades sísmicas com aceleração característica de $0,5 \mathrm{~g}$ e terreno de classificação $\mathrm{B}$, o modelo estudado com base fixa sofreria grandes danos não estruturais e danos estruturais leves a moderados, enquanto o modelo com isolamento de base estaria em perfeitas condições de operação logo em seguida ao evento sísmico, confirmando a expectativa de que estruturas com isolamento possuem um desempenho superior.

Foi observado que mesmo isoladores dimensionados para sismo de intensidades superiores possuem comportamento adequado quando a estrutura é excitada por sismos de intensidades menores, mostrando que o sistema é robusto.

Com respeito ao amortecimento, mostrou-se que a adoção de taxas muito elevadas pode excitar modos de vibração superiores ao fundamental, de tal modo que os esforços cortantes basais deixam de ser os mais críticos para a estrutura.

Duas implementações do LRB, a linearizada e a bilinear, foram estudadas. Notou-se que as respostas linearizadas tendem a ser um pouco mais conservadoras em relação às respostas da análise bilinear. Além disso, algumas limitações são impostas para os dispositivos lineares equivalentes, que, quando não respeitadas, podem levar a resultados que não modelam corretamente os esforços cortantes nos modos superiores ao fundamental, resultando em esforços inferiores e, portanto, menos seguros. Essas restrições usualmente limitam o diâmetro do núcleo de chumbo permitido, que consequentemente reduz a 
quantidade de amortecimento do dispositivo. Entretanto, a Análise 3 do estudo de caso mostra que taxas de amortecimento superiores a 20\% acabam gerando ganhos muito pequenos em deslocamentos, enquanto produzem esforços na estrutura que podem superar os obtidos por sistemas com amortecimento inferior a $20 \%$.

Assim, conclui-se que, em geral, a maioria dos dispositivos LRB otimizados podem ser analisados como lineares equivalentes, embora análises do tipo FNA, que considerem seu comportamento bilinear, produzam resultados melhores e capturem de maneira mais fidedigna as respostas estruturais do conjunto.

\subsection{SUGESTÕES PARA ESTUDOS FUTUROS}

Os resultados obtidos no estudo de caso deste trabalho podem, guardadas as devidas proporções, serem extrapolados para alguns outros sistemas estruturais semelhantes; entretanto, novos estudos considerando outras tipologias de edificações são importantes para avaliar o comportamento do isolamento de base em uma gama mais ampla de situações. Edifícios envolvendo outros materiais, como estruturas metálicas e prémoldadas, ou edificações com uma ou múltiplas irregularidades geométricas em planta ou em altura, ou mesmo edificações regulares com períodos fundamentais em base fixa significativamente diferentes dos considerados neste trabalho são alguns dos exemplos que podem contribuir para a extensão dos dados pesquisados.

Estruturas muito altas, que em geral também possuem períodos naturais mais elevados, podem sofrer ações de vento mais desfavoráveis do que algumas ações sísmicas; assim, estudos envolvendo a eficiência do isolamento de base nesses casos, em comparação com seu desempenho frente a carregamentos de vento severos, também são importantes para verificar novos potenciais ou riscos circunstanciais na sua utilização.

Nesta pesquisa, não foram consideradas as ações sísmicas verticais; portanto, estudos que avaliem as respostas de estruturas com isolamento, frente a ações sísmicas horizontais e verticais, podem ser interessantes para verificar a influência que as ações verticais podem ter nas respostas estruturais finais.

Aumentando a complexidade, novos estudos que proponham o comparativo entre estruturas com base fixa e isolada, em análises que considerem propriamente as não linearidades físicas e geométricas de toda a estrutura, bem como a calibração dos modelos não lineares para este tipo de aplicação, podem contribuir para uma compreensão ainda mais ampla dos resultados obtidos nesta pesquisa. 


\section{REFERÊNCIAS BIBLIOGRÁFICAS}

1. ACAR, Emre. Comparison of design specifications for seismically isolated buildings. 103 f. Tese (Doutorado) - Curso de Engenharia Civil, Middle East Technical University, Oriente Médio, 2006.

2. AMERICAN CONCRETE INSTITUTE. ACI 318: Building Code Requirements for Structural Concrete. 11 ed. Farmington Hills, 2011. 503 p.

3. AMERICAN NATIONAL STANDARDS INSTITUTE. ASCE/SEI 7: Minimum design loads for buildings and other structures. 16. Virginia: Structural Engineering Institute, 2016.

4. ARAI, Ana. Estudo comparativo de normas de projetos de estruturas resistentes a sismos. 92 f. Dissertação (Mestrado) - Curso de Estruturas, Universidade Federal do Rio de Janeiro, Rio de Janeiro, 2013.

5. ASSOCIAÇÃO BRASILEIRA DE NORMAS TÉCNICAS. NBR 15421: Projeto de estruturas resistentes a sismos - procedimentos. 1 ed. Rio de Janeiro: 2006.

6. BISCH, P.; CARVALHO, E.; DEGEE, H.; FARDIS, M.; FRANCHIN, P.; KRESLIN, M.; PECKER, A. Eurocode 8: Seismic Design of Buildings Worked examples. Ispra: Jrc, 2011.

7. CALIÒ, Ivo; MARLETTA, M.; VINCIPROVA, F. Seismic response of multistorey buildings base-isolated by friction devices with restoring properties. Computers and Structures 81. [s. L.], p. 2589-2599. jul. 2003.

8. CALUGARU, Vladimir. Earthquake Resilient Tall Reinforced Concrete Buildings at Near-Fault Sites Using Base Isolation and Rocking Core Walls. 100 f. Tese (Doutorado) - Curso de Engenharia Civil, University Of California, Berkeley, 2013.

9. CANCELLARA, D.; ANGELIS, F. de. A base isolation system for structures subject to extreme seismic events characterized by anomalous values of intensity and frequency content. Composite Structures 157. [s. L.], p. 285-302. set. 2016.

10. CHOPRA, Anil K. Dynamics of structures: Theory and applications to earthquake engineering. 4. ed. Upper Saddle River: Prentice Hall, 1995.

11. CLOUGH, Ray W; PENZIEN, Joseph. Dynamics of structures. 3. ed. Estados Unidos: Computers \& Structures, 2003. 
12. EISENBERGER, M.; RUTENBERG, A.. Seismic base isolation of asymmetric shear buildings. Engineering Structure 8. [s. L.], p. 2-8. ago. 1986.

13. EUROCODE 8. EN 1998-1: Design of structures for earthquake resistance general rules, seismic actions and rules for buildings. Commission of the European Community, 2005.

14. FARDIS, Michael N.; CARVALHO, E. C.; FAJFAR, P.; PECKER, A. Seismic design of concrete buildings to Eurocode 8. Londres: Crc Press, 2015.

15. FARISSI, Amroyni et al. Design and Analysis of Base Isolated Structures. Bandung Institute Of Technology. Indonésia, p. 1-12. jul. 2013. Disponível em: <https://www.researchgate.net/publication/258630935>. Acesso em: 15 fev. 2018.

16. FIGUEIREDO, Filipe Ribeiro de. Isolamento Sísmico de Base: Dimensionamento de Sistemas de Isolamento de Base em Edifícios. 108 f. Dissertação (Mestrado) - Curso de Engenharia Civil, Universidade Técnica de Lisboa, Lisboa, 2007.

17. GALVÃO, Pedro Ivo Ishakewitsch. Definição de requisitos mínimos necessários para o detalhamento sismo-resistente de edifícios em concreto armado no brasil. 119 f. Dissertação (Mestrado) - Curso de Estruturas, Universidade Federal do Rio de Janeiro, Rio de Janeiro, 2013

18. GAVIN, Henri; ALHAN, Cenk. A parametric study of linear and non-linear passively damped seismic isolation systems for buildings. Engineering Structures 26. [s. L.], p. 485-497. nov. 2003.

19. HAN, Mengyu. Application of base isolation systems to reinforced concrete frame buildings. 116 f. Dissertação (Mestrado) - Curso de Civil Engineering, University Of Ottawa, Ottawa, Canada, 2017.

20. HWANG, J. S.; CHIOU, J. M.. An equivalent linear model of lead-rubber seismic isolation bearings. Engineering Structures 18. [s. L.], p. 528-536. abr. 1995.

21. INTERNATIONAL CONFERENCE OF BUILDING OFFICIALS. UBC: Volume 2. Whittier, California: 1997. 
22. JACOBSEN, L.S. Steady forced vibrations as influenced by damping. Transactions of the American Society of Mechanical Engineers 52, p. 169-181. 1930.

23. KELLY, James M.. Aseismic base isolation: review and bibliography. Soil Dynamics And Earthquake Engineering. [s.1], p. 202-216. dez. 1986.

24. KILAR, Vojko; PETROVCIC, S.; KOREN, D.; SILIH, S. Seismic analysis of an asymmetric fixed base and base-isolated high-rack steel structure. Engineering Structures 33. [s. L.], p. 3471-3482. jul. 2011.

25. LIMA, Silvio de Souza; SANTOS, Sergio Hampshire de Carvalho. Análise Dinâmica das Estruturas. Rio de Janeiro: Ciência Moderna, 2008.

26. LIU, Tao. Equivalent linearization analysis method for base-isolated buildings. 210 f. Tese (Doutorado) - Curso de Engenharia Civil, Universidade Iuav de Veneza, Veneza, 2014.

27. MARRS, Nicholas Reidar. Comparison of a fixed-base versus a base-isolated office building. 204 f. Dissertação (Mestrado) - Curso de Architectural Engineering, California Polytechnic State University, San Luis Obispo, 2013.

28. MAZZILLI, Carlos E. N.; ANDRÉ, João C.; BUCALEM, Miguel L.; CIFÚ, Sergio. Lições em mecânica das estruturas: Dinâmica. São Paulo: Blucher, 2016.

29. MORETTI, Sarah; TROZZO, A.; TERZIC, V.; CIMELLARO, G.; MAHIN, S. Utilizing base-isolation systems to increase earthquake resiliency of healthcare and school buildings. Procedia Economics And Finance 18. Salford Quays, p. 969976. set. 2014.

30. MOSLEH, A.; RODRIGUES, H.; VARUM, H.; COSTA, A.; AREDE, A. Seismic behavior of RC building structures designed according to current codes. Structures 7. [s. L.], p. 1-13. maio 2016.

31. MWAFY, A.M.; ELNASHAI, A.S. Static pushover versus dynamic collapse analysis of RC buildings. Engineering Structures 23. [s. L.], p. 407-424. maio 2000.

32. NAEIM, F.; KELLY, J. M. Design of seismic isolated structures: From Theory to Practice, John Wiley and Sons INC., New York, 1999.

33. PARISENTI, Ronaldo. Estudo de análise dinâmica e métodos da nbr 15421 para projeto de edifícios submetidos a sismos. 219 f. Dissertação (Mestrado) - 
Curso de Engenharia Civil, Universidade Federal de Santa Catarina, Florianópolis, 2011.

34. PENG-HSIANG, Charng. Base isolation for multistorey building structures. 298 f. Tese (Doutorado) - Curso de Engenharia Civil, University of Canterbury, Christchurch, 1998.

35. QUINTERO, Patrícia Murad. Análise sísmica no domínio do tempo versus no domínio da frequência para uma ponte em seção celular. 117 f. Dissertação (Mestrado) - Curso de Engenharia de Estruturas, Universidade de São Paulo, São Paulo, 2017.

36. RAUFASTE, Noel J. et al. Survey Report on Framing of the Guidelines for Technological Development of Base- Isolation Systems for Buildings. 832. ed. Washington: U.s. Department of Commerce, 1992. 575 p.

37. RODRIGUES, R.M.R. Geração de acelerogramas sísmicos artificiais compatíveis com um espectro de resposta. $80 \mathrm{f}$. Monografia (Graduação) Curso de Engenharia Civil, Universidade Federal do Rio de Janeiro, Rio de Janeiro, 2012.

38. SANTOS, Sergio Hampshire de C. Um modelo semi-analítico em elementos finitos para interação inercial em análise sísmica. 100 f. Dissertação (Mestrado) - Curso de Engenharia, Universidade Federal do Rio de Janeiro, Rio de Janeiro, 1980.

39. SAP 2000, Versão 20, Computers \& Structures software, 2018. Disponível em: https://www.csiamerica.com

40. SeismoArtif, Versão 2016, SeismoSoft software, 2018. Disponível em: https://www.seismosoft.com

41. SOMWANSHI, Minal Ashok; PANTAWANE, Rina N. Seismic Analysis of Fixed Based and Base Isolated Building Structures. International Journal Of Multidisciplinary And Current Research 3. [s. L.], p. 747-757. ago. 2015.

42. SUN, Weixiao. Performance assessment and design of lead rubber seismic isola tors using a bilinear spectrum method. 2011. 109 f. Dissertação (Mestrado) - Curso de Ciências Aplicadas, McMaster University, Hamilton, 2011. 
43. U.S. Seismic Design Maps. USGS, 2018. Disponível em: http://earthquake.usgs.gov/designmaps

44. WANG, Shiang-jung; CHANG, K.; HWANG, J.; HSIAO, J.; LEE, B.; HUNG, Y. Dynamic behavior of a building structure tested with base and mid-story isolation systems. Engineering Structures 42. [s. L.], p. 420-433. abr. 2012.

45. WILES, Jessica Irene. An overview of the technology and design of base isolated buildings in high seismic regions in the united states. $96 \mathrm{f}$. Dissertação (Mestrado) - Curso de Architectural Engineering, Kansas State University, Kansas, 2008.

46. WILSON, E.L.; KIUREGHIAN, A. Der; Bavo, E.P. A replacement for the SRSS method in seismic analysis. Short Communications, Earthquake Engineering and Structural Dynamics, Vol. 9, p. 187-194, 1981

47. YENIDOGAN, Cem; ERDIK, Mustafa. A comparative evaluation of design provisions for seismically isolated buildings. Soil Dynamics And Earthquake Engineering 90. [s. L.], p. 265-286. ago. 2016. 